ALEXANDRE AUGUSTO ANGELO DE SOUZA

\title{
PLANEJAMENTO OPERACIONAL INTEGRADO DA REDE DE BAIXA E MÉDIA TENSÃO CONSIDERANDO GERAÇÃO DISTRIBUÍDA
}

São Paulo 



\section{ALEXANDRE AUGUSTO ANGELO DE SOUZA}

\section{PLANEJAMENTO OPERACIONAL INTEGRADO DA REDE DE BAIXA E MÉDIA TENSÃO CONSIDERANDO GERAÇÃO DISTRIBUÍDA}

Tese apresentada à Escola Politécnica da Universidade de São Paulo para obtenção do título de Doutor em Ciências

São Paulo

2018 



\section{ALEXANDRE AUGUSTO ANGELO DE SOUZA}

\section{PLANEJAMENTO OPERACIONAL INTEGRADO DA REDE DE BAIXA E MÉDIA TENSÃO CONSIDERANDO GERAÇÃO DISTRIBUÍDA}

Tese apresentada à Escola Politécnica da Universidade de São Paulo para obtenção do título de Doutor em Ciências

Área de concentração: Sistemas de Potência

Orientador: Prof. Dr. Nelson Kagan

São Paulo 
Este exemplar foi revisado e corrigido em relação à versão original, sob responsabilidade única do autor e com a anuência de seu orientador.

São Paulo, de de

Assinatura do autor:

Assinatura do orientador:

Catalogação-na-publicação

Souza, Alexandre Augusto Angelo de

PLANEJAMENTO OPERACIONAL INTEGRADO DA REDE DE BAIXA E MÉDIA TENSÃO CONSIDERANDO GERAÇÃO DISTRIBUÍDA / A. A. A. Souza -versão corr. -- São Paulo, 2018.

$161 \mathrm{p}$.

Tese (Doutorado) - Escola Politécnica da Universidade de São Paulo. Departamento de Engenharia de Energia e Automação Elétricas.

1.Distribuição de energia elétrica 2.Computação evolutiva 3.Otimização combinatória I.Universidade de São Paulo. Escola Politécnica. Departamento de Engenharia de Energia e Automação Elétricas II.t. 
A meus pais, Alice e João (in memorium) por tudo que fizeram por mim ao longo de minha vida. 



\section{AGRADECIMENTOS}

Desejo expressar meus sinceros agradecimentos:

Ao Professor Nelson Kagan pela orientação e paciência que tornou possível a finalização deste trabalho.

Aos amigos da Copel que de forma frequente me encorajaram.

À Regina, minha irmã, que sempre me deu força para superar os obstáculos. 

"O cientista não é o homem que fornece as verdadeiras respostas;

é quem faz as verdadeiras perguntas."

Claude Lévi-Strauss 



\section{RESUMO}

\section{SOUZA, A. A. A. PLANEJAMENTO OPERACIONAL INTEGRADO DA REDE DE}

BAIXA E MÉDIA TENSÃO CONSIDERANDO GERAÇÃO DISTRIBUÍDA. 2018. 159p. Tese (Doutorado) - Escola Politécnica, Universidade de São Paulo, São Paulo, 2018.

O planejamento operacional de redes de média e baixa tensão consiste em determinar as melhores intervenções a serem aplicadas nas redes atuais de forma a otimizar os investimentos e atender aos critérios técnicos de operação. Na Média Tensão (MT) são usuais alterações como alocação de capacitores, alteração de cabos e remanejamento de cargas para obter uma melhoria para o sistema. Normalmente os objetivos são a minimização de perdas, melhora do nível de tensão e redução do custo das intervenç̃oes realizadas. Na Baixa Tensão (BT) são aplicadas intervenções relacionadas a substituição de cabos, alteração da posição do transformador e balanceamento de cargas. As alterações propostas visam melhorar os índices de equilíbrio de cargas, carregamento de transformadores e queda de tensão ao longo da rede $M T$ e $B T$. Neste trabalho considerase a minimização dos investimentos para a realização de alterações nos alimentadores e circuitos de $B T$, levando em conta a inserção de Geração Distribuída (GD) como solução alternativa. As dificuldades do problema de otimização resultam do tamanho dos sistemas reais e da possibilidade de alternativas que podem ser aplicadas durante o estudo. Para resolver o problema de explosão combinatória resultante das possíveis combinações de alternativas, os modelos propostos neste trabalho utilizam técnicas de computação evolutiva. Os modelos desenvolvidos respeitam aspectos técnicos e econômicos envolvidos em cada solução. A metodologia é aplicada em uma rede real partindo-se de uma base de dados georrefenciada.

Palavras-chave: Distribuição de energia elétrica, Computação evolutiva, Otimização combinatória. 



\begin{abstract}
SOUZA, A. A. A. PLANEJAMENTO OPERACIONAL INTEGRADO DA REDE DE BAIXA E MÉDIA TENSÃO CONSIDERANDO GERAÇÃO DISTRIBUÍDA. 2018. 159p. Tese (Doutorado) - Escola Politécnica, Universidade de São Paulo, São Paulo, 2018.

The operational planning of medium and low voltage networks consists in determining the best interventions to be applied to existing networks in order to optimize investments and meet the technical criteria for operation. In the Medium Voltage $(M V)$ capacitor allocation, recabling and relocation of loads are useful to achieve an improvement to the system. Usually the objectives are power losses minimization, voltage level improvement and cost reduction of the interventions carried out. In the Low Voltage $(L V)$ interventions for replacing cables and transformer position and load relocation are commonly considered. The proposed changes are aimed at improving the load balance, transformer loading and voltage drops across $L V$ network circuits. This work considers the investment minimization to intervene in $M V$ and $L V$ networks, considering Distributed Generation ( $D G)$ insertion as an alternative solution. The difficulties of optimization problem result from the size of the real systems and the possibility of alternatives that can be applied during the study. In order to solve the combinatorial explosion problem resulting from possible combinations of alternatives, the model proposed in this work uses evolutionary computational techniques. The developed models take into account technical and economical aspects involved in each solution. The methodology is applied in a real network starting from a georeferenced database.
\end{abstract}

Keywords: Electric Power Distribution, Evolutionary computation, Combinatorial optimization. 



\section{LISTA DE FIGURAS}

Figura 1 - Representação de um sistema de distribuição. . . . . . . . . . . . 2

Figura 2 - Número de conexões versus número de consumidores com crédito. . 11

Figura 3 - Espaço viável para a aplicação e concepção de modelos . . . . . . . 29

Figura 4 - Fluxograma básico para construção de modelos . . . . . . . . . . 30

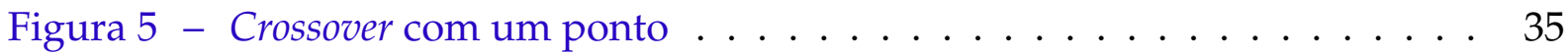

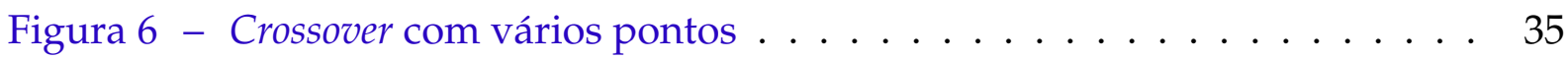

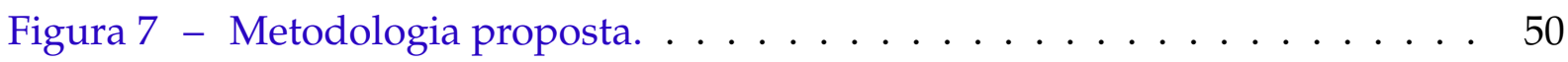

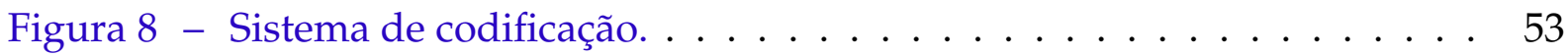

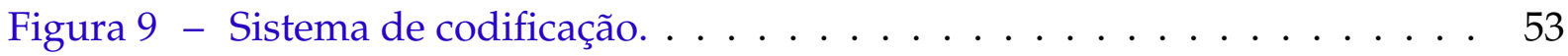

Figura 10 - Metodologia proposta para a BT. . . . . . . . . . . . . . . 64

Figura 11 - Cromossomo rede BT. . . . . . . . . . . . . . . . . 67

Figura 12 - Sistema de codificação. . . . . . . . . . . . . . . . . . . . 68

Figura 13 - Fluxo de execução do planejamento integrado . . . . . . . . . . 72

Figura 14 - Fluxograma detalhado de execução do planejamento integrado . . 73

Figura 15 - Troca de mensagens dos agentes. . . . . . . . . . . . . . 83

Figura 16 - Grafo dirigido. . . . . . . . . . . . . . . . . . . . 84

Figura 17 - Alimentador escolhido. . . . . . . . . . . . . . . . . 92

Figura 18 - Circuito $\mathrm{C} 13$ original. . . . . . . . . . . . . . . . . . . 103

Figura 19 - Alterações propostas para o circuito C13. . . . . . . . . . . . . . 103

Figura 20 - Alocação ótima de GD para o circuito C13. . . . . . . . . . . . . . 104

Figura 21 - Alocação de GD para o circuito C13. . . . . . . . . . . . . . . . . 104

Figura 22 - Grafo das movimentações. . . . . . . . . . . . . . . . . . . . . 115 



\section{LISTA DE TABELAS}

Tabela 1 - Relação potência instalada e nível de tensão de conexão. . . . . . . . 12

Tabela 2 - Tabela verdade instalação/retirada de cabos. . . . . . . . . . . . . . . 44

Tabela 3 - Valores dos cabos . . . . . . . . . . . . . . . . . 52

Tabela 4 - Faseamento dos Transformadores . . . . . . . . . . . . . 52

Tabela 5 - Tabela verdade instalação/retirada de cabos. . . . . . . . . . . . . 59

Tabela 6 - Valores dos cabos . . . . . . . . . . . . . . . 66

Tabela 7 - Tabela Faseamento do Consumidor . . . . . . . . . . . . . . . . . 67

Tabela 8 - Custos agrupados. . . . . . . . . . . . . . 80

Tabela 9 - Custo instalação de novos transformadores. . . . . . . . . . . . . . . . 80

Tabela 10 - Valores dos parâmetros iniciais para o AG . . . . . . . . . . . . . 89

Tabela 11 - Valores dos parâmetros escolhidos para o AG . . . . . . . . . . . . . 89

Tabela 12 - Tempo de processamento do planejamento integrado de redes de MT e $B T \ldots \ldots \ldots \ldots$. . . . . . . . . . . . . . . . 90

Tabela 13 - Dados do Alimentador . . . . . . . . . . . . . . . . . . . . . . 91

Tabela 14 - Valores de Simulação do Alimentador . . . . . . . . . . . . . . . . . 91

Tabela 15 - Especificação e valores de condutores. . . . . . . . . . . . . . . . . . 92

Tabela 16 - Custo de Capacitores. . . . . . . . . . . . . . . . . . . . . 93

Tabela 17 - Resultado da simulação. . . . . . . . . . . . . . . . . . . . 93

Tabela 18 - Valores de Simulação do Alimentador sem GD . . . . . . . . . . . . . 94

Tabela 19 - Resultado da simulação. . . . . . . . . . . . . . . . . . . . . . . . . . . 94

Tabela 20 - Valores de Simulação do Alimentador com GD ótima . . . . . . . . . 95

Tabela 21 - Resultado da simulação do alimentador com GD em pontos determinados . . . . . . . . . . . . . . . . . . . 95

Tabela 22 - Valores de Simulação do Alimentador com GD em pontos determinados 96

Tabela 23 - Dados dos circuitos analisados. . . . . . . . . . . . . . . . . . . . 97

Tabela 24 - Especificação e valores de condutores. . . . . . . . . . . . . . . . . . . 98

Tabela 25 - Especificação e valores de transformadores. . . . . . . . . . . . . . . . 98

Tabela 26 - Valores das operações de conexão de rede. . . . . . . . . . . . . . . . 99

Tabela 27 - Resultados simulação rede BT sem GD. . . . . . . . . . . . . . . . . 100

Tabela 28 - Resultados simulação rede BT alocação ótima GD . . . . . . . . . . . . 101

Tabela 29 - Resultados simulação rede BT com GD . . . . . . . . . . . . . . . . . . 102

Tabela 30 - Resultados obtidos das simulações para o circuito C13. . . . . . . . . 105

Tabela 31 - Dados do Alimentador . . . . . . . . . . . . . . . . . . . . . 105

Tabela 32 - Dados dos circuitos analisados. . . . . . . . . . . . . . . . 106

Tabela 33 - Resultado da simulação. . . . . . . . . . . . . . . . . . . . . . . 107 
Tabela 34 - Valores de Simulação do Alimentador no Planejamento Integrado sem GD . . . . . . . . . . . . . . . . . . . 107

Tabela 35 - Resultados obtidos das simulações sem GD . . . . . . . . . . . . 108

Tabela 36 - Resultado da simulação com alocação ótima de GD . . . . . . . . 108

Tabela 37 - Valores de Simulação do Alimentador no Planejamento Integrado com alocação ótima de $G D$. . . . . . . . . . . . . . . . . . 109

Tabela 38 - Resultados alocação ótima GD. . . . . . . . . . . . . . . . . . . . 109

Tabela 39 - Resultado da simulação com GD . . . . . . . . . . . . . . . . 1110

Tabela 40 - Valores de Simulação do Alimentador no Planejamento Integrado com GD . . . . . . . . . . . . . . . . . . . 110

Tabela 41 - Resultados alocação GD. . . . . . . . . . . . . . . . . . . . . . 111

Tabela 42 - Resumo dos Custos da rede de MT . . . . . . . . . . . . . . . 111

Tabela 43 - Sumário das simulações. . . . . . . . . . . . . . . . . . . . . . 112

Tabela 44 - Sumário planejamento MT e BT. . . . . . . . . . . . . . . . . 113

Tabela 45 - Dados dos transformadores . . . . . . . . . . . . . . . . . . 114

Tabela 46 - Lista de Coalizões . . . . . . . . . . . . . . . . . . . . . . . . . . 114

Tabela 47 - Custo das Coalizões .. . . . . . . . . . . . . . . . . . . 115

Tabela 48 - Movimentações sugeridas. . . . . . . . . . . . . . . . . . . . 115 


\section{LISTA DE ABREVIATURAS E SIGLAS}

AG

Algoritmos Genéticos

ANEEL Agência Nacional de Energia Elétrica

BT

Baixa Tensão

GD

Geração Distribuída

IA Inteligência Artificial

MT Média Tensão

RNA Redes Neurais Artificiais

SA Serviços Ancilares

SEP Sistema Elétrico de Potência

SMA Sistemas Multiagentes

PLIM Programação Linear Inteira Mista

PNLIM Programação Não Linear Inteira Mista

PRODIST Procedimentos de Distribuição de Energia Elétrica no Sistema Elétrico Nacional 



\section{SUMÁRIO}

$1 \quad$ INTRODUÇÃO $\ldots \ldots \ldots \ldots \ldots \ldots \ldots \ldots \ldots$

1.1 CONTEXTUALIZAÇÃO $\ldots \ldots \ldots \ldots \ldots \ldots$

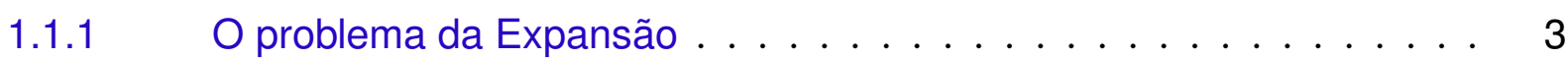

1.1.2 O Planejamento Operacional do Sistema de Distribuição . . . . . . . . 3

1.1.3 Ferramentas Computacionais para o Planejamento Operacional do Sistema de Distribuição . . . . . . . . . . . . . . . . . . 4

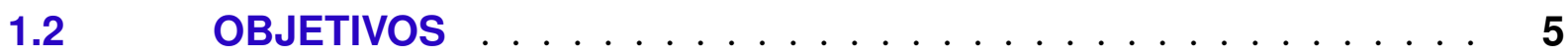

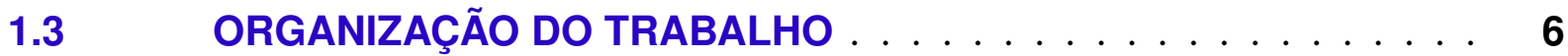

2 CONCEITUAÇÃO: GERAÇÃO DISTRIBUÍDA, SERVIÇOS ANCILARES E REVISÃO TEÓRICA DO PLANEJAMENTO DE MT E BT . . $\quad 9$

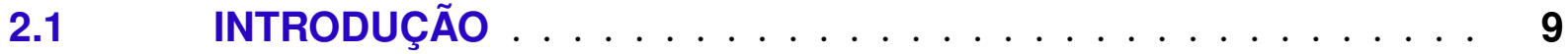

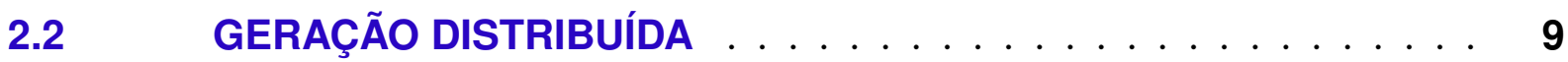

2.2.1 Tecnologias utilizadas em Geração Distribuída . . . . . . . . . . . 10

2.2.2 Pequenas Centrais de Geração . . . . . . . . . . . . . . . . . . . 10

2.2.3 Conexão da Geração Distribuída no Sistema Elétrico . . . . . . . . . . 11

2.2.4 Benefícios relacionados à Geração Distribuída . . . . . . . . . . . . . 12

2.2.5 Impactos na Qualidade de Energia . . . . . . . . . . . . . . 13

2.2.5.1 Variações de tensão de longa duração . . . . . . . . . . . . . . . 14

2.2.5.2 Baixo nível de tensão relacionado a compensação de perdas na linha 14

2.2.5.3 Interação com os equipamentos de regulação de tensão . . . . . . . . 14

2.2.5.4 Variações de tensão de curta duração . . . . . . . . . . . . . . . 14

2.2.5.5 Distorções da forma de Onda . . . . . . . . . . . . . . . . . 15

2.2.5.6 Variações da frequência . . . . . . . . . . . . . . . . . . 15

2.2.5.7 Flutuação de tensão . . . . . . . . . . . . . . . . . . . . . 15

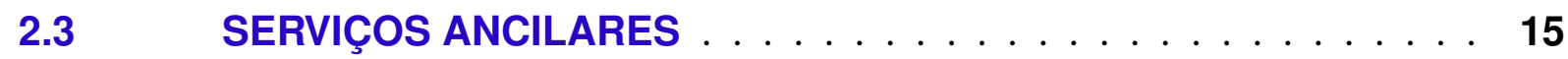

2.3.1 Visão Geral dos Serviços Ancilares . . . . . . . . . . . . . . . 16

2.3.1.1 Suporte de Potência Reativa . . . . . . . . . . . . . . . . . 17

2.3.1.2 Autorrestabelecimento . . . . . . . . . . . . . . . . . 18

$2.4 \quad$ REVISÃO TEÓRICA DO PLANEJAMENTO DE MT E BT . . . . . 18

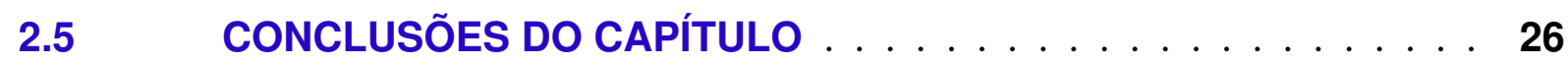

3 METAHEURÍSTICAS APLICADAS DO PLANEJAMENTO DE REDES ELÉTRICAS . . . . . . . . . . . . . . . . . . . 27

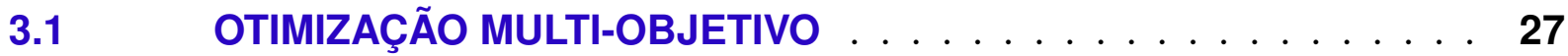

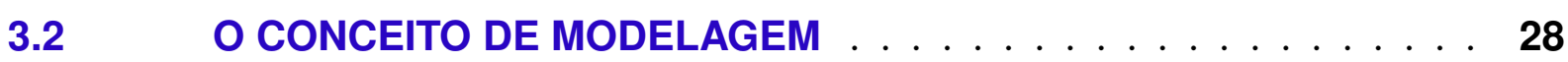




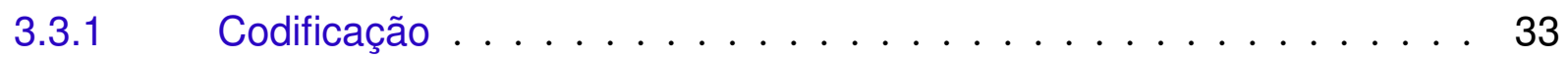

3.3.2 Métodos de Seleção . . . . . . . . . . . . . . . . . . . . . . 34

3.3.3 Operadores Genéticos . . . . . . . . . . . . . . . . . . . . 35

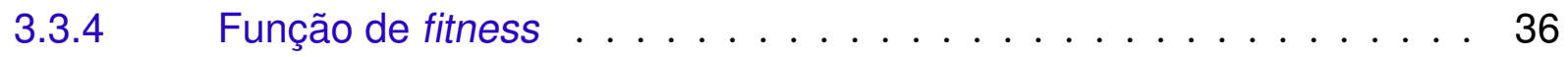

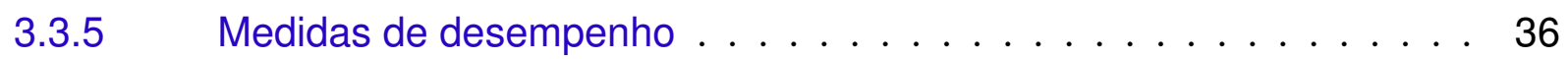

3.3.6 Critérios de parada . . . . . . . . . . . . . . . . . 37

3.4 AGENTES E SISTEMAS MULTIAGENTES SMA . . . . . . . . . 37

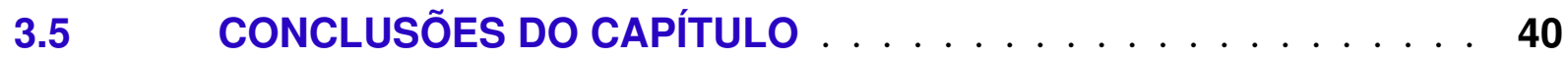

4 PLANEJAMENTO OPERACIONAL DE REDES DE DISTRIBUIÇÃO DE MÉDIA TENSÃO . . . . . . . . . . . . . . . . 41

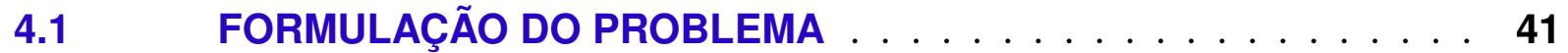

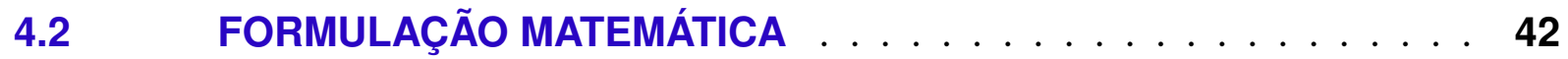

4.2.1 Recondutoramento de Cabos . . . . . . . . . . . . . . 42

4.2 .1 .1 Função Objetivo . . . . . . . . . . . . . . . . . . . . . 44

4.2.1.2 Restrições. . . . . . . . . . . . . . . . . . . . . . . . . 44

4.2.2 Troca de faseamento dos transformadores . . . . . . . . . . . 45

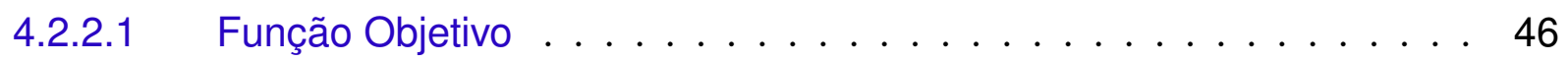

4.2.2.2 Restrições. . . . . . . . . . . . . . . . . . 46

4.2.3 Alocação de Banco de Capacitores . . . . . . . . . . . . . . . 46

4.2.3.1 Função Objetivo . . . . . . . . . . . . . . . . . . . . . . . . . 48

4.2.3.2 Restrições. . . . . . . . . . . . . . . . . . . . . 48

4.2.4 Alocação de Geração Distribuída na $M T \ldots \ldots$. . . . . . . 48

4.2 .4 .1 Função Objetivo . . . . . . . . . . . . . . . . . . 49

4.2.4.2 Restrições . . . . . . . . . . . . . . . . . . . . . . . . . 49

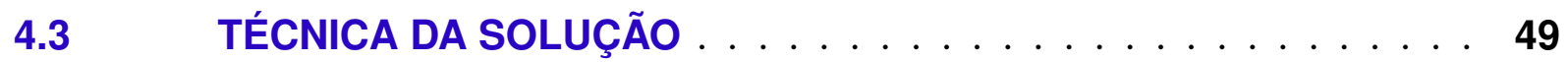

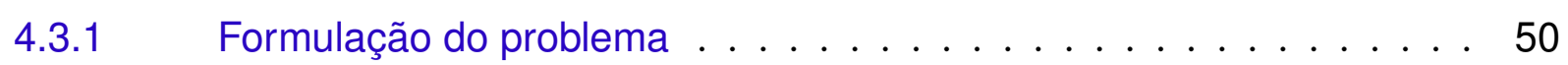

4.3.1.1 Representação do Cromossomo . . . . . . . . . . . . . . . . 51

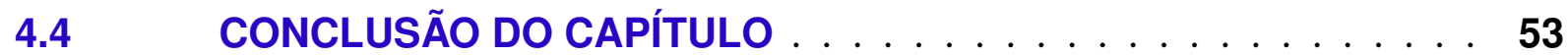

5 PLANEJAMENTO OPERACIONAL DE REDES DE DISTRIBUIÇÃO

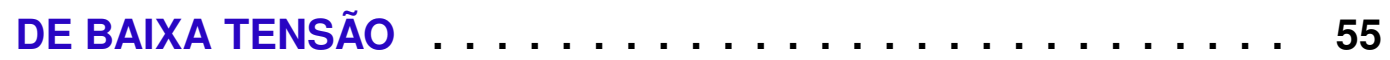

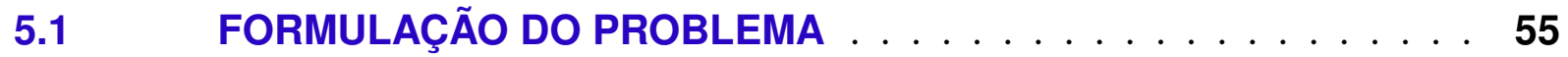

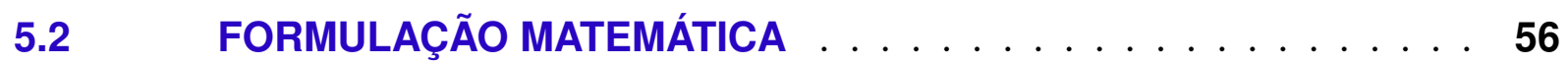

5.2 .1 Recondutoramento de Cabos . . . . . . . . . . . . 57

5.2 .1 .1 Função Objetivo . . . . . . . . . . . . . . . . . . . . 58

5.2 .1 .2 Restrições. . . . . . . . . . . . . . . . . . . 58

5.2.2 Troca de faseamento dos consumidores . . . . . . . . . . . 59

5.2 .2 .1 Função Objetivo . . . . . . . . . . . . . . . . . . . . 60 
5.2.2.2 Restrições. . . . . . . . . . . . . . . . . . . . . . 60

5.2.3 Movimentação de transformadores . . . . . . . . . . . . . . . 61

$5.2 .3 .1 \quad$ Função Objetivo . . . . . . . . . . . . . . . . . . . . . 62

5.2.3.2 Restrições. . . . . . . . . . . . . . . . . . . 62

5.2.4 Alocação de Geração Distribuída na $B T \ldots \ldots$. . . . . . . . 62

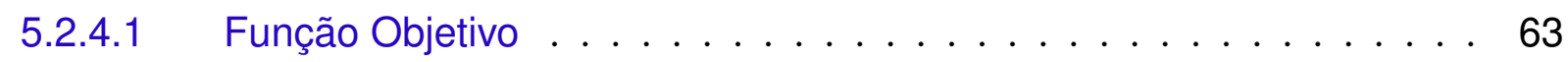

5.2 .4 .2 Restrições. . . . . . . . . . . . . . . . . 63

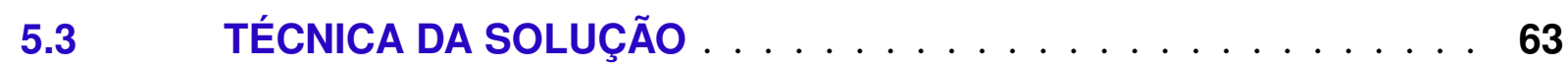

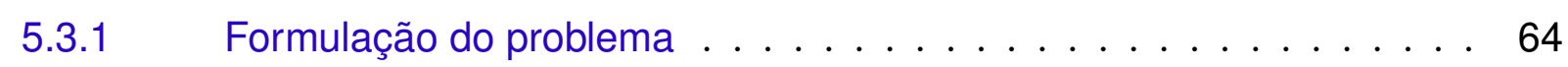

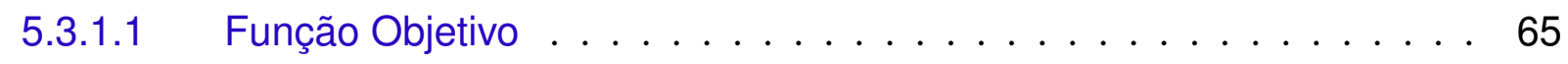

5.3.1.2 Representação do Cromossomo . . . . . . . . . . . . . 66

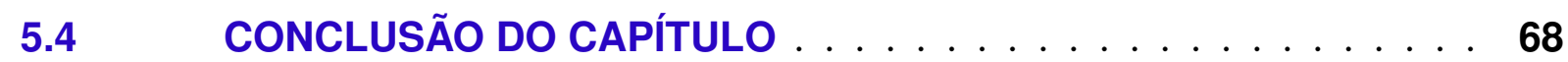

6 PLANEJAMENTO OPERACIONAL INTEGRADO DE REDES DE MT E $B T \ldots \ldots \ldots \ldots \ldots \ldots \ldots$

6.1 PLANEJAMENTO OPERACIONAL INTEGRADO . . . . . . . 69

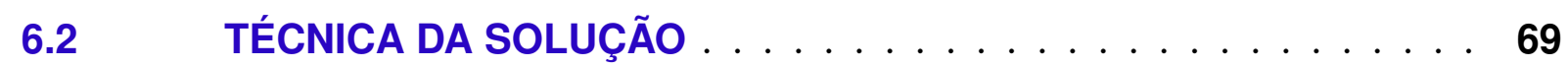

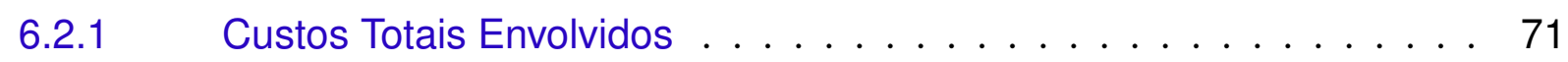

6.2.2 Resolução Integrada Proposta . . . . . . . . . . . . . . . 71

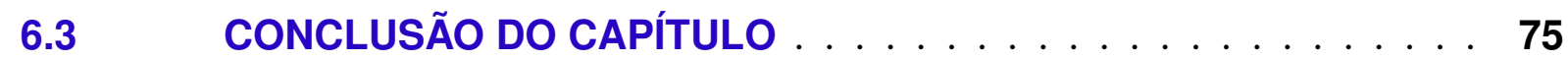

7 REMANEJAMENTO DE TRANSFORMADORES EM REDES DE DISTRIBUIÇÃO DE MÉDIA TENSÃO . . . . . . . . . . . . . . 77

7.1 FORMULAÇÃO MATEMÁTICA DO REMANEJAMENTO . . . . . 78

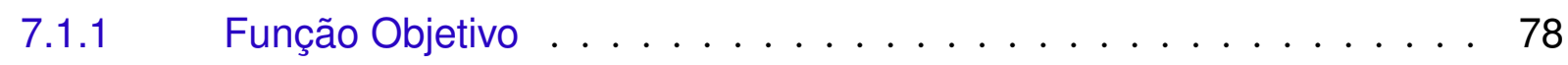

7.2 MODELANDO TRANSFORMADORES COMO AGENTES . . . 80

7.3 MODELAGEM LINEAR INTEIRA . . . . . . . . . . . . . . . 84

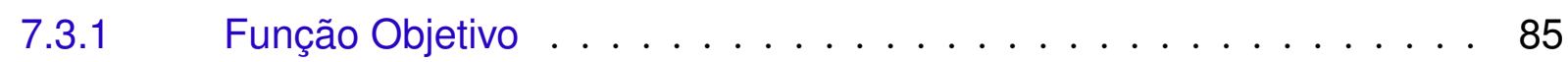

7.3.2 Restrições. . . . . . . . . . . . . . . . . . 85

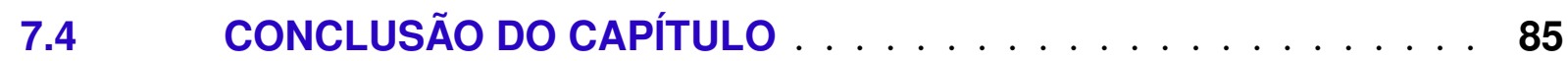

8 APLICAÇÃO DA METODOLOGIA . . . . . . . . . . . 87

$8.1 \quad$ ANÁLISE INICIAL DOS PARÂMETROS DO AG . . . . . . . . . 87

8.1.1 Simulações para Análise dos Parâmetros do AG . . . . . . . . . 89

8.2 ANÁLISE DO TEMPO DE PROCESSAMENTO . . . . . . . . 90

8.3 PLANEJAMENTO OPERACIONAL DE REDES DE DISTRIBUIÇÃO DE MT SEM INTEGRAÇÃO COM REDES DE DISTRIBUIÇÃO DE BT 90

8.3.1 Simulações na rede de $M T$ sem considerar GD . . . . . . . . . 93

8.3.2 Simulação da rede de $M T$ considerando alocação ótima de $G D$. . . 94

8.3.3 Simulação da rede de MT considerando GD em pontos determinados 95 
8.4 PLANEJAMENTO OPERACIONAL DE REDES DE DISTRIBUIÇÃO DE BT SEM INTEGRAÇÃO COM REDES DE DISTRIBUIÇÃO DE MT 96

8.4.1 Simulações na rede de BT sem GD . . . . . . . . . . . . . 99

8.4.2 Simulações na rede de $B T$ com alocação ótima de GD . . . . . . 100

8.4.3 Simulações na rede de $B T$ com inserção de $G D$ em pontos determinados 101

8.4.3.1 Simulações no circuito $C 13$ considerando inserção de GD . . . . . 102

8.5 PLANEJAMENTO OPERACIONAL INTEGRADO DE MT E BT . . 105

8.5.1 Planejamento Operacional Integrado de MT e BT sem considerar GD 106

8.5.2 Planejamento Operacional Integrado de MT e BT com alocação ótima

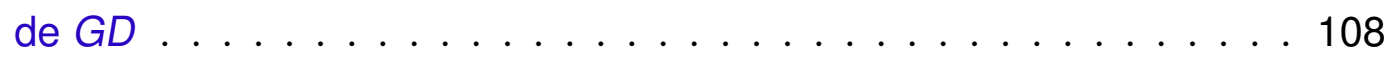

8.5.3 Planejamento Operacional Integrado de $M T$ e $B T$ com GD em pontos determinados . . . . . . . . . . . . . . . . . . . . . . . . 110

8.5.4 Sumário das Simulações do Planejamento Operacional Integrado de

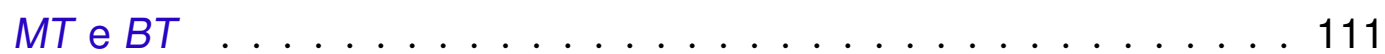

8.6 REMANEJAMENTO DE TRANSFORMADORES NO SISTEMA DE DISTRIBUIÇÃO DE ENERGIA . . . . . . . . . . . . . . . . . . . 114

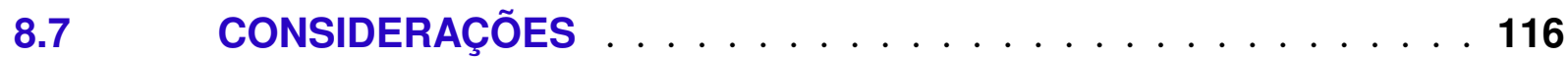

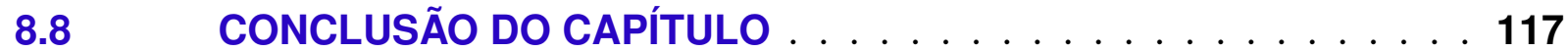

9 CONCLUSÕES DO TRABALHO $\ldots \ldots \ldots \ldots \ldots \ldots$

9.1 ASPECTOS GERAIS . . . . . . . . . . . . . . . . 119

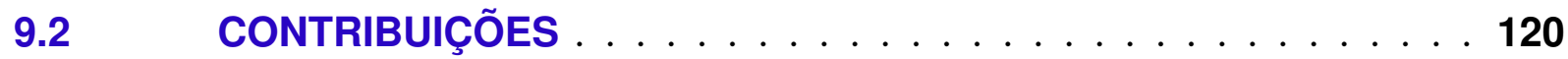

9.3 LIMITAÇÕES DA METODOLOGIA . . . . . . . . . . . . . . . 122

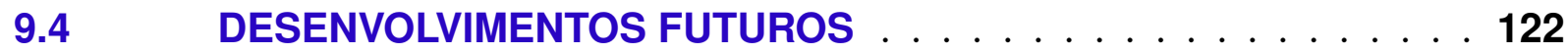

REFERÊNCIAS . . . . . . . . . . . . . . . . . . . 125

APÊNDICES

APÊNDICE A - DADOS DO ALIMENTADOR . . . . . . . . . . 135

APÊNDICE B - TRABALHOS PUBLICADOS . . . . . . . . 159 


\section{INTRODUÇÃO}

\subsection{CONTEXTUALIZAÇÃO}

As empresas de energia elétrica gastam hoje centenas de horas mensais em atividades de planejamento dos seus sistemas elétricos, seja para sua operação como para sua expansão. Os estudos realizados para o planejamento da rede elétrica exigem elevado grau de intervenção humana, bem como um tempo considerável para a sua análise. O planejamento da rede elétrica é realizado em virtude da constante necessidade de expansão das redes de distribuição devido ao rápido crescimento de demanda nas áreas urbanas, rurais e das políticas públicas de inclusão social. Esta expansão acarreta o aumento do volume não só de obras de ampliação e criação de novas redes, mas também de obras de melhoria e reforço de redes, sobrecarregando os setores responsáveis pela análise e elaboração de estudos elétricos.

No Brasil, a qualidade do produto fornecido pelas concessionárias, bem como dos serviços por elas prestados, é objeto de diversas resoluções normativas da Agência Nacional de Energia Elétrica (ANEEL) que realiza uma regulamentação dinâmica, em constante estudo e evolução, retratando a importância dada ao assunto. Neste âmbito consolidam-se os Procedimentos de Distribuição de Energia Elétrica no Sistema Elétrico Nacional (PRODIST) (ANEEL, 2009), que normatizam e padronizam as atividades técnicas relacionadas ao funcionamento e desempenho dos sistemas de distribuição, abrangendo tópicos como planejamento, expansão, operação, medição, qualidade de energia elétrica e intercâmbio de informações entre agentes e entidades competentes.

A qualidade do produto é avaliada por índices que mensuram, entre outros, a conformidade dos níveis de tensão, frequência e carregamento da rede em regime permanente. Eventuais transgressões devem ser regularizadas dentro de prazos definidos, sujeitas a penalidades como multas e compensações de crédito aos consumidores. Todas essa regras estão definidas no módulo 8 do PRODIST(ANEEL, 2018).

De forma a complementar à avaliação da qualidade do produto, rapidez e eficiência na resolução de problemas também são avaliadas sob o quesito qualidade dos serviços prestados. Observa-se, assim, o papel do órgão regulamentador no estímulo de melhorias e zelo, direto e indireto, pelo atendimento de qualidade às necessidades do consumidor final, observando inclusive o disposto na legislação vigente de proteção e defesa do consumidor. Desta forma, a elaboração dos estudos de planejamento das 
redes de distribuição exige dos projetistas da concessionária a busca de soluções que atendam não só aos critérios técnicos e econômicos da própria concessionária, mas também à regulamentação estabelecida pela ANEEL.

Um sistema elétrico de potência é constituído por usinas, subestações, linhas de transmissão e redes de distribuição. Normalmente, para efeito de análise e estudos, os sistemas elétricos de potência são subdivididos em três grandes blocos, a saber, geração, transmissão e distribuição. Um sistema de distribuição pode ser visualizado na figura 1 mostrando parte das subestações de distribuição e de subtransmissão.

Figura 1 - Representação de um sistema de distribuição.

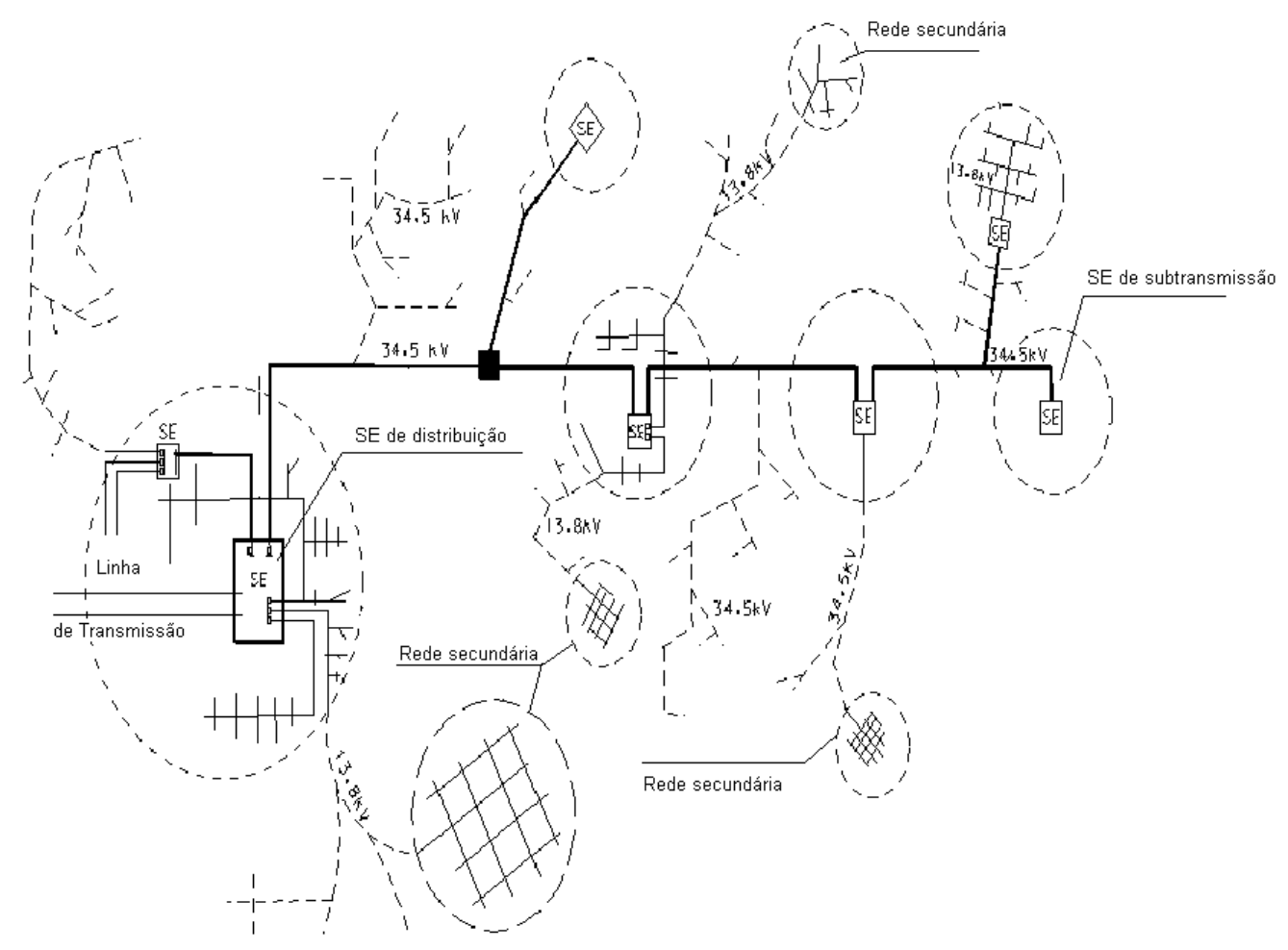

Fonte: Elaboração própria.

Duas modalidades de redes constituem o sistema de distribuição:

a) Redes primárias, que partem das subestações distribuidoras para atender consumidores com níveis superiores de carga e transformadores de distribuição;

b) Redes secundárias, constituídas pelos transformadores de distribuição, circuitos secundários e ramais de serviço que conectam os consumidores finais 
de baixa tensão à rede pública.

\subsubsection{O problema da Expansão}

Com a necessidade requerida dos usuários por crescimento de demanda, a expansão e as alterações na rede elétrica de distribuição na rede tornam-se indispensáveis. Em geral as obras envolvem altos custos, sendo, portanto, necessária a realização de um bom planejamento. O problema consiste em determinar o tamanho, número e localização das subestações e os caminhos de conexões nos alimentadores de tal forma que os custos de instalação e de operação sejam mínimos e que atendam às restrições do órgão regulador, no caso do Brasil, a ANEEL. Devido a natureza combinatória do problema, o planejamento de redes de Média Tensão e de Baixa Tensão, geralmente são realizados de forma separada, conforme Gonen e Foote (1981).

Os principais requisitos para serem considerados no problema, são:

- Horizonte de estudo;

- Capacidade física das subestações (existentes e novas);

- Número máximo de subestações a serem instaladas;

- Número máximo de alimentadores por subestação;

- Capacidade de carga por alimentador;

- Possível roteamento dos novos alimentadores;

- Taxa de crescimento das cargas na área de estudo;

- Custo de construção de subestações;

- Custo de construção de alimentadores;

- Custo de perdas elétricas na rede;

- Restrições referente aos limites operacionais dos equipamentos;

- Critérios de confiabilidade da rede.

1.1.2 O Planejamento Operacional do Sistema de Distribuição

O planejamento dos sistemas de distribuição de energia pode ser separados nas modalidades, a saber:

- Planejamento Estratégico; 
- Planejamento Tático;

- Planejamento Operacional.

O planejamento estratégico tem horizontes de estudo de longo prazo e tem o obetivo de indicar às concessionárias de distribuição o investimento necessário para a manutenção de níveis de qualidade de fornecimento, face ao crescimento e evolução do sistema elétrico. Como resultado destes estudos têm-se a propecção das principais obras estruturantes para o atendimento aos critérios técnicos e econômicos para um horizonte de 10 anos (ANEEL, 2009).

O planejamento tático, por sua vez, tem a finalidade de analisar as características técnicas e econômicas do sistema de distribuição em um horizonte de 5 anos. Portanto, cabe ao planejamento tático detalhar a expansão, ampliação e reforços no sistema de distribuição tendo como produto um plano de obras (ANEEL, 2009).

Conforme (OLIVEIRA, 1997) o planejamento operacional trata da operação da rede de curto prazo, analisando o sistema existente e intervenções a serem realizadas. Desta forma, este planejamento trabalha com o mínimo de incertezas e o máximo de informações para auxiliar o processo decisório, sendo usado para estudos com um horizonte de até 1 ano (ANEEL, 2009).

1.1.3 Ferramentas Computacionais para o Planejamento Operacional do Sistema de Distribuição

Existe um amplo conjunto de métodos computacionais para a realização de simulações e estudos na rede elétrica. Com o desenvolvimento de aplicativos para o auxílio aos planejadores, as questões mais importantes a serem abordadas são a necessidade de facilitar a visualização dos dados, a seleção dos casos de estudo, e a análise dos resultados.

Os motivos são:

- As ferramentas de simulação têm sido operadas por profissionais cada vez menos experientes;

- Um profissional tem pouco tempo disponível para proceder à análise dos resultados;

- Cada profissional tem uma abordagem para resolver determinados tipos de problemas, não tendo, desta forma, uma solução padrão adotada pelos profissionais.

O desenvolvimento de um produto de apoio à decisão no que concerne ao planejamento de redes aumentará a qualidade dos serviços, uma vez que as empresas 
de energia nacional começam a ser geridas pela iniciativa privada. Com isso, o monitoramento dos serviços prestados pelas empresas de distribuição de energia tende a ser mais constante e com critérios de avaliações mais rígidos.

\subsection{OBJETIVOS}

O principal objetivo do presente trabalho consiste em desenvolver uma nova metodologia para resolver o Problema de Planejamento Operacional de Redes de Média Tensão (MT) e de Baixa Tensão (BT) pela utilização de modelos desenvolvidos utilizando a técnica de Algoritmos Genéticos $(A G)$ para o balanceamento de cargas, troca de condutores, alocação de capacitores, além da inserção da GD e da posterior integração dos modelos. Os trabalhos existentes de planejamento de redes não contemplam o planejamento operacional, sendo geralmente aplicados para a expansão do sistema em áreas sem rede instalada. Neste trabalho, são analisados alimentadores e circuitos existentes que necessitam de intervenções para a resolução de problemas de qualidade de fornecimento de energia. Portanto, as considerações relativas ao planejamento operacional diferem muito dos planejamentos estratégico e tático, tendo uma atuação mais presente em preservar a topologia atual do alimentador e circuitos sem considerar expansões na rede.

Outro objetivo é utilizar o conceito de Sistemas Multiagentes (SMA) aplicado ao problema de realocação de transformadores subcarregados e sobrecarregados em uma rede de $M T$. Desta forma, procura-se priorizar trocas entre os transformadores instalados na rede ao invés de instalar um novo transformador.

A possibilidade de inserção de GD permite que as concessionárias, analisando seu processo de planejamento, possam reduzir custos e priorizar seus investimentos de forma a conduzir a uma modicidade tarifária, em consonância com o atual contexto no qual estão inseridas as concessionárias de distribuição.

A tese defendida neste trabalho é que as concessionárias de distribuição devem considerar as características técnicas específicas de seu sistema elétrico, especialmente em um cenário de ampliação do uso de $G D$, visando aprimorar o seu processo de planejamento operacional de redes. Com a utilização de métodos de otimização, procurase conjugar a busca pela melhor alternativa técnica-econômica com a qualidade de fornecimento de energia conforme normas estabelecidas pela ANEEL.

O objetivo geral da pesquisa é desenvolver metodologia para análise do planejamento operacional integrado de redes de $M T$ e BT considerando a possibilidade de inserção de $G D$, de maneira a minimizar os investimentos na rede e respeitar as solicitações de qualidade de fornecimento impostas pelo órgão regulador.

Foram estabelecidas as seguintes etapas para alcançar os objetivos deste trabalho: 
- Em primeiro lugar, foi realizada uma pesquisa bibliográfica referente ao assunto de planejamento de redes e as técnicas utilizadas para a sua realização. Além disso foram analisados os processos de planejamento operacional nas redes de $M T$ e BT em uma concessionária de distribuição de energia elétrica e as possibilidades de alterações a serem realizadas advindos destes processos;

- Na abordagem teórica são utilizados os conceitos, modelos matemáticos e as técnicas de solução de algoritmos de otimização evolutivos. Os algoritmos evolutivos foram utilizados para resolver o planejamento operacional integrado de redes de MT e BT;

- Foi avaliada a utilização do conceito de sistemas multiagentes para a resolução de um problema de realocação de transformadores na rede de $M T$ de distribuição de energia;

- Foi realizada a integração do planejamento operacional integrado de redes de MT e $B T$ e realizados testes para a validação da metodologia.

\subsection{ORGANIZAÇÃO DO TRABALHO}

No presente capítulo apresentaram-se a introdução ao tema do trabalho desenvolvido, os objetivos a serem alcançados e a metodologia utilizada.

No capítulo 2 é apresentada uma revisão bibliográfica sobre as técnicas de otimização utilizadas na modelagem proposta do planejamento de $M T$ e BT. Além de uma contextualização sobre GD e Serviços Ancilares (SA).

No capítulo 3, apresentam-se os conceitos teóricos das técnicas de otimização e metaheurísticas utilizadas para o desenvolvimento dos modelos propostos do planejamento de $M T$ e $B T$.

O capítulo 4 apresenta a metodologia desenvolvida para a resolução do planejamento de $M T$ utilizando $A G$ para os modelos contemplando as atividades, a saber: faseamento de cargas, troca de condutores, alocação de capacitores e inserção de GD. Os modelos desenvolvidos contemplam restrições técnicas e custos de materiais.

O capítulo 5 apresenta a metodologia desenvolvida para a resolução do planejamento de $B T$ utilizando $A G$ para os modelos contemplando as atividades, a saber: faseamento de cargas, troca de condutores, movimentação de transformadores e inserção de GD. Os modelos desenvolvidos contemplam restrições técnicas e custos de materiais.

O capítulo 6 apresenta o modelo integrado para a resolução do planejamento de MT e BT. 
O capítulo 7 apresenta a metodologia desenvolvida para o remanejamento de transformadores utilizando sistemas multiagentes e Programação Linear Inteira Mista (PLIM).

O capítulo 8 descreve a aplicação da metodologia desenvolvida em redes elétricas, apresentando simulações computacionais para todos os modelos desenvolvidos.

Por fim, no capítulo 9 são apresentadas as conclusões deste trabalho, destacandose as características de cada modelo e a integração proposta. 



\section{CONCEITUAÇÃO: GERAÇÃO DISTRIBUÍDA, SERVIÇOS ANCILARES E REVI- SÃO TEÓRICA DO PLANEJAMENTO DE MT E BT}

\subsection{INTRODUÇÃO}

Neste capítulo é apresentado uma conceituação de GD, Serviços Ancilares ( $S A$ ) e os trabalhos relacionados aos planejamentos de $M T$ e $B T$, em especial aqueles que tiveram como objetivo as intervenções na rede que são tratadas neste trabalho.

O tema de planejamento de redes de distribuição tem sido tratado em muitas publicações. Durante a pesquisa bibliográfica observou-se que nos trabalhos desenvolvidos nesta área de pesquisa foram utilizadas diferentes metodologias, desde técnicas determinísticas até métodos de inteligência artificial, para encontrar, a solução ótima do problema, ou uma solução muito próxima da ótima.

\subsection{GERAÇÃO DISTRIBUÍDA}

A Geração Distribuída (GD) é uma fonte de produção de energia elétrica, geralmente de porte limitado com localização próxima ao consumidor final, que pode utilizar fontes primárias diversas com a possibilidade de integração com um sistema de cogeração. A geração de energia elétrica se desenvolve, simultaneamente, com a geração de energia mecânica ou térmica a partir da queima de um combustível tal como os derivados de petróleo, o gás natural, o carvão, a biomassa ou solar.

Conforme a ANEEL, por meio do PRODIST módulo 1 (ANEEL, 2016), define a GD como sendo: "Geração de energia elétrica, de qualquer potência, conectada diretamente no sistema elétrico de distribuição ou através de instalações de consumidores, podendo operar em paralelo ou de forma isolada". O decreto $n^{\circ} 5.163$ de 30 de julho de 2004 define geração distribuída no artigo 14 como sendo "a produção de energia elétrica proveniente de empreendimentos de agentes concessionários, permissionários ou autorizados, incluindo aqueles tratados no art. 8 da Lei no 9.074, de 1995, conectados diretamente no sistema elétrico de distribuição do comprador, exceto aquela provenientes de empreendimento:

- Hidrelétrico com capacidade instalada não superior a 30 MW e;

- Termelétrico, inclusive de cogeração, com eficiência energética inferior a setenta e cinco por cento, conforme regulação da ANEEL." 
2.2.1 Tecnologias utilizadas em Geração Distribuída

As tecnologias mais utilizadas para a geração distribuída são mostradas abaixo, conforme (BARJA, 2006) e (HADDAD, 2006).

- Sistemas fotovoltaicos;

- Turbinas a vapor;

- Turbinas a gás;

- Microturbinas a gás;

- Ciclo combinado com vapor e turbina a gás;

- Motor de combustão interna;

- Motor Stirling;

- Células a combustível;

- Sistemas híbridos;

- Turbina eólica.

É observada uma evolução constante nas tecnologias empregadas em geração distribuída, incluindo para comando, controle e medição, proporcionando uma redução no custo e aplicação em várias modalidades operativas, a saber: geração de emergência, complementação no horário de ponta e cogeração.

\subsubsection{Pequenas Centrais de Geração}

As pequenas centrais de geração são conectadas em redes de baixa tensão, tendo a sua potência nominal limitada a um determinado valor e relacionada a consumidores individuais. A contabilização da energia consumida descontando a exportada pelo consumidor diretamente nos medidores de BT, conhecida como net metering (ERGE; HOFFMANN; KIEFER, 2001) viabiliza e incentiva o uso de fontes renováveis de energia dispersos na rede elétrica.

Com a utilização de medidores bidirecionais é possível realizar um balanço entre o que foi consumido e o gerado, dentro de um período estabelecido. Tecnicamente são estabelecidas classes de consumidores e de tecnologias de geração para o uso de net metering, estabelecendo sua aplicação a tecnologias de geração renovável em pequenos consumidores (ANEEL, 2010). Na Europa os usos de pequenas centrais de geração expandiram muito, especialmente com o incentivo governamental. 
Devido ao alto custo de instalação e um elevado tempo de retorno de investimento, a disseminação da geração distribuída enfrenta dificuldades no Brasil, além do desinteresse das concessionárias por potencial perda de mercado. Após a publicação da Resolução Normativa ${ }^{\circ}$ 482, em 2012, iniciou-se no país um lento processo de difusão de micro e minigeradores distribuídos, o qual começou a acelerar a partir de 2016. A figura 2 apresenta os valores acumulados de conexões e consumidores que recebem os créditos de micro e minigeração distribuída até o dia 23/05/2017, conforme (ANEEL, 2017).

Figura 2 - Número de conexões versus número de consumidores com crédito.

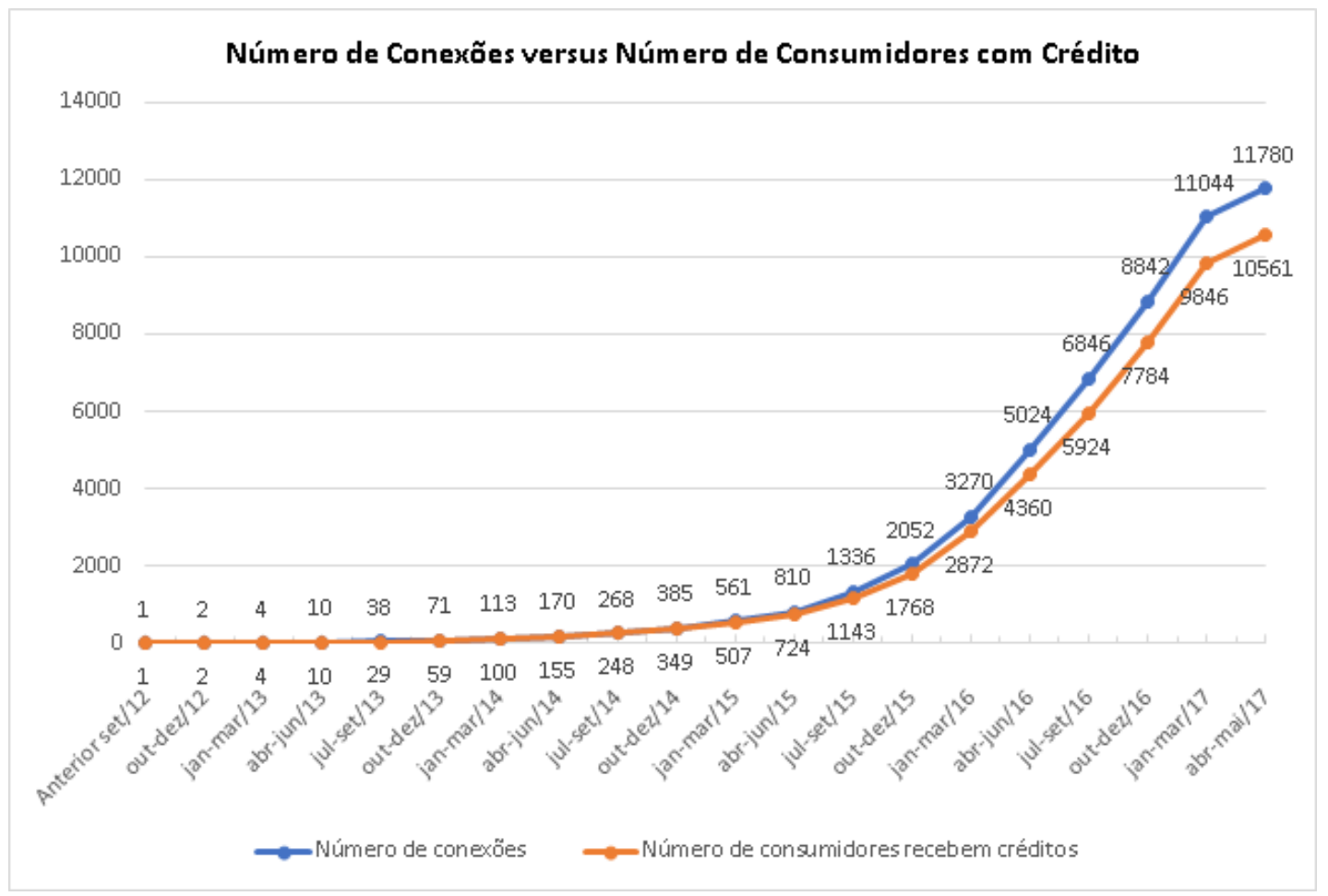

Fonte: Nota Técnica número 0056/2017-SRD/ANEEL.

\subsubsection{Conexão da Geração Distribuída no Sistema Elétrico}

A responsabilidade da realização dos estudos para a integração da GD ao sistema elétrico compete à distribuidora conforme módulo 3 do PRODIST (ANEEL, 2009). Vários estudos, tais como (MENDONÇA, 2006) e (GUEDES, 2006) foram elaborados com o objetivo de analisar os impactos na conexão da geração distribuída no sistema de distribuição. As concessionárias adotam regras mais conservadoras acerca do assunto, proporcionando limitações nos benefícios provenientes da conexão de unidades de maior capacidade. Além de restrições de valores de demanda para conexão de consumidores em cada nível de tensão, há também para a capacidade de GD. A seção 5.1 do módulo 3 do PRODIST estabelece os seguintes limites de potência para conexão a cada nível de tensão, conforme tabela 1 . 
Tabela 1 - Relação potência instalada e nível de tensão de conexão.

\begin{tabular}{c|c}
\hline Potência Instalada & Nível de Tensão de Conexão \\
\hline$<10 \mathrm{~kW}$ & Baixa Tensão \\
10 a $75 \mathrm{~kW}$ & Baixa Tensão \\
76 a $150 \mathrm{~kW}$ & Baixa Tensão / Média Tensão \\
151 a $500 \mathrm{~kW}$ & Baixa Tensão / Média Tensão \\
$501 \mathrm{~kW}$ a $10 \mathrm{MW}$ & Média Tensão / Alta Tensão \\
11 a $30 \mathrm{MW}$ & Média Tensão / Alta Tensão \\
> $30 \mathrm{MW}$ & Alta Tensão \\
\hline
\end{tabular}

Fonte: Nota Técnica número 0056/2017-SRD/ANEEL.

A GD tem a flexibilidade de implantação em curto espaço de tempo em relação às grandes centrais. Além da utilização da $G D$ para operação nos horários de ponta, evitando a flutuação no preço da energia, uma vez que as tarifas são diferenciadas nestes horários. Ainda referente à tarifa, nos casos em que seu valor cobrado pode ser diferenciado em função da localização da instalação, aumenta o interesse do investidor em implantar sua geração próximo a centros de carga, com claras vantagens para a tecnologia de $G D$.

\subsubsection{Benefícios relacionados à Geração Distribuída}

A conexão de unidades de geração distribuída na rede, tem sido avaliada e discutida em diversos trabalhos, a exemplo de (PEREIRA et al., 2004), (KOSANOVIC; BEEBE, 2005) e (CAO et al., 2006). Diversos setores são envolvidos na instalação de uma geração distribuída em um determinado ponto do sistema elétrico, a saber: produtor, concessionária, consumidores adjacentes e sociedade. Proveniente do produtor é a iniciativa de instalação de uma $G D$, analisando-a como uma fonte de receita na venda do seu excedente de energia à concessionária. Com a representatividade do órgão regulador, a sociedade pode obter benefícios ambientais, além da melhoria na qualidade e confiabilidade no fornecimento de energia por meio da descentralização da geração. Uma análise mais aprofundada de valores referente aos custos e benefícios pode ser verificado em (PEREIRA et al., 2004), (KOSANOVIC; BEEBE, 2005) e (CAO et al., 2006), permitindo uma melhor decisão sobre investimentos e subsídios relacionados ao setor.

Os principais benefícios referentes à utilização de $G D$ são listados abaixo:

- redução na emissão de poluentes quando a tecnologia de $G D$ utiliza fontes renováveis ou substitui geração com maior impacto;

- aumento da confiabilidade do sistema de distribuição;

- aumento da elasticidade entre preços e demanda da energia elétrica; 
- postergação de investimentos em transmissão e distribuição;

- possíveis reduções das perdas no sistema em função de sua localização na rede;

- melhoria na regulação de tensão;

- redução dos terrenos necessários para implementação de centrais de geração e linhas de transmissão e distribuição;

- aumento da eficiência de plantas com geração de calor ou frio, no caso de aplicação de cogeração;

- redução da dependência em relação à concessionária;

- provisão de serviços ancilares tais como reserva girante, regulação, reativos;

- ganhos com a comercialização de excedentes e redução de custos, principalmente em cogeração.

As principais desvantagens referentes à utilização de GD são listados abaixo:

- custo de implementação;

- custos de combustível;

- custo de conexão;

- aumento do nível de curto circuito e possíveis efeitos associados;

- manutenção da confiabilidade e controle do sistema para GD de grande porte;

- aumento na emissão de ruídos.

\subsubsection{Impactos na Qualidade de Energia}

A rede elétrica pode ter a sua qualidade afetada por falhas e operações de chaveamento na rede, pela ocorrência de transitórios ou distúrbios causados pela operação de cargas poluidoras, referente à ocorrência de flicker, harmônicos e desequilíbrio entre as fases. A natureza desses distúrbios está relacionada à capacidade de curto-circuito, correspondente à uma medida da impedância interna, que depende da configuração da rede, potências geradas e impedâncias de seus componentes. O ponto de conexão da GD e o tipo de tecnologia empregada pode contribuir para a melhora ou não da qualidade de energia. Abaixo são listados os aspectos técnicos que podem ser influenciados com a alocação de uma $G D$ no sistema elétrico. 


\subsubsection{Variações de tensão de longa duração}

A variação de tensão de longa duração é caracterizada pela manutenção do valor eficaz da tensão seja acima ou abaixo dos limites admissíveis por um período de tempo superior a 1 minuto. A utilização da GD pode atuar de forma positiva ou negativa com relação ao nível de tensão em regime permanente, causando impactando aos usuários finais. Quando a GD é utilizada com a finalidade de suporte de tensão, é proporcionada uma melhora na regulação de tensão. Entretanto, o suporte de tensão não é garantido, sendo que em alguns casos há que se considerar de forma bastante detalhada a atuação da GD de forma a evitar a degradação da tensão. Assim, a GD é operada de forma a não controlar a tensão, pois simplesmente fornece potência ativa a um fator de potência constante e a tensão no alimentador altera de acordo com o efeito da inserção de potência.

\subsubsection{Baixo nível de tensão relacionado a compensação de perdas na linha}

A compensação de perdas na linha é uma técnica comumente aplicada nos comutadores de tap sob carga (LTC) e nos reguladores de linha para controlar a tensão na barra de carga de um alimentador. Caso a GD esteja localizada imediatamente após esta compensação, a corrente observada pelo equipamento reduz em função da geração da $G D$, conduzindo à falhas no controle da regulação da tensão na barra de carga, acarretando em um nível de subtensão na barra.

\subsubsection{Interação com os equipamentos de regulação de tensão}

Outro aspecto a ser observado, é a interação da GD com os equipamentos de regulação. Caso a GD tenha uma potência ativa gerada variável isto pode alterar a tensão do sistema conectado de forma a causar uma constante operação de reguladores de tensão ou de bancos de capacitores reduzindo a vida útil dos equipamentos ou causar impactos na qualidade da tensão.

\subsubsection{Variações de tensão de curta duração}

A variação de tensão de curta duração é caracterizada pela manutenção do valor eficaz da tensão acima ou abaixo dos limites aceitáveis por um período de tempo entre 0,5 ciclos e 1 minuto. Caso a tensão esteja entre 0,1 e 0,9 por unidade (p.u.) chama-se a esse fenômeno de afundamento de curta duração, caso a tensão esteja entre 1,1 e 1,8 chama-se elevações de curta duração, conforme definido em (IEEE, 1995). A GD geralmente não afeta ou influi de forma determinante na ocorrência da variação de tensão de curta duração, pois esta é originada nas redes de transmissão e distribuição, podendo afetar a tensão da barra na qual cargas e geradores estão conectados. Durante afundamentos severos, cargas tais como motores de indução tendem a diminuir sua 
rotação e parar, enquanto as plantas de geração síncronas e assíncronas tendem a acelerar podendo levar a instabilidade.

\subsubsection{Distorções da forma de Onda}

As unidades de GD que possuem uma interface baseada em conversores eletrônicos podem introduzir correntes harmônicas na rede. Quando os geradores convencionais são conectados à rede, podem alterar a impedância harmônica do sistema sendo necessária uma avaliação da resposta dos harmônicos já existentes na rede sob essa nova condição de impedância. Os sistemas fotovoltaicos também contribuem para a injeção de harmônicos no sistema elétrico.

\subsubsection{Variações da frequência}

Variações de frequência na rede podem ser ocasionadas em virtude do desequilíbrio entre demanda e suprimento de energia. Deve-se monitorar os desvios para que não ultrapassem uma margem pré-definida, permitindo a operação de processos industriais e de cargas que dependem da frequência para um bom funcionamento. Caso essas variações ocorram de forma não controlada será exigido grande esforço do operador da rede para manter as variações de frequência dentro dos limites permitidos. Assim, é uma preocupação por parte da GD na busca de maior eficiência das plantas, para que sua operação evite impactos referente à variações de frequência mediante sua conexão na rede elétrica.

\subsubsection{Flutuação de tensão}

A flutuação de tensão, conhecida como flicker, é uma variação dinâmica na tensão da rede que pode ser causada tanto pela inserção de uma GD quanto pela carga. A análise da flutuação de tensão deve ser considerada nas situações nas quais as GDs podem parar e iniciar a geração frequentemente na situações que podem estar sujeitos à continua variação na fonte primária de energia. Alguns tipos de GD que requerem avaliações por causa de seu potencial de geração de flicker, incluem:

- Conexão e desconexão de geradores de indução;

- Operação de turbinas eólicas;

- Operação de geradores fotovoltaicos.

\subsection{SERVIÇOS ANCILARES}

Em essência os serviços ancilares são reservas operacionais de potências ativas e reativas necessárias para operar o sistema com um grau de segurança e qualidade 
adequado. Segundo Shahidehpour (SHAHIDEHPOUR, 2002), muitos serviços como suporte de tensão, regulação e reservas de potência com níveis variáveis de tempo de resposta de suporte de tensão são classificados como serviços ancilares. Desta forma, os serviços ancilares são definidos como os serviços que contribuem para segurança e confiabilidade do fornecimento de energia elétrica, sendo importante à operação eficiente do sistema elétrico em um ambiente de mercado.

\subsubsection{Visão Geral dos Serviços Ancilares}

Geralmente os serviços ancilares são definidos como os serviços essenciais para que possa ser assegurada a operação segura de um sistema de potência. Desta forma, os serviços ancilares podem ser aplicados nas atividades:

1. Controle de perfil de tensão do sistema;

2. Manter a estabilidade do sistema;

3. Reserva para contingências;

4. Capacidade de restauração autônoma (black-start);

5. Suprimento de perdas.

Conforme GOMES et al. (1997), os principais participantes do mercado que fornecem ou requerem os serviços são:

- Geradores;

- Provedores do sistema de transmissão;

- Produtores independentes de energia;

- Corretores;

- Gestores comerciais de energia;

- Concessionárias de distribuição;

- Operador independente do sistema;

- Consumidores (carga ou demanda).

Cada participante do mercado pode ser classificado como um provedor ou usuário de serviços ancilares de acordo com a sua posição. Conforme Gjerde (GJERDE, 2007) pode ser feita uma distinção entre os serviços de balanço de geração e demanda, serviços de interconexão e serviços locais, a saber: 
- Serviços de balanço geração e demanda:

- Resposta de regulação: É a habilidade de responder ao desbalanços calculados entre geração e demanda.

- Acompanhamento de carga: É a habilidade de responder a qualquer sinal de demanda.

- Reserva de contingência: É a habilidade de responder a eventos inesperados.

- Serviços de interconexão:

- Serviços de resposta de frequência: O serviço provido por meio de um sistema de controle baseado exclusivamente em variações de frequência e de forma constante.

- Serviços de proteção especiais: Os serviços são usados para aprimorar a capacidade de transferência sem necessidade de construir novas linhas.

- Serviços locais:

- Serviços de reativos: É a habilidade de prover potência reativa, reservas e suporte de tensão com o propósito de controlar e suportar o transporte de potência ativa do sistema.

- Autorrestabelecimento: É a habilidade de reinício autônomo.

De acordo com a distinção apresentada dos serviços ancilares, pode-se identificar como principais os seguintes serviços: suporte de potência reativa e autorrestabelecimento. Esses serviços serão detalhados nas seções seguintes.

\subsubsection{Suporte de Potência Reativa}

Este serviço tem a finalidade de controlar o fluxo de potência reativa sendo importante para que o sistema de potência possa operar dentro de limites aceitáveis de tensão. Em virtude disso, este serviço também é conhecido como controle de tensão. A inserção do fluxo de potência reativa pode conduzir a modificações significativas de valores de tensão no sistema, implicando na necessidade de manter o equilíbrio de potência reativa entre fontes de geração e pontos de atendimento de demanda.

Diferentemente do controle de frequência cuja abrangência compreende todo o sistema, o suporte de potência reativa atua de forma limita em uma pequena região. Outro aspecto importante refere-se ao fato da necessidade de manter reservas de reativos que sejam suficientes para responder a qualquer mudança nos requisitos do sistema. Na ocorrência de perda de geradores, linhas de transmissão e equipamentos reativos, as exigências reativas de toda a rede serão afetadas. Desta forma, as reservas reativas 
podem ser alocadas de maneira otimizada na rede para poder responder de forma eficaz, além de manter a segurança de todo os sistema. Um aspecto a ser considerado na utilização deste tipo de reserva é relacionado ao elevado custo de investimento nos equipamentos de fornecimento de potência reativa, porém tem um custo marginal de operação inexpressivo.

Para o efetivo controle de tensão, podemos ter o controle básico e o controle enriquecido de tensão (REBOURS et al., 2007). No controle básico são levados em consideração os requisitos mínimos que as unidades geradoras têm de cumprir ao serem conectadas no sistema. O controle enriquecido é um serviço não obrigatório que complementa o controle básico. Assim (REBOURS et al., 2007) classifica o controle de tensão nos níveis, a saber:

- Controle primário de tensão: Controle automático local que mantém a tensão dentro de limites estabelecidos;

- Controle secundário de tensão: Controle automático centralizado que coordena a ação dos reguladores locais na injeção de potência reativa em um determino local especifico do sistema;

- Controle de tensão terciário: Controle manual do fluxo de potência reativa no sistema.

\subsubsection{Autorrestabelecimento}

A capacidade de se recuperar de uma interrupção do sistema, seja de forma parcial ou total é definida como reestabelecimento. Para realizar esta operação as estações necessitam de fontes de energia para que possa ser possível o reestabelecimento, em condições normais o próprio sistema de transmissão ou distribuição seria esta fonte. No caso de emergências, as fontes de energia seriam estações de autorrestabelecimento compostas por pequenos geradores locais com a finalidade de injetar energia no sistema.

Por questões econômicas o operador do sistema procura contratar geradores que podem ser eficazes em área do sistema, pois torna-se inviável que uma grande parte de estações geradoras tenham um serviço de reestabelecimento. Segundo National Grid Company (NGET, 2009), o reestabelecimento não é muito utilizado, uma vez que é muito raro o sistema apresentar um colapso por completo.

\subsection{REVISÃo TEÓRICA do PLANEJAMENTO DE MT E BT}

Os primeiros esforços no sentido de obter uma metodologia para o auxilio no planejamento das redes de distribuição primárias concentravam-se exclusivamente no problema da localização das novas subestações. Masud, em 1974 e em 1978 (MASUD, 
1974; MASUD, 1978) foi pioneiro ao estudar essas questões. Seus trabalhos consistiam na utilização de um modelo matemático em variáveis inteiras para obter a localização e o dimensionamento ótimo das subestações.

A primeiras tentativas de se representar o custo da rede de alimentadores foram feitas por Holt e Crawford (HOLT; CRAWFORD, 1975) e por Adams et al. (ADAMS et al., 1984). Nestes trabalhos, o custo da rede era representado através do momento elétrico, dado pelo produto distância x carga. Os modelos, baseados no problema de transporte da programação linear, continham uma série de deficiências: não conseguiam considerar a rede existente, não contemplavam o custo de perdas, não tratavam a questão de custos fixos das subestações e não consideravam a capacidade dos alimentadores.

Um modelo mais apurado para o planejamento dos alimentadores primários foi proposto por (THOMPSON; WALL, 1981), onde a área do planejamento era dividida em quadrículas e, em seguida, transformada em um grafo, de forma a fornecer uma aproximação da rede real. A necessidade de se tratar o problema de forma mais realista levou à utilização de modelos mais elaborados de programação inteira mista, permitindo representar a forma adequada o custo fixo das subestações e dos alimentadores. Entretanto, a utilização destes modelos esbarra no crescimento exponencial do esforço do cálculo com a dimensão do problema. Para contornar este problema, opta-se pela simplificação do modelo, ignorando-se os custos fixos dos alimentadores. Uma formulação mais leve é o resultado do processo, com variáveis binárias apenas para as subestações. Esta metodologia de caráter estático pode ser observada nos trabalhos de Hindi e Brameller (1977), Thompson e Wall (1981), Gonen e Foote (1981) e Sun et al. (SUN; FARRIS; COTE, 1982).

Outra simplificação possível é a divisão do problema em subproblemas. Inicialmente trata-se o problema de localização e dimensionamento das subestações e, em seguida, considera-se o roteamento dos alimentadores. Backlund e Bubenko (BACKLUND; BUBENKO, 1979) resolveram o problema de roteamento de alimentadores com uma técnica baseada em roteamento de veículos. Rotas de custo mínimo foram obtidas, começando e terminando nas subestações e as rotas foram abertas em alguns pontos determinados para satisfazer critérios de radialidade da rede. No trabalho de Fawzi (FAWZI; ALL; EL-SOBKI, 1983) o roteamento é efetuado através de um método heurístico considerando um custo fixo por meio de um ajuste de custo linear, realizando a abertura da rede nos arcos de menor fluxo.

Os primeiros trabalhos a realizarem uma abordarem dinâmica do problema pode ser vista em El-Kadi (EL-KADI, 1984) e Gonen e Ramirez-Rosado (GONEN; RAMIREZ-ROSADO, 1987), esta abordagem se contrapõem a proposta pseudo-dinâmica apresentada por Sun et al. (SUN; FARRIS; COTE, 1982). Entretanto, a complexidade dos modelos limitou a aplicação dos métodos propostos a sistemas de pequeno porte. 
O trabalho de Kauhaniem et al (KAUHHANIEMI; KAUHHANIEMI; LAKERVI, 1988) apresenta um modelo matemático para o dimensionamento de redes que engloba a rede primária e secundária. Este modelo difere dos modelos baseados em grafos que são normalmente encontrados em outros trabalhos tais como o de Cruz et al (CRUZ; SMITH; MATHEUS, 1999). O modelo de otimização determina a quantidade de subestações, a capacidade nominal dos transformadores e a bitola de condutores.

Gonen e Ramirez-Rosado (GONEN; RAMIREZ-ROSADO, 1986) analisaram 16 publicações, classificando-as segundo a abordagem realizada: dinâmica, estática ou pseudo-dinâmica. Uma grande quantidade dos artigos utilizando a abordagem estática tratava de forma independente o problema de alocação das subestações e o roteamento dos alimentadores. Outra análise importante realizada nesse trabalho foi a classificação dos trabalhos que tratavam o problema de uma forma global, correspondendo a 9 no total de 16 trabalhos avaliados. Os autores também classificaram os artigos de acordo com a metodologia adotada: programação matemática (13), programação dinâmica (2) e métodos heurísticos (1).

Outro trabalho importante para a área, foi realizado por Khator e Leung (KHATOR; LEUNG, 1997), onde foram avaliados 38 trabalhos, sendo 24 dos quais posteriores à revisão de Gonen e Ramirez-Rosado (GONEN; RAMIREZ-ROSADO, 1986). A avaliação classificou os trabalhos em duas categorias a saber: planejamento sob condições de emergência (15 artigos) e planejamento sob condições normais (23 artigos).

Posterior a análise de Khator e Leung (KHATOR; LEUNG, 1997), Vaziri, Tomsovic e Gonen (VAZIRI; TOMSOVIC; GONEN, 2000) publicaram uma revisão analisando 42 trabalhos, tendo 6 dos quais posteriores a análise realizada em (KHATOR; LEUNG, 1997). A classificação utilizada foi baseada no método de otimização e na abordagem utilizados por cada trabalho. Ao final da análise verificou-se um total de 36 trabalhos baseados em programação matemática e 9 trabalhos sobre métodos heurísticos. $O$ total de trabalhos que utilizaram uma abordagem mono-período foi de 33, contra 11 trabalhos que utilizaram uma metodologia multi-período.

No trabalho de Aoki et al (AOKI. et al., 1990), a programação inteira mista foi combinada com uma das mais eficientes técnicas heurísticas de otimização de redes radiais chamada de Método de Mudança de Ramos. Este algoritmo híbrido é menos sensível ao rápido crescimento em complexidade comparado com o crescimento dos números de pontos de demanda a serem supridos, mas não consegue garantir o ponto ótimo de acordo com a natureza de aproximação do método adotado.

Chen e Wu (CHEN; WU, 1998) apresentam uma formulação de programação dinâmica para a alocação de transformadores de acordo com a carga de consumidores para o aumento do ciclo de vida do equipamento. Neste trabalho, o faseamento de consumidores foi formulado através de programação dinâmica. 
No trabalho de Islam e Ghani (ISLAM; GUANI, 1999), foi desenvolvida uma solução empregando técnicas heurísticas para a determinação do material e seção transversal dos cabos do alimentador considerando critérios técnicos e financeiros. A metodologia apresentada avalia a capacidade de condução de corrente dos condutores, queda de tensão em cada trecho do alimentador, além das perdas técnicas.

Uma solução comumente aplicada para o planejamento operacional da rede de MT é a aplicação de capacitores na rede. Antes de 1950, a alocação de capacitores era feita no ponto onde a subestação era conectada ao alimentador de distribuição. A colocação de capacitores ao longo do alimentador primário de distribuição mostrou-se favorável, desta forma a instalação de capacitores seria mais próxima às cargas e poderiam ser usados equipamentos de menor porte. Entretanto, a complexidade do problema cresceu, pois agora era preciso determinar onde, ao longo do alimentador, de qual tamanho, e em que quantidades, capacitores deveriam ser aplicados aos alimentadores primários de distribuição. No trabalho de Neagle e Samson (NEAGLE; SAMSON, 1956) é feita uma análise da instalação de capacitores shunt nos alimentadores, considerando uma carga uniformemente distribuída ao longo dos mesmos.

Cook (COOK, 1959) também analisou a aplicação de bancos de capacitores fixos a uma carga uniformemente distribuída. A otimização considerada no trabalho focou na redução de perdas de energia considerando uma carga variável no tempo. Cook estabelece que o local de bancos de capacitores fixos deveria estar baseado na carga reativa média, e então definiu a regra dos $2 / 3$. Nesta regra é estabelecido que para a máxima redução de perdas, um banco de capacitores com tamanho dois-terços do pico de carga reativa, deveria ser instalado a uma distância da subestação igual a dois terços do comprimento total do alimentador.

No trabalho de Duran (DURAN, 1968), o problema é tratado como uma abordagem de programação dinâmica, utilizando um processo multi-estágio de otimização. Chang (CHANG, 1967) desenvolve uma análise matemática da aplicação de capacitores shunt para redução de perdas em um alimentador de distribuição. Equações generalizadas para calcular redução de perdas em um alimentador apresentando cargas de combinação qualquer, cargas concentradas e uniformemente distribuídas, são derivadas, e as condições para redução ótima de perdas são desenvolvidas. Os resultados são apresentados em famílias separadas de curvas para determinação conveniente de redução de perdas devido ao uso de capacitores.

Métodos analíticos para alocação de capacitores foram também apresentados por Bae (BAE, 1978), revisitando o trabalho de Neagle e Samson (NEAGLE; SAMSON, 1956), mas ao contrário desses, Bae investigou aplicação de capacitores sob uma grande gama de condições de carga reativa. Capacitores são primeiro alocados de maneira ótima para um nível de carga fixo. A metodologia é estendida para determinar as localizações 
ótimas dos capacitores para todos os níveis de carga acima do nível fixo, sem levar em conta o tempo de duração de cada nível de carga.

Uma abordagem utilizando técnicas heurísticas foi mostrada por Kaplan (KAPLAN, 1984) que, ao contrário de muitas abordagens anteriores, não assume simplificações comumente usadas. As principais diferenças propostas são: a) As cargas não são consideradas distribuídas uniformemente nos alimentadores; b) Custos de instalação são considerados; c) Tamanho não uniforme dos condutores; d) Consideração sobre a disponibilidade das unidades de potências especificadas; e) Possibilidade de instalação de capacitores em troncos e ramais.

O método heurístico determinava inicialmente as localizações e tipos (fixo ou chaveado) para o menor tamanho de banco de capacitores padrão disponível. No próximo passo, é realizada uma tentativa de melhorar os ganhos pela adição de grandes bancos ou pela combinação de pequenos bancos em grandes unidades. O modelo necessário para sistemas de distribuição radiais é consideravelmente complicado pela consideração de que alimentadores primários de distribuição são assimétricos, multiaterrados, suprem cargas desbalanceadas, e envolvem ramais trifásicos, bifásicos, e monofásicos.

Baran e Wu em (BARAN; WU, 1989) formulam o problema como um problema de programação não linear inteira mista. O método de solução é dividido em dois níveis, os custos dos bancos de capacitores são aproximados por uma função linear e a carga é considerada fixa.

Vários pequenos subsistemas representam o sistema de distribuição no trabalho de Santoso e Tan (SANTOSO; TAN, 1989), onde cada qual é otimizado. No processo são atualizadas variáveis denominadas iterações e o processo é repetido até que o valor absoluto das economias entre iterações seja pequeno. Os problemas dos subsistemas são resolvidos por um método de busca pelo gradiente e o custo dos capacitores é uma função diferenciável do tamanho do banco.

Vários aspectos foram sendo incorporados ao longo do tempo ao planejamento de redes elétricas, na década de 90 foi adicionada a questão da confiabilidade de redes ao problema. A abordagem deste problema passa por uma avaliação das possibilidades de falhas dos equipamentos, do tempo de reparo e dos custos econômicos causados por uma contingência no sistema. Esta preocupação é abordada nos trabalhos de Kjolle (KJOLLE; ROLFSENG; DAHL, 1990), Jonnavithula e Billington (JONNAVITHULA; BILLINGTON, 1996), Tang (TANG, 1996), Chowdhury e Koval (CHOWDHURY; KOVAL, 2000) e Ramirez-Rosado e Bernal-Augustín (RAMIREZ-ROSADO; BERNAL-AGUSTÍN, 2001).

Com a popularidade da Inteligência Artificial $(I A)$ muitos pesquisadores investi- 
garam sua possibilidade de uso em aplicações de engenharia de potência. Em particular, algoritmos genéticos $(A G)$, simulação de resfriamento, redes neurais artificiais $(R N A)$ e teoria de conjuntos Fuzzy foram implementados no problema de planejamento de redes elétricas.

Alguns exemplos de implementações utilizando algoritmos genéticos podem ser encontradas nos trabalhos de Miranda et al. (MIRANDA; RANITO; PROENÇA, 1994) e Ramirez-Rosado e Bernal-Augustín (RAMIREZ-ROSADO; BERNAL-AGUSTÍN, 2001). Outras referências são encontradas na coletânea apresentada por Miranda et al. (MIRANDA; SRINIVASAN; PROENÇA, 1998). Um dos primeiros autores a aplicarem a técnica de otimização por algoritmos genéticos ao problema do planejamento do sistema de distribuição foi Miranda et al (MIRANDA; RANITO; PROENÇA, 1994). Neste trabalho é realizada uma abordagem multi-período considerando a confiabilidade do sistema.

Ramirez-Rosado e Bernal-Augustín (RAMIREZ-ROSADO; BERNAL-AGUSTÍN, 1995) propõem uma série de artigos usando algoritmos genéticos voltados ao problema do planejamento de redes. Nos trabalhos (RAMIREZ-ROSADO; BERNAL-AGUSTÍN, 1998) o problema do planejamento é apenas voltado para a minimização de custos. Em (RAMIREZ-ROSADO; BERNAL-AGUSTÍN, 1998) é utilizada uma codificação binária e resultados promissores são obtidos para redes de tamanhos reais. Já em (RAMIREZ-ROSADO; BERNAL-AGUSTÍN, 2001) uma nova codificação é usada e novos operadores são desenvolvidos, fazendo o aprimoramento do modelo desenvolvido em (RAMIREZ-ROSADO; BERNAL-AGUSTÍN, 1995). No artigo (RAMIREZ-ROSADO; BERNAL-AGUSTÍN, 2001), a metodologia é estendida para englobar o problema da confiabilidade, além da minimização de custos.

Vários trabalhos são desenvolvidos para a parte de alocação de capacitores aplicando técnicas de IA, em Chiang et al. (CHIANG; BARAN, 1990) é apresentada uma formulação levando em consideração aspectos práticos dos capacitores, as restrições de carga, e restrições de operação em diferentes níveis de carga. A formulação é um problema de otimização combinatória com uma função objetivo não diferenciável. Uma metodologia de solução baseada em simulação de resfriamento (simulated annealing) para determinar as localizações para instalação de capacitores, os tipos e tamanhos dos capacitores a serem instalados, e os ajustes de controle desses capacitores em diferentes níveis de carga é proposta. Os autores reivindicam que a metodologia pode fornecer a solução ótima global para o problema geral de alocação de capacitores.

No trabalho de Yang et al. (YANG; HUANG; HUANG, 1995) é proposta uma abordagem utilizando o método de Busca Tabu (TS) para o problema de alocação de capacitores em um sistema de distribuição radial. A meta usando uma solução baseada em TS é para determinar os locais de instalação, os tipos, potência e quantidade dos 
bancos de capacitores e estabelecer os esquemas de controle dos bancos em diferentes níveis de carga.

Chiang et al (CHIANG et al., 1994) resolvem o problema de alocação de capacitores em redes de distribuição de grande escala utilizando uma metodologia de solução baseada em simulação de resfriamento. No modelo são considerados diferentes níveis de carga, restrições de carga, restrições de rede e de operação (nível de tensão). O problema é formulado como um problema de otimização combinatória com uma função objetivo não diferenciável.

Uma abordagem híbrida é apresentada por Miu et al. (MIU; CHIANG; CHIANG, 1997), sendo desenvolvido um algoritmo em dois estágios para alocação, realocação, e controle de capacitores, de sistemas gerais de distribuição de grande escala e desbalanceados. O primeiro estágio do algoritmo proposto consiste de um algoritmo genético seguido pelo segundo estágio que consiste de um método heurístico baseado em sensibilidades construído para o problema.

Mekhamer et al. (MEKHAMER et al., 2002a; MEKHAMER et al., 2002b) introduzem duas novas técnicas heurísticas para compensação reativa em alimentadores radiais de distribuição. Os métodos podem ser considerados como ideias generalizadas que emergiram de estratégias de buscas heurísticas e conduzem a resultados melhores. Os métodos formulados são derivados e as técnicas são aplicadas a três alimentadores. Um novo algoritmo utilizando a técnica variacional é apresentado para obtenção da alocação ótima de capacitores de acordo com tamanhos padrões disponíveis de capacitores.

No trabalho de González (GONZÁLEZ, 2003) são apresentadas inovações conceituais e de implementação utilizando abordagem por programação dinâmica para a solução do problema de instalação e dimensionamento de capacitores fixos em redes de distribuição. Outra abordagem do trabalho refere-se ao problema de controle de capacitores chaveados propondo duas alternativas. A primeira desenvolve uma versão de sistemas complexos adaptativos, os chamados sistemas classificadores. A segunda corresponde a uma especialização dos conceitos de programação dinâmica desenvolvidos para o problema de instalação de capacitores.

Uma abordagem utilizando raciocínio aproximado para determinar nós candidatos é mostrado em Balakumaran e Thanuskodi (BALAKUMARAN; THANUSKODI, 2004). Neste trabalho os índices de tensão e de redução de perdas de potência de nós de sistemas de distribuição são modelados por funções de pertinência fuzzy. A determinação da adequabilidade de cada nó a alocar capacitores no sistema de distribuição é feita por um sistema especialista fuzzy contendo um conjunto de regras heurísticas.

Em Menenes e Mantovani (2013), os autores utilizam um algoritmo de busca tabu para alocação e operação ótima de unidades de GD e o projeto de proteção de rede 
para melhoria da confiabilidade.

A alocação ótima de unidades de GD no planejamento de $M T$ levando em consideração as incertezas aleatórias de geração renovável e demanda de carga é avaliada em (ZHANG et al., 2017).

No trabalho de (KAREEM et al., 2016) é apresentado uma revisão das técnicas para otimizar a instalação de unidades de GD e uma análise dos seus efeitos na rede e nos consumidores. Outra contribuição é a realização de comparação entre os métodos para a localização ideal de GD avaliados no estudo.

Em Rahmani et al. (2017) é avaliada a distorção de harmônicos e mudança na corrente de curto-circuito, sendo proposto o dimensionamento ótimo das fontes de GD de modo que o esquema de proteção de rede não sofra alterações.

Uma visão geral da abordagem utilizando o algoritmo de Enxame de Partículas para determinar a posição ótima da GD na rede de MT é mostrado em (NIAZI; LALWANI, 2017), examinando e segregando os vários modelos e métodos nesta aplicação.

Lei et al. (2017) avalia um método para a localização e dimensionamento da GD na rede de distribuição de $M T$, considerando o problema de reconfiguração da rede e de alocação da GD em conjunto. A alocação de GD é baseado em uma estrutura de rede fixa, que é supostamente inalterável durante o período de planejamento, não considerando a dinâmica da reconfiguração de rede. O objetivo é minimizar os custos totais da rede durante o planejamento considerando a reconfiguração da rede.

Uma abordagem utilizando SMA é mostrada em (PENG et al., 2017), avaliando a resposta de novos fornecedores ao serem solicitados de fornecimento de energia para a rede. $\mathrm{O}$ estudo propõe definições de políticas de quantificação no fornecimento de energia por consumidor de maneira que possa ter uma melhor resposta de perfil de energia para o sistema.

No trabalho (AMPOFO; OTCHERE; FRIMPONG, 2017) é investigado o efeito da inserção de GD nos limites térmicos das linhas de distribuição e o aumento do nível de tensão. Os resultados demonstram que o aumento do nível de tensão é o fator limitante para a determinação do fator de penetração da GD nas redes.

Zehir et al. (2017) avalia os impactos do uso de GD em redes de BT referentes à violação do limite de tensão, sobrecargas dos cabos e aumento das perdas de rede. $\mathrm{O}$ estudo determina a localização e o dimensionamento das unidades de $G D$, bem como uma abordagem de gerenciamento nas redes para mitigar os impactos negativos.

A localização de GD com o objetivo de minimização de perdas elétricas é avaliada em (SAINI; KAUR, 2016), sendo descritas várias técnicas para obter a localização ideal das unidades $G D$ e seus tamanhos preliminares para a redução de perdas. Os resultados 
obtidos demonstram uma redução de perdas de energia para as redes analisadas de até $49,58 \%$ na rede de referência da IEEE de 12 barras.

Montoya et al. (2017) apresenta um modelo de programação não linear para a operação de sistemas de distribuição considerando a inserção de GD. Na formulação são considerados os custos da operação da rede, redução da emissão de gases de efeito estufa, redução das perdas elétricas e melhora no perfil de tensão. O modelo matemático desenvolvido reduziu os impactos gerados pela emissão de gases de efeito estufa, além de ser um bom indicador de sensibilidade para a localização e dimensionamento das unidades de GD.

Em (SIMONE; SALLES, 2017) é realizada uma análise dos impactos financeiros na receita das concessionárias no Brasil com o aumento da penetração da GD nas redes. Em análise preliminar é estimado que o a queda do EBITD $A^{1}$ pode ser de $38 \%$ até 2025 , podendo levar à incapacidade das concessionárias em realizar novos investimentos para a modernização do sistema de distribuição.

\subsection{CONCLUSÕES DO CAPÍTULO}

A pesquisa da literatura técnica associado ao tema do planejamento de redes de distribuição expõe as diferentes técnicas utilizadas na resolução deste problema, principalmente quando se trata da minimização de custos e de intervenções a serem realizadas na rede.

Percebe-se que as operações destinadas para a melhora da qualidade de sistemas de distribuição são bem conhecidas, e destaca-se a dificuldade de encontrar a solução ótima devido à natureza combinatória do problema. Durante várias décadas foram desenvolvidos vários métodos para resolver o problema do planejamento podendo ser classificados em quatro categorias: analíticos, de programação numérica, heurísticos e baseados em inteligência artificial. A complexidade do problema constitui um aspecto impeditivo para a aplicação de algumas técnicas. Além disso, os algoritmos os quais podem considerar muitos dos parâmetros requerem mais dados detalhados do sistema, e tendem a ser mais difíceis de serem implementados.

Com relação ao planejamento de redes de $B T$, poucos trabalhos são encontrados, sendo que a grande maioria dos trabalhos tratam apenas do planejamento a longo prazo, não considerando o planejamento operacional. Geralmente o planejamento das redes de $M T$ e $B T$ são tratados na literatura pesquisada sem uma integração, devido a sua complexidade e relações físicas e elétricas existentes entre os sistemas.

1 O EBITDA é a sigla para lucro antes de juros, impostos, depreciação e amortização. Sendo assim, esse indicador corresponde a uma forma de calcular o resultado de empresa, sem levar em consideração estes itens (RODRIGUES; GOMES, 2016). 
A utilização da alocação da GD para melhora nos critérios técnicos para as redes de $M T$ e $B T$ é objeto de estudo em vários trabalhos, sendo uma alternativa a ser utilizada nos cenários de planejamento. 



\section{METAHEURÍSTICAS APLICADAS DO PLANEJAMENTO DE REDES ELÉTRI- CAS}

Neste capítulo, são apresentadas as ferramentas utilizadas para solução dos modelos matemáticos para o planejamento operacional de MT e BT. Serão abordados tópicos relativos a problemas de otimização, a saber

- Conceitos na formulação de problemas de otimização multiobjetivo;

- Fundamentos teóricos e estrutura da metaheurística Algoritmo Genético;

- Conceitos e os principais aspectos práticos para implementação de algoritmos genéticos;

- Conceitos e os principais aspectos práticos de Sistema de Multiagentes.

\subsection{OTIMIZAÇÃO MULTI-OBJETIVO}

Os planejamento de MT e BT tratados nesta tese podem ser considerados como um problema de otimização combinatória, uma vez que visa à utilização ótima de um conjunto de recursos, de acordo com a disponibilidade e com o objetivo de minimização do custo ou a maximização do lucro. Existem várias técnicas para resolver problemas de otimização combinatória, cabendo destacar:

- Programação matemática (inteira mista);

- Métodos heurísticos;

- Metaheurística (algoritmos genéticos, simulated annealing, busca tabu, entre outros);

- Métodos híbridos.

A diferença entre programação matemática e metaheurísticas está na busca pelo ótimo e pela aceitação de uma boa resposta. O principal argumento utilizado pelos adeptos de metaheurística é que, como o modelo matemático é uma abstração da realidade, o ponto ótimo obtido pela programação matemática é um ponto idealizado, não é real. A primeira justificativa para este fato é que a própria construção do modelo se baseia em hipóteses que levam a uma simplificação da realidade. A segunda é associada aos parâmetros e dados de entrada utilizados na simulação do modelo (ALLE, 2003). Por outro lado, os adeptos de programação matemática destacam as principais vantagens da programação matemática em relação às demais abordagens (heurísticas, metaheurísticas e de inteligência artificial), a saber (ALLE, 2003): 
- A capacidade de traduzir o problema sistematicamente em uma série de equações, inequações e variáveis, que tornam explícita a relação entre os componentes;

- O vasto número de algoritmos de solução disponível para a solução de modelos de programação matemática que, no caso de problemas convexos, asseguram convergência para o ótimo em um número finito de iterações.

- A possibilidade de se obter uma estimativa rigorosa do melhor valor possível para a função objetivo de problema de programação inteira mista com relação convexa.

\subsection{O CONCEITO DE MODELAGEM}

A modelagem procura representar uma abstração através de uma visão bem estruturada da realidade. Relacionados à área de programação matemática, os modelos são interpretados como sendo representações simplificadas da realidade que preservam, para determinadas situações e enfoques, uma equivalência adequada. O poder de representatividade é a característica do modelo que o torna desejável. A capacidade de simplificação lhe confere uma aplicabilidade e uma implementação viável do ponto de vista matemático e computacional. O processo de verificação da representatividade de um modelo é chamado de validação do modelo, sendo uma etapa indispensável em qualquer procedimento científico (GOLBARG; LUNA, 2000).

A finalidade dos modelos é configurar uma importante ferramenta de auxílio ao processo de tomada de decisões, tendo como objetivo um melhor aproveitamento dos recursos disponíveis nos processos analisados. Os modelos podem ser entendidos como um conjunto de equações, inequações e dependências lógicas, que correspondem a relacionamentos apresentados por estruturas reais. Segundo Williams (WILLIANS, 1999), os motivos principais para a elaboração de modelos são:

- O procedimento de construção de um modelo geralmente revela relacionamentos que não são evidentes para um grande número de pessoas, propiciando um melhor entendimento do objeto que está sendo modelado;

- É usualmente possível analisar matematicamente um modelo, sugerindo novas tendências e procedimentos que podem não ser aparentes;

- Um modelo permite a realização de experimentos.

A complexidade de um modelo está relacionada diretamente ao meio ambiente, ao domínio de atuação e a dinâmica do processo (SUNTHERLAND, 1975). A figura 3 apresenta o relacionamento entre o meio ambiente, ao domínio de atuação e a dinâmica do processo, sendo mostrado um espaço viável para a concepção e aplicação de modelos de otimização. O plano interior define modelos determinísticos tratáveis 
e de pequeno porte. $\mathrm{O}$ plano exterior define modelos tratáveis que apresentam uma dinâmica estocástica com um número médio de variáveis. Um espaço viável para a concepção e aplicação de modelos de otimização pode ser definido entre os planos interior e exterior. Pode-se constatar também que a complexidade das situações reais impossibilita a concepção de modelos em um grande espaço definido pelo trinômio meio ambiente, domínio da atuação e dinâmica do processo.

Figura 3 - Espaço viável para a aplicação e concepção de modelos

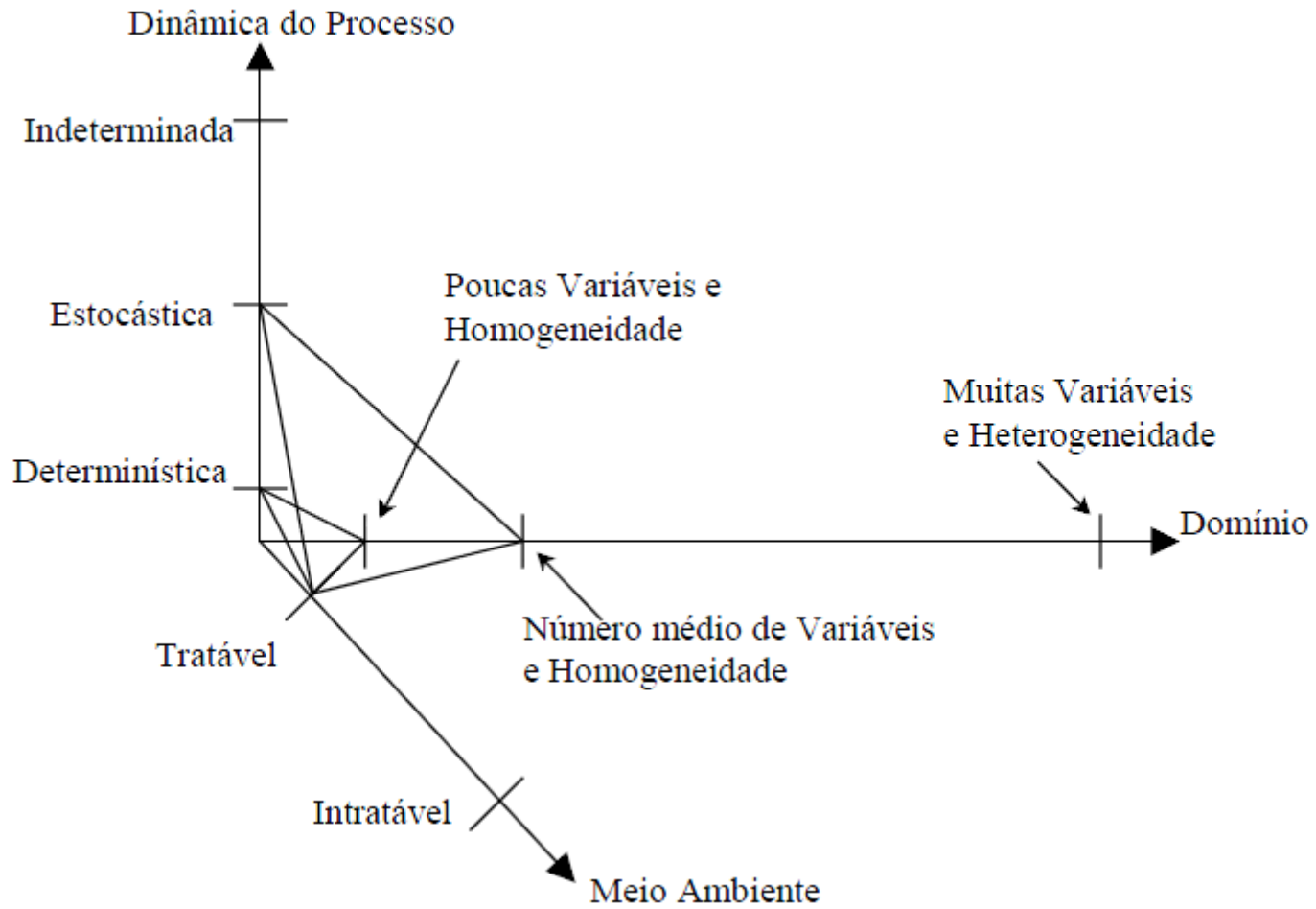

Fonte: Elaboração própria.

A abordagem sistêmica surge como sendo uma boa estratégia para a elaboração dos processos de modelagem. Esta abordagem permite a configuração de um mapeamento entre a realidade e o modelo a ser representado. Dentro desta abordagem sistêmica, modelar significa representar a realidade através de sistemas de substituição estruturados denominados de modelos. A fase de formulação do modelo é a fase mais crítica e importante do processo, pois através dela é obtida a concepção e visão matemática do modelo. Esta estruturação matemática é obtida através de processos que captam o poder de síntese e a experiência do projetista. Nesta etapa também são efetivadas as restrições do modelo, as variáveis a serem utilizadas e a adequação do modelo ao universo de análise. Os modelos podem ser classificados como descritivos, físicos, simbólicos e procedimentais (EMSHOFF; SISSON, 1970). Os modelos descritivos são expressos em linguagem corrente, porém são muito limitados, uma vez que seu método de predição é interno. Os modelos físicos procuram fazer uma representação 
em tamanho reduzido do sistema a ser estudado, possuem um alto custo e são muito específicos. Os modelos procedimentais podem ser também denominados de simulação. Um processo de modelagem na ótica operacional pode ser demonstrado pela figura 4 que representa um fluxograma básico para a construção de modelos.

Figura 4 - Fluxograma básico para construção de modelos

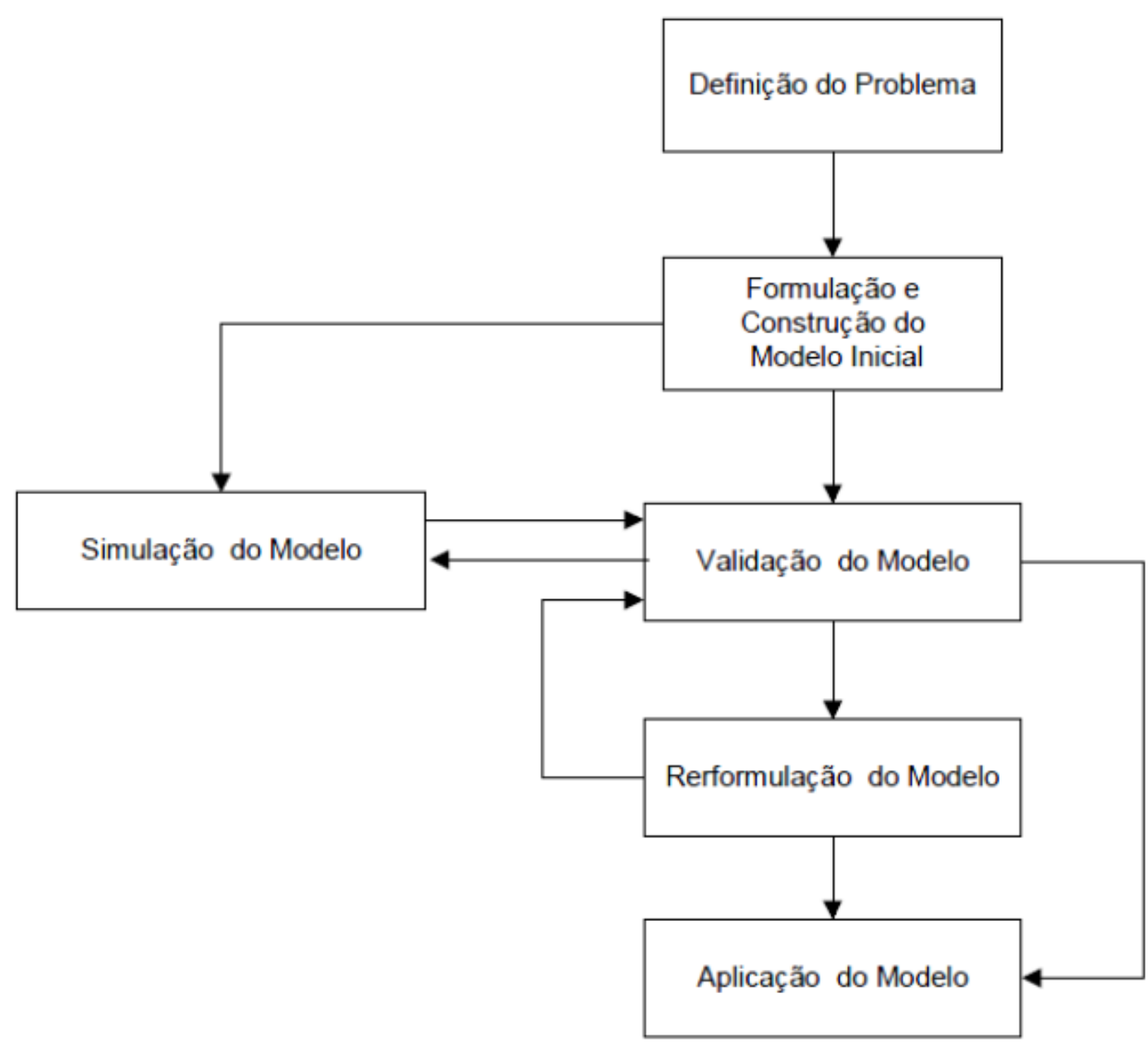

Fonte: Elaboração própria.

\subsection{ALGORITMO GENÉTICO}

AG é um método de otimização meta-heurística que busca resolver de forma iterativa um problema por meio da seleção, reprodução e sobrevivência dos mais aptos (PACHECO, 2011; GOLDBERG, 1989; LINDEN, 2008). Trata-se, portanto, de um método genérico adaptativo de busca que utiliza o processo genético e da Teoria de Evolução Natural de Charles Darwin. Ao contrário das técnicas convencionais, o AG é uma heurística de otimização global que utiliza um conjunto inicial randômico de soluções chamado de população, tendo cada indivíduo desta população como sendo um candidato à solução do problema modelado. Os cromossomos artificiais são compostos 
por cadeias de bits, definidos como genes. Os valores que um determinado gene pode assumir são chamados de alelos (GOLDBERG, 1989).

Em problemas de otimização, a aplicação do AG dá-se inicialmente com a geração de uma população composta por indivíduos. Cada indivíduo representa uma população inicial que corresponde a um conjunto de soluções para o problema a ser otimizado, geralmente utilizando funções aleatórias. Cada solução candidata da população inicial é mensurada por uma função de adaptação que indica o seu grau de qualidade para o problema a ser otimizado. Os requisitos básicos para a implementação de um $A G$ de acordo com $(\mathrm{POZO}, 2002)$ são:

1. Representações das possíveis soluções do problema no formato de um código genético;

2. População inicial que contenha diversidade suficiente para permitir ao algoritmo combinar características e produzir novas soluções;

3. Existência de um método para medir a qualidade de uma solução potencial;

4. Um procedimento de combinação de soluções para gerar novos indivíduos na população, denominado de cruzamento;

5. Um critério de escolha das soluções que permanecerão na população ou que serão retirados desta;

6. Um procedimento para introduzir periodicamente alterações em algumas soluções da população. Assim, mantém-se a diversidade da população e a possibilidade de se produzir soluções inovadoras para serem avaliadas pelo critério de seleção dos mais aptos.

O princípio básico de funcionamento dos algoritmos genéticos é de tratar as possíveis soluções do problema como indivíduos de uma população, sendo necessária a avaliação da adaptabilidade de cada indivíduo ao meio. O problema é representado pelo meio e, a adaptabilidade do indivíduo, é determinada por um valor obtido através das características deste indivíduo para o problema de acordo com a função de fitness. $\mathrm{O}$ valor do fitness indica o grau de adequação da solução representada pelo indivíduo com relação ao problema em análise. A aplicação de algoritmos genéticos consiste basicamente em gerar inicialmente uma população de indivíduos de forma aleatória, os quais são inseridos em um meio. Através de um processo interativo é feito o cruzamento entre os indivíduos, tendo como critério de escolha, o valor do fitness de cada indivíduo. Sucessivas gerações são criadas procurando preservar o indivíduo de melhor desempenho para as gerações futuras. Após um determinado número pré-definido de 
gerações ou um critério de parada definido, o melhor indivíduo de acordo com o valor de fitness, é escolhido como a melhor solução para o problema.

O esquema a seguir exemplifica a execução do $A G$ :

1. Geração de uma população inicial

2. calcule a função fitness (avaliação) de cada indivíduo

3. fim $=$ falso

4. geração $=1$

5. enquanto fim $=$ falso faça

5.1. varie a população de 1 até população/2

5.2. selecione 2 indivíduos para o cruzamento

5.3. recombine-os gerando 2 filhos

5.4. calcule o fitness dos filhos

5.5. coloque os filhos na nova população

5.6. geração $=$ geração +1

5.7. se a condição de parada for alcançada faça fim = verdadeiro

6. fim do processo

Para melhor compreensão da aplicação de $A G s$, há necessidade do conhecimento de alguns termos empregados na biologia e sua analogia com os elementos usados na modelagem de sistemas reais.

- Indivíduo: é o exemplar de uma espécie que interage com o meio ambiente;

- Espécie: é um conjunto de indivíduos com as mesmas características genéticas com capacidade de cruzamento que possa gerar descendentes;

- Genótipo: é a combinação de genes contidos nos cromossomos de um indivíduo, representa a estrutura do indivíduo;

- Fenótipo: é o conjunto das características de um indivíduo, observadas ou descritas por outros métodos, fornecidas pelo genótipo. Significa o valor da solução que o indivíduo representa;

- Cromossomo: é o componente genético responsável pelo fenótipo do indivíduo; 
- Genes: são as unidades básicas do cromossomo, que definem, de acordo com seus valores e posições, uma característica do indivíduo;

- Alelo: valor do gene.

A extinção de determinados indivíduos da população no decorrer das gerações impossibilita um $A G$ de explorar completamente o espaço de busca. Como resultado, o $A G$ pode convergir para um mínimo ou máximo local. Este problema é conhecido como convergência prematura. Com taxas adequadas de mutação, é possível manter uma boa diversidade de indivíduos da população a fim de compensar estas perdas de indivíduos. A convergência prematura é um conhecido problema e ocorre com o surgimento de cromossomos de alta aptidão, mas não com aptidão ótima, enquanto os cromossomos realmente ótimos ainda não estão presentes na população. Os cromossomos geram um número excessivo de filhos que dominam a população. Estes cromossomos espalham seus genes por toda a população, enquanto outros genes desaparecem. Como conseqüência, o algoritmo converge para um máximo ou mínimo local. Combate-se à convergência prematura limitando o número de filhos por cromossomos. Esta limitação pode ser realizada através do escalonamento da aptidão, outra alternativa de combate à convergência prematura é a manutenção da diversidade dos cromossomos na população. Isto pode ser alcançado através do aumento da taxa de mutação, e também evitando-se a inserção de filhos duplicados na população.

A perda da diversidade genética ao longo das gerações é outro problema que pode ocorrer quando da utilização do $A G$. Uma das formas para minimizar esse problema é através da utilização do fator de crowding (GOLDBERG, 1989). O fator de crowding é um operador de diversidade que tem a finalidade de garantir que as soluções se apresentem espalhadas ao longo da linha de Pareto ao invés de se apresentarem concentradas em pontos próximos entre si.

\subsubsection{Codificação}

A codificação é a maneira como um problema do mundo real é modelado para ser utilizado pelo método do algoritmo genético. Cabe, portanto, uma definição adequada para que seja inviabilizada a chegada a uma solução satisfatória através do algoritmo genético. Em alguns casos, pode ocorrer um efeito chamado epistasia, interferência muito significativa quando da alteração de um gene sobre os demais. As restrições definidas no problema podem estar contidas na codificação, caso não sejam aplicadas, alguns mecanismos devem ser criados para que ocorra a penalização dos indivíduos que não satisfaçam estas restrições. Em geral, as penalidades são aplicadas sobre o valor do fitness dos indivíduos que violem as restrições, fazendo com que a sua escolha não tenha prioridade no processo de seleção. 
Os principais tipos de codificação são:

- Binária: os indivíduos são representados por vetores de dígitos binários, onde cada elemento de um vetor denota a presença, representado por 1, ou a ausência, representado por 0 , de uma determinada característica. A representação binária dos cromossomos é adotada na maioria das implementações por facilidade nos processos de seleção e reprodução dos indivíduos.

- Inteira: é utilizada em problemas combinatoriais e necessita de operadores genéticos específicos (GOLDBERG, 1989);

- Real: é utilizada em problemas de otimização de parâmetros com variáveis sobre domínios contínuos. Nesta codificação um cromossomo é um vetor de números reais cuja precisão é determinada pela precisão da linguagem que implementa o algoritmo. Os valores dos genes do cromossomo são obrigados a ficar no intervalo estabelecido para a variável que este representa e os operadores genéticos utilizados também devem respeitar estas restrições. A codificação real necessita de operadores genéticos específicos (GOLDBERG, 1989).

\subsubsection{Métodos de Seleção}

Os métodos de seleção são responsáveis pela seleção dos indivíduos para o cruzamento, considerando o grau de adaptação da solução que estes representam para o problema em estudo. Os mecanismos mais comuns de seleção são, a saber:

- Roleta: Esse método consiste na amostragem estocástica com reposição desenvolvida por (HOLLAND, 1975), sendo o primeiro método de seleção utilizado. O método é idealizado como uma roleta de cassino com fendas. O número de fendas é igual ao número de indivíduos da população e o tamanho de cada fenda é definido através da relação entre o fitness de cada indivíduo com o somatório dos fitness de toda a população. Ou seja, quanto maior o grau de adaptação do indivíduo, maior será a probabilidade de ser selecionado.

- Torneio: São escolhidos aleatoriamente $k$ indivíduos de um população para formar uma subpopulação temporária, sendo que o melhor indivíduo desta subpopulação é selecionado.

Como o processo de seleção é de natureza probabilística, o algoritmo pode não escolher os melhores indivíduos para participarem do processo de seleção. Para evitar esse problema, pode-se utilizar do elitismo, que garante a preservação de bons indivíduos nas próximas gerações através da introdução de cópia dos melhores indivíduos da população na próxima geração. 


\subsubsection{Operadores Genéticos}

As ações sobre os genes dos indivíduos causando alteração de suas características e, consequentemente gerando descendentes modificados, são realizadas por operadores genéticos. Para cada operador é relacionada uma probabilidade de ocorrência da ação, tendo o crossover (recombinação) e mutação os principais operadores genéticos.

O operador crossover é responsável por realizar uma recombinação de genes de dois indivíduos ancestrais, gerando dois novos indivíduos descendentes. O efeito deste operador relaciona-se a uma exploração local por indivíduos mais adaptados ao meio. O crossover pode ser:

a) Um ponto, ou seja, é definido um ponto para realizar o corte em dois cromossomos. A troca é feita após a definição do ponto de corte, conforme a figura 5.

Figura 5 - Crossover com um ponto

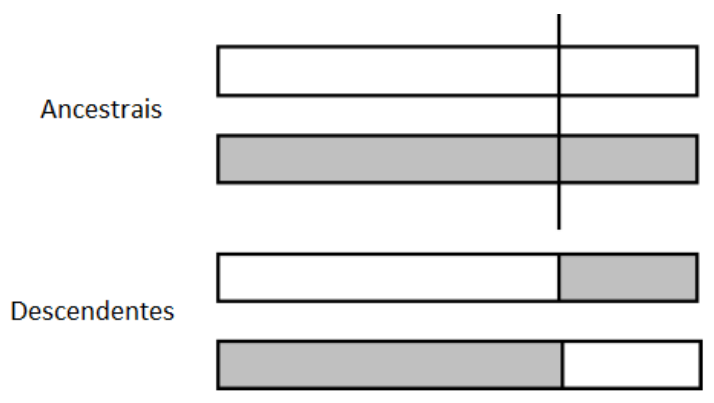

Fonte: Elaboração própria.

b) Multi-ponto, é escolhido mais de um ponto de corte nos dois cromossomos para realizar a troca do conteúdo genético. Pode ser observado na figura 6.

Figura 6 - Crossover com vários pontos

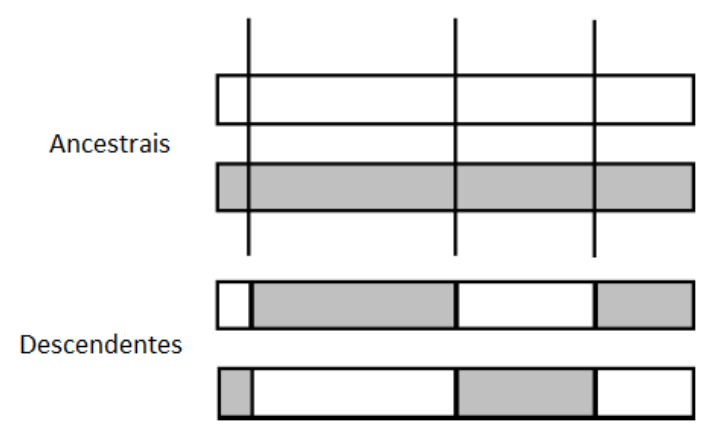

Fonte: Elaboração própria.

O operador de mutação é responsável pela alteração do alelo de um gene presente no cromossomo. Procura-se, desta forma, introduzir novos indivíduos com 
características diferentes, para evitar a perda de diversidade genética da população. De acordo com o valor de probabilidade associada a este operador, podemos ter as seguintes situações, a saber:

a) Busca aleatório, quando é escolhido um valor elevado para o operador;

b) Busca local, quando atribuído um valor pequeno.

Em geral, os valores usuais para a probabilidade do operador de mutação encontram-se entre 1 e $3 \%$ por alelo.

\subsubsection{Função de fitness}

Para a validação do indivíduo deve ser calculado, através de uma determinada função, o valor de sua aptidão. Esta é uma das partes mais importantes de qualquer $A G$, pois é através desta função que se determina se o indivíduo está próximo da solução desejada. Para tal, a função deve ser muito representativa e, diferenciar na proporção correta, as soluções boas das más. Caso ocorra pouca precisão na avaliação, uma ótima solução pode ser posta de lado durante a execução do algoritmo, além de gastar mais tempo explorando soluções pouco promissoras (POZO, 2002). Por definição, a função de fitness é sempre positiva, desta forma, caso o objetivo seja de minimização, é necessário estabelecer um valor máximo possível para a função objetivo. Esse valor será utilizado como sendo a pior situação, portanto, será utilizado para transformar o problema de minimização em maximização.

\subsubsection{Medidas de desempenho}

A avaliação da evolução dos indivíduos após cada geração é realizada pelos seguintes parâmetros, a saber:

a) Fitness mínimo: É o menor fitness calculado de uma população em uma geração;

b) Fitness máximo: É o maior fitness calculado de uma população em uma geração;

c) Fitness médio: É a média dos valores de fitness de uma população em uma geração;

d) off-line performance: Média do fitness dos melhores indivíduos de uma geração;

e) on-line performance: Média do fitness de todos os indivíduos de uma geração.

Cabe ressaltar que, quando os valores de fitness mínimo, máximo e médio estão próximos, existe uma indicação que o algoritmo convergiu para um valor. A diferença entre os valores off-line performance e on-line performance representa a diversidade genética de cada geração. Assim, quanto maior a diferença, maior a diversidade genética. Quando os valores forem iguais é uma indicação que o a população evoluiu para uma solução. 


\subsubsection{Critérios de parada}

Para a parada do $A G$ podemos utilizar os seguintes critérios básicos, a saber:

a) Número determinado de gerações;

b) Média de fitness da população estiver próxima do valor do fitness máximo;

c) Máximo ou mínimo global é atingido.

\subsection{AGENTES E SISTEMAS MULTIAGENTES SMA}

Um agente é uma entidade que tem a capacidade de perceber o ambiente em que está imerso e atuar sobre este ambiente na busca por atingir algum objetivo ou reproduzir um determinado comportamento (RUSSELL; NORVIG, 2010). O agente tem como principal característica a sua forma autônoma de agir, sem um controle executado por qualquer ente exterior a ele próprio.

Um agente inteligente possui as seguintes características de um sistema inteligente:

- Base de conhecimentos que auxilia na resolução do tipo de problema para o agente foi modelado;

- Métodos de busca e manipulação aplicados nesta base, que auxiliam o agente para encontrar as informações que proverão a tomada de decisão da entidade.

O agente utiliza de sensores para perceber o ambiente e possui atuadores que executam a ação resultante da tomada de decisão feita a partir do estado em que o agente se encontra e da busca feita na base de conhecimento. Desta forma é possível que um agente possa interagir com outros agentes e o ambiente em que se encontra.

Conforme (WOOLDRIDGE; JENNINGS, 1998) algumas características são essenciais para uma melhor caracterização dos agentes, a saber:

- Autonomia: o agente deve tomar decisões e ações para a conclusão de uma tarefa ou objetivo sem a necessidade da interferência externa. Além disso, deve ser capaz de agir independentemente com seu ambiente por meio de seus sensores ou com as suas próprias percepções, de modo a realizar uma tarefa externa ou gerada por ele próprio;

- Proatividade: o agente deve tomar iniciativas, não somente respondendo de acordo com o meio e seu comportamento deve ser baseado em objetivos; 
- Reatividade: o agente deve ter capacidade de reagir rapidamente a alterações no ambiente;

- Robustez: capacidade de tomar decisões baseadas em informações, sejam elas incompletas ou escassas, ter uma capacidade de adaptação e aprendizagem através da experiência;

- Habilidade de comunicação: capacidade de comunicação com repositório de dados, outros agentes ou ambiente;

- Raciocínio: o agente dever ter capacidade de analisar e inferir suas decisões baseado em seu conhecimento atual e nas suas experiências.

A capacidade de reatividade, proatividade e sociabilidade são suficientes para que um agente possa ser classificado como inteligente (WEISS., 2000).

O agente é uma entidade que está situado em algum ambiente e é autonomamente capaz de reagir às mudanças nesse ambiente (WOOLDRIDGE; JENNINGS, 1998). Por sua vez, o ambiente é tudo externo ao agente, podendo ser físico, como o sistema elétrico, ou interno, como um banco de dados. $\mathrm{O}$ agente pode causar uma alteração no ambiente, através de uma ação física, solicitando o fechamento ou abertura de um determinado equipamento, ou virtual, como o controle de armazenamento de informação em um banco de dados. O agente deve manter sua capacidade de raciocínio independente do ambiente no qual ele está inserido.

Um sistema que é constituído por um conjunto de agentes em um ambiente computacional distribuído que implementa técnicas de inteligência artificial é denominado de sistemas multiagentes (SMA) (WOOLDRIDGE; JENNINGS, 1998). Os agentes em $(S M A)$ representam os objetivos de um sistema que possuem capacidade de interagir entre si, a fim de alcançar seus objetivos individuais, quando eles não têm conhecimentos suficientes e habilidades para alcançar individualmente os seus objetivos (WOOLDRIDGE, 2002). São conhecidos também como agentes inteligentes, sendo estes agentes possuidores de autonomia que permite ao mesmo ser capaz de agir sem a intervenção direta de seres humanos ou de outros agentes, devendo ter o controle sobre suas próprias ações e estado interno (JENNINGS; SYCARA; WOOLDRIDGE, 1998).

Nos SMA os agentes são distinguidos em reativos e cognitivos (WOOLDRIDGE; JENNINGS, 1998). Os agentes reativos são aqueles que selecionam ações com base na percepção atual, ignorando o restante do histórico de percepções (RUSSELL; NORVIG, 2010). Os $S M A$ com agentes reativos são constituídos por uma quantidade elevada de agentes, sendo agentes simples. Como são reativos não possuem inteligência ou representação de seu ambiente e interagem entre si utilizando um comportamento simples de ação e reação. Conforme ocorrem as interações entres os agentes e o ambiente, 
emerge uma inteligência. Isso ocorre devido ao fato que os agentes não são inteligentes individualmente, mas o comportamento global sim. Nos $S M A$ reativos, o ambiente desempenha um papel importante, considerando que os agentes reativos não possuem memória, sendo que a percepção do ambiente que permite que eles tomem as decisões sobre suas ações.

Os agentes cognitivos têm uma representação simbólica explícita do seu ambiente, no qual eles podem argumentar e predizer eventos futuros. São dirigidos por intenções, ou seja, por metas explícitas que conduzem seu comportamento e os tornam capazes de escolher entre possíveis ações. Por sua vez, no caso dos SMAs serem compostos por agentes cognitivos, a quantidade de agentes é menor, comparado ao de sistemas compostos por agentes reativos. Os agentes cognitivos são inteligentes e têm uma representação do seu ambiente e dos outros agentes envolvidos. Desta forma, podem comunicar-se entre si, realizar negociações por informações e planejar suas ações futuras. O planejamento somente é possível em virtude dos agentes serem dotados de conhecimentos, competências, intenções e crenças (RUSSELL; NORVIG, 2010).

Em um $S M A$, cada agente tem a capacidade de implementar técnicas de inteligência artificial, obtenção de dados, tendo a interação entre os agentes, sendo o fator determinante para resolução dos problemas. Desta forma, a interação entre os agentes é uma característica essencial do sistema, sendo que o aprendizado em sistemas multiagentes é propiciado com a troca de informações entre os agentes. Por meio destas interações entre os agentes é possível observar os comportamentos que emergem da sociedade de agentes. A partir da análise e obtenção distribuída de dados as decisões são tomadas coletivamente reforçando a característica de aprendizado social. É importante que os comportamentos dos agentes possam gerar um encadeamento de ações para a resolução do problema ou atingimento do objetivo proposto (GARCIA; SICHMAN, 2003).

Em virtude do processo de interação e tomada de decisão nos sistemas multiagentes, são necessários modelos organizacionais a serem utilizados, a saber (LESSER, 2004):

a) Hierárquico - modelo centralizado onde os agentes recebem estímulos de seus sensores e enviam os dados para um agente central, que tratará de tomar a decisão e reenviar a resposta para os demais agentes do sistema;

b) Holoarquia - baseado na ideia de hólon (KOESTLER, 1969), cada grupo de agentes é responsável por uma seção de um dado nível de organização; o conjunto de seções de um mesmo nível forma um hólon que, agrupado a outros hólons, formam o próximo nível da pirâmide organizacional; 
c) Sociedade - modelo organizacional em que se pretende observar o comportamento dos agentes diante de situações de dinâmica social, não necessariamente voltada para resolução de problemas. Normalmente implementada em sistemas abertos;

d) Federação - um dado agente é líder de um subgrupo de agentes. Todas as interações entre agentes de grupos diferentes devem ser realizadas sob mediação dos líderes, que também são responsáveis pela coordenação da execução de tarefas de seus respectivos times;

e) Mercado - os agentes interagem a partir de regras de mercado, tais como oferta e procura. Cada agente tem uma função que pretende maximizar (lucros) e todas as interações são realizadas em termos de negociação;

f) Modelos híbridos - formas de organização que implementam características de uma ou mais outras formas organizacionais.

\subsection{CONCLUSÕES DO CAPÍTULO}

Neste capítulo foram apresentados os conceitos de programação matemática utilizada para a modelagem do problema de planejamento operacional, $A G$ e $S M A$. A abordagem de $A G$ é exaustivamente utilizada neste trabalho para o desenvolvimento de ferramentas computacionais para o planejamento operacional da rede de distribuição de $M T$ e $B T$, sendo apresentados como abordagens eficientes para a solução de problemas combinatórios. Uma grande quantidade de artigos, dissertações e teses utilizam estas ferramentas para análise de otimização de processos em diversas áreas de atuação. Neste trabalho a utilização dos $S M A$ é aplicada para a questão de remanejamento de transformadores em uma rede de distribuição de energia de $B T$. 


\section{PLANEJAMENTO OPERACIONAL DE REDES DE DISTRIBUIÇÃO DE MÉDIA TENSÃO}

Neste capítulo, é apresenta uma proposta para o planejamento de $M T$, abordando uma modelagem para o problema considerando custos relacionados as substituições realizadas na rede, bem como minimização de perdas e queda de tensão. São realizados operações em alimentadores radiais, procurando manter todos os pontos de demanda devidamente atendidos, além de considerar a integração com a entrada de GD. A complexidade do modelo matemático está realizado com as condições topológicas do sistema a ser analisado, portanto, quanto maior a quantidade de pontos a serem analisados, maior será o tempo de análise das possibilidades de alteração analisadas no modelo.

No modelo geral proposto para o planejamento, são levados em consideração o custo de investimentos, de operação (representado pelas perdas elétricas) e restrições de tensão mínima, caracterizando a natureza multiobjetivo da formulação. Os custos do investimento e operação são baseados nas substituições dos equipamentos e materiais em análise no alimentador, considerando a sua conectividade na rede. Assim, o planejamento é formulado como um problema de Programação Não Linear Inteiro Misto (PNLIM) multiobjetivo, resolvido por meio de uma Algoritmo Genético AG.

Para validar as alternativas sugeridas pelo $A G$ para os diferentes modelos do planejamento operacional de $M T$, foi desenvolvido um fluxo de potência trifásico desequilibrado utilizando o método backward-forward sweep, cargas representadas pelo modelo potência constante, com a GD sendo modelada como uma barra de tensão controlada $(P V)$. Foi considerado o patamar de carga pesada para as simulações no alimentador.

\subsection{FORMULAÇÃO DO PROBLEMA}

Para a análise do planejamento foi proposto um modelo multiobjetivo considerando os custos de investimentos na realização de recondutoramento de cabos, transformadores, capacitores e GD de forma a atender critérios técnicos de tensão, corrente, além das perdas elétricas. A melhoria nos valores de tensão e redução de perdas correspondem a importantes critérios de qualidade dos alimentadores. O modelo geral de planejamento de redes de $M T$ pode ser observado da seguinte forma: 


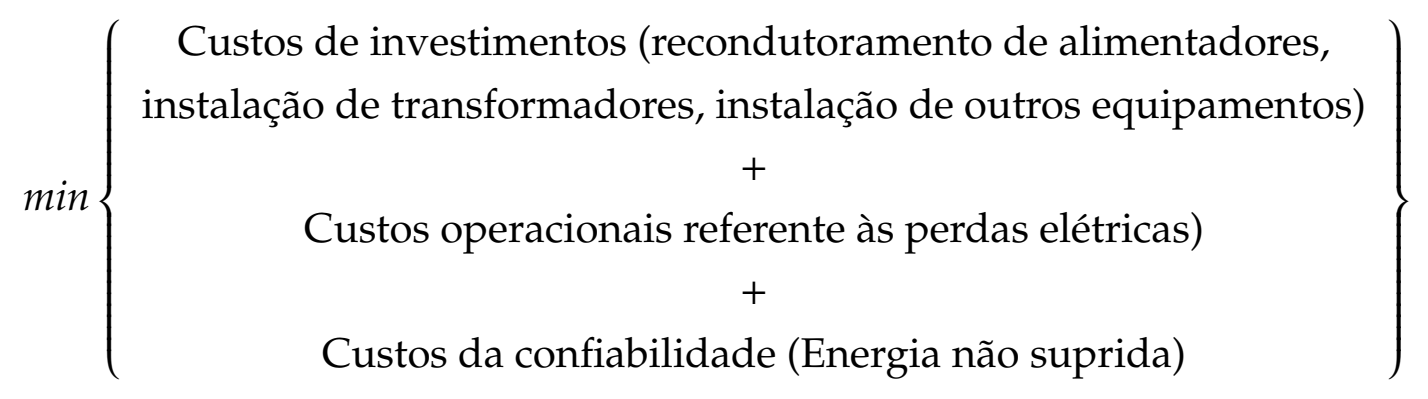

Sujeito às restrições:

1. Topologia radial;

2. Valores limites mínimos de tensão nas barras;

3. Valores limites máximos de corrente nos cabos;

4. Disponibilidade de recursos financeiros.

A seguir é detalhado o modelo matemático elaborado para o problema de planejamento multiobjetivo sendo detalhado a função objetivo e relacionadas as restrições pertinentes.

\subsection{FORMULAÇÃO MATEMÁTICA}

Para a determinação de valores aceitáveis de tensão e perdas em um alimentador da rede de distribuição de MT, as alternativas avaliadas neste trabalho foram as seguintes:

1. Recondutoramento de cabos;

2. Troca de faseamento dos transformadores;

3. Inserção de Capacitores;

4. Inserção de GD.

\subsubsection{Recondutoramento de Cabos}

Dado um alimentador, a troca de condutores consiste em substituir os cabos existentes por outros de menor impedância, objetivando reduzir as perdas na rede e atender os valores de fornecimento de tensão normativos. Em (PAIVA et al., 2005) o problema é modelado como PLIM e no trabalho (DÍAZ-DORADO; CIDRÁS, 2002) é utilizada uma abordagem evolucionária.

O modelo sugerido consiste em determinar a solução mais econômica, atendendo aos aspectos técnicos solicitados. Para tanto são considerados os custos estimados de 
instalação dos novos cabos, bem como os valores de retorno dos cabos removidos passíveis de reaproveitamento. Na formulação procura-se maximizar o valor da tensão do alimentador.

Em função das características de topologia dos alimentadores e dos cabos que estão disponíveis para instalação, as substituições podem ser realizadas até se atingir o limite de queda de tensão mínima possível. É necessário sugerir uma configuração com redução gradual da bitola ao longo do alimentador, no sentido da fonte para as cargas. Deve-se evitar que haja aumento de bitola de um trecho para outro conseguinte. O modelo contempla esta situação e, inclusive, em casos em que esta condição não é atendida inicialmente pelo alimentador em análise, não sugere a redução da bitola do trecho superdimensionado e nem o aumento de todas as bitolas anteriores. Por se tratar de planejamento operacional, pode-se ter esse tipo de situação em virtude de um planejamento inicial feito com critérios muito estimados ou alterações topológicas na rede que diminuiram a demanda no alimentador ao longo do tempo.

Baseado nas considerações de operação do sistema segue-se o equacionamento da função objetivo e das restrições operacionais de acordo com a nomenclatura das variáveis utilizadas no modelo.

\section{Nomenclatura}

\section{Conjuntos}

\begin{tabular}{|c|c|c|}
\hline Nos & 1..N_n & Nós da topologia da rede \\
\hline Fase & $1 . .3$ & Fase $A, B$ e $C$ \\
\hline Cond & & Tipos de condutores \\
\hline \multirow[t]{2}{*}{ Tre } & $\subset \operatorname{Nos} x$ Nos & Trechos instalados no alimentador \\
\hline & Índices & \\
\hline$f$ & $\subseteq$ Fase & Fase da rede \\
\hline$i$ & $\subseteq$ Nos & Nó da rede \\
\hline J & $\subseteq$ Nos & Nó da rede \\
\hline & $\subseteq$ Cond $\mathrm{Cab}$ & Cabo condutor \\
\hline
\end{tabular}

\section{Parâmetros}

$\mathrm{CiCm}_{c}$ Custo de instalação do condutor $c(\mathrm{R} \$ / \mathrm{m})$

$\mathrm{CrCm}_{c}$ Retorno financeiro com a remoção do condutor $c(\mathrm{R} \$ / \mathrm{m})$

Comp $_{i j}$ Comprimento do cabo entre os nós $i$ e $j$

$Z_{C} d_{c} \quad$ Reatância do cabo $c(\Omega)$

\section{Variável}


$C n d P_{c i j} \in 0,1 \quad$ Condutor $c$ proposto entre os nós $i$ e $j$

$\operatorname{CndI}_{c i j} \in 0,1 \quad$ Condutor $c$ instalado entre os nós $i$ e $j$

\subsubsection{Função Objetivo}

A função objetivo (FO) (4.1)consiste na minimização do valor da troca de condutores incluindo os custos de instalação e o desconto do valor de retorno do cabo removido. O primeiro termo da função objetivo (a) contabiliza o custo da instalação de um cabo, o segundo termo (b) representa o desconto do valor de retorno do cabo removido.

$$
\begin{aligned}
\min \sum_{c \in C o n d} \sum_{(i j) \in T r e}\{\underbrace{C i c m_{c} * C o m p_{i j} *\left(C n d P_{c i j}-C n d P_{c i j} * C n d l_{c i j}\right)}_{a}) & \underbrace{C r c m_{c} * C o m p_{i j} *\left(C n d l_{c i j}-C n d l_{c i j} * C n d p_{c i j}\right)}_{b}\}
\end{aligned}
$$

A tabela 2 mostra as operações entre as variáveis binárias utilizadas nos itens (a) e (b) da função objetivo para a composição do custo de instalação e retorno com a remoção do cabo

Tabela 2 - Tabela verdade instalação/retirada de cabos.

\begin{tabular}{c|c|c|c|c}
\hline Cndl $_{\mathrm{cij}}$ & $\mathrm{CndP}_{\mathrm{cij}}$ & $\mathrm{CndP}_{\mathrm{cij}}-\mathrm{CndP}_{\mathrm{cij}}{ }^{*} \mathrm{Cndl}_{\mathrm{cij}}$ & $\mathrm{Cndl}_{\mathrm{cij}}-\mathrm{Cndl}_{\mathrm{cij}}{ }^{*} \mathrm{Cndp}_{\mathrm{cij}}$ & Ação \\
\hline 0 & 0 & 0 & 0 & Nenhuma \\
0 & 1 & 1 & 0 & Instalar \\
1 & 0 & 0 & 1 & Remover \\
1 & 1 & 0 & 0 & Nenhuma \\
\hline
\end{tabular}

Fonte: Elaborada pelo autor.

\subsubsection{Restrições}

Cada trecho do alimentador deve ter apenas um tipo de condutor instalado conforme restrição (4.2).

$$
\sum_{c \in \operatorname{Cond}(i j)} C_{n d P_{c i j}}=1
$$


Os trechos não podem ser substituídos por cabos de menor bitola. Esta restrição impede que cabos já instalados no alimentador com alto valor de retorno sejam substituídos por cabos de menor bitola de acordo com a restrição (4.3).

$$
C n d P_{c i j}=0 \forall(i j) \in \operatorname{Tre}, c \in \operatorname{Cond} \mid Z C d_{c}>Z C d_{C n d l}
$$

O cálculo do fluxo de potência deve ser realizado para o alimentador para verificar a restrição de tensão mínima nos nós da rede. Para realizar o processamento, na recuperação dos dados do alimentador para a execução do modelo, é obtida a topologia da rede. Com a informação da topologia da rede é possível fazer o processamento do cálculo, identificando os nós iniciais e finais de cada trecho do alimentador.

\subsubsection{Troca de faseamento dos transformadores}

A troca do faseamento dos transformadores é uma das soluções técnicas possíveis de serem aplicadas para elevar o nível de tensão de um alimentador. Consiste na distribuição uniforme das cargas dos diversos transformadores no alimentador, reduzindo assim o desequilíbrio de corrente entre as fases. Esta redução é essencial, dado que o desequilíbrio prejudica a fase mais carregada, ocasionando uma queda de tensão mais significativa e maior carregamento dos cabos. Cabe ressaltar que a análise do balanceamento de cargas procura otimizar a distribuição de carga em cada trecho do alimentador. No trabalho (CHEN; CHERNG, 2002) é feita uma análise de alimentadores desbalanceados utilizando uma metodologia baseada em programação dinâmica. $\mathrm{O}$ modelo matemático desenvolvido sugere a reconfiguração da conexão dos postos do alimentador às fases da rede, minimizando o número de operações (trocas de fase) necessárias para que o alimentador atenda ao índice exigido de tensão mínima. A sugestão pretende apresentar não só a solução com menor custo operacional, representado aqui pelo número de trocas de fases dos postos, mas também aquela que forneça o melhor índice de queda de tensão dentre as alternativas de mesmo custo. Baseado nas considerações de operação do sistema segue-se o equacionamento da função objetivo e das restrições operacionais de acordo com a nomenclatura das variáveis utilizadas no modelo.

\section{Nomenclatura}

\section{Conjuntos}

Nos 1..N_n Nós da topologia da rede

Fase $1 . .3$ Fase A, B e C

Índices 


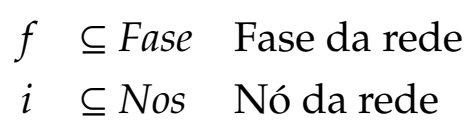

Parâmetros

Calt Custo de alteração do faseamento (R\$)

FasTrafo $_{i} \quad$ Faseamento do transformador instalado no nó $i$

\section{Variável}

$T P_{\text {if }} \quad$ 0,1 Faseamento proposto do transformador instalado no nó $i$ fase $f$

$T I_{i f} \quad 0,1$ Faseamento existente do transformador instalado no nó $i$ fase $f$

\subsubsection{Função Objetivo}

A função objetivo (4.4) consiste na minimização do custo da troca de faseamento de um transformador instalado em um determinado ponto da rede.

$$
\min \sum_{i \in \text { Nos }} \sum_{f \in \text { Fase }}\left\{\text { Calt } *\left(T P_{i f}-T P_{i f} * T I_{i f}\right)\right\}
$$

\subsubsection{Restrições}

A natureza do faseamento das cargas deve permanecer inalterada durante todo os estudo. Desta forma, por exemplo, um transformador bifásico, durante todo o estudo, será considerado bifásico. A restrição (4.5) representa a necessidade descrita.

$$
\sum_{f \in \text { Fase }} T P_{i f}=\text { FasTrafo } o_{i}
$$

O cálculo do fluxo de potência deve ser realizado para o alimentador para verificar a restrição de tensão mínima nos nós da rede após a solução apresentada pelo modelo.

\subsubsection{Alocação de Banco de Capacitores}

Dado um alimentador, a alocação de capacitores consiste em indicar a localização e a capacidade de bancos de capacitores a serem instalados na rede. O modelo sugerido consiste em determinar a solução mais econômica, atendendo aos aspectos técnicos solicitados. Para tanto são considerados os custos estimados de instalação dos capacitores indicados na execução do modelo. Na formulação procura-se maximizar o valor da tensão do alimentador. 
Em função das características de topologia dos alimentadores e das potências de banco de capacitores disponíveis para instalação, as substituições podem ser realizadas até se atingir o limite de queda de tensão mínima possível.

Para a elaboração do modelo foram consideradas as seguintes premissas:

1. A rede em análise é radial;

2. Cada nó de conexão da rede são pontos candidatos a receberem bancos de capacitores;

3. Cada nó de conexão só pode receber um tipo de banco de capacitor;

4. É considerada a carga individual por fase, sendo o cálculo trifásico determinando-se os valores de corrente e queda de tensão por fase.

Baseado nas considerações de operação do sistema segue-se o equacionamento da função objetivo e das restrições operacionais de acordo com a nomenclatura das variáveis utilizadas no modelo.

\section{Nomenclatura}

\section{Conjuntos}

Nos

1..N_n Nós da topologia da rede

Capacitores

Tipos de capacitores classificados por potência

Índices

$\begin{array}{lll}i \subseteq \text { Nos } & \text { Nó da rede } \\ j \subseteq \text { Nos } & \text { Nó da rede } \\ c & \subseteq \text { Capacitores } & \text { Capacitor }\end{array}$

Parâmetros

$\mathrm{CiCap}_{i c}$ Custo de instalação do capacitor no nó $i$ sendo do tipo $c(\mathrm{R} \$)$

\section{Variável}

CapP $_{i c} \in 0,1 \quad$ Capacitor proposto no nó $i$ sendo do tipo $c$ 


\subsubsection{Função Objetivo}

A função objetivo (4.6) consiste na minimização do valor da instalação de banco de capacitores.

$$
\min \sum_{i \in \text { Nos }} \sum_{c \in \text { Capacitores }}\left\{\text { CiCap }_{i c} * \mathrm{CapP}_{i c}\right\}
$$

\subsubsection{Restrições}

Cada nó pode ter apenas um tipo de banco de capacitores indicado para instalação conforme restrição (4.7).

$$
\sum_{i \in \text { Nos }} \sum_{c \in \text { Capacitores }} \operatorname{CapP}_{i c} \leq 1
$$

O cálculo do fluxo de potência deve ser realizado para o alimentador para verificar a restrição de tensão mínima nos nós da rede.

\subsubsection{Alocação de Geração Distribuída na MT}

Dado um alimentador, a alocação de geração distribuída consiste em indicar a localização e a capacidade de cada unidade a ser instalada na rede. O modelo sugerido consiste em determinar a solução mais econômica, atendendo aos aspectos técnicos solicitados. Para tanto são considerados custos estimados de instalação na rede de cada unidade de geração distribuída proposta no estudo.

Para a elaboração do modelo foram consideradas as seguintes premissas:

1. A rede em análise é radial;

2. Cada nó de conexão da rede é ponto candidato a receber geração distribuída;

3. Cada nó de conexão só pode receber uma unidade de geração distribuída.

Baseado nas considerações de operação do sistema segue-se o equacionamento da função objetivo e das restrições operacionais de acordo com a nomenclatura das variáveis utilizadas no modelo.

\section{Nomenclatura}

\section{Conjuntos}

Nos 1..N_n Nós da topologia da rede

GD Tipos de geração distribuída classificados por potência 


\author{
Índices \\ $i \subseteq$ Nos Nó da rede \\ $j \subseteq$ Nos Nó da rede \\ $g d \subseteq G D$ Geração Distribuída
}

\title{
Parâmetros
}

$C i G d_{\text {igd }}$ Custo de instalação da geração distribuída no nó $i$ sendo do tipo $g d(\mathrm{R} \$)$

\section{Variável}

$G D P_{i g d} \in 0,1 \quad$ Geração distribuída proposta no nó $i$ sendo do tipo gd

\subsubsection{Função Objetivo}

A função objetivo (4.8) consiste na minimização do valor da instalação de unidades de geração distribuída.

$$
\min \sum_{i \in N o s} \sum_{g d \in G D}\left\{C i G d_{i g d} * G D P_{i g d}\right\}
$$

\subsubsection{Restrições}

Cada nó pode ter apenas um tipo de geração distribuída indicada para instalação conforme restrição (4.9).

$$
\sum_{i \in N o s} \sum_{g d \in G D} G D P_{i g d} \leq 1
$$

\subsection{TÉCNICA DA SOLUÇÃO}

Foi adotada uma abordagem heurística para a solução do problema do planejamento através da utilização de um Algoritmo Genético $(A G)$. Os modelos descritos nas seções anteriores foram contemplados na função objetivo para a validação das melhores soluções envolvidas em um alimentador de $M T$. O AG resolve o problema da troca de condutores, faseamento dos transformadores, instalação de capacitores e de GD. Um fluxo de potência valida a qualidade das soluções, determinando valores de tensão e corrente no todos as barras da rede, bem como valores de perdas elétricas. A figura 7 ilustra a metodologia proposta neste trabalho para a solução do planejamento operacional de $M T$. 
Figura 7 - Metodologia proposta.

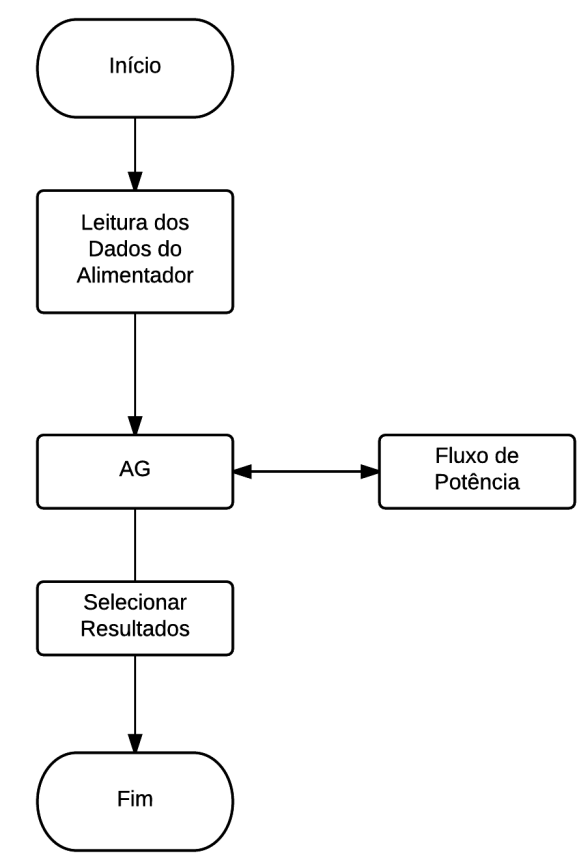

Fonte: Elaboração própria.

A seguir é descrito o $A G$ desenvolvido neste trabalho, detalhando a modelagem utilizada.

\subsubsection{Formulação do problema}

Para a determinação de valores aceitáveis de tensão, limites de carregamento dos cabos e transformadores e perdas em um alimentador da rede de distribuição de $M T$, as alternativas avaliadas neste trabalho foram as seguintes:

1. Troca de cabos;

2. Troca de faseamento dos transformadores;

3. Instalação de capacitor;

4. Instalação de GD.

Para encontrar a melhor opção tanto do ponto de vista econômico quanto técnico, deve-se procurar simular várias situações para determinar a mais viável. Quando da realização deste estudo, já é prevista uma determinada taxa de crescimento de cargas. Esse procedimento é realizado para que as alterações realizadas possam ter uma maior adequação ao crescimento de cargas, evitando alterações frequentes no alimentador. Para o problema analisado, foi definida uma função objetivo (4.10) que avalia a queda de 
tensão, perdas e custos operacionais de troca de cabos, faseamento de transformadores e instalação do capacitor. Cada um desses critérios a serem considerados caracteriza um problema multi-critérios que considera a minimização das funções relativas ao nível de tensão, perdas no alimentador e custos envolvidos.

$$
\text { F.O.min }(f 1, f 2, f 3)
$$

Onde:

f1: Violação da queda de tensão;

f2: Violação das perdas;

f3: Custo de realização das trocas.

Como são considerados critérios com grandezas diferentes, foi utilizado o Método do Critério Global (RAO, 1996), normalizando cada objetivo através da determinação do valor ótimo e do pior caso. Desta forma, a função objetivo pode ser definida conforme (4.11).

$$
\min \left(\frac{f A}{f \max A}+\frac{f B}{f \max B}+\frac{f C}{f \max C}\right)
$$

Onde:

$f A$ : Maior queda de tensão da simulação;

$f B$ : Soma das perdas do alimentador na simulação;

$f C$ : Custo de realização das trocas de cabos, faseamento do transformador, capacitor;

fmax A: Pior caso de queda de tensão. Considera-se a situação original do alimentador;

fmaxB: Pior caso de perdas no alimentador. Considera-se a situação original do alimentador;

fmaxC: Pior caso de custo de trocas. Considera-se o maior custo possível.

\subsubsection{Representação do Cromossomo}

O cromossomo tem tamanho variável, a primeira sequência de genes está reservada para representar os cabos, a segunda o faseamento dos transformadores, a terceira para representar a posição e potência do capacitor e, finalmente, a posição e potência da GD. 
A representação dos cabos no sistema é feita através da relação mostrada na tabela 3 em ordem decrescente de resistência.

Tabela 3 - Valores dos cabos

\begin{tabular}{c|c}
\hline Codificação binária do cabo & Cabo comercial \\
\hline 001 & Alumínio 06 AWG \\
010 & Alumínio 04 AWG \\
011 & Alumínio 02 AWG \\
100 & Alumínio 1/0AWG \\
101 & Alumínio 2/0 AWG \\
110 & Alumínio 3/0 AWG \\
111 & Alumínio 4/0 AWG \\
\hline
\end{tabular}

Fonte: Elaborada pelo autor.

A representação do faseamento dos transformadores é feita através da relação mostrada na tabela 4 .

Tabela 4 - Faseamento dos Transformadores

\begin{tabular}{c|c}
\hline Codificação binária do faseamento & Faseamento \\
\hline 001 & $\mathrm{~A}$ \\
010 & $\mathrm{~B}$ \\
011 & $\mathrm{C}$ \\
100 & $\mathrm{AB}$ \\
101 & $\mathrm{BC}$ \\
110 & $\mathrm{AC}$ \\
111 & $\mathrm{ABC}$ \\
\hline
\end{tabular}

Fonte: Elaborada pelo autor.

O sistema de codificação pode ser visualizado na figura 8. Na situação mostrada, o problema possui cinco cabos e três transformadores, além da informação do índice do poste proposto para a instalação do capacitor e da GD. Os genes dos cabos e dos faseamentos estão dimensionados para representar sete valores, conforme tabela 3 e 4 . No entanto, o gene do posicionamento do capacitor e GD suporta 32 valores, ou seja, para uma quantidade maior de postes a codificação da posição do capacitor e GD deve ser alterada.

Para cada indivíduo é feita a decodificação do alimentador e executado o fluxo de potência para determinar valores de queda de tensão, correntes por fase e perdas. Um indivíduo é considerado inválido quando apresenta um faseamento incompatível ou um cabo de resistência menor que o cabo original. Caso o indivíduo seja inválido, é 
Figura 8 - Sistema de codificação.

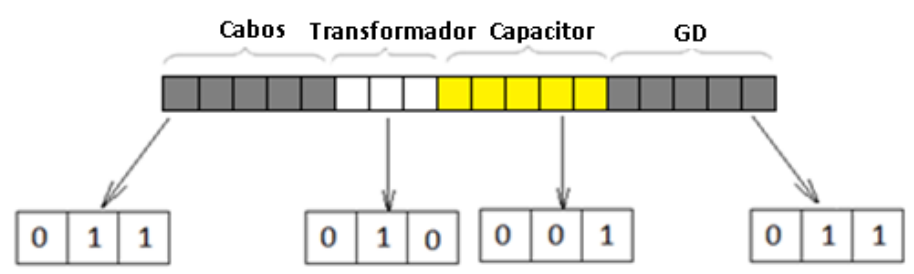

Fonte: Elaboração própria.

realizada uma correção para que possa ser avaliado o fluxo de potência e atribuído o seu valor de fitness.

A figura 9 exemplifica o caso da recombinação que resulta em um indivíduo com problema na geração da informação de cabo, as linhas vermelhas indicam o ponto escolhido para a recombinação. Após a recombinação, foi feita a decodificação dos indivíduos e constatou-se que o cabo 3 ficou com valor 010 . No entanto, o cabo instalado em campo é o 011, desta forma a troca proposta pelo algoritmo não deve ser realizada. Consultando a tabela 1, percebe-se que o cabo de identificação 011, que representa a bitola $02 A W G$ não pode ser substituído por um de bitola $04 A W G$. A alteração acarreta em um aumento da resistência do cabo, regra que não é permitida. O procedimento adotado é simplesmente a correção do indivíduo para um valor viável, ou seja, seu valor original.

Figura 9 - Sistema de codificação.

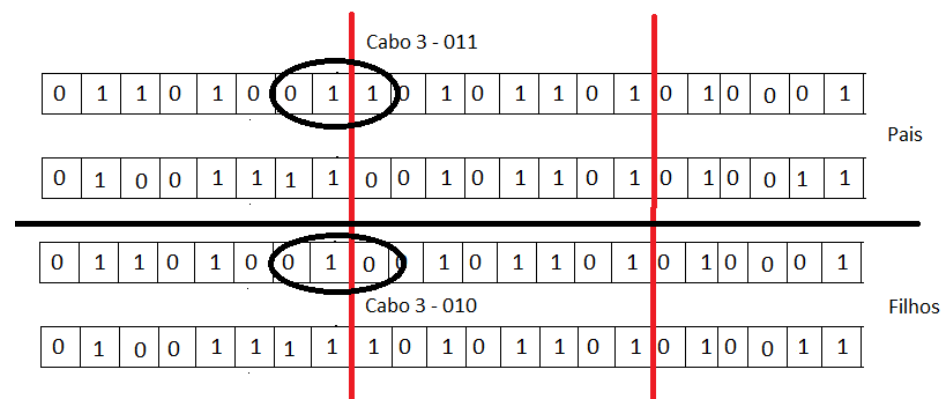

Fonte: Elaboração própria.

\subsection{CONCLUSÃO DO CAPÍTULO}

Neste capítulo o planejamento operacional da MT foi formulado como um PNLIM, incorporando-se a este modelo as restrições elétricas que devem ser atendidas durante os estudos de sistemas reais. Estas restrições afetam diretamente os custos de investimentos e as intervenções que podem ser aplicadas para a resolução do planejamento. 
A solução estudada para o desenvolvimento de um modelo de otimização foi a de $A G$ que é capaz de encontrar uma solução que minimiza a multa global de continuidade, mesmo que não encontre o valor ótimo, já que os algoritmos evolutivos não garantem o ótimo. O modelo desenvolvido é capaz de combinar as restrições técnicas necessárias considerando as características construtivas dos alimentadores. 


\section{PLANEJAMENTO OPERACIONAL DE REDES DE DISTRIBUIÇÃO DE BAIXA TENSÃO}

Neste capítulo, é apresenta uma proposta para o planejamento da BT, abordando uma modelagem para o problema considerando custos relacionados as substituições realizadas na rede, bem como minimização de perdas e queda de tensão. São realizados operações em circuitos radiais, procurando manter todos os pontos de demanda devidamente atendidos, além de considerar a integração com a entrada de GD.

No modelo geral proposto para a BT, são levados em consideração o custo de investimentos, das perdas elétricas e restrições de tensão mínima, caracterizando a natureza multiobjetivo da formulação. O custo do investimento e operação é baseado nas substituições dos cabos, troca de transformador, troca de faseamento de consumidores e inclusão de GD. Assim, a BT é formulada como um problema de Programação Linear Inteira Mista (PLIM) multiobjetivo.

Neste trabalho não foi considerada a possibilidade de divisão de um ou mais circuitos preexistentes, atribuindo parte de suas cargas e postes para um novo circuito. Assim, nesta operação os consumidores, cabos, postes e transformadores devem ser alocados adequadamente aos circuitos finais, ocasionando uma melhora nos níveis de tensão e carregamento dos circuitos.

Foi utilizado um algoritmo baseado em $A G$ para a solução dos circuitos de $B T$, sendo que, em cada alternativa obtida, é realizado um fluxo de potência para a determinação de valores de tensão e perdas. Neste trabalho foi implementado um fluxo de potência trifásico desequilibrado a quatro fios utilizando o método backward-forward sweep, modelo corrente constante com a GD sendo modelada como uma barra de tensão controlada $(P V)$. Foi assumido que as cargas na BT são do tipo corrente constante, portanto, o módulo da corrente e o fator de potência destas são invariantes com o correspondente módulo da tensão. Em virtude das redes de distribuição terem uma composição de diferentes equipamentos, esta modelagem é bastante aceitável.

\subsection{FORMULAÇÃO DO PROBLEMA}

Para a análise do planejamento foi proposto um modelo multiobjetivo considerando os custos de investimentos na realização de alteração de cabos, troca de transformadores, balanceamento consumidores e GD de forma a atender critérios técnicos de tensão e perdas elétricas. A melhoria nos valores de tensão e redução de perdas correspondem a importantes critérios de qualidade dos circuitos de BT. Os modelos desenvolvidos são representações matemáticas das possíveis intervenções a serem aplicadas na rede, considerando circuitos existentes. O modelo geral de planejamento 
de redes de BT pode ser observado da seguinte forma:

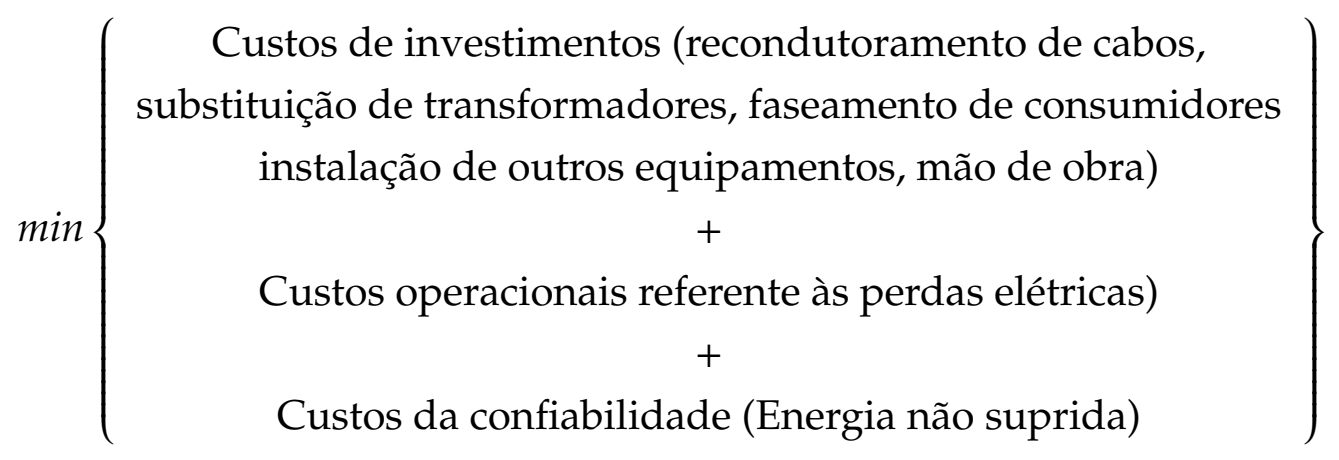

Sujeito às restrições:

1. Topologia radial;

2. Valores limites mínimos de tensão nos postes;

3. Valores limites máximos de corrente nos cabos;

4. Capacidade dos transformadores;

5. Natureza de faseamento dos consumidores;

6. Financeiras.

A seguir é detalhado o modelo matemático elaborado para o problema de planejamento multiobjetivo sendo detalhado a função objetivo e relacionadas as restrições aplicadas.

\subsection{FORMULAÇÃO MATEMÁTICA}

Para a determinação de valores aceitáveis de tensão e perdas em um circuito da rede de distribuição de $B T$, as alternativas avaliadas neste trabalho foram as seguintes:

1. Recondutoramento de cabos;

2. Troca de faseamento dos consumidores;

3. Movimentação de transformadores;

4. Inserção de GD. 


\subsubsection{Recondutoramento de Cabos}

Dado um determinado circuito, a troca de condutores consiste em substituir os cabos existentes por outros de menor impedância, objetivando reduzir as perdas na rede e atender os valores de fornecimento de tensão normativos. O modelo desenvolvido consiste em determinar a melhor solução financeira atendendo aos critérios técnicos requisitados. São estimados custos de instalação de novos cabos, além de considerar os valores de retorno de cabos removidos da rede. $\mathrm{O}$ valor de retorno refere-se ao fato de que os cabos retirados possam ser reutilizados em outra obra.

Em função das características de topologia dos circuitos e dos cabos que estão disponíveis para instalação, as substituições podem ser realizadas até se atingir o limite de queda de tensão mínima possível. Um aspecto importante que deve ser mantido refe-se ao fato da redução gradual da bitola no circuito no sentido das cargas. Com isso, não podemos ter um cabo de bitola maior que seu anterior, portanto a topologia deve ser avaliada e corrigido esse problema. Outra consideração do modelo está relacionado ao fato que não deve ser sugerido um cabo com bitola inferior ao instalado, indicando nesse caso, um erro no planejamento. É necessário sugerir uma configuração com redução gradual da bitola ao longo do circuito, no sentido do transformador para as cargas. Deve-se evitar que ocorra um aumento de bitola de um trecho para outro conseguinte. O modelo contempla esta situação e, inclusive, em casos em que esta condição não é atendida inicialmente pelo circuito em análise, não sugere a redução da bitola do trecho superdimensionado e nem o aumento de todas as bitolas anteriores.

Baseado nas considerações de operação do sistema segue-se o equacionamento da função objetivo e das restrições operacionais de acordo com a nomenclatura das variáveis utilizadas no modelo.

\section{Nomenclatura}

\section{Conjuntos}

$\begin{array}{lll}\text { Nos } & 1 . . \mathrm{N}_{\mathrm{n}} & \text { Nós da topologia da rede } \\ \text { Fase } & 1 . .3 & \text { Fase A, B e C } \\ \text { Cond } & & \text { Tipos de condutores } \\ \text { Tre } & \subset \text { NosxNos } & \text { Trechos instalados no circuito }\end{array}$




$$
\begin{array}{lll}
f & \subseteq \text { Fase } & \text { Fase da rede } \\
i & \subseteq \text { Nos } & \text { Nó da rede } \\
j & \subseteq \text { Nos } & \text { Nó da rede } \\
c, d & \subseteq \text { Cond } & \text { Cabo condutor }
\end{array}
$$

\section{Parâmetros}

$\mathrm{CiCm}_{c}$ Custo de instalação do condutor $c(\mathrm{R} \$ / \mathrm{m})$

$\mathrm{CrCm} m_{c}$ Retorno financeiro com a remoção do condutor $c(\mathrm{R} \$ / \mathrm{m})$

Comp $_{i j}$ Comprimento do cabo entre os nós $i$ e $j(\mathrm{~m})$

$Z C d_{c} \quad$ Reatância do cabo $c(\Omega)$

\section{Variável}

CndP $P_{c i j} \quad 0,1 \quad$ Condutor $c$ proposto entre os nós $i$ e $j$

$C_{n d I} \quad 0,1 \quad$ Condutor $c$ instalado entre os nós $i$ e $j$

\subsubsection{Função Objetivo}

A função objetivo (FO)(5.1)consiste na minimização do valor da troca de condutores incluindo os custos de instalação e o desconto do valor de retorno do cabo removido. $\mathrm{O}$ primeiro termo da função objetivo (a) contabiliza o custo da instalação de um cabo, o segundo termo (b) representa o desconto do valor de retorno do cabo removido.

$$
\begin{aligned}
\min \sum_{c \in C o n d} \sum_{(i j) \in T r e}\{\underbrace{C i c m_{c} * C o m p_{i j} *\left(C n d P_{c i j}-C n d P_{c i j} * C n d l_{c i j}\right)}_{a}- & \underbrace{C r c m_{c} * C o m p_{i j} *\left(C n d l_{c i j}-C n d l_{c i j} * C n d p_{c i j}\right)}_{b}\}
\end{aligned}
$$

A tabela 5 mostra as operações entre as variáveis binárias utilizadas nos itens (a) e (b) da função objetivo para a composição do custo de instalação e retorno com a remoção do cabo

\subsubsection{Restrições}

Cada trecho do circuito deve ter apenas um tipo de condutor instalado conforme restrição (5.2).

$$
\sum_{c \in C o n d(i j)} C n d P_{c i j}=1
$$


Tabela 5 - Tabela verdade instalação/retirada de cabos.

\begin{tabular}{c|c|c|c|c}
\hline Cndl $_{\mathrm{cij}}$ & $\mathrm{CndP}_{\mathrm{cij}}$ & $\mathrm{CndP}_{\mathrm{cij}}-\mathrm{CndP}_{\mathrm{cij}}{ }^{*} \mathrm{Cndl}_{\mathrm{cij}}$ & $\mathrm{Cndl}_{\mathrm{cij}}-\mathrm{Cndl}_{\mathrm{cij}}{ }^{*} \mathrm{Cndp}_{\mathrm{cij}}$ & $\mathrm{Ação}$ \\
\hline 0 & 0 & 0 & 0 & Nenhuma \\
0 & 1 & 1 & 0 & Instalar \\
1 & 0 & 0 & 1 & Remover \\
1 & 1 & 0 & 0 & Nenhuma \\
\hline
\end{tabular}

Fonte: Elaborada pelo autor.

Os trechos não podem ser substituídos por cabos de menor bitola. Esta restrição impede que cabos já instalados no circuito com alto valor de retorno sejam substituídos por cabos de menor bitola de acordo com a restrição (5.3).

$$
C n d P_{c i j}=0 \forall(i j) \in \text { Tre }_{,} \in \operatorname{Cond} \mid Z C d_{c}>Z C d_{C n d l_{i j}}
$$

O cálculo do fluxo de potência deve ser realizado para o circuito para verificar a restrição de tensão mínima nos pontos da rede. Para realizar tal processamento, na recuperação dos dados do circuito para a execução do modelo, é obtida a topologia da rede. Com a informação da topologia da rede é possível fazer o processamento do cálculo, identificando os nós iniciais e finais de cada trecho do circuito. Com os dados de carga e de valores de resistência e reatância dos cabos, são determinados valores de tensão, corrente e perdas de cada circuito analisado.

\subsubsection{Troca de faseamento dos consumidores}

A troca do faseamento dos consumidores é uma das soluções técnicas possíveis de serem aplicadas para elevar o nível de tensão de um circuito. Consiste na distribuição uniforme das cargas dos diversos consumidores conectados no circuito, reduzindo assim o desequilíbrio de corrente entre as fases e a tensão de neutro. Esta redução é essencial, dado que o desequilíbrio prejudica a fase mais carregada, ocasionando uma queda de tensão mais significativa e maior carregamento dos cabos. Cabe ressaltar que a análise do balanceamento de cargas, procura otimizar a distribuição de carga em cada trecho do circuito.

O modelo matemático desenvolvido sugere a reconfiguração do faseamento dos consumidores conectados no transformador, minimizando o número de operações (trocas de fase) necessárias para que o circuito atenda ao índice exigido de tensão mínima. A sugestão pretende apresentar não só a solução com menor custo operacional, representado aqui pelo número de trocas de fases dos consumidores, mas também aquela que forneça o melhor índice de queda de tensão dentre as alternativas de mesmo custo. Baseado nas considerações de operação do sistema segue-se o equacionamento 
da função objetivo e das restrições operacionais de acordo com a nomenclatura das variáveis utilizadas no modelo.

\section{Nomenclatura}

\section{Conjuntos}

Nos $\quad 1 . . \mathrm{N}_{\mathrm{n}} \quad$ Nós da topologia da rede

Fase $1 . .3$ Fase A, B e C

Índices

$f \subseteq$ Fase Fase da rede

$i \subseteq$ Nos Nó da rede

\section{Parâmetros}

Calt Custo de alteração do faseamento $(\mathrm{R} \$)$

$\mathrm{Nn}$ Número de consumidores

Variável

$F P_{\text {if }} \quad 0,1 \quad$ Faseamento proposto do consumidor $i$ na fase $f$

$F I_{\text {if }} \quad 0,1 \quad$ Faseamento original do consumidor $i$ na fase $f$

\subsubsection{Função Objetivo}

A função objetivo (5.4) consiste na minimização do custo médio da troca de faseamento de um transformador instalado em um determinado nó da rede.

$$
\min \sum_{i \in N n} \sum_{f \in F a s e}\left\{C a l t *\left(F P_{i f}-F P_{i f} * F I_{i f}\right)\right\}
$$

\subsubsection{Restrições}

A natureza do faseamento dos consumidores cargas deve permanecer inalterada durante todo os estudo. Desta forma, por exemplo, um consumidor bifásico, durante todo o estudo, será considerado bifásico. A restrição (5.5) representa a necessidade descrita.

$$
\sum_{f \in \text { Fase }} F P_{i f}=\text { FasCons }_{i}
$$




\subsubsection{Movimentação de transformadores}

A movimentação de transformador consiste no deslocamento do transformador para outro poste, com a finalidade de posicioná-lo mas próximo do centro de carga do circuito. Com um posicionamento mais adequado do transformador, ocorre uma homogeneização dos valores da queda de tensão ao longo do circuito. Nem sempre é possível instalar o transformador no ponto geográfico correspondente ao centro de carga, desta forma, deve ser instalar no poste mais próximo do ponto calculado.

Em (SILVA; FRANÇA; SILVEIRA, 1996) é utilizado o conceito de momento elétrico (distância x carga) para representar a relação dos postes candidatos com as cargas distribuídas pelo circuito. O poste escolhido para o posicionamento do transformador é o que apresenta o menor valor para o somatório dos momentos elétricos referentes às demais cargas. A alteração do centro de carga do circuito é muito comum em virtude do crescimento das cargas ao longo do tempo.

Para a elaboração do modelo foram consideradas as seguintes premissas:

1. O custo de movimentação corresponde a um valor médio;

2. Somente os postes que têm rede de MT podem receber o transformador.

\section{Nomenclatura}

\section{Conjuntos}

Postes $\quad 1 . . N p \quad$ Número de postes

PsP $\subseteq$ Postes Postes com MT instalada

Índices

$i \subseteq$ Postes Identificação do poste

Parâmetros

$\operatorname{Mom}_{i} \quad$ Momento elétrico do poste $i$

Np Número de postes

\section{Variável}

PsEscolhido $_{i} \in 0,1$ Poste $i$ escolhido para instalação do transformador. 


\subsubsection{Função Objetivo}

A função objetivo (5.6) consiste na minimização do momento elétrico.

$$
\min \sum_{i \in \text { Postes }}^{N p} \text { Mom }_{\mathrm{i}} * \text { PsEscolhido }_{\mathrm{i}}
$$

\subsubsection{Restrições}

Cada circuito deve ter um posto associado, conforme restrição (5.7).

$$
\sum_{i \in \text { Postes }}^{N p} P_{s} \text { sscolhido }_{\mathrm{i}}=1
$$

O poste escolhido tem que fazer parte do conjunto de postes com rede de $M T$, conforme restrição (5.8).

$$
\text { PsEscolhido } \subseteq \text { PSP }
$$

\subsubsection{Alocação de Geração Distribuída na BT}

A alocação de geração distribuída consiste em indicar a localização e a capacidade de cada unidade a ser instalada nos circuitos da rede de BT. O modelo sugerido consiste em determinar a solução mais econômica, atendendo aos aspectos técnicos solicitados de orgão regulador. Para tanto são considerados custos estimados de instalação na rede de cada unidade de geração distribuída proposta no estudo.

Para a elaboração do modelo foram consideradas as seguintes premissas:

1. A rede em análise é radial;

2. Cada nó de conexão da rede é ponto candidato a receber geração distribuída;

3. Cada nó de conexão só pode receber uma unidade de geração distribuída.

Baseado nas considerações de operação do sistema segue-se o equacionamento da função objetivo e das restrições operacionais de acordo com a nomenclatura das variáveis utilizadas no modelo.

\section{Nomenclatura}

\section{Conjuntos}


Nos 1..N_n Nós da topologia da rede

GD Tipos de geração distribuída classificados por potência

Índices

$i \subseteq$ Nos Nó da rede

$j \subseteq$ Nos Nó da rede

gd $\subseteq G D$ Geração Distribuída

\section{Parâmetros}

$C i G d_{i g d}$ Custo de instalação da geração distribuída no nó $i$ sendo do tipo $g d(\mathrm{R} \$)$

\section{Variável}

$G D P_{i g d} \in 0,1 \quad$ Geração distribuída proposta no nó $i$ sendo do tipo $g d$

\subsubsection{Função Objetivo}

A função objetivo (5.9) consiste na minimização do valor da instalação de unidades de geração distribuída.

$$
\min \sum_{i \in N o s} \sum_{g d \in G D}\left\{C i G d_{i g d} * G D P_{i g d}\right\}
$$

\subsubsection{Restrições}

Cada nó pode ter apenas um tipo de geração distribuída indicada para instalação conforme restrição (5.10).

$$
\sum_{i \in N o s} \sum_{g d \in G D} G D P_{i g d} \leq 1
$$

\subsection{TÉCNICA DA SOLUÇÃO}

Foi adotada uma abordagem heurística para a solução do planejamento de $B T$ através da utilização de um $A G$. Os modelos descritos nas seções anteriores foram contemplados na função objetivo para a validação das melhores soluções envolvidas em um circuito de $B T$. O $A G$ resolve o problema da troca de condutores, faseamento dos consumidor, movimentação de transformadores e inserção de GD. Um fluxo de potência valida a qualidade das soluções, determinando valores de tensão e corrente no 
todos as postes do circuito. A figura 10 ilustra a metodologia proposta neste trabalho para a solução do planejamento operacional da $B T$.

Figura 10 - Metodologia proposta para a BT.

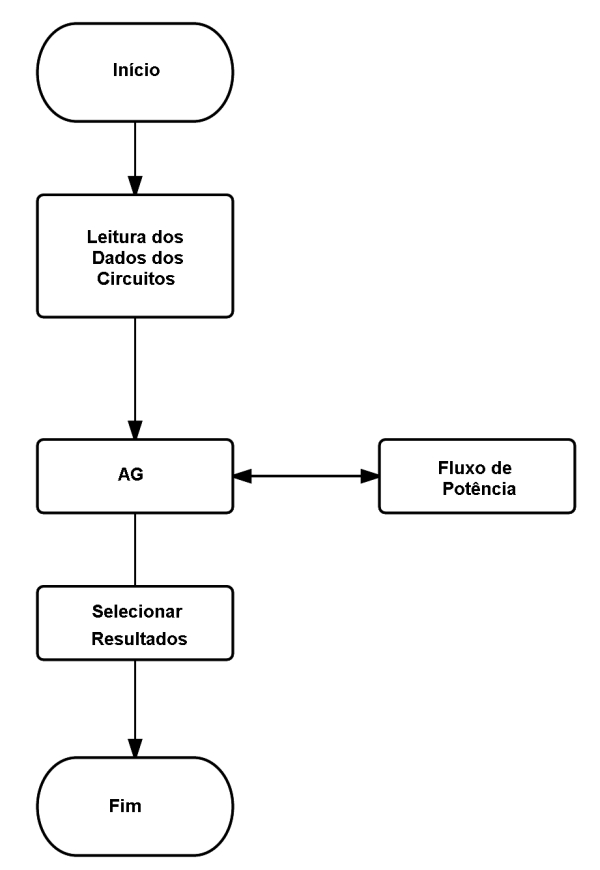

Fonte: Elaboração própria.

A seguir é descrito o $A G$ desenvolvido neste trabalho, detalhando a modelagem utilizada.

\subsubsection{Formulação do problema}

Para a determinação de valores aceitáveis de tensão e perdas em um circuito da rede de distribuição de $B T$, as alternativas avaliadas neste trabalho foram as seguintes:

1. Troca de cabos;

2. Troca de faseamento dos consumidores;

3. Posição do transformador;

4. Inserção de GD.

Dado um circuito pré-instalado, a troca de condutores consiste em substituir os tipos de cabo em determinados trechos, reduzindo as perdas de energia na distribuição a fim de atender uma queda máxima de tensão estabelecida. O modelo sugerido consiste em determinar a solução mais econômica, atendendo aos aspectos técnicos solicitados. Para tanto, são considerados os custos estimados de instalação dos novos cabos. 
A troca de faseamento dos consumidores é uma das soluções técnicas possíveis para elevar os níveis de tensão de um circuito, consistindo em alocar uniformemente as cargas de um circuito às fases do sistema de distribuição, reduzindo assim o desequilíbrio de corrente entre estas. Esta redução é essencial, dado que o desequilíbrio prejudica a fase mais carregada, comprometendo o circuito como um todo pelo surgimento de corrente no condutor neutro, quedas de tensão mais representativas e maior carregamento dos cabos e do transformador.

O posicionamento do transformador em um ponto mais adequado de um circuito propicia uma distribuição de cargas equilibrada, homogeneizando as quedas de tensão ao longo dos ramos. Embora possa se determinar o ponto ideal de posicionamento, a proposta de movimentação presume um reparo em um circuito fisicamente instalado, considerando assim apenas a relocação para posições onde já existam postes.

Para encontrar a melhor opção tanto do ponto de vista econômico quanto técnico, deve-se procurar simular várias situações para determinar a mais viável. Quando da realização deste estudo, já é prevista uma determinada taxa de crescimento de cargas. Esse procedimento é realizado para que as alterações realizadas possam ter uma maior adequação ao crescimento de cargas, evitando alterações frequentes nos circuitos. A troca de faseamento dos consumidores no circuito é a situação mais barata e mais viável, porém é adequada apenas em situações em que o circuito está com um grande desequilíbrio entre as fases. A solução geralmente adotada é a troca de cabos que acaba provocando uma melhora significativa das restrições de queda de tensão, carregamento de cabos e perdas. Considera-se também a ação de GD nos circuitos, simulando o circuito no processo de otimização com e sem a presença da GD.

\subsubsection{Função Objetivo}

Para o problema analisado, foi definida uma função objetivo conforme (5.11) que avalia a queda de tensão, perdas e custos operacionais de troca de cabos, faseamento de consumidores, posição do transformador e GD. Cada um desses critérios a serem considerados caracteriza um problema multi-critérios que considera a minimização das seguintes funções:

$$
\text { F.O.min }(f 1, f 2, f 3)
$$

Onde:

f1: Violação da queda de tensão;

f2: Violação das perdas;

f3: Custo de realização das trocas. 
Como são considerados critérios com grandezas diferentes, foi utilizado o Método do Critério Global (RAO, 1996), normalizando cada objetivo através da determinação do valor ótimo e do pior caso. Desta forma, a função objetivo pode ser definida conforme (5.12).

$$
\min \left(\frac{f A}{f \max A}+\frac{f B}{f \max B}+\frac{f C}{f \max C}\right)
$$

Onde:

$f A$ : Maior queda de tensão da simulação;

$f B$ : Soma das perdas do circuito na simulação;

fC: Custo de realização das trocas de cabos, faseamento de consumidores, posição do transformador e GD;

fmaxA: Pior caso de queda de tensão. Considera-se a situação original do circuito;

fmaxB: Pior caso de perdas no circuito. Considera-se a situação original do circuito;

fmaxC: Pior caso de custo de trocas. Considera-se o maior custo possível.

\subsubsection{Representação do Cromossomo}

O cromossomo tem tamanho variável, a primeira sequencia de genes está reservada para representar os cabos, a segunda o faseamento dos consumidores, a terceira a posição do transformador e, finalmente, a GD.

A representação dos cabos no sistema é feita através da relação mostrada na tabela 6 em ordem decrescente de resistência.

Tabela 6 - Valores dos cabos

\begin{tabular}{c|c}
\hline Codificação binária do cabo & Cabo comercial \\
\hline 001 & Alumínio 04 AWG \\
010 & Alumínio 02 AWG \\
011 & Alumínio 2/0 AWG \\
100 & Alumínio 4/0 AWG \\
101 & $35 \mathrm{~mm} 2$ Quadruplex Alumínio \\
110 & $70 \mathrm{~mm} 2$ Quadruplex Alumínio \\
111 & 120(70) mm2 Quadruplex Alumínio \\
\hline
\end{tabular}

Fonte: Elaborada pelo autor. 
A representação do faseamento dos consumidores é feita através da relação mostrada na Tabela 7.

Tabela 7 - Tabela Faseamento do Consumidor

\begin{tabular}{c|c}
\hline Codificação binária do faseamento & Faseamento \\
\hline 001 & $\mathrm{~A}$ \\
010 & $\mathrm{~B}$ \\
011 & $\mathrm{C}$ \\
100 & $\mathrm{AB}$ \\
101 & $\mathrm{BC}$ \\
110 & $\mathrm{AC}$ \\
111 & $\mathrm{ABC}$ \\
\hline
\end{tabular}

Fonte: Elaborada pelo autor.

O sistema de codificação pode ser visualizado na figura 11. Na situação mostrada, o problema possui cinco cabos e seis unidades consumidoras, além da informação do índice do poste proposto para a instalação do transformador. Os genes dos cabos e dos faseamentos estão dimensionados para representar sete valores, conforme tabela 6 e 7 . No entanto, o gene do posicionamento do transformador suporta 32 valores, ou seja, para uma quantidade maior de postes a codificação da posição do transformador deve ser alterada.

Figura 11 - Cromossomo rede BT.

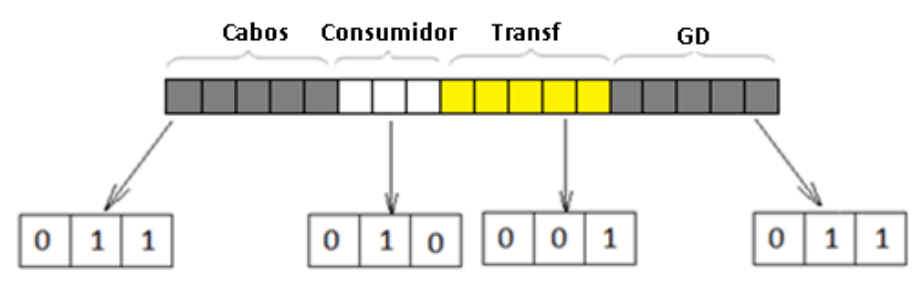

Fonte: Elaboração própria.

Para cada indivíduo é feita a decodificação do circuito e executado o fluxo de potência para determinar valores de queda de tensão e perdas. Caso o indivíduo seja inválido, é realizada uma correção para que possa ser avaliado o fluxo de potência e atribuição do seu valor de fitness. Um indivíduo é considerado inválido quando apresenta um faseamento incompatível, um cabo de resistência menor que o cabo original e a posição sugerida do transformador em um poste em rede de $M T$. 
A figura 12 exemplifica o caso da recombinação que resulta em um indivíduo com problema na geração da informação de cabo. Após a recombinação, foi feita a decodificação dos indivíduos e constatou-se que o cabo 3 ficou com valor 010. No entanto, o cabo instalado em campo é o 011 , desta forma a troca proposta pelo algoritmo não deve ser realizada. Consultando a tabela 1, percebe-se que o cabo de identificação 011, que representa a bitola $02 A W G$ não pode ser substituído por um de bitola 04 AWG. A alteração acarreta em um aumento da resistência do cabo, regra que não é permitida. O procedimento adotado é simplesmente a correção do indivíduo para um valor viável, ou seja, seu valor original.

Figura 12 - Sistema de codificação.

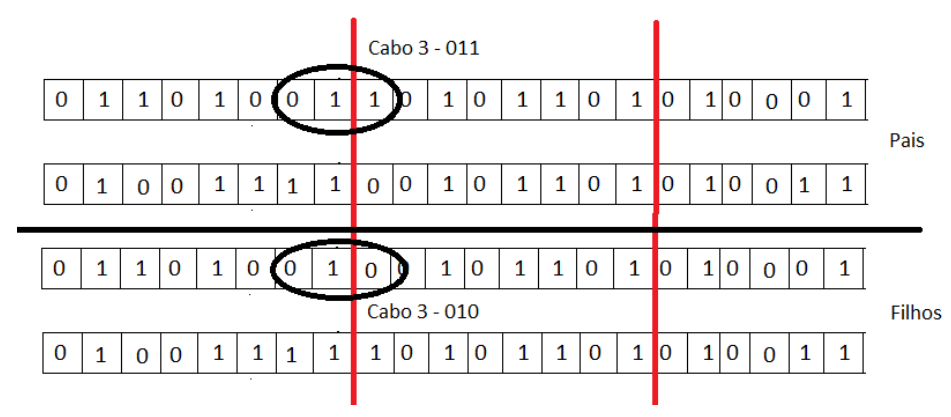

Fonte: Elaboração própria.

\subsection{CONCLUSÃO DO CAPÍTULO}

Neste capítulo o planejamento operacional da BT foi formulado como um PNLIM, incorporando-se à este modelo as restrições elétricas que devem ser atendidas durante os estudos de sistemas reais. Estas restrições afetam diretamente os custos de investimentos e as intervenções que podem ser aplicadas para a resolução do planejamento.

A solução estudada para o desenvolvimento de um modelo de otimização foi a de Algoritmos Genéticos que é capaz de encontrar uma solução que minimiza a multa global de continuidade, mesmo que não encontre o valor ótimo, já que os algoritmos evolutivos não garantem o ótimo. $\mathrm{O}$ modelo desenvolvido é capaz de combinar as restrições técnicas necessárias considerando a troca de cabos, posicionamento do transformador e balanceamento das cargas entre as fases dos consumidores e custos relacionados com as perdas elétricas. Com a característica da rede BT operar nos menores níves de tensão do sistema elétrica e consequentemente temos as maiores perdas técnicas, a análise simultânea da realização das intervenções propostas permite a obtenção de uma solução de reforma de rede com menores custos de investimento e operação. 


\section{PLANEJAMENTO OPERACIONAL INTEGRADO DE REDES DE MT E BT}

Neste capítulo é proposto um método para o planejamento operacional integrado de redes de $M T$ e $B T$, nos modelos são utilizadas as técnicas de $A G$ desenvolvidas nos capítulos 4 e 5 . A integração dos modelos dá-se através da resolução de forma hierárquica, sendo que, para cada solução de $M T$ proposta, existe uma coleção de soluções para os circuitos de BT relacionados. É determinado, desta forma, um conjunto de alternativas de integração entre os sistemas, resolvendo-se o planejamento de MT e BT e avaliado o efeito destas alternativas nos custos de operação e melhoria dos dois sistemas simultaneamente. Para avaliar esta metodologia foram realizados testes em um sistema real, composto de rede de MT e circuitos de BT.

\subsection{PLANEJAMENTO OPERACIONAL INTEGRADO}

No planejamento integrado procura-se verificar os resultados do planejamento da $M T$ e $B T$ e a influência dos valores para o processo de minimização dos custos de investimentos e operação do sistema de distribuição. Desta forma, o planejamento procura considerar as alternativas de cada sistema, bem como as restrições operacionais envolvidas nos sistemas.

Dada a natureza combinatória do problema de planejamento para as redes de $M T$ e $B T$, tem-se um elevado grau de dificuldade para resolver o planejamento de forma integrada. Geralmente as ferramentas computacionais voltadas para o planejamento tratam o problema do planejamento de redes de $M T$ de forma separada do planejamento das redes de $B T$, reduzindo a dimensão do espaço de busca do problema.

A análise integrada tem o objetivo de determinar resultados de forma conjunta, melhorando a qualidade técnica do serviço de fornecimento de energia elétrica com um custo total de obras reduzido. A abordagem é muito importante uma vez que os resultados do planejamento de um segmento influencia nos resultados do outro, permitindo um planejamento mais completo, com redução dos custos totais e das perdas. Cada solução na rede de MT contêm um conjunto de soluções de BT, resolvido de forma hierárquica e observando a topologia da rede para as conexões e dependências entre os sistemas.

\subsection{TÉCNICA DA SOLUÇÃO}

Inicialmente, para cada rede de $M T$ selecionada no estudo, são simulados os seus valores de tensão, carregamento e perdas para determinar se é necessária alguma alteração para melhorar seus índices de fornecimento de energia. Quando da realização 
da análise inicial da rede de $M T$, os elementos da rede de $B T$ conectados também são analisados e é elaborado um conjunto de circuitos de $B T$ que deverão entrar no estudo integrado. Os circuitos de BT que deverão ser analisados são os circuitos que apresentam problemas em valores de tensão, carregamento de transformador e carregamento de cabos. Desta forma, para cada rede de MT analisada, é elaborada uma lista de circuitos de $B T$ correspondente para a análise em conjunto. O processo de resolução parte da rede de MT utilizando técnica de $A G$ descrita no capítulo 4 e cada solução encontrada torna-se entrada para uma análise dos circuitos de $B T$ que apresentam algum problema e devem sofrem uma intervenção. Para cada rede de $B T$ relacionada na lista do alimentador, é executado o $A G$ descrito no capítulo 5 para a determinação das intervenções possíveis e determinado o valor total dos custos envolvidos na rede de MT e BT.

Neste trabalho considera-se que o planejamento operacional integrado é efetuado da seguinte forma:

1. A rede de $M T$ é analisada identificando problemas de tensão e carregamento

2. Os circuitos da rede de BT associados à rede de $M T$ são analisados e os seus problemas de tensão e carregamentos identificados

3. Resolve-se o planejamento da rede de $M T$ dos alimentadores nos quais os circuitos de BT estão instalados

4. Para cada indivíduo proposto pela técnica de $A G$ para a rede de $M T$ faça

4.1. Atualize a topologia da rede de $M T$ para simular a rede de $B T$

4.2. Para cada circuito da rede de $B T$ da rede de $M T$ faça

4.2.1. Execute a técnica de $A G$ para cada rede de $B T$

4.2.2. Armazene a melhor solução encontrada para cada circuito de $B T$

4.3. Armazene o conjunto de soluções para cada circuito de $B T$

4.4. Fim do processo para os circuitos de $B T$

5. Armazene a melhor solução encontrada para a rede de $M T$ e o conjunto de soluções da rede de $B T$ associada

6. Fim do processo para os circuitos de $M T$

Para cada indivíduo da rede de $M T$ gerado pela técnica de $A G$ relacionado no capítulo 4, deverá ser realizada uma análise de todos os circuitos de BT conectados. Para cada circuito de $B T$ é aplicada a técnica de $A G$ descrita no capítulo 5 para a determinação das intervenções a serem realizadas. Desta forma, existe uma elevada combinação de soluções, exigindo um considerável tempo de processamento para cada situação 
proposta. É utilizada uma técnica de memoização para otimizar o processo de avaliação do indivíduo gerado, seja da rede de MT ou BT. Segundo (CORMEN et al., 2009) a técnica de memoização mantêm uma entrada em uma tabela para a solução de cada subproblema, evitando processamento de soluções previamente avaliadas. Inicialmente, todas as entradas da tabela contêm um valor especial indicando que ela ainda tem que ser preenchida e que o subproblema ainda não foi resolvido. Quando um subproblema é encontrado pela primeira vez, sua solução é calculada e armazenada em uma posição da tabela. Em outros momentos quando o mesmo subproblema é encontrado, o valor armazenado é pesquisado e retornado evitando processamentos desnecessários. Todos os cromossomos da rede de $M T$ e BT são armazenados em tabelas, bem como seus valores de tensão, corrente e custos calculados na execução do $A G$. Desta forma, ao serem gerados os indivíduos, são consultadas as tabelas de informação de execução da rede de $M T$ e $B T$ para verificar se a decodificação do indivíduo, bem como o fluxo de potência e validação da função de fitness já foi realizado.

\subsubsection{Custos Totais Envolvidos}

Com base nos valores determinados nos dois planejamentos, é calculado o valor total das intervenções, através da equação (6.1);

$$
C_{\text {Total }}=C_{M T_{i}}+\sum_{k=1}^{n} C_{B T_{k}}
$$

Onde:

$i \quad$ Indivíduo da rede de $M T$;

$k \quad$ Circuito $k$ da rede de $B T$;

$n \quad$ Total de circuitos da rede de $B T$ com problema na rede de $A T$;

$C_{\text {Total }}$ Custo total do planejamento integrado;

$C_{M T_{i}} \quad$ Custo do planejamento de MT para o indivíduo $i$;

$C_{B T_{k}} \quad$ Custo do planejamento de BT para o circuito $k$.

A função de avaliação do custo total do planejamento considera, além do custo de cada indivíduo da rede de $M T$, a somatória dos custos de intervenção de todos os circuitos de $B T$ que necessitam de alteração. Do conjunto total dos indivíduos de $M T$ com a sua devida coleção de soluções de BT é escolhida a que apresenta o menor soma dos valores da função de fitness do indivíduo $M T$ e de todos os valores das funções de fitness dos indivíduos de BT.

\subsubsection{Resolução Integrada Proposta}

A melhor solução é aquela que contempla a integração com um menor custo de planejamento, obedecendo aos critérios técnicos de operação da rede, na figura 13 é 
mostrado o fluxo de execução do modelo de planejamento integrado entre os sistemas de $M T$ e de $B T$.

Figura 13 - Fluxo de execução do planejamento integrado

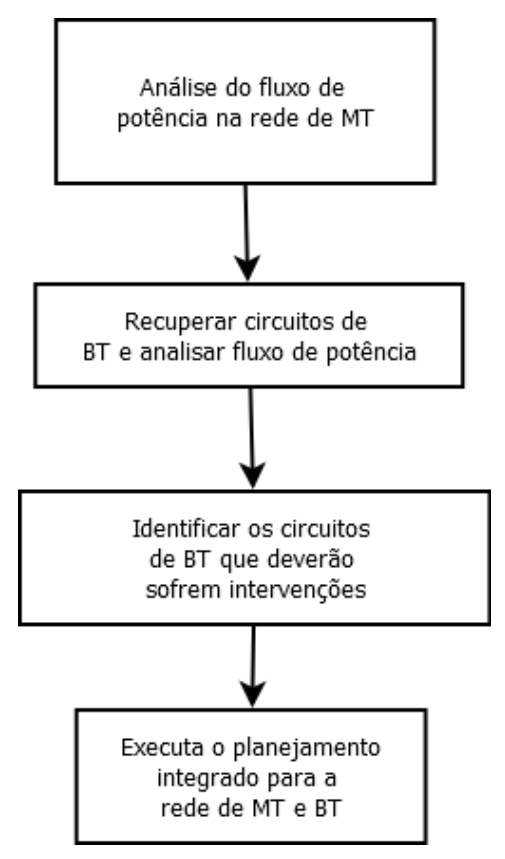

Fonte: Elaboração própria.

A análise da rede de $M T$ inicia com o cálculo dos valores de tensão, corrente e perdas da rede de $M T$, bem como a recuperação de todos os circuitos de BT conectados. Para cada circuito de BT é realizado o calculo de tensão, corrente e perdas para identificar quais deverão sofrer uma intervenção. Após a seleção da necessidade de realização de intervenções na rede de $M T$ ou $B T$ ou ambas, é realizado o planejamento integrado. $\mathrm{O}$ fluxograma representado na figura 14 exemplifica o processo de execução. 
Figura 14 - Fluxograma detalhado de execução do planejamento integrado

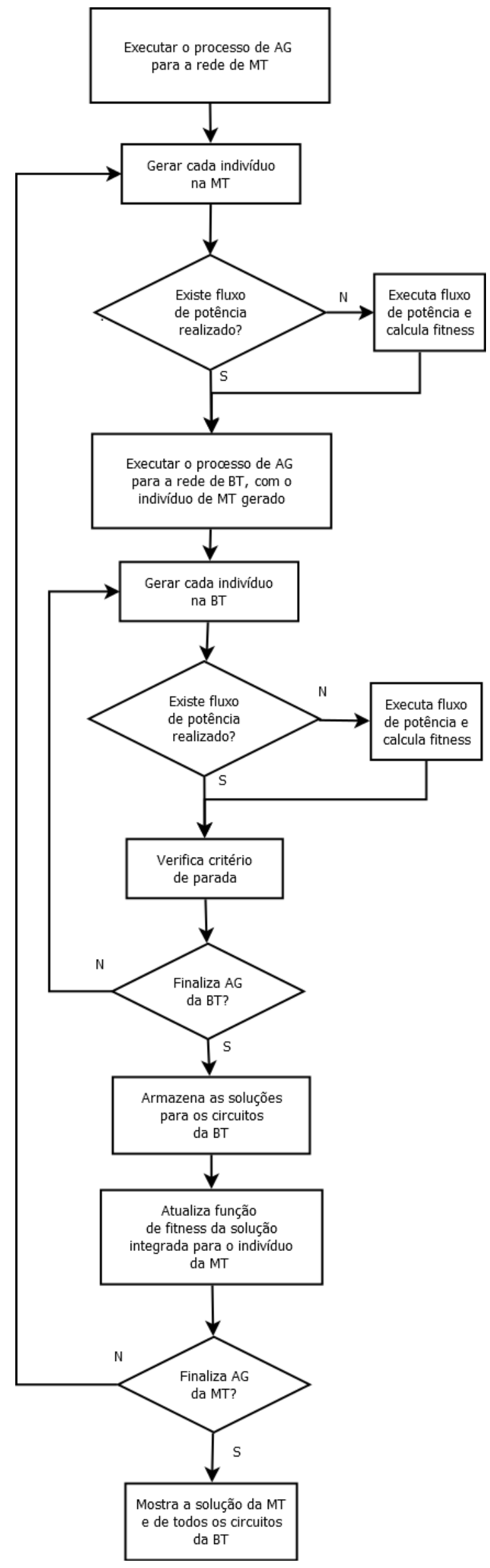

Fonte: Elaboração própria. 
Durante a execução do $A G$ para a rede de $M T$, cada indivíduo gerado para avaliação tem um processo do $A G$ para a rede de $B T$ associado. Desta forma, uma definição de topologia na rede de $M T$ influencia a geração de indivíduos na rede de BT. Após a análise de tensão, carregamento e perdas do indivíduo da $M T$, são atualizados os valores de tensão secundária nos transformadores com rede de $B T$ e realizado o processo de $A G$ dos circuitos identificados com problemas na $B T$. O valor da tensão do secundário do transformador considera o valor calculado na rede de MT aplicando a relação de transformação do transformador e sua queda de tensão interna. Para cada processamento da rede de $M T$ este processo é realizado para atualização dos valores de tensão no secundário de cada transformador instalado no alimentador.

No processo de $A G$ para a rede de $B T$ é verificado se para a solução já existe uma simulação de fluxo de potência e cálculo da função de fitness, através do processo de memoização. Caso não exista, o processo de cálculo é realizado e armazenados os valores resultantes do fluxo de potência fitness calculado. A tendência é que no início do processo cada circuito de $B T$ tenha muitas simulações de fluxo de potência, reduzindo gradativamente após algumas gerações no processo do $A G$. A tabela de soluções é armazenada por circuito de $B T$ e disponível para consulta em qualquer instante da simulação dos circuitos, assim cada circuito de BT têm uma quantidade grande de simulações armazenadas para evitar processamento desnecessário.

O controle de processamento de fluxo de potência que é aplicado para a rede de $B T$ é aplicado para rede de MT proporcionando o armazenamento de várias coleções de soluções. A consulta das soluções é importante para que o tempo de processamento possa ser reduzido, uma vez que ocorre uma explosão combinatória durante o processo de resolução dos modelos. Ou seja, cada indivíduo gerado na MT têm uma coleção de circuitos de BT que devem ser analisados e escolhido o melhor para compor o valor final dos custos do planejamento integrado.

Deve ser aplicado um tratamento diferenciado na metodologia proposta quando surge a alternativa de alteração de posicionamento de transformador na rede de $B T$. Assim, todas as sugestões de remanejamento de transformador são atualizadas na topologia do alimentador e refeito o seu processamento do fluxo de potência. Com os novos valores do fluxo de potência resultantes do remanejamento do transformador, é atualizado o valor da função fitness do alimentador e processado o fluxo de potência de todos os circuitos do alimentador. Após o processamento do fluxo de potência dos circuitos, é realizada a atualização da função de fitness de cada circuito para a nova configuração do alimentador em virtude do remanejamentodos transformadores.

Assim, no processo de análise integrada dos modelos de MT e BT, o remanejamento de transformadores é tratado da seguinte forma: 
1. A rede de $M T$ é analisada identificando problemas de tensão e carregamento

2. Os circuitos da rede de $B T$ associados à rede de $M T$ são analisados e os seus problemas de tensão e carregamentos identificados

3. Resolve-se o planejamento da rede de MT dos alimentadores nos quais os circuitos de BT estão instalados

4. Para cada indivíduo proposto pela técnica de $A G$ para a rede de $M T$ faça

4.1. Atualize a topologia da rede de $M T$ para simular a rede de $B T$

4.2. Para cada circuito da rede de BT da rede de $M T$ faça

4.2.1. Execute a técnica de $A G$ para cada rede de $B T$

4.2.2. Armazene a melhor solução encontrada para cada circuito de $B T$

4.3. Caso as soluções propostas dos circuitos de BT tenham alteração da posição do transformador faça

4.3.1. Atualize a topologia da rede de MT, simule e atualize função de fitness do indivíduo da $M T$

4.3.2. Atualize os valores de tensão no secundário dos transformadores das soluções propostas dos circuitos de BT, simule e atualize função de fitness

4.4. Armazene o conjunto de soluções para cada circuito de $B T$

4.5. Fim do processo para os circuitos de $B T$

5. Armazene a melhor solução encontrada para a rede de $M T$ e o conjunto de soluções da rede de $B T$ associada

6. Fim do processo para os circuitos de $M T$

\subsection{CONCLUSÃO DO CAPÍTULO}

Neste capítulo foi apresentado a metodologia proposta para a planejamento operacional integrado da rede $M T$ e $B T$, detalhamento do procedimento de resolução e avaliação dos custos totais envolvidos no processo.

A integração dos modelos apresentados nos capítulos 4 e 5 permitiu a realização de uma análise mais detalhada para melhorar a qualidade técnica das soluções com um custo total de obras reduzido. Desta forma, o planejador consegue ter uma noção mais ampla da possibilidade de alternativas que podem ser aplicadas ao problema do planejamento operacional. 



\section{REMANEJAMENTO DE TRANSFORMADORES EM REDES DE DISTRIBUIÇÃO DE MÉDIA TENSÃO}

Neste capítulo, é apresenta uma proposta para o remanejamento de transformadores sobrecarregados por subcarregados e vice-versa em detrimento a uma simples substituição do transformador. O problema de remanejamento de transformadores de distribuição consiste na substituição de transformadores sobrecarregados por transformadores subcarregados e vice-versa. Considerando uma área urbana, as combinações são elevadas, tratando-se de um problema de otimização combinatória. O problema apresenta uma característica não linear, referente aos valores de perdas no ferro e no cobre dos transformadores.

Os principais ganhos esperados no remanejamento dos transformadores são:

- Redução dos custos de perdas elétricas;

- Redução da perda de vida do equipamento;

- Melhoria do nível de tensão dos circuitos;

- Aumento da eficiência do sistema elétrico de distribuição;

- Aumento da confiabilidade.

Os custos operacionais dos transformadores são compostos de duas parcelas: o custo das perdas no ferro e o custo das perdas no cobre. Os investimentos necessários para remanejamento correspondem aos gastos com mão de obra própria e de terceiros, transporte, remoção, materiais e despesas administrativas. Considera-se também o custo de interrupção do fornecimento de energia elétrica durante a instalação e remoção dos transformadores. O procedimento normal da substituição de transformadores corresponde à troca dos transformadores sobrecarregados por transformadores de potência superior. Com a aplicação deste procedimento de remanejamento, espera-se resolver o problema do carregamento dos transformadores via remanejamento, caso não tenha disponibilidade de transformadores na rede é recuperado um transformador do almoxarifado.

Para a análise do remanejamento foi proposto um modelo baseado em programação linear inteira, utilizando o conceito de sistemas multiagentes para a elaboração da formulação resultante da negociação dos agentes. A seguir é detalhado o modelo matemático elaborado para o problema de planejamento multiobjetivo com a função objetivo e relacionadas as restrições pertinentes. 


\subsection{FORMULAÇÃO MATEMÁTICA DO REMANEJAMENTO}

Para a determinação de trocas aceitáveis de transformadores na rede, foram considerados os seguintes critérios:

- Transformador subcarregado: potência máxima menor ou igual a 65\% de sua potência nominal;

- Transformador sobrecarregado: potência máxima maior ou igual a 150\% de sua potência nominal;

- Distância máxima de $30 \mathrm{~km}$ entre possíveis trocas de transformador para o caso do remanejamento;

- Caso não seja possível o remanejamento, o transformador pode ser substituído por um no almoxarifado.

Os valores de potência máxima dos transformadores referem-se aos do horário de pico de cada transformador, mesmo o horário não sendo coincidente. Considera-se, desta forma, a pior situação de potência de cada transformador instalado na rede que pode sofrer algum remanejamento. $O$ critério da distância máxima entre as possíveis trocas de transformadores é em geral utilizado pelas empresas em virtude de problemas logísticos. Para o caso da intervenção do almoxarifado, foi considerado que existe uma disponibilidade imediata do transformador a ser fornecido para a rede.

\subsubsection{Função Objetivo}

Foi definida uma função objetivo que avalia o custo das perdas no ferro, custo das perdas no cobre, custos de interrupção custos agrupados e custo de instalação de transformadores novos. Os custos agrupados de remanejamento para cada transformador compreendem os itens, a saber: mão de obra, transporte, remoção, despesas administrativas e custo de materiais.

A consideração de cada um desses objetivos caracteriza um problema multicritérios que considera a minimização das funções representadas na função objetivo (7.1).

$$
\text { F.O. }=\min (f 1+f 2+f 3+f 4+f 5)
$$

Onde:

f1: Custo das perdas no ferro; 
f2: Custo das perdas no cobre;

f3: Custo de interrupção;

f4: Custos agrupados para o remanejamento;

f5: Custo de instalação de novos transformadores.

O cálculo das perdas no ferro é demonstrado na equação (7.2).

$$
\left.\min \sum_{k=1}^{j} \sum_{t=1}^{n}\left\{C_{U P C_{k}} * P_{F E_{k}} * \frac{1}{(1+T x)^{t}}\right)\right\}
$$

Onde:

$k$ : Índice do Transformador;

j: Total de transformadores no estudo;

t: Ano;

$n$ : Número de anos;

$C_{U P C_{k}}:$ Custo unitário de perdas constantes para o transformador $k(\mathrm{R} \$ / \mathrm{kW})$;

$P_{F E_{k}}$ : Perda de demanda nominal no ferro para o transformador $k(\mathrm{~kW})$;

$T x$ : Taxa de atualização $=12 \%$ ao ano.

O cálculo das perdas no cobre é demonstrado na equação (7.3).

$$
\left.\min \sum_{k=1}^{j} \sum_{t=1}^{n}\left\{C_{U P V_{k}} * P_{C U_{k}} * f_{u}^{2} * \frac{\left((1+g)^{t}\right)^{2}}{(1+T x)^{t}}\right)\right\}
$$

Onde:

$k$ : Índice do Transformador;

j: Total de transformadores no estudo;

t: Ano;

$n$ : Número de anos;

$C_{U P V_{k}}:$ Custo unitário de perdas variáveis para o transformador $k(\mathrm{R} \$ / \mathrm{kW})$;

$P_{\mathrm{CU}_{k}}$ : Perda de demanda nominal no cobre para o transformador $k(\mathrm{~kW})$; 
$f_{U}:$ Fator de utilização;

$T x$ : Taxa de atualização $=12 \%$ ao ano.

$g$ : Taxa de crescimento $=6 \%$ ao ano.

O custo de interrupção corresponde ao total de consumidores alimentados por cada transformador selecionado para troca multiplicada pela tarifa média. O custo do transporte considera a distância a ser percorrida multiplicada pelo valor do transporte especificado na tabela 8 de acordo com a potência do transformador. Os custos agrupados são mostrados na tabela 8 .

Tabela 8 - Custos agrupados.

\begin{tabular}{c|c|c|c}
\hline \multicolumn{2}{c|}{$\begin{array}{c}\text { Remanejamento } \\
(\mathrm{kVA})\end{array}$} & $\begin{array}{c}\text { Transporte } \\
(\mathrm{R} \$ / \mathrm{km})\end{array}$ & $\begin{array}{c}\text { Demais custos } \\
(\mathrm{R} \$)\end{array}$ \\
\hline 35 & 45 & 200 & 2000,00 \\
45 & 75 & 215 & 2500,00 \\
75 & 112,5 & 230 & 3000,00 \\
\hline
\end{tabular}

Fonte: Dados fornecidos por projetistas.

Os custos de instalação de novos transformadores são mostrados na tabela 9 .

Tabela 9 - Custo instalação de novos transformadores.

\begin{tabular}{c|c}
\hline Descrição & Instalação (R\$) \\
\hline Transformador Trifásico 15 kVA 13,8 kV 220/127 V & $5.812,40$ \\
Transformador Trifásico 30 kVA 13,8 kV 220/127 V & $6.512,63$ \\
Transformador Trifásico 45 kVA 13,8 kV 220/127 V & $8.651,99$ \\
Transformador Trifásico 75 kVA 13,8 kV 220/127 V & $11.218,65$ \\
Transformador Trifásico 112,5 kVA 13,8 kV 220/127 V & $12.994,95$ \\
\hline
\end{tabular}

Fonte: Dados fornecidos por projetistas.

\subsection{MODELANDO TRANSFORMADORES COMO AGENTES}

A característica de comunicação entre agentes foi de fundamental importância para a modelagem do sistema, considerando cada transformador como um agente 
no sistema multiagente. $\mathrm{O}$ transformador foi definido como um agente contendo características de carga, potência nominal, coordenadas e quantidade de consumidores alimentados.

O tratamento adotado permite que os transformadores possam mudar de posição sem a necessidade de troca em pares. Desta forma, objetiva-se analisar uma variedade maior de possibilidades de trocas entre os transformadores.

Os agentes foram inseridos na solução com um identificador único, servindo de base para a localização do agente para a troca de mensagens. Na modelagem foram criados agentes chamados de Transformador onde a quantidade varia de acordo com cada estudo a ser realizado. O agente Transformador tem a finalidade de negociar com outros agentes do mesmo tipo a possibilidade de troca de posição na rede, de maneira tal que um transformador subcarregado possa ser substituído por um sobrecarregado e vice-versa.

Na inicialização de cada agente do tipo Transformador é calculado o carregamento, podendo identificar os casos de sobrecarregamento ou subcarregamento. O processo de troca de mensagens inicialmente é feito entre os agentes do tipo Transformador para que cada agente possa montar sua lista de possíveis movimentações.

Para fazer a validação da solução, foi criado um agente denominado Supervisor que tem uma visão global da distribuição dos transformadores e pode ter restrições adicionais, tais como custo total e número de movimentações permitidas em virtude da quantidade de equipes de manutenção disponíveis. O Supervisor recebe a lista de possíveis coalizões de cada agente Posto, determinando quais são possíveis de serem realizadas. Após a consistência das soluções, calcula o custo de cada associação para poder ordená-las e colocar uma prioridade de execução.

Outro agente utilizado na modelagem do problema foi o Almoxarifado, cuja finalidade é de responder ao agente Supervisor os transformadores novos disponíveis a serem instalados na rede. Desta forma, caso não seja possível a adequação dos transformadores via remanejamento, o transformador seja provido pelo almoxarifado.

O processo de troca de mensagens entre os agentes do tipo Posto obedece a seguinte sequência:

1. Cada Transformador é inicializado, informando seus valores de carga, potência e posicionamento;

2. Cada Transformador consulta os agentes criados no estudo;

3. Cada Transformador envia uma mensagem para os agentes transformadores analisados, solicitando que informem sua potência e coordenadas; 
4. Cada Transformador recebe a solicitação e responde ao Transformador solicitante sua potência e coordenadas;

5. Cada Transformador recebe a mensagem e calcula se o Transformador remetente pode entrar na sua lista de coalizões;

6. Cada Transformador, após receber as mensagens de todos os Transformadores do estudo, envia sua lista de coalizões para o Supervisor;

7. O Supervisor, com base nas listas de coalizões dos postos, envia solicitação para o Almoxarifado;

8. O Almoxarifado envia sua lista de coalizões para o Supervisor;

9. O Supervisor, com base nas listas de coalizões dos postos e do almoxarifado, elabora um modelo matemático para ser executado;

10. O Almoxarifado e cada Transformador, esperam a resposta de sugestões de coalizões sugeridas pelo Supervisor.

O processo de troca de mensagens entre os agentes do tipo Transformador e Supervisor ocorre conforme a sequência:

1. O Supervisor controla o recebimento da mensagem de cada Posto informando seus valores de carga, potência e posicionamento, além da sua lista de coalizões;

2. O Supervisor consulta as inconsistências nas listas de coalizões de todos os Transformadores;

3. O Supervisor calcula os valores de custos envolvidos em cada coalizão sugerida;

4. O Supervisor elabora uma formulação matemática de acordos com as coalizões com seus respectivos custos associados;

5. O modelo matemático é executado e o Supervisor define as coalizões de acordo com o modelo executado.

O diagrama de sequência para a negociação entre três agentes do tipo Transformadores e, posteriormente a passagem da lista de coalizões para o Supervisor, pode ser visualizado conforme figura 15. 
Figura 15 - Troca de mensagens dos agentes.

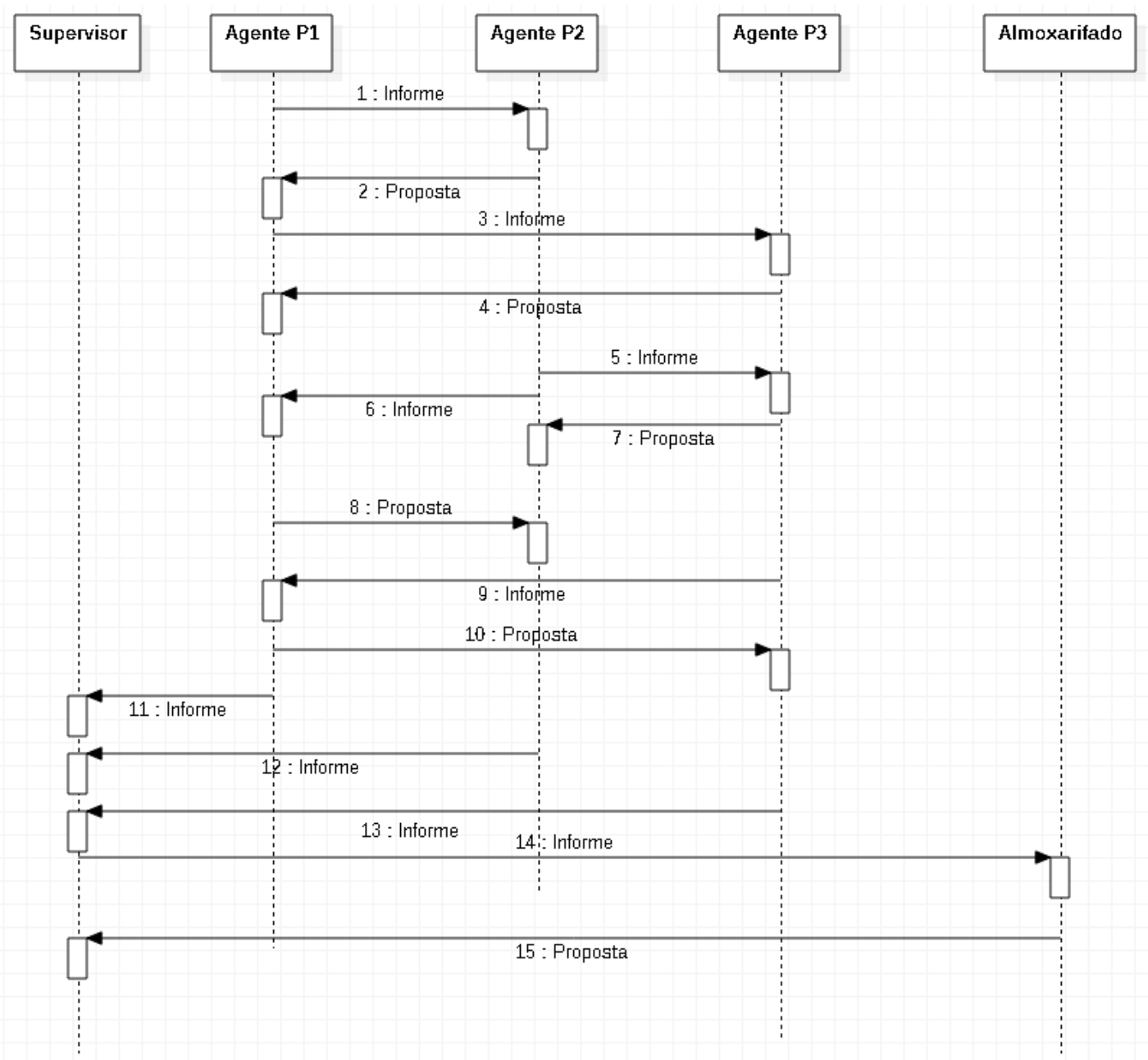

Fonte: Elaboração própria.

As coalizões especificadas por cada lista do agente do tipo Transformadores é tratada pelo Supervisor como um grafo dirigido. Um grafo é definido por um par ordenado de conjuntos $(V, E)$ tal que o grafo $V$ é finito e cada elemento de $E$ é um subconjunto formado por dois elementos de $V$. Cada elemento de $V$ é chamado de vértice e $E$ é chamado de aresta do grafo. Em um grafo dirigido as arestas têm sentido e formam um multiconjunto. Na modelagem cada vértice é representado por um agente do tipo Transformador e as arestas correspondem às coalizões que podem ser realizadas. A figura 16 exemplifica uma situação que o agente Transformador1 pode ser trocar de lugar com o agente Transformador2, bem como o Transformador2 com o Transformador3. Entretanto, a combinação Transformador1 e Transformador3 não pode ser efetivada. Isso acontece devido ao fato que o Transformador1 pode assumir a carga do Transformador3, mas o Transformador3 não tem potência suficiente para assumir a carga do Transformador1. 
Figura 16 - Grafo dirigido.

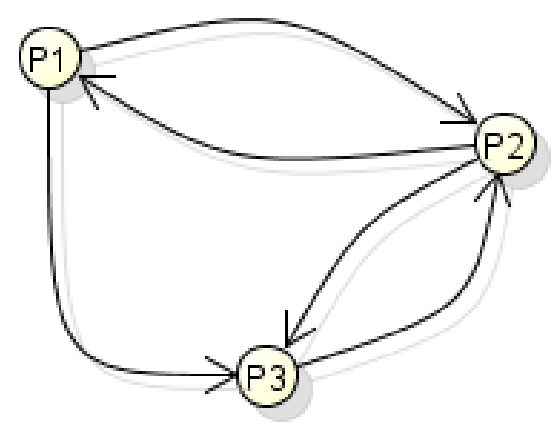

Fonte: Elaboração própria.

Neste caso o grafo representando a figura 16 pode ser definido através das equações (7.4), (7.5) e (7.6).

$$
\begin{gathered}
G=(V, E) \\
V=\{P 1, P 2, P 3\} \\
E=\{\{P 1, P 2\},\{P 1, P 3\},\{P 2, P 1\},\{P 2, P 3\},\{P 3, P 2\}\}
\end{gathered}
$$

O agente Supervisor deve validar o grafo resultante das listas de possíveis coalizões dos agentes Transformadores e gerar a formulação matemática correspondente. Os agentes Transformadores auxiliam na redução do espaço de busca da solução, passando para o agente Supervisor somente as movimentações válidas.

\subsection{MODELAGEM LINEAR INTEIRA}

A formulação refere-se a um problema tradicional no contexto da otimização de fluxo de redes. As arestas representam as possíveis conexões dos transformadores com o seu respectivo custo. No grafo os vértices são conservativos obedecendo a Primeira Lei de Kirchhoff (GOLDBERG, 1989). Essa característica é importante porque garante que cada vértice sempre terá um transformador associado, evitando soluções que algum ponto da rede avaliada fique sem um transformador. A troca pode ocorrer entre os transformadores instalados na rede, bem como os transformadores da rede com os relacionados pelo almoxarifado. 


\subsubsection{Função Objetivo}

A função objetivo pode ser visualizada na equação (7.7).

$$
\min \left\{\sum_{i=1}^{n} \sum_{j=1}^{n} C_{i j} * \text { Troca }_{i j}+\sum_{j=1}^{n} \sum_{i=1}^{n} C_{j i} * \text { Troca }_{j i}\right\}
$$

Onde:

$i$ : Índice do transformador;

$j:$ Índice do transformador;

n: Total de transformadores no estudo;

$C_{i j}$ : Custo unitário da troca do transformador $i$ pelo $j$;

Troca $a_{i j}$ : Variável binária indicando a troca do transformador $i$ pelo $j$;

$C_{j i}$ : Custo unitário da troca do transformador $j$ pelo $i$;

$\operatorname{Troca}_{j i}$ : Variável binária indicando a troca do transformador $j$ pelo $i$.

\subsubsection{Restrições}

As restrições são mostradas nas equações (7.8) e (7.9). As restrições garantem que, com a realização de movimentações, cada ponto do estudo terá um transformador associado, evitando situações que a movimentação de um transformador deixe um ponto sem um equipamento.

$$
\begin{aligned}
& \sum_{i=1}^{n} \sum_{j=1}^{n} \text { Troca }_{i j}=n \\
& \sum_{j=1}^{n} \sum_{i=1}^{n} \text { Troca }_{j i}=n
\end{aligned}
$$

\subsection{CONCLUSÃO DO CAPÍTULO}

Neste capítulo foi apresentado um modelo baseado em SMA para auxiliar o planejamento operacional de circuitos de redes de $B T$ com relação ao remanejamento de transformadores. Foram desenvolvidos agentes do tipo Transformador para elaborar possíveis coalizões indicando a transferência de transformadores sempre em pares. Após a determinação da lista de prováveis Transformadores, o agente Supervisor com uma visibilidade global de todos os postos, faz a validação das transferências e determina 
quais são as mais viáveis do ponto de vista econômico. O agente Supervisor também relaciona as possíveis alterações com o agente Almoxarifado para verificar qual a melhor alternativa de atendimento. A existência de um Supervisor permite que restrições adicionais possam ser incorporadas no sistema, afetando a negociação inicialmente realizada pelos agentes do tipo Transformador. 


\section{APLICAÇÃO DA METODOLOGIA}

Neste capítulo são mostrados os resultados obtidos da aplicação das metodologias para o planejamento operacional integrado de redes de $M T$ e BT especificadas nos capítulos 4, 5, 6 e 7. Para avaliar estas metodologias foram realizados testes em um sistema de distribuiç̧ão de energia elétrica real, composto de rede $M T$ e $B T$.

Para a avalição da alocação ótima de GD nas redes de $M T$ foi considerado um nível de penetração de $20 \%$ em relação ao valor da potência total do alimentador. De forma similar, foi considerado o valor de penetração de $20 \%$ do total de potência instalada em cada circuito da rede de BT. Assim, pode-se avaliar o impacto na GD nos resultados. A localização ótima da $G D$ corresponde à determinação da quantidade e localização de unidades que minimizem as violações de perdas, queda de tensão e custos de instalação relacionadas conforme funções objetivos (4.11) e (5.12).

Os códigos-fonte foram implementados na linguagem de programação C\# e C++, e os resultados relatados foram obtidos em um PC-Core i5, 2.53 GHz com 8 Gbytes de memória, sistema operacional Windows 10 pro.

\subsection{ANÁLISE INICIAL DOS PARÂMETROS DO AG}

Inicialmente a análise concentrou-se em verificar a formação da população inicial. Desta forma, foram avaliadas três possibilidades de populações iniciais $(100,200$ e 300 indivíduos), mantendo-se os outros parâmetros fixos e comparando os resultados com o valor da configuração atual. Realizando uma análise dos resultados, observou-se que os valores de avaliação dos indivíduos foram muito baixos, inferiores ao valor da configuração atual, mesmo com uma população inicial com 300 indivíduos. Desta forma, foi escolhida a quantidade de 100 indivíduos para as simulações.

O número de gerações escolhido inicialmente deveria ser grande o suficiente para evidenciar o desempenho das simulações com os parâmetros escolhidos, mas pequeno suficiente para não sobrecarregar as análises iniciais. $\mathrm{O}$ valor escolhido foi de 500 gerações.

Como é conhecido, a função avaliação tem um papel decisivo no desempenho dos AG. Porém, com a função escolhida para os modelos de BT, MT e integrado, e aplicação de penalidades nos indivíduos, não foi percebido resultados diferentes nas diversas simulações.

Por sua vez a simulação sem utilizar o elitismo resultou na perda dos melhores indivíduos, resultando em variações grandes de valores dos melhores indivíduos e soluções. Entretanto, com a utilização de valores elevados, em torno de $10 \%$, direciona a 
solução à valores muito baixos, sem apresentar uma melhora da melhor solução nem da média da população. Utilizando uma taxa de 3\% de elitismo verificou-se uma melhora no desempenho do $A G$, sendo o melhor avaliado.

Com relação ao processo de seleção, a roleta apresentou-se muito convergente, em uma quantidade menor de gerações, fazendo com que os valores médios de avaliação dos indivíduos tornam-se muito próximos da melhor solução. Na seleção por torneio simulou-se, foram considerados as opções de 2, 4, 6 e 8 indivíduos. A convergência com a definição de 6 e 8 indivíduos para o torneio foi muito rápida. Os indivíduos melhores avaliados sempre venciam o torneio, sendo um problema, pois a geração seguinte tornava-se precocemente pouco diversificada. Desta forma, foi escolhido o torneio com apenas dois indivíduos. Com a utilização do ranking para o processo de seleção, foi observado uma convergência mais lenta comparado aos outros métodos, mas os valores obtidos são comparáveis aos anteriores.

Na recombinação foi utilizada a divisão do indivíduo em duas e quatro partes. A recombinação em dois pontos foi que apresentou um melhor desempenho de valores e convergência mais rápida. $\mathrm{Na}$ análise do intervalo de cruzamento, indicando uma taxa de sucesso para o cruzamento, nas simulações o valor ficou entre 0.85 e 1, porém não foi observado diferença nos resultados obtidos. Para as simulações foi adotada uma taxa de 0.9 .

Com relação ao processo de seleção, foi observado pouco diferença entre os métodos de roleta, ranking e torneio. O cruzamento em várias partes melhora o desempenho do algoritmo, mas precisava ser testado em simulações com mais gerações. A taxa de mutação mais adequada foi de 5\%, embora seja um método secundário a sua utilização melhora substancialmente a performance do $A G$.

Para simulações da otimização, foram escolhidos inicialmente os valores dos parâmetros para a $A T$ e BT conforme a tabela 10 . 
Tabela 10 - Valores dos parâmetros iniciais para o $A G$

\begin{tabular}{cccc}
\hline Parâmetros & & Mínimo & Máximo \\
\hline População inicial & & 100 & 300 \\
Método de Seleção & & & \\
& Elitismo & $1 \%$ & $10 \%$ \\
& Torneio & 2 & 8 \\
& Ranking & 1,2 & 1,5 \\
& Roleta & & \\
Cruzamento & & & \\
& pontos & 2 & 4 \\
Intervalo de cruzamento & & 0,8 & 1 \\
Mutação & & $1 \%$ & $10 \%$ \\
Número de gerações & & 100 & 500 \\
\hline
\end{tabular}

Fonte: Elaborada pelo autor.

\subsubsection{Simulações para Análise dos Parâmetros do AG}

Várias simulações foram feitas com a finalidade de testar os diversos parâmetros de entrada dos $A G$ para os modelos de BT e MT. Alguns parâmetros definidos inicialmente não determinaram diferentes comportamentos nas simulações, sendo mantidos constantes para as simulações. Os valores são apresentados na tabela 11 .

Tabela 11 - Valores dos parâmetros escolhidos para o $A G$

\begin{tabular}{cc}
\hline Parâmetros & Valor \\
\hline População inicial & 100 \\
Método de Seleção & \\
Elitismo & $3 \%$ \\
Cruzamento & 2 pontos \\
Intervalo de cruzamento & 0,9 \\
Mutação & $5 \%$ \\
Número de gerações & 100 \\
\hline
\end{tabular}

Fonte: Elaborada pelo autor. 


\subsection{ANÁLISE DO TEMPO DE PROCESSAMENTO}

Conforme descrito no capítulo 6, existe uma elevada combinação de soluções na análise integrada do planejamento operacional da rede de BT e $M T$, exigindo um considerável tempo de processamento do fluxo de potência para cada situação proposta. Para reduzir o tempo de processamento do $A G$, procura-se evitar o processamento de soluções previamente avaliadas através do armazenamento em memória dos seus resultados. Em outros momentos, ao identificar uma solução já previamente calculada, o valor armazenado é pesquisado e retornado evitando um novo processamento.

Para a situação do planejamento operacional integrado da rede de $M T$ e $B T$, os tempos levantados para a sua execução sem ou com otimização são mostrados na tabela 12.

Tabela 12 - Tempo de processamento do planejamento integrado de redes de MT e BT

\begin{tabular}{c|c|c}
\hline Rede & Sem Otimização (horas) & Com Otimização (horas) \\
\hline MT & 3 & 1 \\
BT & 41 & 17 \\
\hline Total & 44 & 18 \\
\hline
\end{tabular}

Fonte: Elaborada pelo autor.

\subsection{PLANEJAMENTO OPERACIONAL DE REDES DE DISTRIBUIÇÃO DE MT SEM INTEGRAÇÃO COM REDES DE DISTRIBUIÇÃO DE BT}

Para a validação do modelo apresentado no capítulo 4 foi utilizado um alimentador real com problema de nível de tensão e perdas, cujos dados foram obtidos diretamente da base georeferenciada da Companhia Paranaense de Energia. O estudo apresentado retrata a execução do $A G$ para a situação atual do alimentador com a abordagem de análise tradicional e, em uma segunda análise, considera-se a possibilidade de inserção de uma GD. As características das cargas e detalhamento dos cabos podem ser vistos no apêndice A. Os dados gerais do alimentador são mostrados na tabela 13. 
Tabela 13 - Dados do Alimentador

\begin{tabular}{c|c}
\hline Característica & Valor \\
\hline Comprimento rede trifásica & $18,00 \mathrm{~km}$ \\
Numero de consumidores resid. & 7.248 \\
Consumo Residencial & $1.281 .261 \mathrm{kWh}$ \\
Numero de consumidores comerc. & 1.225 \\
Consumo comercial & $1.046 .887 \mathrm{kWh}$ \\
Numero de consumidores industr. & 73 \\
Consumo industrial & $73.980 \mathrm{kWh}$ \\
Consumo de iluminação pública & $184.324 \mathrm{kWh}$ \\
Circuitos de BT Convencional & 146 \\
Circuitos de BT Exclusivo & 46 \\
\hline
\end{tabular}

Fonte: Elaborada pelo autor.

Os dados elétricos iniciais do alimentador pode sem observados conforme a tabela 14.

Tabela 14 - Valores de Simulação do Alimentador

\begin{tabular}{c|c}
\hline Característica & Valor \\
\hline Corrente máxima & $226 \mathrm{~A}$ \\
Tensão normal de operação & $13,8 \mathrm{KV}$ \\
Tensão máxima & $1,00 \mathrm{pu}$ \\
Tensão mínima & $0,9435 \mathrm{pu}$ \\
Queda de Tensão máxima & $5,41 \%$ \\
Perdas & $3,2473 \%$ \\
Fluxo Emitido kVA & 5.210 .12 \\
Fluxo Emitido kW & 4.968 .00 \\
\hline
\end{tabular}

Fonte: Elaborada pelo autor.

A figura 17 mostra o alimentador escolhido para a análise do modelo de $A G$ desenvolvido. Os dados detalhados de carga e cabos estão mostrados no apêndice A. 
Figura 17 - Alimentador escolhido.

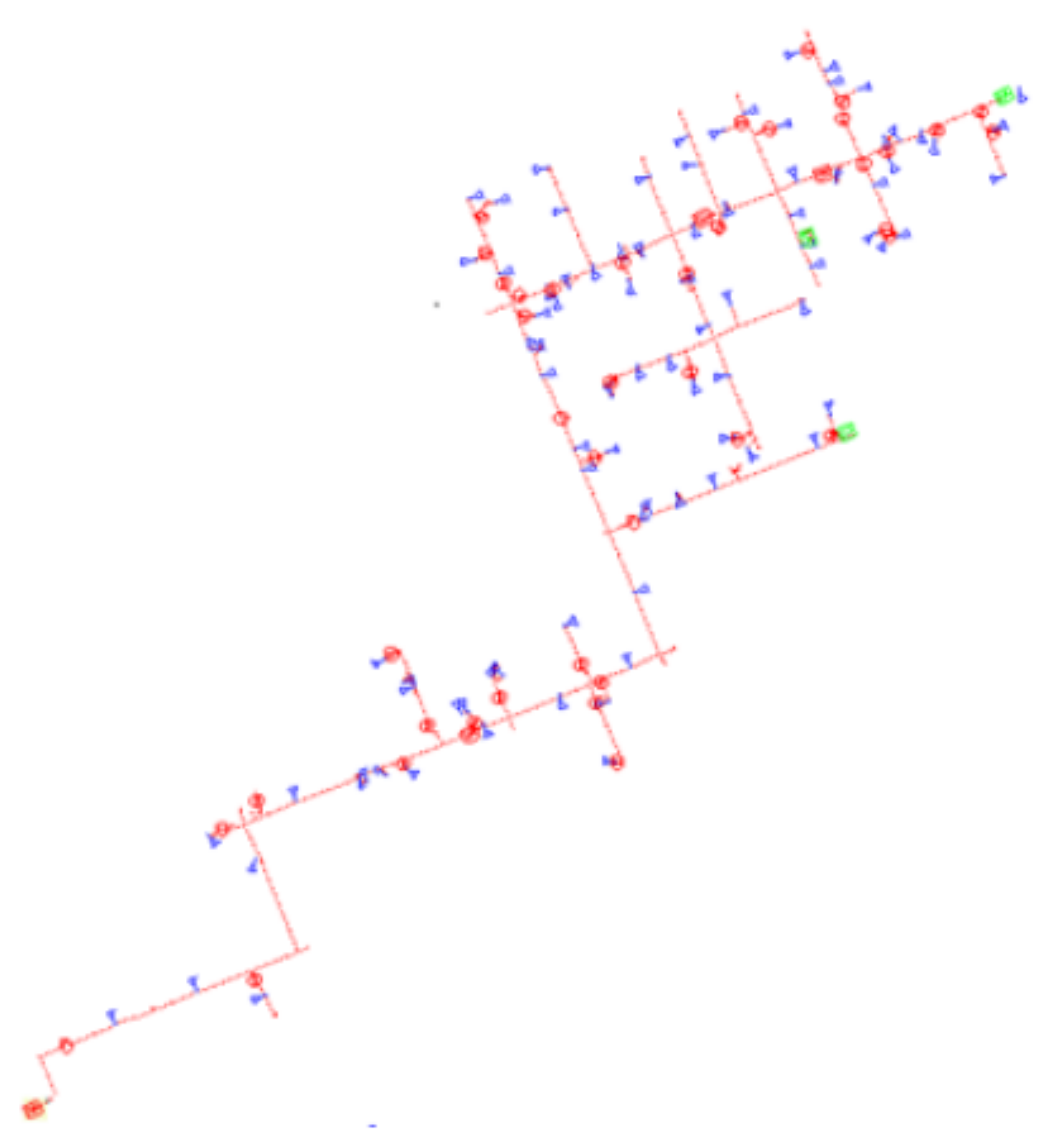

Fonte: Elaboração própria.

Os valores de instalação e retorno dos condutores utilizados nas execuções são mostrados na tabela 15 .

Tabela 15 - Especificação e valores de condutores.

\begin{tabular}{c|cc}
\hline Descrição & \multicolumn{2}{|c}{ Valor Médio (R\$/m) } \\
& Instalação & Retorno \\
\hline Alumínio 06 AWG & 12,92 & 4,75 \\
Alumínio 04 AWG & 25,30 & 12,26 \\
Alumínio 02 AWG & 33,05 & 18,25 \\
Alumínio 1/0AWG & 15,65 & 9,72 \\
Alumínio 2/0 AWG & 23,46 & 15,78 \\
Alumínio 3/0 AWG & 29,90 & 20,76 \\
Alumínio 4/0 AWG & 32,00 & 24,52 \\
\hline
\end{tabular}

Fonte: Dados fornecidos por projetistas. 
Os valores de custo de capacitores considerados no estudo estão mostrados na tabela 16.

Tabela 16 - Custo de Capacitores.

\begin{tabular}{c|c}
\hline Tipo & Custo de Instalação (R\$) \\
\hline 300 kVar & $3.070,00$ \\
600 kVar & $3.500,00$ \\
900 kVar & $5.600,00$ \\
1200 kVar & $8.200,00$ \\
1500 kVar & $10.200,00$ \\
\hline
\end{tabular}

Fonte: Dados fornecidos por projetistas.

Para a validação da metodologia foram simulados os seguintes cenários, a saber:

1. Simulação da rede de $M T$ sem considerar $G D$;

2. Simulação da rede de $M T$ considerando alocação ótima de GD;

3. Simulação da rede de $M T$ considerando GD em pontos determinados.

O detalhamento está mostrado nas seções seguintes.

\subsubsection{Simulações na rede de $M T$ sem considerar GD}

Inicialmente foi realizada a simulação sem a inserção de $G D$, neste caso a solução predominante no alimentador foi a combinação de troca de cabos, sem a alteração no faseamento do transformador e instalação de capacitor. Os resultados obtidos estão mostrados na tabela 17 .

Tabela 17 - Resultado da simulação.

\begin{tabular}{c|c}
\hline Intervenção & Custo (R\$) \\
\hline Capacitor - 1200 kVar & $8.200,00$ \\
Troca de Cabos & $17.760,00$ \\
\hline Total & $25.960,00$
\end{tabular}

Fonte: Elaborada pelo autor.

Nesta simulação foram consideradas as seguintes intervenções:

1. Troca de cabos; 
2. Troca de faseamento dos transformadores;

3. Instalação de Capacitor.

O resultado obtido indica a instalação de capacitor e recondutoramento de cabos, fazendo com que sejam obtidas as características elétricas conforme a tabela 18.

Tabela 18 - Valores de Simulação do Alimentador sem GD

\begin{tabular}{c|c}
\hline Característica & Valor \\
\hline Tensão normal de operação & $13,8 \mathrm{KV}$ \\
Tensão máxima & $1,00 \mathrm{pu}$ \\
Tensão mínima & $0,9659 \mathrm{pu}$ \\
Queda de Tensão máxima & $3,46 \%$ \\
Perdas & $1,1473 \%$ \\
\hline
\end{tabular}

Fonte: Elaborada pelo autor.

8.3.2 Simulação da rede de $M T$ considerando alocação ótima de GD

Nesta simulação de inserção de $G D$, considera-se o processo de alocação ótima de $G D$ na rede. Desta forma, a metodologia deverá indicar quais unidades de GD e pontos de posicionamento no alimentador para instalação. Portanto, a GD tem comportamento similar a instalação de um capacitor neste estudo.

Os resultados obtidos estão mostrados na tabela 19.

Tabela 19 - Resultado da simulação.

\begin{tabular}{c|c}
\hline Intervenção & Custo $(\mathrm{R} \$)$ \\
\hline Troca de Cabos & $2.664,00$ \\
\hline
\end{tabular}

Fonte: Elaborada pelo autor.

O resultado obtido indica a instalação de GD com um total de 0,5 MVA (5 unidades de $100 \mathrm{~kW}$ ) no alimentador e recondutoramento de cabos, fazendo com que sejam obtidas as características elétricas conforme a tabela 20. 
Tabela 20 - Valores de Simulação do Alimentador com GD ótima

\begin{tabular}{c|c}
\hline Característica & Valor \\
\hline Tensão normal de operação & $13,8 \mathrm{KV}$ \\
Tensão máxima & $1,00 \mathrm{pu}$ \\
Tensão mínima & $0,9825 \mathrm{pu}$ \\
Queda de Tensão máxima & $1,75 \%$ \\
Perdas & $1,09 \%$ \\
\hline
\end{tabular}

Fonte: Elaborada pelo autor.

Observou-se uma melhora no nível de tensão do alimentador, bem como uma redução das perdas com a indicação da instalação das unidades de GD. A simulação da alocação da GD ótima é importante para determinar quais pontos na rede são mais benéficos para que a concessionária possa definir melhor o contrato a ser estabelecido com o consumidor proprietário da GD.

\subsubsection{Simulação da rede de $M T$ considerando GD em pontos determinados}

Nesta simulação de inserção de $G D$, foram simulados pontos na rede que possibilitariam a sua inclusão. Os pontos ótimos de alocação de GD indicados na seção 8.2.2. foram retirados dos pontos candidatos de seleção para esta simulação. Desta forma, pode-se simular algumas situações referentes ao comportamento do alimentador mediante o posicionamento de cada GD. O algoritmo, com esta possibilidade adicional, fez a determinação de cada GD a ser conectada na rede de acordo com os critérios técnicos estabelecidos. Procura-se, simular uma situação na qual os pontos ótimos de inserção da $G D$ indicados na seção 8.2.2 não possam ser considerados, sendo necessária a determinação de pontos alternativos para a obtenção das melhores soluções.

No alimentador em estudo, tem-se 46 consumidores com transformadores exclusivos e foram considerados 5 pontos no alimentador com possibilidade de interligar unidades de GD de 100kW. Os resultados podem ser visualizados na tabela 21.

Tabela 21 - Resultado da simulação do alimentador com GD em pontos determinados

\begin{tabular}{c|c}
\hline Intervenção & Custo (R\$) \\
\hline Troca de Cabos & $6.660,00$ \\
\hline
\end{tabular}

Fonte: Elaborada pelo autor.

O resultado obtido indica a instalação de GD com um total de 0,5 MVA (5 unidades de $100 \mathrm{~kW}$ ) no alimentador e recondutoramento de cabos, fazendo com que 
sejam obtidas as características elétricas conforme a tabela 22.

Tabela 22 - Valores de Simulação do Alimentador com GD em pontos determinados

\begin{tabular}{c|c}
\hline Característica & Valor \\
\hline Tensão normal de operação & $13,8 \mathrm{KV}$ \\
Tensão máxima & $1,00 \mathrm{pu}$ \\
Tensão mínima & $0,9690 \mathrm{pu}$ \\
Queda de Tensão máxima & $3,10 \%$ \\
Perdas & $1,147 \%$ \\
\hline
\end{tabular}

Fonte: Elaborada pelo autor.

Nesta simulação, excetuando-se os pontos ótimos determinados na seção 8.2.2., foi obtida uma melhora no nível de tensão do alimentador e redução das perdas. Porém, os resultados indicaram a necessidade de uma combinação de inserção de GD e recondutoramento de alguns cabos.

\subsection{PLANEJAMENTO OPERACIONAL DE REDES DE DISTRIBUIÇÃO DE BT SEM INTEGRAÇÃO COM REDES DE DISTRIBUIÇÃO DE MT}

Para a validação do modelo apresentado no capítulo 5 foram utilizados circuitos reais com problemas, cujos dados foram obtidos diretamente da base georeferenciada da Companhia Paranaense de Energia. O estudo apresentado retrata a execução do $A G$ para a situação atual dos circuitos com a abordagem de análise tradicional e, em uma segunda análise, considera-se a possibilidade de inserção de GD. Entre diversos estudos de caso efetivamente realizados, os circuitos apresentados compreendem os casos representativos para a análise dos resultados. Estes circuitos foram selecionados a fim de permitir uma análise significativa das características do modelo proposto. As características dos circuitos são mostrados na tabela 23, referenciando os valores de tensão, balanceamento de carga e carregamento dos transformadores. Na tabela são relacionados valores de referência para cada característica técnica, limites adotados como padrões desejados pelos projetistas ${ }^{1}$.

1 Valores obtidos em entrevistas com especialistas da área de projetos da Companhia Paranaense de Energia 
Tabela 23 - Dados dos circuitos analisados.

\begin{tabular}{c|c|c|c|c|c|c}
\hline Identificação & $\begin{array}{c}\text { Quantidade de } \\
\text { consumidores }\end{array}$ & $\begin{array}{c}\text { Transformador } \\
(\mathrm{kVar})\end{array}$ & $\begin{array}{c}\text { Demanda } \\
(\mathrm{kVA})\end{array}$ & $\begin{array}{c}\text { Balanceamento } \\
(\%)\end{array}$ & $\begin{array}{c}\text { Tensão Mínima } \\
(\mathrm{V})\end{array}$ & $\begin{array}{c}\text { Carregamento } \\
(\%)\end{array}$ \\
\hline Referência & - & - & - & $\geq 90$ & $\geq 116,84$ & $\leq 100$ \\
\hline C1 & 126 & 112,5 & 94,5 & 93,9 & 111,82 & 84,00 \\
C2 & 133 & 75 & 59,3 & 84,8 & 115,76 & 79,07 \\
C3 & 129 & 45 & 61,2 & 91,8 & 114,23 & 136,00 \\
C4 & 80 & 75 & 42,8 & 87,4 & 119,25 & 56,67 \\
C5 & 130 & 112,5 & 88,1 & 94,9 & 110,18 & 78,31 \\
C6 & 107 & 75 & 68,7 & 92,9 & 115,35 & 91,60 \\
C7 & 77 & 75 & 52,1 & 97,6 & 113,13 & 69,47 \\
C8 & 54 & 45 & 41,6 & 86,7 & 113,18 & 92,44 \\
C9 & 97 & 112,5 & 102,6 & 90,3 & 114,35 & 91,20 \\
C10 & 86 & 75 & 62,3 & 85,7 & 114,63 & 83,07 \\
C11 & 88 & 75 & 59,3 & 94,2 & 112,88 & 79,07 \\
C12 & 62 & 45 & 38,2 & 88,9 & 114,45 & 84,89 \\
C13 & 132 & 112,5 & 99,2 & 83,2 & 113,00 & 88,18 \\
C14 & 78 & 75 & 62,1 & 92,1 & 114,60 & 82,80 \\
C15 & 52 & 45 & 40,9 & 90,2 & 115,99 & 90,89 \\
\hline
\end{tabular}

Fonte: Dados fornecidos por projetistas.

O índice de balanceamento do transformador indica o percentual de distribuição uniforme das cargas nas fases. Uma melhora na distribuição de carga entre fases pode proporcionar uma melhora no nível de tensão e perdas. Entretanto, quando temos um valor elevado para esse índice, intervenções no faseamento do consumidor não surtem bons resultados nos indicadores de qualidade. A tensão mínima é mensurada em relação à tensão no secundário do transformador.

Os valores de instalação e retorno dos condutores utilizados nas execuções são mostrados na tabela 24 . 
Tabela 24 - Especificação e valores de condutores.

\begin{tabular}{c|c|c}
\hline Descrição & $\begin{array}{c}\text { Valor Médio }(\mathrm{R} \$ / \mathrm{m}) \\
\text { Instalação }\end{array}$ & Retorno \\
\hline 02 AWG Alumínio & 12,92 & 4,75 \\
2/0 AWG Alumínio & 25,30 & 12,26 \\
4/0 AWG Alumínio & 33,05 & 18,25 \\
35 mm2 Quadruplex Alumínio & 15,65 & 9,72 \\
70 mm2 Quadruplex Alumínio & 23,46 & 15,78 \\
120(70) mm2 Quadruplex Alumínio & 29,90 & 20,76 \\
\hline
\end{tabular}

Fonte: Dados fornecidos por projetistas

Os transformadores utilizados e respectivos valores de instalação e movimentação são listados na tabela 25 .

Tabela 25 - Especificação e valores de transformadores.

\begin{tabular}{c|c|c}
\hline Descrição & Instalação (R\$) & Movimentação (R\$) \\
\hline Transformador Trifásico 15 kVA 13,8 kV 220/127 V & $5.812,40$ & 670,90 \\
Transformador Trifásico 30 kVA 13,8 kV 220/127 V & $6.512,63$ & 670,90 \\
Transformador Trifásico 45 kVA 13,8 kV 220/127 V & $8.651,99$ & 670,90 \\
Transformador Trifásico 75 kVA 13,8 kV 220/127 V & $11.218,65$ & 670,90 \\
Transformador Trifásico 112,5 kVA 13,8 kV 220/127 V & $12.994,95$ & 670,90 \\
\hline
\end{tabular}

Fonte: Dados fornecidos por projetistas. 
Os custos de operação da rede são mostrados na tabela 26.

Tabela 26 - Valores das operações de conexão de rede.

\begin{tabular}{c|c|c}
\hline Operação & Descrição & Valor Médio (R\$) \\
\hline Faseamento & Operação de troca de conexão de fase de um consumidor & 45,00 \\
\hline
\end{tabular}

Fonte: Dados fornecidos por projetistas.

Para todas as simulações realizadas foram consideradas as seguintes limitações recomendadas pelos especialistas, a saber:

- Limite mínimo de tensão: 116,84 V;

- Limite mínimo de balanceamento: 85\%;

- Limite de carregamento máximo de transformador: $100 \%$.

Para a validação da metodologia foram simulados os seguintes cenários, a saber:

1. Simulação da rede de $B T$ sem considerar $G D$;

2. Simulação da rede de $B T$ considerando alocação ótima de $G D$;

3. Simulação da rede de BT considerando GD em pontos determinados.

O detalhamento está mostrado nas seções seguintes.

\subsubsection{Simulações na rede de BT sem GD}

Executando o modelo sem a inclusão de GD e sem integração com a rede de $M T$, foram encontrados os valores mostrados na tabela 27. 
Tabela 27 - Resultados simulação rede BT sem GD.

\begin{tabular}{c|c|c|c|c|c}
\hline \multirow{2}{*}{ Circuito } & \multicolumn{2}{|c|}{ Balanceamento (\%) } & \multicolumn{2}{|c|}{ Tensão Mínima(V) } & \multirow{2}{*}{ Custo (R\$) } \\
\cline { 2 - 5 } & Inicial & Final & Inicial & Final & \\
\hline C1 & 93,90 & 98,59 & 111,82 & 117,29 & 270,00 \\
C2 & 84,80 & 90,00 & 115,76 & 116,97 & 135,00 \\
C3 & 91,80 & 91,80 & 114,23 & 116,97 & $1.154,00$ \\
C4 & 87,40 & 91,20 & 119,25 & 119,28 & 180,00 \\
C5 & 94,90 & 94,90 & 110,18 & 118,87 & $3.063,00$ \\
C6 & 92,90 & 92,90 & 115,35 & 117,06 & $2.780,00$ \\
C7 & 97,60 & 97,60 & 113,13 & 117,59 & $1.879,00$ \\
C8 & 86,70 & 86,70 & 113,18 & 117,48 & $1.693,00$ \\
C9 & 90,30 & 90,30 & 114,35 & 118,75 & $2.308,00$ \\
C10 & 85,70 & 85,70 & 114,63 & 117,86 & $2.280,00$ \\
C11 & 94,20 & 94,20 & 112,88 & 117,35 & $2.842,00$ \\
C12 & 88,90 & 88,90 & 114,45 & 118,36 & $2.667,00$ \\
C13 & 83,20 & 83,20 & 113,00 & 117,86 & $2.368,00$ \\
C14 & 92,10 & 92,10 & 114,60 & 118,44 & $1.438,00$ \\
C15 & 90,20 & 90,20 & 115,99 & 119,13 & $1.776,00$ \\
\hline
\end{tabular}

Fonte: Elaborada pelo autor.

Em alguns casos a troca de faseamento dos consumidores (circuitos C1, C2 e C4) já resolveu o problema de queda de tensão no circuito, entretanto a grande maioria das soluções são concentradas na troca de cabos. Não houve caso com a sugestão da movimentação do transformador, cabe ressaltar que a movimentação de transformador só é permita se existe rede de MT no poste, portanto cada poste tem uma indicação se possui rede de $M T$ disponível para conexão do transformador.

8.4.2 Simulações na rede de BT com alocação ótima de GD

Nesta simulação foi considerada a alocação ótima de $G D$, assim todos os postes com consumidores foram considerados pontos de possível conexão.

A tabela 28 mostra os valores encontrados nesta execução. 
Tabela 28 - Resultados simulação rede BT alocação ótima GD.

\begin{tabular}{c|c|c|c|c|c}
\hline \multirow{2}{*}{ Circuito } & \multicolumn{2}{|c|}{ Balanceamento (\%) } & \multicolumn{2}{c|}{ Tensão Mínima(V) } & \multirow{2}{*}{ Custo (R\$) } \\
\cline { 2 - 5 } & Inicial & Final & Inicial & Final & \\
\hline C1 & 93,90 & 98,59 & 111,82 & 117,29 & 0,00 \\
C2 & 84,80 & 90,00 & 115,76 & 116,97 & 135,00 \\
C3 & 91,80 & 91,80 & 114,23 & 120,40 & 521,00 \\
C4 & 87,40 & 91,20 & 119,25 & 119,28 & 180,00 \\
C5 & 94,90 & 94,90 & 110,18 & 118,49 & 0,00 \\
C6 & 92,90 & 92,90 & 115,35 & 119,13 & 518,00 \\
C7 & 97,60 & 97,60 & 113,13 & 120,02 & 0,00 \\
C8 & 86,70 & 86,70 & 113,18 & 119,38 & 0,00 \\
C9 & 90,30 & 90,30 & 114,35 & 118,90 & 562,00 \\
C10 & 85,70 & 85,70 & 114,63 & 119,38 & 0,00 \\
C11 & 94,20 & 94,20 & 112,88 & 117,86 & 0,00 \\
C12 & 88,90 & 88,90 & 114,45 & 120,14 & 0,00 \\
C13 & 83,20 & 83,20 & 113,00 & 118,75 & 0,00 \\
C14 & 92,10 & 92,10 & 114,60 & 119,13 & 0,00 \\
C15 & 90,20 & 90,20 & 115,99 & 118,11 & 0,00 \\
\hline
\end{tabular}

Fonte: Próprio autor.

Em todos os circuitos foi sugerida a alocação de $G D$, nos circuitos $C 3$, $C 6$ e $C 9$ houve a necessidade adicional de recondutoramento de cabos.

\subsubsection{Simulações na rede de BT com inserção de GD em pontos determinados}

Para as simulações dos circuitos com a inserção de GD foram considerados alguns pontos que poderiam assumir as unidades. Os pontos ótimos de alocação de $G D$ indicados na seção 8.3.2. foram retirados dos pontos candidatos de seleção para esta simulação. Desta forma, pode-se simular algumas situações referentes ao comportamento do circuito mediante o posicionamento de cada GD. Em geral, foram considerados aleatoriamente de dois a três pontos de inserção de GD por circuito nesta simulação.

Executando o modelo com a inclusão de GD, foram encontrados os valores mostrados na tabela 29. 
Tabela 29 - Resultados simulação rede BT com GD.

\begin{tabular}{c|c|c|c|c|c}
\hline \multirow{2}{*}{ Circuito } & \multicolumn{2}{|c|}{ Balanceamento (\%) } & \multicolumn{2}{c|}{ Tensão Mínima(V) } & \multirow{2}{*}{ Custo (R\$) } \\
\cline { 2 - 5 } & Inicial & Final & Inicial & Final & \\
\hline C1 & 93,90 & 98,59 & 111,82 & 117,30 & 0,00 \\
C2 & 84,80 & 90,00 & 115,76 & 116,97 & 135,00 \\
C3 & 91,80 & 91,80 & 114,23 & 119,25 & 663,00 \\
C4 & 87,40 & 91,20 & 119,25 & 119,28 & 180,00 \\
C5 & 94,90 & 94,90 & 110,18 & 118,30 & 0,00 \\
C6 & 92,90 & 92,90 & 115,35 & 118,94 & $1.184,00$ \\
C7 & 97,60 & 97,60 & 113,13 & 119,82 & 0,00 \\
C8 & 86,70 & 86,70 & 113,18 & 119,00 & 0,00 \\
C9 & 90,30 & 90,30 & 114,35 & 118,87 & $1.243,00$ \\
C10 & 85,70 & 85,70 & 114,63 & 119,00 & 0,00 \\
C11 & 94,20 & 94,20 & 112,88 & 116,97 & 498,00 \\
C12 & 88,90 & 88,90 & 114,45 & 119,51 & 0,00 \\
C13 & 83,20 & 83,20 & 113,00 & 118,24 & 503,00 \\
C14 & 92,10 & 92,10 & 114,60 & 118,87 & 0,00 \\
C15 & 90,20 & 90,20 & 115,99 & 117,22 & 0,00 \\
\hline
\end{tabular}

Fonte: Elaboração própria.

Nas seções seguintes são detalhadas as simulações realizadas no circuito de identificação C13 para exemplificar a aplicação da metodologia.

8.4.3.1 Simulações no circuito $C 13$ considerando inserção de GD

Considerando o circuito $\mathrm{C} 13$ do estudo, conforme diagrama unifilar representado na figura 18. O poste de índice 11 apresenta o menor valor de tensão do circuito, no valor de 113,00 volts. 
Figura 18 - Circuito C13 original.

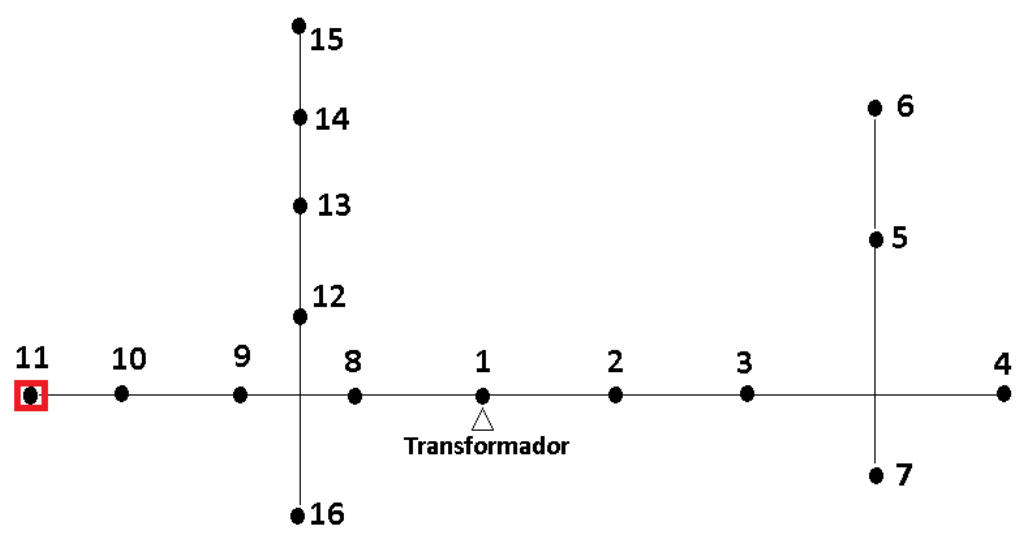

Fonte: Elaboração própria.

Ao executar a otimização original sem a inserção de $G D$ no estudo, foram sugeridas alterações em 4 trechos de cabos, indicadas na figura 19. O valor de queda de tensão final com as alterações propostas foi de 117,86 volts com um total de $\mathrm{R} \$ 2.368,00$.

Figura 19 - Alterações propostas para o circuito C13.

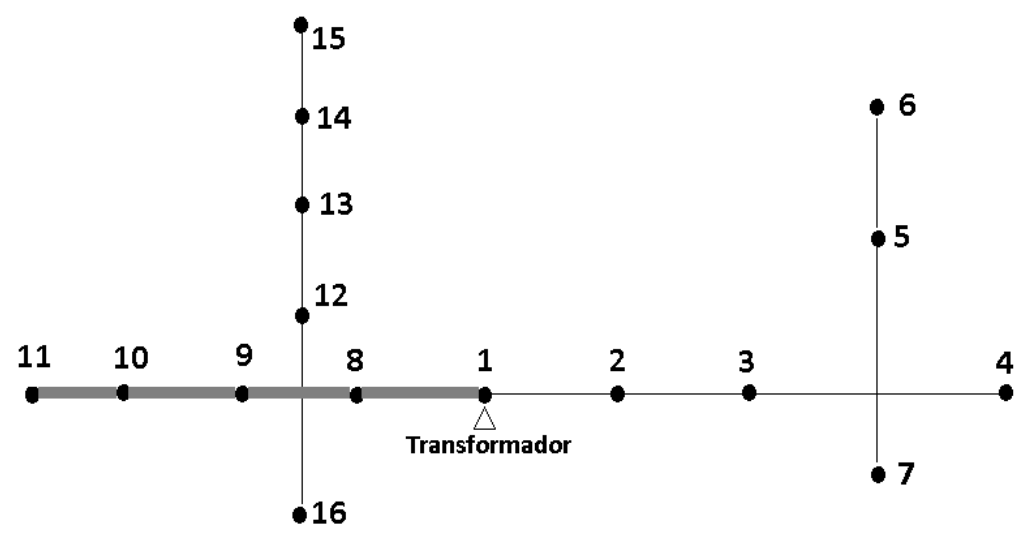

Fonte: Elaboração própria.

Ao executar o modelo de otimização com a alocação ótima de $G D$, a solução encontrada foi a de alocar uma GD no poste de índice 11. Como era o ponto mais crítico de nível de tensão no circuito devido à concentração de consumidores, somente a alocação da GD no poste resolveu o problema, sem a necessidade de alterar cabos. Como resultado foi obtida a solução conforme figura 20. 
Figura 20 - Alocação ótima de GD para o circuito C13.

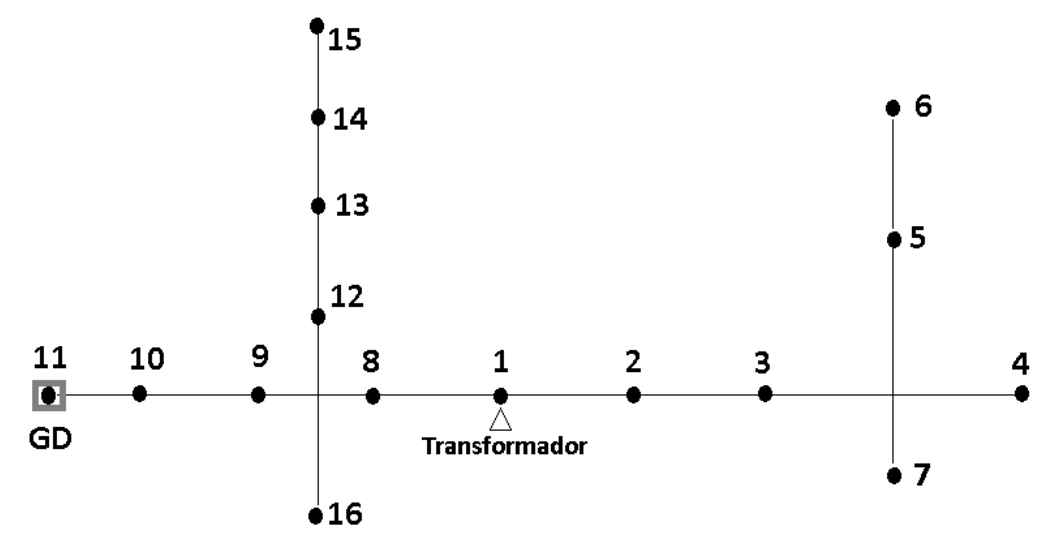

Fonte: Elaboração própria.

Ao executar o modelo de otimização com a possibilidade de alternativas de posicionamento de $G D$, foi colocada a possibilidade de inserção de $G D$ nos postes de índice 3, 10 e 14. A GD selecionada foi a do poste índice 10, entretanto foi necessário o recondutoramento de um trecho devido ao seu carregamento. $\mathrm{O}$ cabo escolhido neste caso foi inferior ao sugerido na otimização sem GD. Como resultado foi obtida a solução conforme figura 21.

Figura 21 - Alocação de GD para o circuito C13.

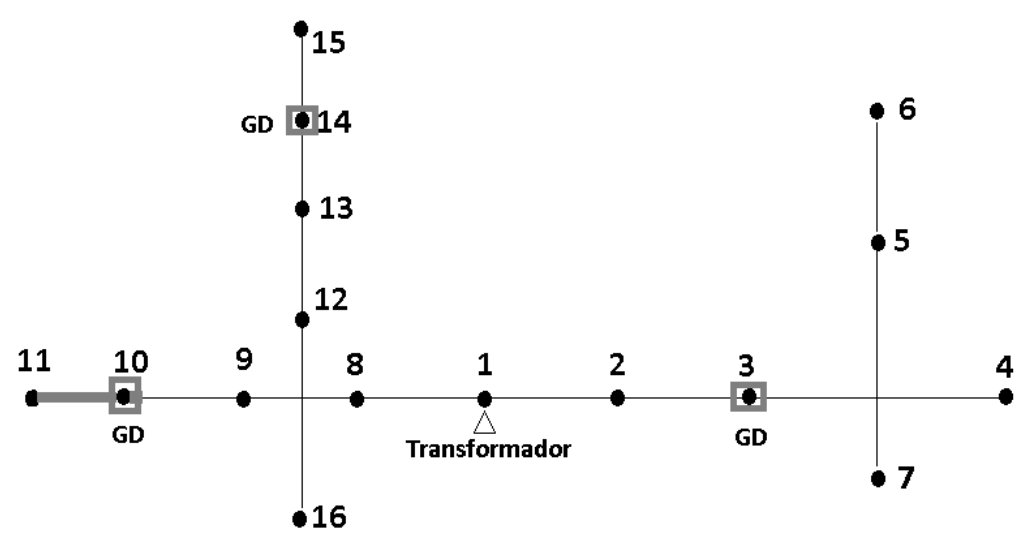

Fonte: Elaboração própria.

O sumário das simulações para o circuito C13, pode ser observado na tabela 30 . 
Tabela 30 - Resultados obtidos das simulações para o circuito C13.

\begin{tabular}{c|c|c|c|c|c}
\hline \multirow{2}{*}{ Circuito } & \multicolumn{2}{|c|}{ Balanceamento (\%) } & \multicolumn{2}{c|}{ Tensão Mínima (V) } & \multirow{2}{*}{ Custo (R\$) } \\
\cline { 2 - 5 } & Inicial & Final & Inicial & Final & \\
\hline Sem GD & 83,2 & 83,2 & 113,00 & 117,86 & $2.368,00$ \\
Com GD ótima & 83,2 & 83,2 & 113,00 & 118,75 & 0,0 \\
Com GD & 83,2 & 83,2 & 113,00 & 118,24 & 503,00 \\
\hline
\end{tabular}

Fonte: Elaborada pelo autor.

\subsection{PLANEJAMENTO OPERACIONAL INTEGRADO DE MT E BT}

Para a validação do modelo apresentado no capítulo 6 foi utilizado um alimentador de $M T$ real com circuitos de $B T$ que apresentavam problemas de nível de tensão, carregamento e perdas, cujos dados foram obtidos diretamente da base georeferenciada da Companhia Paranaense de Energia. O estudo apresentado retrata a execução do $A G$ para a análise integrada da rede de $M T$ e $B T$ com a abordagem de análise tradicional e, em uma segunda análise, considera-se a possibilidade de inserção de GD nos dois subsistemas.

As características das cargas e detalhamento dos cabos podem ser vistos no apêndice A. Os dados gerais do alimentador são mostrados na tabela 31.

Tabela 31 - Dados do Alimentador

\begin{tabular}{c|c}
\hline Característica & Valor \\
\hline Comprimento rede trifásica & $18,00 \mathrm{~km}$ \\
Numero de consumidores resid. & 7.248 \\
Consumo Residencial & $1.281 .261 \mathrm{kWh}$ \\
Numero de consumidores comerc. & 1.225 \\
Consumo comercial & $1.046 .887 \mathrm{kWh}$ \\
Numero de consumidores industr. & 73 \\
Consumo industrial & $73.980 \mathrm{kWh}$ \\
Consumo de iluminação pública & $184.324 \mathrm{kWh}$ \\
Circuitos de BT Convencional & 146 \\
Circuitos de BT Exclusivo & 46 \\
Circuitos de BT a serem estudados com $M T$ & 15 \\
\hline
\end{tabular}

Fonte: Dados fornecidos pelos projetistas.

Os dados dos circuitos BT a serem analisados em conjunto com a rede de $M T$ podem ser observados na tabela 32. 
Tabela 32 - Dados dos circuitos analisados.

\begin{tabular}{c|c|c|c|c|c|c}
\hline Identificação & $\begin{array}{c}\text { Quantidade de } \\
\text { consumidores }\end{array}$ & $\begin{array}{c}\text { Transformador } \\
(\mathrm{kVar})\end{array}$ & $\begin{array}{c}\text { Demanda } \\
(\mathrm{kVA})\end{array}$ & $\begin{array}{c}\text { Balanceamento } \\
(\%)\end{array}$ & $\begin{array}{c}\text { Tensão Mínina } \\
(\mathrm{V})\end{array}$ & $\begin{array}{c}\text { Carregamento } \\
(\%)\end{array}$ \\
\hline Referência & - & - & - & $\geq 90$ & $\geq 116,84$ & $\leq 100$ \\
\hline C1 & 126 & 112,5 & 94,5 & 93,9 & 111,82 & 84,00 \\
C2 & 133 & 75 & 59,3 & 84,8 & 115,76 & 79,07 \\
C3 & 129 & 45 & 61,2 & 91,8 & 114,23 & 136,00 \\
C4 & 80 & 75 & 42,8 & 87,4 & 119,25 & 56,67 \\
C5 & 130 & 112,5 & 88,1 & 94,9 & 110,18 & 78,31 \\
C6 & 107 & 75 & 68,7 & 92,9 & 115,35 & 91,60 \\
C7 & 77 & 75 & 52,1 & 97,6 & 113,13 & 69,47 \\
C8 & 54 & 45 & 41,6 & 86,7 & 113,18 & 92,44 \\
C9 & 97 & 112,5 & 102,6 & 90,3 & 114,35 & 91,20 \\
C10 & 86 & 75 & 62,3 & 85,7 & 114,63 & 83,07 \\
C11 & 88 & 75 & 59,3 & 94,2 & 112,88 & 79,07 \\
C12 & 62 & 45 & 38,2 & 88,9 & 114,45 & 84,89 \\
C13 & 132 & 112,5 & 99,2 & 83,2 & 113,00 & 88,18 \\
C14 & 78 & 75 & 62,1 & 92,1 & 114,60 & 82,80 \\
C15 & 52 & 45 & 40,9 & 90,2 & 115,99 & 90,89 \\
\hline
\end{tabular}

Fonte: Dados fornecidos por projetistas.

Para a validação da metodologia foram simulados os seguintes cenários, a saber:

1. Simulação da rede de $M T$ e $B T$ sem considerar $G D$;

2. Simulação da rede de $M T$ e $B T$ considerando $G D$ alocação ótima;

3. Simulação da rede de $M T$ e $B T$ considerando $G D$ em pontos determinados.

\subsubsection{Planejamento Operacional Integrado de MT e BT sem considerar GD}

Inicialmente foi considerado a otimização aplicada ao alimentador de $M T$ e aos circuitos de $B T$ sem possibilidade de inclusão de GD para posterior comparação com a inclusão da GD. Foram considerados na análise em conjunto com o alimentador, a atuação em 15 circuitos de BT listados como problemáticos.

Os custos envolvidos nesta solução para a rede de MT é mostrada na tabela 33. 
Tabela 33 - Resultado da simulação.

\begin{tabular}{c|c}
\hline Intervenção & Custo (R\$) \\
\hline Capacitor - 1200 kVar & $8.200,00$ \\
Troca de Cabos & $17.760,00$ \\
\hline Total & $25.960,00$
\end{tabular}

Fonte: Elaborada pelo autor.

A solução encontrada para o alimentador nesta simulação é mostrada na tabela 34.

Tabela 34 - Valores de Simulação do Alimentador no Planejamento Integrado sem GD

\begin{tabular}{c|c}
\hline Característica & Valor \\
\hline Tensão normal de operação & $13,8 \mathrm{KV}$ \\
Tensão máxima & $1,00 \mathrm{pu}$ \\
Tensão mínima & $0,96540 \mathrm{pu}$ \\
Queda de Tensão máxima & $3,460 \%$ \\
Perdas & $1,36 \%$ \\
\hline
\end{tabular}

Fonte: Elaborada pelo autor.

Para o caso dos circuitos de BT foram encontrados os seguintes valores, conforme tabela 35 . 
Tabela 35 - Resultados obtidos das simulações sem GD

\begin{tabular}{c|c|c|c|c|c}
\hline \multirow{2}{*}{ Circuito } & \multicolumn{2}{|c|}{ Balanceamento (\%) } & \multicolumn{2}{c|}{ Tensão Mínima (V) } & \multirow{2}{*}{ Custo (R\$) } \\
\cline { 2 - 5 } & Inicial & Final & Inicial & Final & \\
\hline C1 & 93,90 & 98,59 & 111,82 & 117,29 & 270,00 \\
C2 & 84,80 & 90,00 & 115,76 & 116,97 & 135,00 \\
C3 & 91,80 & 91,80 & 114,23 & 117,86 & $2.153,00$ \\
C4 & 87,40 & 91,20 & 119,25 & 119,28 & 180,00 \\
C5 & 94,90 & 94,90 & 110,18 & 117,48 & $2.190,00$ \\
C6 & 92,90 & 92,90 & 115,35 & 117,28 & $2.090,00$ \\
C7 & 97,60 & 97,60 & 113,13 & 117,09 & $1.269,00$ \\
C8 & 86,70 & 86,70 & 113,18 & 118,14 & $1.330,00$ \\
C9 & 90,30 & 90,30 & 114,35 & 119,00 & $2.308,00$ \\
C10 & 85,70 & 85,70 & 114,63 & 117,70 & $2.280,00$ \\
C11 & 94,20 & 94,20 & 112,88 & 118,36 & $2.558,00$ \\
C12 & 88,90 & 88,90 & 114,45 & 117,60 & $2.050,00$ \\
C13 & 83,20 & 83,20 & 113,00 & 117,69 & $2.308,00$ \\
C14 & 92,10 & 92,10 & 114,60 & 118,25 & $1.438,00$ \\
C15 & 90,20 & 90,20 & 115,99 & 116,97 & $1.065,00$ \\
\hline
\end{tabular}

Fonte: Próprio autor.

8.5.2 Planejamento Operacional Integrado de $M T$ e BT com alocação ótima de GD

Nesta simulação foi aplicada a alocação ótima da $G D$, assim a otimização do planejamento para o alimentador de $M T$ e aos circuitos de $B T$ tem a finalidade de alocar a GD na melhor posição além da determinação do seu valor. Foram considerados na análise em conjunto com o alimentador, a atuação em 15 circuitos de BT listados como problemáticos.

Os custos envolvidos nesta solução para a rede de MT é mostrada na tabela 36.

Tabela 36 - Resultado da simulação com alocação ótima de GD

\begin{tabular}{c|c}
\hline Intervenção & Custo (R\$) \\
\hline Troca de Cabos & $2.664,00$ \\
\hline Total & $2.664,00$
\end{tabular}

Fonte: Elaborada pelo autor. 
A solução encontrada para o alimentador nesta simulação é mostrada na tabela 37.

Tabela 37 - Valores de Simulação do Alimentador no Planejamento Integrado com alocação ótima de GD

\begin{tabular}{c|c}
\hline Característica & Valor \\
\hline Tensão normal de operação & $13,8 \mathrm{KV}$ \\
Tensão máxima & $1,00 \mathrm{pu}$ \\
Tensão mínima & $0,9825 \mathrm{pu}$ \\
Queda de Tensão máxima & $1,75 \%$ \\
Perdas & $1,09 \%$ \\
\hline
\end{tabular}

Fonte: Elaborada pelo autor.

Para o caso dos circuitos de BT foram encontrados os seguintes valores, conforme tabela 38.

Tabela 38 - Resultados alocação ótima GD.

\begin{tabular}{c|c|c|c|c|c}
\hline \multirow{2}{*}{ Circuito } & \multicolumn{2}{|c|}{ Balanceamento (\%) } & \multicolumn{2}{c|}{ Tensão Mínima(V) } & \multirow{2}{*}{ Custo (R\$) } \\
\cline { 2 - 5 } & Inicial & Final & Inicial & Final & \\
\hline C1 & 93,90 & 98,59 & 111,82 & 117,29 & 0,00 \\
C2 & 84,80 & 90,00 & 115,76 & 116,97 & 135,00 \\
C3 & 91,80 & 91,80 & 114,23 & 120,40 & 521,00 \\
C4 & 87,40 & 91,20 & 119,25 & 119,28 & 180,00 \\
C5 & 94,90 & 94,90 & 110,18 & 119,13 & 0,00 \\
C6 & 92,90 & 92,90 & 115,35 & 119,51 & 518,00 \\
C7 & 97,60 & 97,60 & 113,13 & 121,54 & 0,00 \\
C8 & 86,70 & 86,70 & 113,18 & 120,27 & 0,00 \\
C9 & 90,30 & 90,30 & 114,35 & 119,00 & 562,00 \\
C10 & 85,70 & 85,70 & 114,63 & 120,14 & 0,00 \\
C11 & 94,20 & 94,20 & 112,88 & 118,36 & 0,00 \\
C12 & 88,90 & 88,90 & 114,45 & 120,14 & 0,00 \\
C13 & 83,20 & 83,20 & 113,00 & 118,75 & 0,00 \\
C14 & 92,10 & 92,10 & 114,60 & 119,39 & 0,00 \\
C15 & 90,20 & 90,20 & 115,99 & 119,00 & 0,00 \\
\hline
\end{tabular}

Fonte: Próprio autor. 
8.5.3 Planejamento Operacional Integrado de MT e BT com GD em pontos determinados

Nesta simulação foi aplicada a otimização considerando a possibilidade de instalação de $G D$ em alguns pontos da rede previamente estabelecidos. Os pontos ótimos de alocação de GD indicados para a rede de $M T$ e $B T$ na seção 8.4.2. foram retirados dos pontos candidatos de seleção para esta simulação. Para o alimentador foram considerados pontos em todos os blocos e, para os circuitos de BT avaliados, três posições distintas. Foram considerados na análise em conjunto com o alimentador, a atuação em 15 circuitos de BT listados como problemáticos.

Os custos envolvidos nesta solução para a rede de MT é mostrada na tabela 39.

Tabela 39 - Resultado da simulação com GD

\begin{tabular}{c|c}
\hline Intervenção & Custo $(\mathrm{R} \$)$ \\
\hline Troca de Cabos & $6.660,00$ \\
\hline Total & $6.660,00$ \\
\hline
\end{tabular}

Fonte: Elaborada pelo autor.

A solução encontrada para o alimentador nesta simulação é mostrada na tabela 40.

Tabela 40 - Valores de Simulação do Alimentador no Planejamento Integrado com GD

\begin{tabular}{c|c}
\hline Característica & Valor \\
\hline Tensão normal de operação & $13,8 \mathrm{KV}$ \\
Tensão máxima & $1,00 \mathrm{pu}$ \\
Tensão mínima & $0,969 \mathrm{pu}$ \\
Queda de Tensão máxima & $3,10 \%$ \\
Perdas & $1,147 \%$ \\
\hline
\end{tabular}

Fonte: Elaborada pelo autor.

Para o caso dos circuitos de BT foram encontrados os seguintes valores, conforme tabela 41 . 
Tabela 41 - Resultados alocação GD.

\begin{tabular}{c|c|c|c|c|c}
\hline \multirow{2}{*}{ Circuito } & \multicolumn{2}{|c|}{ Balanceamento (\%) } & \multicolumn{2}{c|}{ Tensão mínima(V) } & \multirow{2}{*}{ Custo (R\$) } \\
\cline { 2 - 5 } & Inicial & Final & Inicial & Final & \\
\hline C1 & 93,90 & 98,59 & 111,82 & 117,29 & 0,00 \\
C2 & 84,80 & 90,00 & 115,76 & 116,97 & 135,00 \\
C3 & 91,80 & 91,80 & 114,23 & 119,00 & 592,00 \\
C4 & 87,40 & 91,20 & 119,25 & 119,28 & 180,00 \\
C5 & 94,90 & 94,90 & 110,18 & 119,13 & 0,00 \\
C6 & 92,90 & 92,90 & 115,35 & 118,75 & 547,00 \\
C7 & 97,60 & 97,60 & 113,13 & 119,76 & 0,00 \\
C8 & 86,70 & 86,70 & 113,18 & 120,27 & 0,00 \\
C9 & 90,30 & 90,30 & 114,35 & 118,36 & $1.121,00$ \\
C10 & 85,70 & 85,70 & 114,63 & 120,14 & 0,00 \\
C11 & 94,20 & 94,20 & 112,88 & 117,48 & 426,00 \\
C12 & 88,90 & 88,90 & 114,45 & 117,48 & 0,00 \\
C13 & 83,20 & 83,20 & 113,00 & 117,86 & 503,00 \\
C14 & 92,10 & 92,10 & 114,60 & 118,24 & 0,00 \\
C15 & 90,20 & 90,20 & 115,99 & 117,60 & 0,00 \\
\hline
\end{tabular}

Fonte: Próprio autor.

8.5.4 Sumário das Simulações do Planejamento Operacional Integrado de MT e BT

Para a rede de $M T$, considerando a análise não integrada e a integrada com as possibilidades de inserção de $G D$, alocação ótima de $G D$ e alocação de $G D$ em pontos estabelecidos, temos a comparação dos valores mostradas na tabela 42.

Tabela 42 - Resumo dos Custos da rede de $M T$

\begin{tabular}{c|c|c|c}
\hline Planejamento & Sem GD (R\$) & Alocação GD ótima (R\$) & Alocação GD (R\$) \\
\hline Não integrado & $25.960,00$ & $2.664,00$ & $6.660,00$ \\
Integrado & $25.960,00$ & $2.664,00$ & $6.660,00$ \\
\hline
\end{tabular}

Fonte: Elaborada pelo autor.

Para a rede de $B T$, considerando a análise não integrada e a integrada com as possibilidades de inserção de $G D$, alocação ótima de $G D$ e locação de $G D$ em pontos 
estabelecidos, temos a comparação dos valores mostradas na tabela 43.

Tabela 43 - Sumário das simulações.

\begin{tabular}{c|c|c|c|c|c|c}
\hline \multirow{2}{*}{ Circuito } & \multicolumn{3}{|c|}{ Planejamento sem Integração $M T$ e $B T$} & \multicolumn{3}{|c}{ Planejamento com Integração $M T$ e $B T$} \\
\cline { 2 - 7 } & Sem GD (R\$) & GD Ótima (R\$) & GD & Sem GD (R\$) & GD Ótima (R\$) & GD \\
\hline C1 & 270,00 & 0,00 & 0,00 & 270,00 & 0,00 & 0,00 \\
C2 & 135,00 & 135,00 & 135,00 & 135,00 & 135,00 & 135,00 \\
C3 & $1.154,00$ & 521,00 & 663,00 & $2.153,00$ & 521,00 & 592,00 \\
C4 & 180,00 & 180,00 & 180,00 & 180,00 & 180,00 & 180,00 \\
C5 & $3.063,00$ & 0,00 & 0,00 & $2.190,00$ & 0,00 & 0,00 \\
C6 & $2.780,00$ & 518,00 & $1.184,00$ & $2.090,00$ & 518,00 & 547,00 \\
C7 & $1.879,00$ & 0,00 & 0,00 & $1.269,00$ & 0,00 & 0,00 \\
C8 & $1.693,00$ & 0,00 & 0,00 & $1.330,00$ & 0,00 & 0,00 \\
C9 & $2.308,00$ & 562,00 & $1.243,00$ & $2.308,00$ & 562,00 & $1.121,00$ \\
C10 & $2.280,00$ & 0,00 & 0,00 & $2.280,00$ & 0,00 & 0,00 \\
C11 & $2.842,00$ & 0,00 & 498,00 & $2.558,00$ & $0,0,00$ & 426,00 \\
C12 & $2.667,00$ & 0,00 & 0,00 & $2.050,00$ & 0,00 & 0,00 \\
C13 & $2.368,00$ & 0,00 & 503,00 & $2.308,00$ & 0,00 & 503,00 \\
C14 & $1.438,00$ & 0,00 & 0,00 & $1.438,00$ & 0,00 & 0,00 \\
C15 & $1.776,00$ & 0,00 & 0,00 & $1.065,00$ & 0,00 & 0,00 \\
\hline Total & $26.833,00$ & $1.916,00$ & $4.406,00$ & $23.624,00$ & $1.916,00$ & $3.504,00$ \\
\hline
\end{tabular}

Fonte: Elaborada pelo autor.

Os valores totais para o planejamento $M T$ e $B T$ podem ser observados na tabela 44. 
Tabela 44 - Sumário planejamento MT e BT.

\begin{tabular}{c|c|c|c|c|c|c}
\hline \multirow{2}{*}{ Rede } & \multicolumn{2}{|c|}{ Planejamento sem Integração MT e BT } & \multicolumn{3}{|c}{ Planejamento com Integração $M T$ e $B T$} \\
\cline { 2 - 7 } & Sem GD (R\$) & GD Ótima (R\$) & GD (R\$) & Sem GD (R\$) & GD Ótima (R\$) & GD (R\$) \\
\hline \multirow{2}{*}{ MT } & $25.960,00$ & $2.664,00$ & $6.660,00$ & $25.960,00$ & $2.664,00$ & $6.660,00$ \\
BT & $26.833,00$ & $1.916,00$ & $4.091,00$ & $23.624,00$ & $1.916,00$ & $3.504,00$ \\
\hline Total & $52.793,00$ & $4.580,00$ & $11.066,00$ & $49.584,00$ & $4.580,00$ & $10.164,00$ \\
\hline
\end{tabular}

Fonte: Elaborada pelo autor.

As análises da MT sem aplicar GD e considerando cenários com ou sem integração com $B T$ não apresentaram alteração de valores, pois no cenário de integração com a $B T$, as alterações propostas na $B T$ não influenciaram as alterações na $M T$. Da mesma forma, no caso da alocação ótima e da alocação em pontos determinados da GD na MT também não apresentaram diferenças na análise dos cenários com ou sem integração com a $B T$, devido a não influência das alterações na $B T$ na rede de $M T$. Alterações no posicionamento dos transformadores na $B T$ poderiam ocasionar influência na rede de $M T$ na análise integrada, entretanto, para este estudo, não foram sugeridas movimentações de transformadores na análise realizada na $B T$.

Para as análises da $B T$ sem aplicar GD e considerando cenários com ou sem integração com $M T$, houve uma redução de custos de $R \$ 26.833,00$ para $R \$ 23.624,00$ $(11,89 \%)$ devido à melhora do nível de tensão e redução de perdas proporcionado pela análise integrada. No caso da alocação ótima de GD na BT para os cenários com ou sem integração com a $M T$, foram observados os mesmos valores. Nesses casos, somente a possibilidade de alocação ótima de $G D$ na rede de $B T$ foi suficiente para melhorar os níveis de tensão e perdas elétricas. Nos casos da alocação de GD em pontos determinados na rede de $B T$ para os cenários com ou sem integração, foi observada uma redução de custos de $R \$ 4.091,00$ para $R \$ 3.504,00$ (14,31\%) para a análise integrada. Isso ocorre devido ao fato que não podendo considerar a alocação ótima de $G D$ na $B T$, a melhora no nível de tensão no secundário dos transformadores da análise integrada influencia as soluções na BT.

A análise integrada de rede de $M T$ e $B T$ sem $G D$ apresentou uma redução de $R \$ 52.793,00$ para $R \$ 49.584,00$ (6,07\%), estima-se que em alimentadores com níveis de tensão menores que o alimentador estudado $(0,9435 \mathrm{pu})$ os ganhos da análise integrada sejam maiores. 


\subsection{REMANEJAMENTO DE TRANSFORMADORES NO SISTEMA DE DISTRIBUI- ÇÃO DE ENERGIA}

Para o alimentador em análise, foram identificados transformadores sobrecarregados e subcarregados, após a análise de planejamento integrado, foi aplicada a metodologia proposta de remanejamento dos transformadores. O modelo proposto dos agentes foi codificado em linguagem de programação Java utilizando o framework $J A D E$. O modelo matemático foi desenvolvido para ser executado no solver livre GNU LP/MILP Solver Kit (GLPK). O estudo apresentado ilustra a execução do sistema de multiagentes, os dados dos circuitos são mostrados na tabela 45.

Tabela 45 - Dados dos transformadores

\begin{tabular}{c|c|c|c}
\hline Identificador & $\begin{array}{c}\text { Potência } \\
(\mathrm{kVA})\end{array}$ & $\begin{array}{c}\text { Carga } \\
(\mathrm{kVA})\end{array}$ & $\begin{array}{c}\text { Carregamento } \\
\%\end{array}$ \\
\hline P1 & 45 & 80 & 177 \\
P2 & 40 & 14,4 & 36 \\
P3 & 45 & 60 & 133 \\
P4 & 75 & 50 & 67 \\
\hline
\end{tabular}

As coalizões retornadas por cada agente do tipo Posto podem ser visualizadas na tabela 46.

Tabela 46 - Lista de Coalizões

\begin{tabular}{c|c}
\hline Identificador & Lista de Coalizões \\
\hline P1 & $(\mathrm{P} 1, \mathrm{P} 2),(\mathrm{P} 1, \mathrm{P} 4)$ \\
P2 & $(\mathrm{P} 2, \mathrm{P} 1),(\mathrm{P} 2, \mathrm{P} 3),(\mathrm{P} 2, \mathrm{P} 4)$ \\
P3 & $(\mathrm{P} 3, \mathrm{P} 2),(\mathrm{P} 3, \mathrm{P} 4)$ \\
P4 & $(\mathrm{P} 4, \mathrm{P} 1),(\mathrm{P} 4, \mathrm{P} 2),(\mathrm{P} 4, \mathrm{P} 3)$ \\
\hline
\end{tabular}

A lista inicial de coalizões passadas pelos agentes do tipo Posto para o Supervisor pode ser representado pelo grafo mostrado na figura 22.

Os valores calculados pelo Supervisor para cada aresta são ordenados são mostrados na tabela 47.

O Supervisor de acordo com as coalizões sugeridas por cada agente elabora o modelo matemático a ser processado, o resultado pode ser visualizado na tabela 48.

Após a determinação da lista de prováveis Postos, o agente Supervisor com uma visibilidade global de todos os postos, elabora um grafo para realizar uma formulação baseada em programação linear inteira e executa a chamada ao solver GLPK. A atuação dos agentes postos é importante para limitar o espaço de busca na solução. A existência 
Figura 22 - Grafo das movimentações.

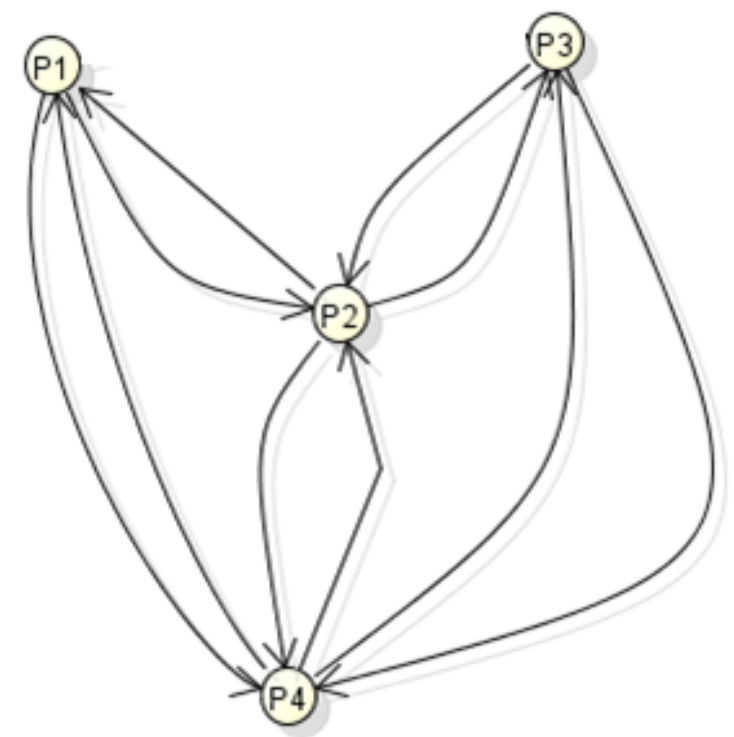

Fonte: Elaboração própria.

Tabela 47 - Custo das Coalizões

\begin{tabular}{c|c}
\hline Coalizões & Custo $(\mathrm{R} \$)$ \\
\hline P1-P2 & 12.700 \\
P1-P4 & 26.500 \\
P2-P1 & 12.700 \\
P2-P3 & 8.100 \\
P2-P4 & 17.300 \\
P3-P2 & 8.100 \\
P3-P4 & 15.000 \\
P4-P1 & 26.500 \\
P4-P2 & 17.300 \\
P4-P3 & 15.000 \\
\hline
\end{tabular}

Tabela 48 - Movimentações sugeridas.

\begin{tabular}{c|c}
\hline Movimentação & Custo (R\$) \\
\hline P1-P2 & 12.700 \\
P2-P1 & 12.700 \\
P3-P4 & 15.000 \\
P4-P3 & 15.000 \\
\hline
\end{tabular}


de um Supervisor permite que restrições adicionais possam ser incorporadas no sistema, afetando a negociação inicialmente realizada pelos agentes do tipo Transformador.

\subsection{CONSIDERAÇÕES}

Inicialmente foram realizadas simulações para a determinação dos melhores parâmetros de execução do $A G$, sendo os valores escolhidos demonstrados na tabela 11 da seção 8.1.1.

Para a validação do impacto da GD foi considerado uma taxa de penetração de $20 \%$ em relação ao valor da potência total do alimentador ou do circuito para poder simular as condições técnicas ocasionadas por sua utilização. Desta forma, a ação da GD pode ser um pouco limitada não dominando as soluções do estudo. Caso contrário não seria possível analisar com detalhes os cenários montados, pois a seleção da GD teria uma grande prioridade de escolha em detrimento das outras alternativas.

Após simulação de alocação ótima para a rede $M T$ e $B T$, os pontos selecionados nesta otimização não eram colocados como opção para a simulação de escolha de pontos na rede de $M T$ e $B T$. Assim, foi possível simular outras situações, especialmente não direcionando a GD nos pontos ótimos dos circuitos e do alimentador. Procura-se, desta forma, simular diversas situações, na qual vários consumidores podem fornecer energia para a rede, não sendo obrigatoriamente na posição ótima para o circuito ou alimentador. A informação do ponto ótimo da GD é importante para a concessionária, podendo ser um fator determinante na escolha de contratos com os proprietários de GDs.

Em circuitos de $B T$ cujo problema de tensão está concentrado em postes próximos a alocação da $G D$, o resultado acabou sendo muito efetivo, sendo que na maioria dos casos a resolução concentrou-se somente em sua inclusão. Em alguns casos, na situação em que o carregamento do cabos já era muito elevado, foi necessário realizar a troca.

Nos circuitos avaliados, não houve a necessidade de remanejamento do transformador, motivo pelo qual as soluções da rede de $M T$ sem e com integração não se alteraram. Nas simulações, o remanejamento do transformador sugerido na otimização de $B T$ é atualizado na topologia do alimentador e realizada uma nova simulação de fluxo de potência para o alimentador. Nestes casos, o planejamento da rede de BT pode influenciar nos custos da rede de $M T$, evitando a troca de cabos na MT somente com a movimentação do transformador para outro ponto válido da rede de $B T$.

A análise integrada proporcionou ganhos para o planejamento de $M T$ e BT, pois permite analisar diversas opções de integração entre os subsistemas primário e secundário. Podendo, neste caso, obter diversas soluções e adotar aquela que é mais conveniente dos pontos de vista econômico e técnico. No caso da análise integrada das redes de $M T$ e $B T$ sem a utilização da $G D$, foi obtido uma redução de $6,08 \%$ nos custos 
envolvidos nas intervenções. Ganhos mais expressivos são esperados em alimentadores com valores de tensão mínima mais elevados.

\subsection{CONCLUSÃO DO CAPÍTULO}

Neste capítulo foram realizados testes com dados de redes reais para verificar os modelos desenvolvidos nos capítulos 4, 5, 6 e 7. Para cada modelo proposto foi realizada uma validação individual e, por fim, o tratamento da integração do planejamento operacional da rede de BT e $M T$. A qualidade das soluções da análise conjunta dos sistemas de BT e MT depende do conjunto de opções possíveis para realizar a integração. Características como condições geográficas, elétricas e físicas do sistemas, além da construção dos sistemas baseado na experiência do planejador, são fatores que influenciam na determinação das melhores soluções.

Com resultado pode-se ter uma melhor avaliação do problema do planejamento operacional considerando os cenários, a saber:

1. Planejamento Operacional da MT com e sem GD;

2. Planejamento Operacional da BT com e sem GD;

3. Planejamento Operacional Integrado da MT-BT com e sem GD;

Os resultados mostram que a metodologia proposta permite obter soluções otimizadas para o problema de redes de BT e $M T$. 



\section{CONCLUSÕES DO TRABALHO}

\subsection{ASPECTOS GERAIS}

Neste trabalho foram desenvolvidos modelos matemáticos e técnicas de solução para os problemas de planejamento de redes de $M T$ e $B T$, além de considerar planejamento integrado de redes de $M T$ e $B T$ e inserção de GD. Os modelos matemáticos e as técnicas de solução apresentadas são adequadas e tecnicamente viáveis para serem aplicadas em sistemas de distribuição reais de energia elétrica.

Para uma aplicação aos sistemas reais das concessionárias será necessário realizar uma adequação dos dados utilizados nos modelos das redes de $M T$ e $B T$ para considerar diferentes patamares de carga para as simulações. Neste estudo, os valores de carga considerados referem-se ao patamar de carga pesada do alimentador e dos circuitos, não ocorrendo necessariamente no mesmo horário. Desta forma, ocorreram situações em que o horário de ponta de circuitos não coincidiu com a do alimentador, representando um valor de carga maior para o alimentador. Para a implantação em uma concessionária, os valores de carga do alimentador e circuitos deverão estar referenciados a um horário para poder verificar melhor o comportamento da inserção da GD. Com a alteração dos dados de carga do alimentador e circuitos para uma mesma referência de horário, o método proposto pode ser utilizado sem nenhuma modificação.

Outro ponto a ser considerado para a adequação aos sistemas de distribuição de uma concessionária, refere-se ao retorno financeiro com a remoção de um condutor no caso da indicação de um recondutoramento de cabos nas soluções. Deverá ser analisado se a operação para a concessionária resulta somente em despesa ou se tem retorno financeiro com a operação. Neste estudo foi utilizado o valor de retorno financeiro em virtude de entrevistas com projetistas da rede de $M T$ e $B T$ de uma Concessionária de Energia que indicaram ser uma prática usual na concessionária.

Nos modelos desenvolvidos foram consideradas operações de mudança de faseamento de transformador e consumidores, proporcionando uma distribuição uniforme das cargas reduzindo o desequilíbrio de corrente entre as fases. Essa alternativa mostra-se eficiente na rede de $B T$ nos casos que o circuito, após a realização de diversas ligações de novos consumidores, apresenta um desbalanceamento de cargas elevado entre as fases. O modelo desenvolvido auxilia na identificação dos transformadores e consumidores a sofrerem alterações no faseamento, bem como a identificação das operações a serem realizadas. Em algumas situações, a operação de troca de faseamento não pode ser realizada em campo, a exemplo de prédios cujo acesso ao quadro de energia é limitado ou, ainda, a informação de faseamento cadastrada no sistema de 
informação da empresa está errada. Embora seja uma alternativa barata e com um bom retorno, a sua aplicação na prática é limitada em virtude de erros cadastrais, dificuldades de acesso e identificação correta dos consumidores e das fases.

A inserção mais frequente de $G D$ na rede de energia elétrica é um grande motivador para a realização de estudos do ponto de vista da concessionária do impacto na rede. Neste novo modelo de conexão de GD é necessário o provimento de metodologia e ferramentas aos técnicos das concessionárias para uma análise mais detalhada deste novo cenário. Neste contexto, as concessionárias precisam realizar os seus estudos de planejamento considerando novas características para utilizar seus recursos com eficiência, reduzindo os seus custos e fornecer energia de acordo com a qualidade estabelecida pela ANEEL.

O ponto central deste trabalho reside na análise integrada do planejamento operacional das redes de $M T$ e $B T$, além da consideração da inserção de $G D$ de maneira a utilizar ao máximo os recursos financeiros e operativos das concessionárias, evitando multas por fornecimento de energia elétrica fora da qualidade prevista nas resoluções da ANEEL.

\subsection{CONTRIBUIÇÕES}

Esta tese teve como finalidade a análise de uma metodologia para o planejamento operacional integrado da rede de $M T$ e BT de forma a otimizar os custos de planejamento dos dois sistemas simultaneamente considerando a inserção da GD. A consideração das relações de conexões físicas e elétricas entre as redes de MT e BT confere uma característica diferenciada ao trabalho, fornecendo ao modelo mais detalhes das redes de $M T$ e $B T$ para a obtenção de soluções de melhor qualidade. Diferentemente dos planejamentos estratégicos e táticos, o planejamento operacional necessita de toda a informação da rede de $M T$ e BT sem realizar nenhuma simplificação.

Dada a natureza combinatória dos problemas de planejamento integrado das redes de $M T$ e $B T$, a utilização dos Algoritmos Genéticos apresentou-se como a solução para metodologia de otimização. Os resultados obtidos nos testes demonstram a eficiência do modelo na busca por soluções relacionadas ao planejamento operacional das redes de distribuição.

Neste trabalho foram apresentados os estudos para a otimização do processo de planejamento operacional considerando um aspecto teórico de utilização de GD como um equipamento podendo ser instalado em pontos da rede. Como resultado, pode-se ter uma melhor avaliação do problema do planejamento operacional considerando os cenários, a saber:

1. Planejamento Operacional da MT com e sem GD; 
2. Planejamento Operacional da BT com e sem GD;

3. Planejamento Operacional Integrado das redes de MT-BT com e sem GD;

Nas simulações realizadas na rede $M T$ sem integração com a rede de $B T$, pode-se observar um ganho nos aspectos técnicos e financeiros com a possibilidade de inserção de GD. A utilização da GD reduziu o nível de perdas de energia em redes de distribuição de MT e proporcionou uma melhora no nível de tensão.

O uso da GD fornecendo energia, caracteriza uma grande vantagem na redução dos custos totais de geração de energia, uma vez que no horário de ponta tem-se uma diminuição no custo total da produção da energia elétrica pelo uso da GD. Fornecer energia com a $G D$ no períodos de maior demanda permite uma menor perda de energia no sistema. Nos estudos realizados, sempre foi considerado o horário de ponta, tanto para ao alimentador (MT), quanto para os circuitos (BT).

As unidades de GD interligadas ao sistema, sendo operadas em paralelo podem ser definidas através dos $S A$ efetivando-os com baixo custo. $\mathrm{O}$ serviço pressupõe a conexão desses geradores a um sistema que identifica a necessidade de acordo com o horário analisado no planejamento. A consideração da GD no planejamento operacional pode proporcionar para a concessionária a possibilidade de redução de investimentos na rede elétrica via $S A$, cabendo uma atenção especial ao cumprimento do contrato entre fornecedores e concessionária.

As simulações realizadas para a determinação da $G D$ ótima para a rede de $M T$ e $B T$, permite a identificação dos pontos de conexão onde a GD vai ser mais benéfica para a concessionária. Desta forma, o conhecimento destes pontos é importante para auxiliar a concessionária a definir o contrato a ser estabelecido com o proprietário da GD.

Por sua vez, a simulação de GD na rede de $M T$ e BT em pontos determinados, possibilita uma análise de sensibilidade do projetista em avaliar alternativas de instalação de GD e as alterações necessárias para o atendimento dos critérios técnicos estabelecidos pelo órgão regulador.

$\mathrm{Na}$ análise integrada do planejamento operacional da rede de MT e BT sem aplicação da $G D$, observou-se uma redução de 6,08\% nos custos das alterações realizadas. Estima-se que, aplicando esta metodologia para alimentadores mais extensos e com um nível de tensão menor do que o utilizado no estudo, a redução de custos seja mais significativa. Entretanto, a utilização da metodologia apresenta um ganho no sentido de avaliar simultaneamente as redes de $M T$ e $B T$, pois atualmente a análise de cada rede é realizada por equipes distintas devido a complexidade da análise conjunta das soluções.

A metodologia de remanejamento de transformadores utilizando $S M A$ apresentou bons resultados para a análise de transformadores subcarregados e sobrecarregados 
em uma determinada área. A metodologia permite validar a troca de transformadores considerando os instalados na rede atualmente, bem como indicar a instalação de um novo transformador caso não seja possível realizar as trocas com os instalados na rede. A utilização da metodologia proposta de remanejamento de transformadores pode ser aplicada antes da execução do planejamento integrado da rede de $M T$ e BT, proporcionando uma melhor distribuição dos transformadores na rede. Cabe ressaltar que para a sua adoção por uma concessionária, deverão ser analisados os critérios adotados, verificando se a concessionária apenas utiliza a política de instalação de novos transformadores ao invés do remanejamento. Observa-se que é uma operação pouco utilizada nas concessionárias, especialmente pelo elevado número de combinações em áreas maiores, bem como da necessidade de uma ferramenta com recursos de visualização de mapas.

\subsection{LIMITAÇÕES DA METODOLOGIA}

O problema de planejamento operacional integrado de redes de $M T$ e BT é um problema de grande complexidade computacional devido a explosão combinatória decorrente das possibilidades de alterações em elementos das redes.

Algumas limitações podem ser apresentadas:

- Para a solução do problema foi utilizada a técnica de Algoritmos Genéticos que são heurísticas, desta forma possuem uma metodologia que caminha para a solução ótima, mas não necessariamente a encontra. Entretanto, estes algoritmos apresentam um desempenho bom para problemas de explosão combinatória;

- A metodologia prevê a utilização de um único horário de simulação, que corresponde ao horário de ponta do alimentador e circuitos analisados. É necessário uma adequação dos dados para contemplar a análise horária;

- Não foi contemplada a operação de divisão de circuitos para a rede de BT.

\subsection{DESENVOLVIMENTOS FUTUROS}

A princípio, existem três linhas a serem seguidas para a evolução natural dos trabalhos desenvolvidos nesta tese. A primeira linha se refere ao desenvolvimento da opção de divisão de circuito para a rede $B T$, sendo uma alternativa adicional para as intervenções na rede de $B T$. Na divisão de um ou mais circuitos preexistentes, parte de suas cargas e postes são atribuídos para um novo circuito, tendo a necessidade de instalação de um novo transformador.

A segunda linha está relacionada com a necessidade de realização de uma análise considerando diferentes horários de carga. Com a análise de diferentes horários para 
cada carga, ocorre a situação em que um consumidor pode ter o fluxo de potência invertido, ou seja, produção maior que o seu consumo.

A terceira linha que foi originada com o trabalho refere-se à necessidade de realizar mais validações com a rede de $M T$ e $B T$, com relação à diferentes topologias de alimentador e circuitos. Recomenda-se a avaliação da metodologia proposta em alimentadores mais extensos e com problemas mais significativos de nível de tensão e perdas elétricas. É claro que a avaliação da metodologia proposta nesta tese requer um considerável número de análises em diversos alimentadores e circuitos, além de especialistas para fazer ajustes às necessidades das práticas das concessionárias. No entanto, a abordagem está consideravelmente aderente com a tendência atual de redes inteligentes, tendo cada vez uma penetração maior no uso da GD. Dessa forma, a aplicação de técnicas que auxiliem o planejamento neste novo cenário torna-se cada vez mais viável. 



\section{REFERÊNCIAS}

ADAMS, R. N. et al. A methodology for distribution system planning. 8th Power Systems Computation Conference, v. 1, n. 2, p. 230-235, 1984. Citado na página 19.

ALLE, A. Técnicas de programação mista-inteira aplicadas ao scheduling de plantas químicas: Escola politécnica da universidade de são paulo. mar. 2003. Dissertação (Mestrado) - Escola Politécnica da Universidade de São Paulo, São Paulo, mar. 2003. Citado na página 27.

AMPOFO, D. O.; OTCHERE, I. K.; FRIMPONG, E. A. An investigative study on penetration limits of distributed generation on distribution networks. IEEE PES PowerAfrica, v. 1, n. 1, p. 1-1, 2017. Citado na página 25.

ANEEL. Procedimentos de Distribuição de Energia Elétrica no Sistema Elétrico Nacional. 1. ed. [S.1.], 2009. v. 1, 32 p. Citado 3 vezes nas páginas 1, 4 e 11.

Nota Técnica n 0043/2010-SRD/ANEEL, publicada em 8 de setembro de 2010. 1. ed. [S.1.], 2010. v. 146, 1 p. Citado na página 10.

. Procedimentos de Distribuição de Energia Elétrica no Sistema Elétrico Nacional - Módulo 1 - Introdução. 1. ed. [S.1.], 2016. v. 1, 61 p. Citado na página 9.

. Nota Técnica n 0056/2017-SRD. 1. ed. [S.1.], 2017. v. 1, 26 p. Citado na página 11.

. Procedimentos de Distribuição de Energia Elétrica no Sistema Elétrico Nacional - Módulo 8 - Qualidade da Energia Elétrica. 1. ed. [S.l.], 2018. v. 1, 84 p. Citado na página 1.

AOKI., K. et al. New approximate optimization method for distribution system planning. IEEE Transactions Power Systems, v. 1, n. 1, p. 126-132, 1990. Citado na página 20.

BACKLUND, Y.; BUBENKO, J. A. Computer-aided distribution system planning. Electrical Power and Energy Systems, v. 1, n. 1, p. 35-45, 1979. Citado na página 19.

BAE, Y. G. Analytical methods of capacitor allocation on distribution primary feeders. ITPAS, PAS-97, n. 1, p. 1232-1238, 1978. Citado na página 21.

BALAKUMARAN, J.; THANUSKODI, K. Loss reduction in radial distribution systems by capacitor placement: Fuzzy technique. E-Tech, v. 1, n. 1, p. 23-29, 2004. Citado na página 24.

BARAN, M. E.; WU, F. F. Optimal capacitor placement on radial distribution systems. ITPD, PAS-103, n. 1, p. 725-734, 1989. Citado na página 22.

BARJA, G. de J. A. A Cogeração e sua Inserção ao Sistema Elétrico: Departamento de engenharia de sistemas. setembro 2006. Dissertação (Mestrado) - Universidade de Brasília, Brasília, setembro 2006. Citado na página 10. 
CAO, D. et al. Costs and benefits of dg connections to grid system - studies on the uk and finnish systems. Imperial College London, v. 1, n. 1, p. 1-5, 2006. Citado na página 12.

CHANG, N. E. Optimum allocation of shunt capacitors and voltage regulators on primary feeders. IEEE Winter Power Meeting, PAS-87, n. 1, p. 1769 - 1774, 1967. Citado na página 21.

CHEN, C.; WU, T. Optimal distribution transformer sizing by dynamic programming. Electrical Power and Energy Systems, v. 20, n. 1, p. 161-167, 1998. Citado na página 20.

CHEN, T.; CHERNG, J. Optimal phase arrangement of distribution transformers connected to a primary feeder for sytem unbalance improvement and loss reduction using a genetic algorithm. IEEE Transaction on Power Systems, v. 15, n. 3, p. 23-29, 2002. Citado na página 45.

CHIANG, H. D.; BARAN, M. E. On the existence and uniqueness of load flow solution for radial distribution power networks. ITCS, v. 37, n. 1, p. 410-416, 1990. Citado na página 23.

CHIANG, H. D. et al. Solution to capacitor placement problem in radial distribution system using tabu search methods: System solution algorithms and numerical studies. IEEE Power Engineering Society Transmission and Distribution Conference, v. 1, n. 1, p. 180-186, 1994. Citado na página 23.

CHOWDHURY, A. A.; KOVAL, D. O. Current practices and customer value-based distribution system reliability planning. Industry Applications Conference - IEEE, v. 1, n. 1, p. 909-9169, 2000. Citado na página 22.

COOK, R. F. Analysis of capacitor application by load cycle. AIEEET, PAS-75, n. 1, p. 950-957, 1959. Citado na página 21.

CORMEN, T. H. et al. Introduction to Algorithms. 3. ed. New York: McGraw - Hill Science, 2009. Citado na página 71 .

CRUZ, F.; SMITH, J.; MATHEUS, G. Algorithms for a multi-level network optimization problem. European Journal of Operations Research, v. 1, n. 1, p. 164-180, 1999. Citado na página 19.

DÍAZ-DORADO, E.; CIDRÁS, J. Application of evolutionary algorithms for the planning of urban distribution networks of medium voltage. IEEE Transaction on Power Systems, v. 17, n. 3, p. 1-6, 2002. Citado na página 42.

DURAN, H. Optimum number, location, and size of shunt capacitors in radial distribution feeders - a dynamic programming approach. ITPAS, PAS-87, n. 1, p. 1769 1774, 1968. Citado na página 21.

EL-KADI, M. A. Computer aided planning of distribution substation and primary feeders. IEEE Transactions on Power Apparatus and Systems, v. 1, n. 1, p. 1183-1189, 1984. Citado na página 19.

EMSHOFF, J. R.; SISSON, R. L. Design and Use of Computer Simulation Models. 1. ed. New Jersey: MacMillan, 1970. Citado na página 29. 
ERGE, T.; HOFFMANN, V. U.; KIEFER, K. The german experience with grid - connected pv systems. Solar Energy, v. 70, n. 1, p. 1-10, 2001. Citado na página 10.

FAWZI, T. H.; ALL, K. F.; EL-SOBKI, S. M. A new planning model of distribution systems. IEEE Transactions on Power Apparatus and Systems, v. 1, n. 1, p. 3010-3017, 1983. Citado na página 19.

GARCIA, A. C. B.; SICHMAN, J. S. Sistemas Inteligentes: fundamentos e aplicações. 1. ed. São Paulo: Editora Manole, 2003. Citado na página 39.

GJERDE, O. Ancillary services - state of the art in the nordic market. IEEE POWER ENGINEERING SOCIETY GENERAL MEETING, v. 1, n. 1, p. 100-104, 2007. Citado na página 16.

GOLBARG, M. C.; LUNA, H. P. L. Otimização Combinatória e Programação Linear Modelos e Algoritmos. 2. ed. Rio de Janeiro: Editora Campus, 2000. Citado na página 28.

GOLDBERG, D. E. Genetic Algorithms in Search, Optimization, and Machine Learnings. 2. ed. EUA: Addison-Wesley Co. Massachusetts, 1989. Citado 5 vezes nas páginas 30, 31, 33, 34 e 84 .

GOMES, P. et al. Subsídios para a determinação de custos de serviços ancilares para a gestão da rede. XIV Seminário Nacional de Produção e Transmissão de Energia Elétrica, v. 1, n. 1, p. 100-104, 1997. Citado na página 16.

GONEN, T.; FOOTE, B. L. Distribution system planning using mixed-integer programming. Proceedings of the IEE - Part C, v. 1, n. 1, p. 70-79, 1981. Citado 2 vezes nas páginas 3 e 19.

GONEN, T.; RAMIREZ-ROSADO, I. Review of distribution system planning models: a model for optimal multi-stage planning. Proceedings of the IEE - Part C, v. 1, n. 1, p. 397-408, 1986. Citado na página 20.

. Optimal multi-stage planning of power distribution systems. IEEE Trans. on PD, v. 1, n. 1, p. 512-519, 1987. Citado na página 19.

GONZÁlEZ, J. F. V. Redução de Perdas em Redes Primárias de Distribuição de Energia Elétrica por Instalação e Controle de Capacitores: Departamento de engenharia de sistemas. julho 2003. Dissertação (Mestrado) - Universidade de Campinas, São Paulo, julho 2003. Citado na página 24.

GUEDES, L. de M. Localização e Dimensionamento de Unidades de Geração Distribuída em Redes de Distribuição Radiais: Departamento de engenharia de sistemas. setembro 2006. Dissertação (Mestrado) — Universidade de Brasília, Brasília, setembro 2006. Citado na página 11.

HADDAD, J. Geração Distribuída - Aspectos Tecnológicos, Ambientais e Institucionais. 1. ed. Rio de Janeiro: Editora Interciência, 2006. Citado na página 10.

HINDI, K. S.; BRAMELLER, A. Design of low-voltage distribution networks: A mathematical programming method. IEEE Transactions on Power Apparatus and Systems, v. 1, n. 1, p. 54-58, 1977. Citado na página 19. 
HOLLAND, J. H. Adaptation in Natural and Artificial Systems. 2. ed. Ann Arbor: University of Michigan Press, 1975. Citado na página 34.

HOLT, S. B.; CRAWFORD, D. M. A mathematical optimization technique for locating and sizing distribution substations and deriving their optimal service areas. IEEE Transactions on Power Apparatus and Systems, v. 1, n. 2, p. 230-235, 1975. Citado na página 19.

IEEE. Recommended Practice for the Monitoring Electric Power Quality. 1. ed. [S.1.], 1995. v. 1,1159-1995 p. Citado na página 14.

ISLAM, S. J.; GUANI, M. R. A. Economical optimization of conductor selection in planning radial distribution networks. IEE Transactions on Power Systemss, v. 1, n. 1, p. 858-863, 1999. Citado na página 20.

JENNINGS, N. R.; SYCARA, K.; WOOLDRIDGE, M. A roadmap of agent research and development. Power Engineering Journal, v. 38, n. 1, p. 7-38, 1998. Citado na página 38 .

JONNAVITHULA, S.; BILLINGTON, R. Minimum cost analysis of feeder routing in distribution system planning. The economic aspect of reliability in distribution system planning, v. 1, n. 1, p. 1935-1940, 1996. Citado na página 22.

KAPLAN, M. Optimization of number, location, size, control type, and control setting of shunt capacitors on radial distribution feeders. ITPAS, PAS-103, n. 1, p. 2659-2665, 1984. Citado na página 21.

KAREEM, Z. A. et al. A review on optimal location of distributed generation techniques in electrical network. IEEE International Conference on Power and Energy (PECon), v. 1, n. 1, p. 1-1, 2016. Citado na página 24.

KAUHHANIEMI, K.; KAUHHANIEMI, A.; LAKERVI, E. Mathematical modeling of electrical distribution system with several voltage levels. IEEE Proceedings Int. Symp. on Circuits and Systems, v. 1, n. 1, p. 425-428, 1988. Citado na página 19.

KHATOR, S.; LEUNG, L. C. Power distribution planning: A review of models and issues. IEEE Transactions on Power Systems, v. 1, n. 1, p. 1151-1559, 1997. Citado na página 20.

KJOLLE, G.; ROLFSENG, L.; DAHL, E. The economic aspect of reliability in distribution system planning. IEEE Trans. on PD, v. 1, n. 1, p. 1153-1157, 1990. Citado na página 22.

KOESTLER, A. O fantasma da máquina. 1. ed. USA: Zahar, 1969. Citado na página 39.

KOSANOVIC, D.; BEEBE, C. System wide economic benefits of distributed generation in the new england energy market. Center for Energy Efficiency and Renewable Energy University of Massachusetts, v. 1, n. 1, p. 1-5, 2005. Citado na página 12.

LEI, S. et al. Identification of critical switches for integrating renewable distributed generation by dynamic network reconfiguration. IEEE Transactions on Sustainable Energy, PP, n. 99, p. 1-1, 2017. Citado na página 24.

LESSER, B. H. V. A survey of multi-agent organizational paradigms. 1. ed. USA:

Cambridge University Press, 2004. Citado na página 39. 
LINDEN, R. Algoritmos Genéticos: Uma Importante Ferramenta da Inteligência Computacional. 2. ed. Rio de Janeiro: Brasport, 2008. Citado na página 30.

MASUD, E. An interactive procedure for sizing and timing distribution substations using optimization techniques. IEEE Transactions on Power Apparatus and Systems, v. 1, n. 1, p. 1281-1286, 1974. Citado na página 18.

Distribution planning: State-of-the-art and extensions to substation sizing. Electric Power Systems Research, v. 1, n. 1, p. 203-212, 1978. Citado na página 18.

MEKHAMER, S. F. et al. New heuristic strategies for reactive power compensation of radial distribution feeders. IEEE Power Engineering Society Transmission and Distribution Conference, v. 17, n. 3, p. 1127-1135, 2002. Citado na página 24.

Reactive power compensation of radial distribution feeders: A new approach. IEEE Transmission on Power Delivery, v. 17, n. 4, p. 1128-1135, 2002. Citado na página 24.

MENDONÇA, K. R. S. Ajuste Ótimo da potência Inserida por Unidades de Geração Distribuída em Alimentadores de Média Tensão: Departamento de engenharia de sistemas. setembro 2006. Dissertação (Mestrado) - Universidade de Brasília, Brasília, setembro 2006. Citado na página 11.

MENENES, C. A. P.; MANTOVANI, J. R. Improving the grid operation and reliability cost of distribution systems with dispersed generation. IEEE Transactions on Power System, v. 28, n. 3, p. 2485-2496, 2013. Citado na página 24.

MIRANDA, V.; RANITO, J.; PROENÇA, L. M. Genetic algorithms in optimal multistage distribution network planning. IEEE Transactions on Power Systems, v. 1, n. 1, p. 1927-1933, 1994. Citado 2 vezes nas páginas 22 e 23.

MIRANDA, V.; SRINIVASAN, D.; PROENÇA, L. M. Evolutionary computation in power systems. IEEE Transactions on Power Systems, v. 1, n. 1, p. 89-98, 1998. Citado na página 22.

MIU, K. N.; CHIANG, H. D.; CHIANG, G. Capacitor placement, replacement and control in large-scale distribution systems by a ga-based two stage algorithm. IEEE Power Engineering Society Transmission and Distribution Conference, v. 12, n. 3, p. 1160-1166, 1997. Citado na página 23.

MONTOYA, O. D. et al. Distribution systems operation considering energy storage devices and distributed generation. IEEE Latin America Transactions, v. 15, n. 5, p. 890-900, 2017. Citado na página 25.

NEAGLE, N. M.; SAMSON, D. R. Loss reduction from capacitors installed on primary feeders. AIEEET, PAS-75, n. 1, p. 950-959, 1956. Citado na página 21.

NGET, N. G. C. Black start commercial workshop. 1. ed. [S.l.], 2009. v. 1, 1-10 p. Citado na página 18.

NIAZI, G.; LALWANI, M. Pso based optimal distributed generation placement and sizing in power distribution networks: A comprehensive review. International Conference on Computer, Communications and Electronics (Comptelix), v. 1, n. 1, p. 1-1, 2017. Citado na página 24. 
OLIVEIRA, C. C. B. Configuração de Redes de Distribuição de Energia Elétrica com Múltiplos Objetivos e Incertezas Através de Procedimentos Heurísticos. 1997. 225 f. Tese (Doutorado em Sistemas de Potência) - Escola Politécnica da Universidade de São Paulo, Universidade de São Paulo, São Paulo, 1997. Citado na página 4.

PACHECO, M. A. C. Algoritmos Genéticos: Princípios e Aplicações. 1. ed. Rio de Janeiro: Pontifícia Universidade Católica do Rio de Janeiro, 2011. Disponível em: $<$ http://www.ica.ele.puc-rio.br/Downloads/38/CE-Apostila-Comp-Evol.pdf $>$. Acesso em: 25 fev 2015. Citado na página 30.

PAIVA, P. C. et al. Integral planning of primary-secondary distribution systems using mixed integer linear programming. IEEE Transaction on Power Systems, v. 20, n. 2, p. 1-6, 2005. Citado na página 42.

PENG, W. et al. A multi-agent simulation framework for distributed generation with battery storage. 26th International Symposium on Industrial Electronics (ISIE), v. 1, n. 1, p. 1-1, 2017. Citado na página 25.

PEREIRA, B. et al. Distributed generation costs and benefits issue paper. California Public Utilities Commission, v. 1, n. 1, p. 975-984, 2004. Citado na página 12.

POZO, A. Computação Evolutiva. [S.1.], 2002. Disponível em: <http://www.inf.ufpr.br/ aurora/tutoriais/Ceapostila.pdf $>$. Acesso em: 20 jul. 2015. Citado 2 vezes nas páginas 31 e 36.

RAHMANI, R. et al. Determining maximum penetration level of distributed generation sources in distribution network considering harmonic limits and maintain protection coordination scheme. Electrical Power Distribution Networks Conference (EPDC), v. 1, n. 1, p. 1-1, 2017. Citado na página 24.

RAMIREZ-ROSADO, I. J.; BERNAL-AGUSTÍN, J. L. Optimization of the power distribution network design by application of genetic algorithms. International Journal of Power and Energy Systems, v. 1, n. 1, p. 104-110, 1995. Citado na página 23.

. Genetic algorithm applied to the design of large power distribution systems. IEEE Transactions on Power Systems, v. 13, n. 1, p. 696-703, 1998. Citado na página 23.

. Reliability and costs optimization for distribution networks expansion using an evolutionary algorithm. IEEE Transactions on Power Systems, v. 1, n. 1, p. 111-118, 2001. Citado 2 vezes nas páginas 22 e 23.

RAO, S. S. Engineering optimization: theory and practice. 3. ed. USA: John Wiley and Sons, 1996. Citado 2 vezes nas páginas 51 e 66.

REBOURS, Y. G. et al. A survey of frequency and voltage control ancillary services-part ii: economic features. IEEE Transactions on Power Systems, v. 22, n. 1, p. 358-366, 2007. Citado na página 18.

RODRIGUES, A.; GOMES, J. Contabilidade Empresarial: Textos e Casos sobre CPC e IFRS. 1. ed. BRA: Editora Campus, 2016. Citado na página 25.

RUSSELL, S.; NORVIG, P. Artificial intelligence: a Modern Approach. 1. ed. USA: Upper Saddle River: Prentice Hall, 2010. Citado 3 vezes nas páginas 37, 38 e 39. 
SAINI, S.; KAUR, G. Real power loss reduction in distribution network through distributed generation integration by implementing spso. International Conference on Electrical Power and Energy Systems (ICEPES), v. 1, n. 1, p. 1-1, 2016. Citado na página 25.

SANTOSO, N. I.; TAN, O. T. Piecewise method for optimal sizing of distribution capacitors. IASTED International Symposium on Simulation and Modelling, PAS-103, n. 1, p. 725-734, 1989. Citado na página 22.

SHAHIDEHPOUR, M. Market operation in electric power system. 1. ed. New York: John Wiley and Sons, 2002. Citado na página 16.

SILVA, C. M.; FRANÇA, P. M.; SILVEIRA, D. P. Long-range planning of power distribution systems: Secondary networks. Computer Elect. Eng., v. 22, n. 1, p. 179-191, 1996. Citado na página 61.

SIMONE, L. F. C.; SALLES, M. B. C. The impact of distributed generation on the energy tariff and the utility revenue in brazil. 6th International Conference on Clean Electrical Power (ICCEP), v. 1, n. 1, p. 1-1, 2017. Citado na página 25.

SUN, D. I.; FARRIS, D. R.; COTE, P. J. Optimal distribution substation and primary feeder planning via the fixed charge network formulation. IEEE Transactions on Power Apparatus and Systems, v. 1, n. 1, p. 602-609, 1982. Citado na página 19.

SUNTHERLAND, J. W. Systems Analysis, Administration and Architecture. 1. ed. New York: Van Nostrand Reinhold Company, 1975. Citado na página 28.

TANG, Y. Power distribution system planning with reliability modelling and optimization. IEEE Transactions on Power Systems, v. 1, n. 1, p. 181-189, 1996. Citado na página 22.

THOMPSON, L.; WALL, D. L. A branch and bound model for choosing optimal substation locations. IEEE Transactions on Power Apparatus and Systems, v. 1, n. 1, p. 2683-2688, 1981. Citado na página 19.

VAZIRI, M.; TOMSOVIC, K.; GONEN, T. Distribution expansion problem revisited: Part 1 categorical analysis and future directions. Proceedings of the Fourth IASTED International Conference on Power and Energy Systems (PES 2000), v. 1, n. 1, p. 1151-1559, 2000. Citado na página 20.

WEISS., G. Multiagent systems: a modern approach to distributed artificial intelligence. 2. ed. USA: Cambridge: MIT Press, 2000. Citado na página 38.

WILLIANS, H. P. Model building in mathematical programming. Jonh Wiley and Sons, Inc., v. 1, n. 1, p. 71-97, 1999. Citado na página 28.

WOOLDRIDGE, M. An Introduction to Multi-Agent Systems. 1. ed. Liverpool: [s.n.], 2002. Citado na página 38.

WOOLDRIDGE, M.; JENNINGS. Pitfalls of agent oriented development. 2nd International Conference Autonomous Agents, v. 1, n. 1, p. 385-391, 1998. Citado 2 vezes nas páginas 37 e 38. 
YANG, H.; HUANG, Y.; HUANG, C. Solution to capacitor placement problem in radial distribution system using tabu search method. International Conference on Energy Management and Power Delivery, v. 1, n. 1, p. 388-393, 1995. Citado na página 23.

ZEHIR, M. A. et al. Mitigation of negative impacts of distributed generation on lv distribution networks through microgrid management systems. IEEE Manchester PowerTech, v. 1, n. 1, p. 1-1, 2017. Citado na página 25.

ZHANG, C. et al. Optimal location planning of renewable distributed generation units in distribution networks: An analytical approach. IEEE Transactions on Power System, v. 99, n. 99, p. 1-1, 2017. Citado na página 24. 


\section{Apêndices}





\section{APÊNDICE A - DADOS DO ALIMENTADOR}

\begin{tabular}{|c|c|c|c|c|c|c|c|c|c|}
\hline Bloco & Coordenada Inicial & Coordenada Final & A & B & $\mathrm{C}$ & total & Material & Bitola & Fase \\
\hline \multirow[t]{9}{*}{8236210922} & Chave: 8236271136 & $669826-7182986$ & & & & & & & \\
\hline & $669826-7182986$ & $669819-7182984$ & & & & & $\mathrm{~J}$ & 40 & $\mathrm{ABC}$ \\
\hline & $669819-7182984$ & $669799-7183032$ & & & & & $\mathrm{~J}$ & 40 & $\mathrm{ABC}$ \\
\hline & $669799-7183032$ & $669813-7183034$ & & & & & $\mathrm{~J}$ & 40 & $\mathrm{ABC}$ \\
\hline & $669813-7183034$ & $669826-7183041$ & & & & & $\mathrm{~J}$ & 40 & $\mathrm{ABC}$ \\
\hline & $669826-7183041$ & $669854-7183041$ & & & & & $\mathrm{~J}$ & 40 & $\mathrm{ABC}$ \\
\hline & $669854-7183041$ & $669860-7183040$ & & & & & $\mathrm{~J}$ & 40 & $\mathrm{ABC}$ \\
\hline & $669862-7183044$ & $669860-7183040$ & & & & & $\mathrm{P}$ & $3 C$ & $\mathrm{ABC}$ \\
\hline & & Total: & 0.0 & 0.0 & 0.0 & & & & \\
\hline \multirow[t]{17}{*}{8236210745} & Chave: 8236201539 & $669862-7183044$ & & & & & & & \\
\hline & $669845-7183039$ & $669862-7183044$ & & & & & $\mathrm{P}$ & $1 \mathrm{C}$ & $\mathrm{ABC}$ \\
\hline & $669862-7183044$ & $670086-7183114$ & & & & & A & 33 & $\mathrm{ABC}$ \\
\hline & Posto: 82362C8572 & $669845-7183039$ & 1.6 & 2.6 & 2.5 & 6.7 & & & $\mathrm{ABC}$ \\
\hline & $670086-7183114$ & $670125-7183126$ & & & & & $\mathrm{~A}$ & 33 & $\mathrm{ABC}$ \\
\hline & $670125-7183126$ & $670296-7183180$ & & & & & $\mathrm{~A}$ & 33 & $\mathrm{ABC}$ \\
\hline & Posto: 82362C3963 & $670125-7183126$ & 18.3 & 18.6 & 16. & 53.3 & & & $\mathrm{ABC}$ \\
\hline & $670296-7183180$ & $670331-7183188$ & & & & & A & 33 & $\mathrm{ABC}$ \\
\hline & $670331-7183188$ & $670364-7183198$ & & & & & $\mathrm{~A}$ & 33 & $\mathrm{ABC}$ \\
\hline & $670364-7183198$ & $670405-7183211$ & & & & & $\mathrm{~A}$ & 33 & $\mathrm{ABC}$ \\
\hline & Posto: 82362C1293 & $670364-7183198$ & 14.5 & 18.0 & 14. & 46.7 & & & $\mathrm{ABC}$ \\
\hline & $670405-7183211$ & $670441-7183226$ & & & & & $\mathrm{~A}$ & 33 & $\mathrm{ABC}$ \\
\hline & $670441-7183226$ & $670531-7183254$ & & & & & $\mathrm{~A}$ & 33 & $\mathrm{ABC}$ \\
\hline & $670619-7183281$ & $670531-7183254$ & & & & & A & 33 & $\mathrm{ABC}$ \\
\hline & $670652-7183291$ & $670619-7183281$ & & & & & $\mathrm{~A}$ & 33 & $\mathrm{ABC}$ \\
\hline & Posto: 82362C1292 & $670619-7183281$ & 17.3 & 16.5 & 14. & 48.0 & & & $\mathrm{ABC}$ \\
\hline & & Total: & 51.6 & 55.7 & 47. & & & & \\
\hline \multirow[t]{9}{*}{8236207541} & Chave: 8236206248 & 670652 - 7183291 & & & & & & & \\
\hline & $670667-7183296$ & 670652 - 7183291 & & & & & A & 33 & $\mathrm{ABC}$ \\
\hline & 670667 - 7183296 & $670661-7183318$ & & & & & $\mathrm{~A}$ & 02 & $\mathrm{ABC}$ \\
\hline & $670667-7183296$ & $670670-7183288$ & & & & & $\mathrm{~A}$ & 02 & $\mathrm{ABC}$ \\
\hline & $670667-7183296$ & $670718-7183313$ & & & & & $\mathrm{~A}$ & 33 & $\mathrm{ABC}$ \\
\hline & $670661-7183318$ & 670665 - 7183319 & & & & & Z & 01 & $\mathrm{ABC}$ \\
\hline & $670661-7183318$ & 670652 - 7183347 & & & & & $\mathrm{~A}$ & 02 & $\mathrm{ABC}$ \\
\hline & $670713-7183336$ & $670718-7183313$ & & & & & $\mathrm{P}$ & $3 C$ & $\mathrm{ABC}$ \\
\hline & 670718 - 7183313 & $670729-7183275$ & & & & & $\mathrm{~A}$ & 33 & $\mathrm{ABC}$ \\
\hline
\end{tabular}




\begin{tabular}{|c|c|c|c|c|c|c|c|}
\hline Posto: 82362C1291 & $670665-7183319$ & 0.1 & 0.1 & 0.1 & 0.4 & & \\
\hline $670729-7183275$ & $670741-7183237$ & & & & & $\mathrm{~A}$ & 33 \\
\hline Posto: 82362C3568 & $670729-7183275$ & 4.7 & 4.8 & 4.6 & 14.1 & & \\
\hline $670741-7183237$ & $670753-7183198$ & & & & & $\mathrm{~A}$ & 33 \\
\hline $670753-7183198$ & $670764-7183160$ & & & & & $\mathrm{~A}$ & 33 \\
\hline Posto: 82362C3567 & $670753-7183198$ & 6.0 & 6.1 & 4.3 & 16.4 & & \\
\hline $670764-7183160$ & $670777-7183122$ & & & & & $\mathrm{~A}$ & 33 \\
\hline $670777-7183122$ & $670789-7183087$ & & & & & $\mathrm{~A}$ & 33 \\
\hline $670789-7183087$ & $670792-7183075$ & & & & & $\mathrm{~A}$ & 33 \\
\hline $670792-7183075$ & $670810-7183010$ & & & & & $\mathrm{~A}$ & 33 \\
\hline $670762-7183081$ & $670792-7183075$ & & & & & $\mathrm{~A}$ & 33 \\
\hline $670792-7183075$ & $670834-7183068$ & & & & & $\mathrm{~A}$ & 33 \\
\hline $670810-7183010$ & $670821-7182967$ & & & & & $\mathrm{~A}$ & 33 \\
\hline $670729-7183090$ & $670762-7183081$ & & & & & A & 33 \\
\hline $670827-7183038$ & $670834-7183068$ & & & & & A & 02 \\
\hline $670834-7183068$ & $670842-7183106$ & & & & & $\mathrm{~A}$ & 02 \\
\hline $670834-7183068$ & $670880-7183057$ & & & & & A & 33 \\
\hline $670709-7183084$ & $670729-7183090$ & & & & & $\mathrm{~A}$ & 33 \\
\hline & Total: & 10.9 & 11.0 & 9.0 & & & \\
\hline Chave: 8236215222 & $671294-7182849$ & & & & & & \\
\hline $671276-7182852$ & $671294-7182849$ & & & & & $\mathrm{~A}$ & 33 \\
\hline $671234-7182861$ & $671276-7182852$ & & & & & $\mathrm{~A}$ & 33 \\
\hline $671270-7182833$ & $671276-7182852$ & & & & & $\mathrm{~A}$ & 33 \\
\hline $671276-7182852$ & $671277-7182860$ & & & & & $\mathrm{~A}$ & 33 \\
\hline Posto: 82362CJ068 & $671234-7182861$ & 5.1 & 6.4 & 5.7 & 17.2 & & \\
\hline $671202-7182868$ & $671234-7182861$ & & & & & $\mathrm{~A}$ & 33 \\
\hline $671170-7182874$ & $671202-7182868$ & & & & & $\mathrm{~A}$ & 33 \\
\hline $671160-7182876$ & $671170-7182874$ & & & & & $\mathrm{~A}$ & 33 \\
\hline 671065 - 7182897 & $671160-7182876$ & & & & & $\mathrm{~A}$ & 33 \\
\hline $671155-7182858$ & $671160-7182876$ & & & & & $\mathrm{~A}$ & 02 \\
\hline $671160-7182876$ & $671173-7182946$ & & & & & $\mathrm{~A}$ & 02 \\
\hline $671014-7182906$ & 671065 - 7182897 & & & & & $\mathrm{~A}$ & 33 \\
\hline $671061-7182877$ & $671065-7182897$ & & & & & $\mathrm{~A}$ & 02 \\
\hline $671065-7182897$ & $671067-7182906$ & & & & & $\mathrm{~A}$ & 02 \\
\hline Posto: 82362C1243 & $671173-7182946$ & 11.3 & 10.3 & 12. & 34.4 & & \\
\hline $671173-7182946$ & $671179-7182974$ & & & & & $\mathrm{~A}$ & 02 \\
\hline Posto: 82362CK601 & $671014-7182906$ & 9.0 & 8.7 & 8.2 & 25.9 & & \\
\hline $670982-7182913$ & $671014-7182906$ & & & & & A & 33 \\
\hline $671067-7182906$ & $671075-7182935$ & & & & & $\mathrm{P}$ & $1 \mathrm{C}$ \\
\hline $670941-7182921$ & $670982-7182913$ & & & & & A & 33 \\
\hline
\end{tabular}




\begin{tabular}{|c|c|c|c|c|c|c|c|c|c|}
\hline & $670937-7182902$ & $670941-7182921$ & & & & & $\mathrm{~A}$ & 02 & $\mathrm{ABC}$ \\
\hline & $670943-7182931$ & $670941-7182921$ & & & & & $\mathrm{~A}$ & 02 & $\mathrm{ABC}$ \\
\hline & $670877-7182934$ & $670941-7182921$ & & & & & $\mathrm{~A}$ & 33 & $\mathrm{ABC}$ \\
\hline & Posto: 82362CK503 & $670877-7182934$ & 10.4 & 10.0 & 10. & 30.4 & & & $\mathrm{ABC}$ \\
\hline & 670819 - 7182946 & $670877-7182934$ & & & & & $\mathrm{~A}$ & 33 & $\mathrm{ABC}$ \\
\hline & $670821-7182967$ & $670819-7182946$ & & & & & $\mathrm{~A}$ & 33 & $\mathrm{ABC}$ \\
\hline & $670819-7182946$ & $670820-7182936$ & & & & & $\mathrm{~A}$ & 33 & $\mathrm{ABC}$ \\
\hline & $670802-7182949$ & $670819-7182946$ & & & & & A & 33 & $\mathrm{ABC}$ \\
\hline & $670802-7182949$ & $670766-7182971$ & & & & & A & 33 & $\mathrm{ABC}$ \\
\hline & 670766 - 7182971 & $670760-7182975$ & & & & & $\mathrm{~A}$ & 33 & $\mathrm{ABC}$ \\
\hline & 670766 - 7182971 & $670762-7182981$ & & & & & $\mathrm{~A}$ & 02 & $\mathrm{ABC}$ \\
\hline & 670766 - 7182971 & $670770-7182955$ & & & & & $\mathrm{~A}$ & 02 & $\mathrm{ABC}$ \\
\hline & 670642 - 7182938 & $670760-7182975$ & & & & & $\mathrm{P}$ & $3 C$ & $\mathrm{ABC}$ \\
\hline & $670603-7182925$ & $670642-7182938$ & & & & & $\mathrm{P}$ & $3 C$ & $\mathrm{ABC}$ \\
\hline & Posto: 82362C6501 & $670603-7182925$ & 9.7 & 10.3 & 8.0 & 28.0 & & & $\mathrm{ABC}$ \\
\hline & $670561-7182912$ & $670603-7182925$ & & & & & $\mathrm{P}$ & $3 C$ & $\mathrm{ABC}$ \\
\hline 8236200284 & Chave: 8236201632 & $670842-7183106$ & & & & & & & \\
\hline & $670842-7183106$ & $670852-7183156$ & & & & & $\mathrm{~A}$ & 02 & $\mathrm{ABC}$ \\
\hline & Posto: $82362 C 1285$ & $670852-7183156$ & 25.0 & 25.5 & 25. & 76.4 & & & $\mathrm{ABC}$ \\
\hline & 670852 - 7183156 & $670861-7183199$ & & & & & $\mathrm{~A}$ & 02 & $\mathrm{ABC}$ \\
\hline & 670861 - 7183199 & $670867-7183230$ & & & & & A & 02 & $\mathrm{ABC}$ \\
\hline & $670867-7183230$ & $670874-7183268$ & & & & & $\mathrm{~A}$ & 02 & $\mathrm{ABC}$ \\
\hline & Posto: $82362 \mathrm{CN} 394$ & $670874-7183268$ & 7.3 & 7.1 & 5.8 & 20.2 & & & $\mathrm{ABC}$ \\
\hline & $670874-7183268$ & $670878-7183284$ & & & & & $\mathrm{~A}$ & 02 & $\mathrm{ABC}$ \\
\hline & & Total: & 32.3 & 32.6 & 31. & & & & \\
\hline 8236210761 & Chave: 8236200346 & $670880-7183057$ & & & & & & & \\
\hline & $670880-7183057$ & $670965-7183039$ & & & & & $\mathrm{~A}$ & 33 & $\mathrm{ABC}$ \\
\hline & 670965 - 7183039 & $670974-7183085$ & & & & & $\mathrm{~A}$ & 02 & $\mathrm{ABC}$ \\
\hline & 670965 - 7183039 & $670973-7183038$ & & & & & $\mathrm{~A}$ & 33 & $\mathrm{ABC}$ \\
\hline & $670961-7183020$ & $670965-7183039$ & & & & & $\mathrm{~A}$ & 02 & $\mathrm{ABC}$ \\
\hline & $670973-7183038$ & $671004-7183032$ & & & & & $\mathrm{~A}$ & 33 & $\mathrm{ABC}$ \\
\hline & $671004-7183032$ & $671036-7183025$ & & & & & $\mathrm{~A}$ & 33 & $\mathrm{ABC}$ \\
\hline & $671036-7183025$ & $671067-7183019$ & & & & & $\mathrm{~A}$ & 33 & $\mathrm{ABC}$ \\
\hline & $671067-7183019$ & $671090-7183023$ & & & & & $\mathrm{P}$ & $1 \mathrm{C}$ & $\mathrm{ABC}$ \\
\hline & $671099-7183012$ & $671067-7183019$ & & & & & $\mathrm{~A}$ & 33 & $\mathrm{ABC}$ \\
\hline & $671132-7183006$ & $671099-7183012$ & & & & & $\mathrm{~A}$ & 33 & $\mathrm{ABC}$ \\
\hline & $671164-7182999$ & $671132-7183006$ & & & & & $\mathrm{~A}$ & 33 & $\mathrm{ABC}$ \\
\hline & $671164-7182999$ & $671194-7182993$ & & & & & $\mathrm{~A}$ & 33 & $\mathrm{ABC}$ \\
\hline & $671185-7183003$ & $671164-7182999$ & & & & & $\mathrm{~A}$ & 33 & $\mathrm{ABC}$ \\
\hline & $671194-7182993$ & $671227-7182987$ & & & & & $\mathrm{~A}$ & 33 & $\mathrm{ABC}$ \\
\hline
\end{tabular}




\begin{tabular}{|c|c|c|c|c|c|c|c|c|}
\hline $671185-7183003$ & $671191-7183026$ & & & & & $\mathrm{P}$ & $3 C$ & $\mathrm{ABC}$ \\
\hline $671227-7182987$ & $671261-7182979$ & & & & & $\mathrm{~A}$ & 33 & $\mathrm{ABC}$ \\
\hline $671191-7183026$ & $671199-7183059$ & & & & & $\mathrm{P}$ & $3 C$ & $\mathrm{ABC}$ \\
\hline $671261-7182979$ & $671291-7182973$ & & & & & $\mathrm{~A}$ & 33 & $\mathrm{ABC}$ \\
\hline $671199-7183059$ & $671210-7183119$ & & & & & $\mathrm{P}$ & $3 C$ & $\mathrm{ABC}$ \\
\hline $671291-7182973$ & $671300-7182971$ & & & & & $\mathrm{~A}$ & 33 & $\mathrm{ABC}$ \\
\hline $671210-7183119$ & $671227-7183202$ & & & & & $\mathrm{P}$ & $3 C$ & $\mathrm{ABC}$ \\
\hline 671302 - 7182981 & $671300-7182971$ & & & & & A & 33 & $\mathrm{ABC}$ \\
\hline $671300-7182971$ & $671387-7182954$ & & & & & $\mathrm{~A}$ & 33 & $\mathrm{ABC}$ \\
\hline $671300-7182971$ & $671289-7182922$ & & & & & A & 33 & $\mathrm{ABC}$ \\
\hline Posto: 82362C9675 & $671387-7182954$ & 7.4 & 8.1 & 7.9 & 23.4 & & & $\mathrm{ABC}$ \\
\hline $671387-7182954$ & $671438-7182943$ & & & & & A & 33 & $\mathrm{ABC}$ \\
\hline $671422-7182865$ & $671438-7182943$ & & & & & A & 02 & $\mathrm{ABC}$ \\
\hline $671438-7182943$ & $671447-7182986$ & & & & & $\mathrm{~A}$ & 02 & $\mathrm{ABC}$ \\
\hline $671438-7182943$ & $671567-7182918$ & & & & & $\mathrm{~A}$ & 33 & $\mathrm{ABC}$ \\
\hline Posto: 82362C1257 & $671422-7182865$ & 19.0 & 23.8 & 18. & 61.5 & & & $\mathrm{ABC}$ \\
\hline $671416-7182835$ & $671422-7182865$ & & & & & $\mathrm{~A}$ & 02 & $\mathrm{ABC}$ \\
\hline $671447-7182986$ & $671452-7183007$ & & & & & $\mathrm{~A}$ & 02 & $\mathrm{ABC}$ \\
\hline $671557-7182867$ & $671567-7182918$ & & & & & A & 02 & $\mathrm{ABC}$ \\
\hline $671567-7182918$ & 671575 - 7182957 & & & & & $\mathrm{~A}$ & 02 & $\mathrm{ABC}$ \\
\hline $671567-7182918$ & $671605-7182910$ & & & & & A & 33 & $\mathrm{ABC}$ \\
\hline $671452-7183007$ & $671454-7183017$ & & & & & A & 02 & $\mathrm{ABC}$ \\
\hline Posto: $82362 \mathrm{CA} 420$ & $671605-7182910$ & 5.8 & 6.7 & 7.0 & 19.5 & & & $\mathrm{ABC}$ \\
\hline $671605-7182910$ & $671625-7182905$ & & & & & A & 33 & $\mathrm{ABC}$ \\
\hline Posto: 82362C1254 & $671454-7183017$ & 9.0 & 8.7 & 7.9 & 25.6 & & & $\mathrm{ABC}$ \\
\hline $671454-7183017$ & $671460-7183047$ & & & & & $\mathrm{~A}$ & 02 & $\mathrm{ABC}$ \\
\hline $671625-7182905$ & $671684-7182894$ & & & & & $\mathrm{~A}$ & 33 & $\mathrm{ABC}$ \\
\hline $671460-7183047$ & $671468-7183086$ & & & & & $\mathrm{P}$ & $1 C$ & $\mathrm{ABC}$ \\
\hline $671684-7182894$ & $671690-7182921$ & & & & & $\mathrm{~A}$ & 02 & $\mathrm{ABC}$ \\
\hline $671684-7182894$ & $671769-7182875$ & & & & & $\mathrm{~A}$ & 33 & $\mathrm{ABC}$ \\
\hline $671684-7182894$ & $671675-7182843$ & & & & & A & 02 & $\mathrm{ABC}$ \\
\hline $671690-7182921$ & $671693-7182931$ & & & & & A & 02 & $\mathrm{ABC}$ \\
\hline $671769-7182875$ & $671768-7182872$ & & & & & Z & 01 & $\mathrm{ABC}$ \\
\hline $671769-7182875$ & $671801-7182869$ & & & & & A & 33 & $\mathrm{ABC}$ \\
\hline Posto: 82362C1287 & $671675-7182843$ & 10.7 & 11.7 & 12. & 35.2 & & & $\mathrm{ABC}$ \\
\hline $671669-7182814$ & $671675-7182843$ & & & & & A & 02 & $\mathrm{ABC}$ \\
\hline Posto: $82362 \mathrm{CA} 172$ & $671693-7182931$ & 5.9 & 5.8 & 6.5 & 18.2 & & & $\mathrm{ABC}$ \\
\hline Posto: 82362CJ743 & $671768-7182872$ & 4.1 & 4.9 & 3.7 & 12.7 & & & $\mathrm{ABC}$ \\
\hline $671801-7182869$ & $671852-7182858$ & & & & & A & 33 & $\mathrm{ABC}$ \\
\hline Posto: 82362C9317 & $671801-7182869$ & 9.1 & 9.4 & 9.2 & 27.8 & & & $\mathrm{ABC}$ \\
\hline $671852-7182858$ & $671862-7182901$ & & & & & A & 02 & $\mathrm{ABC}$ \\
\hline $671843-7182814$ & $671852-7182858$ & & & & & A & 02 & \\
\hline
\end{tabular}




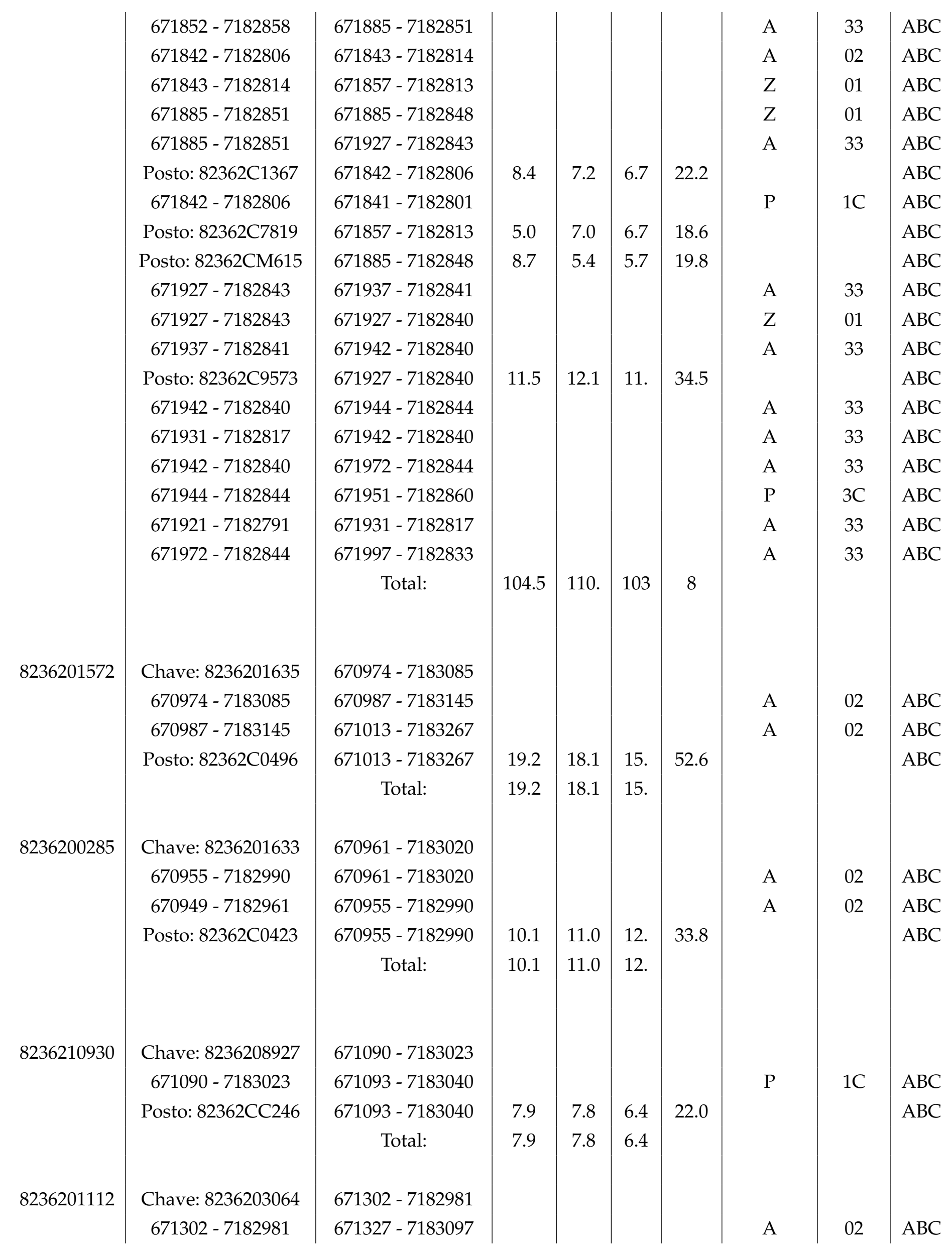


8236210913

8236211107

8236200760

671347 - 7183093
$671327-7183097$
$671327-7183097$
671347 - 7183093
Posto: $82362 C 1248$
671336 - 7183141
671264 - 7183111
Posto: 82362 CJ434
Posto: 82362 C1616

Chave: 8236209281
671264 - 7183111
Posto: 82362 CJ558

Chave: 8236209932 671452 - 7183007

Posto: 82362CC 860

Chave: 8236201634 671575 - 7182957

Posto: 82362C7605 671582 - 7182989 $671534-7183054$ $671597-7183063$ $671593-7183042$

Posto: $82362 \mathrm{C} 2102$ 671602 - 7183086 $671597-7183063$ $671636-7183033$ $671636-7183033$

Posto: 82362C0151 671602 - 7183086

Posto: 82362CJ200

Posto: 82362C8600

Posto: 82362CM388 671609 - 7183117 $671616-7183150$ 671620 - 7183170 671620 - 7183170

\begin{tabular}{|c|c|c|c|c|c|c|c|}
\hline $671327-7183097$ & & & & & A & 02 & $\mathrm{ABC}$ \\
\hline $671336-7183141$ & & & & & $\mathrm{~A}$ & 02 & $\mathrm{ABC}$ \\
\hline $671264-7183111$ & & & & & $\mathrm{~A}$ & 02 & $\mathrm{ABC}$ \\
\hline $671376-7183087$ & & & & & $\mathrm{~A}$ & 02 & $\mathrm{ABC}$ \\
\hline $671336-7183141$ & 17.2 & 20.5 & 17. & 55.0 & & & $\mathrm{ABC}$ \\
\hline $671342-7183170$ & & & & & $\mathrm{~A}$ & 02 & $\mathrm{ABC}$ \\
\hline $671258-7183112$ & & & & & $\mathrm{~A}$ & 02 & $\mathrm{ABC}$ \\
\hline $671376-7183087$ & 2.6 & 4.5 & 3.2 & 10.4 & & & $\mathrm{ABC}$ \\
\hline $671258-7183112$ & 8.6 & 7.9 & 7.3 & 23.7 & & & $\mathrm{ABC}$ \\
\hline Total: & 28.4 & 32.9 & 27. & & & & \\
\hline $671264-7183111$ & & & & & & & \\
\hline 671262 - 7183099 & & & & & $\mathrm{Z}$ & 01 & $\mathrm{ABC}$ \\
\hline 671262 - 7183099 & 6.3 & 4.9 & 5.3 & 16.5 & & & $\mathrm{ABC}$ \\
\hline Total: & 6.3 & 4.9 & 5.3 & & & & \\
\hline $671452-7183007$ & & & & & & & \\
\hline $671439-7183014$ & & & & & $\mathrm{P}$ & $1 C$ & $\mathrm{ABC}$ \\
\hline $671439-7183014$ & 0.7 & 0.1 & 0.6 & 1.3 & & & $\mathrm{ABC}$ \\
\hline Total: & 0.7 & 0.1 & 0.6 & & & & \\
\hline 671575 - 7182957 & & & & & & & \\
\hline $671582-7182989$ & & & & & $\mathrm{~A}$ & 02 & $\mathrm{ABC}$ \\
\hline $671582-7182989$ & 10.4 & 7.9 & 10. & 28.3 & & & $\mathrm{ABC}$ \\
\hline $671593-7183042$ & & & & & $\mathrm{~A}$ & 02 & $\mathrm{ABC}$ \\
\hline $671593-7183042$ & & & & & $\mathrm{~A}$ & 02 & $\mathrm{ABC}$ \\
\hline $671593-7183042$ & & & & & $\mathrm{~A}$ & 02 & $\mathrm{ABC}$ \\
\hline $671636-7183033$ & & & & & $\mathrm{~A}$ & 02 & $\mathrm{ABC}$ \\
\hline $671534-7183054$ & 14.0 & 18.6 & 12. & 44.8 & & & $\mathrm{ABC}$ \\
\hline $671597-7183063$ & & & & & $\mathrm{~A}$ & 02 & $\mathrm{ABC}$ \\
\hline $671585-7183065$ & & & & & $\mathrm{~A}$ & 02 & $\mathrm{ABC}$ \\
\hline $671649-7183031$ & & & & & $\mathrm{~A}$ & 02 & $\mathrm{ABC}$ \\
\hline $671635-7183030$ & & & & & $\mathrm{~A}$ & 02 & $\mathrm{ABC}$ \\
\hline $671602-7183086$ & 9.0 & 11.1 & 10. & 30.1 & & & $\mathrm{ABC}$ \\
\hline $671609-7183117$ & & & & & $\mathrm{~A}$ & 02 & $\mathrm{ABC}$ \\
\hline $671585-7183065$ & 3.4 & 3.3 & 3.2 & 9.9 & & & $\mathrm{ABC}$ \\
\hline $671649-7183031$ & 9.5 & 9.7 & 8.3 & 27.5 & & & $\mathrm{ABC}$ \\
\hline $671635-7183030$ & 3.6 & 2.8 & 3.2 & 9.6 & & & $\mathrm{ABC}$ \\
\hline $671616-7183150$ & & & & & $\mathrm{~A}$ & 02 & $\mathrm{ABC}$ \\
\hline $671620-7183170$ & & & & & $\mathrm{~A}$ & 02 & $\mathrm{ABC}$ \\
\hline $671662-7183161$ & & & & & $\mathrm{~A}$ & 02 & $\mathrm{ABC}$ \\
\hline 671595 - 7183175 & & & & & $\mathrm{~A}$ & 02 & $\mathrm{ABC}$ \\
\hline
\end{tabular}




\begin{tabular}{|c|c|c|c|c|c|c|c|c|c|}
\hline & $671620-7183170$ & $671635-7183238$ & & & & & $\mathrm{~A}$ & 02 & $\mathrm{ABC}$ \\
\hline & $671662-7183161$ & $671680-7183157$ & & & & & A & 02 & $\mathrm{ABC}$ \\
\hline & Posto: 82362C1258 & $671635-7183238$ & 5.3 & 6.3 & 4.6 & 16.1 & & & $\mathrm{ABC}$ \\
\hline & $671635-7183238$ & $671645-7183287$ & & & & & $\mathrm{~A}$ & 02 & $\mathrm{ABC}$ \\
\hline & Posto: 82362CA454 & $671680-7183157$ & 6.3 & 7.8 & 6.0 & 20.1 & & & $\mathrm{ABC}$ \\
\hline & $671680-7183157$ & $671697-7183154$ & & & & & $\mathrm{P}$ & $1 \mathrm{C}$ & $A B C$ \\
\hline & $671645-7183287$ & $671653-7183328$ & & & & & $\mathrm{~A}$ & 02 & $\mathrm{ABC}$ \\
\hline & $671645-7183287$ & $671655-7183285$ & & & & & $\mathrm{~A}$ & 02 & $A B C$ \\
\hline & $671645-7183287$ & $671623-7183292$ & & & & & A & 02 & $A B C$ \\
\hline & $671697-7183154$ & $671729-7183147$ & & & & & $\mathrm{P}$ & $1 \mathrm{C}$ & $A B C$ \\
\hline & Posto: 82362C9647 & $671653-7183328$ & 4.3 & 4.7 & 4.6 & 13.6 & & & $\mathrm{ABC}$ \\
\hline & $671623-7183292$ & $671623-7183289$ & & & & & $\mathrm{Z}$ & 01 & $\mathrm{ABC}$ \\
\hline & $671729-7183147$ & $671736-7183146$ & & & & & $\mathrm{P}$ & $1 \mathrm{C}$ & $\mathrm{ABC}$ \\
\hline & Posto: 82362CE443 & $671623-7183289$ & 2.3 & 2.1 & 2.1 & 6.5 & & & $\mathrm{ABC}$ \\
\hline & $671736-7183146$ & $671738-7183156$ & & & & & $\mathrm{P}$ & $1 \mathrm{C}$ & $\mathrm{ABC}$ \\
\hline & $671736-7183146$ & $671732-7183124$ & & & & & $\mathrm{P}$ & $1 \mathrm{C}$ & $\mathrm{ABC}$ \\
\hline & $671736-7183146$ & $671763-7183140$ & & & & & $\mathrm{P}$ & $1 \mathrm{C}$ & $\mathrm{ABC}$ \\
\hline & & Total: & 68.0 & 74.4 & 64. & & & & \\
\hline 8236208139 & Chave: 8236206492 & $671468-7183086$ & & & & & & & \\
\hline & $671468-7183086$ & $671460-7183097$ & & & & & $\mathrm{P}$ & $1 \mathrm{C}$ & $\mathrm{ABC}$ \\
\hline & Posto: 82362CL897 & $671460-7183097$ & 5.9 & 5.9 & 5.9 & 17.6 & & & $\mathrm{ABC}$ \\
\hline & & Total: & 5.9 & 5.9 & 5.9 & & & & \\
\hline 8236210911 & Chave: 8236208952 & $671690-7182921$ & & & & & & & \\
\hline & $671690-7182921$ & $671704-7182930$ & & & & & $\mathrm{P}$ & $1 \mathrm{C}$ & $\mathrm{ABC}$ \\
\hline & Posto: 82362CC293 & $671704-7182930$ & 0.0 & 0.0 & 0.0 & 0.0 & & & $\mathrm{ABC}$ \\
\hline & & Total: & 0.0 & 0.0 & 0.0 & & & & \\
\hline 8236206707 & Chave: 8236207669 & $671669-7182814$ & & & & & & & \\
\hline & $671669-7182814$ & $671683-7182832$ & & & & & $\mathrm{P}$ & $1 \mathrm{C}$ & $\mathrm{ABC}$ \\
\hline & Posto: 82362CM994 & $671683-7182832$ & 5.0 & 5.1 & 5.2 & 15.3 & & & $\mathrm{ABC}$ \\
\hline & & Total: & 5.0 & 5.1 & 5.2 & & & & \\
\hline 8236201573 & Chave: 8236201535 & $671862-7182901$ & & & & & & & \\
\hline & $671862-7182901$ & $671868-7182934$ & & & & & $\mathrm{~A}$ & 02 & $\mathrm{ABC}$ \\
\hline & $671868-7182934$ & $671879-7182986$ & & & & & $\mathrm{~A}$ & 02 & $\mathrm{ABC}$ \\
\hline & Posto: 82362C1365 & $671868-7182934$ & 7.0 & 3.8 & 2.9 & 13.8 & & & $\mathrm{ABC}$ \\
\hline & $671845-7182993$ & $671879-7182986$ & & & & & A & 02 & $\mathrm{ABC}$ \\
\hline & $671879-7182986$ & $671899-7182981$ & & & & & $\mathrm{~A}$ & 02 & $\mathrm{ABC}$ \\
\hline & $671879-7182986$ & $671903-7183114$ & & & & & A & 02 & $\mathrm{ABC}$ \\
\hline & $671845-7182993$ & $671840-7182971$ & & & & & $\mathrm{P}$ & $1 \mathrm{C}$ & $\mathrm{ABC}$ \\
\hline
\end{tabular}




\begin{tabular}{|c|c|c|c|c|c|c|c|c|}
\hline $671787-7183005$ & $671845-7182993$ & & & & & A & 02 & $A B C$ \\
\hline $671845-7182993$ & $671843-7183000$ & & & & & $\mathrm{P}$ & $1 C$ & $\mathrm{ABC}$ \\
\hline $671899-7182981$ & $671956-7182971$ & & & & & $\mathrm{~A}$ & 02 & $A B C$ \\
\hline $671903-7183114$ & $671912-7183153$ & & & & & A & 02 & $A B C$ \\
\hline $671903-7183114$ & $671890-7183117$ & & & & & $\mathrm{~A}$ & 02 & $\mathrm{ABC}$ \\
\hline $671903-7183114$ & $671952-7183106$ & & & & & A & 02 & $A B C$ \\
\hline $671840-7182971$ & $671827-7182910$ & & & & & $\mathrm{P}$ & $1 \mathrm{C}$ & $A B C$ \\
\hline $671762-7183010$ & $671787-7183005$ & & & & & A & 02 & $\mathrm{ABC}$ \\
\hline Posto: $82362 \mathrm{CN} 294$ & $671787-7183005$ & 7.9 & 7.5 & 6.9 & 22.3 & & & $\mathrm{ABC}$ \\
\hline $671843-7183000$ & $671851-7183036$ & & & & & $\mathrm{P}$ & $1 C$ & $\mathrm{ABC}$ \\
\hline Posto: 82362 CA363 & $671956-7182971$ & 7.3 & 8.1 & 8.6 & 24.0 & & & $\mathrm{ABC}$ \\
\hline Posto: 82362C1085 & $671912-7183153$ & 13.1 & 15.1 & 10. & 38.8 & & & $\mathrm{ABC}$ \\
\hline $671912-7183153$ & $671924-7183216$ & & & & & A & 02 & $\mathrm{ABC}$ \\
\hline $671952-7183106$ & $671952-7183089$ & & & & & A & 02 & $A B C$ \\
\hline $671952-7183106$ & $671980-7183100$ & & & & & A & 02 & $\mathrm{ABC}$ \\
\hline Posto: 82362CL149 & $671827-7182910$ & 3.5 & 2.7 & 2.5 & 8.7 & & & $A B C$ \\
\hline $671733-7183017$ & $671762-7183010$ & & & & & A & 02 & $A B C$ \\
\hline $671762-7183010$ & $671774-7182995$ & & & & & $\mathrm{P}$ & $1 C$ & $\mathrm{ABC}$ \\
\hline Posto: 82362CK094 & $671851-7183036$ & 7.5 & 7.7 & 6.5 & 21.7 & & & $A B C$ \\
\hline $671909-7183219$ & $671924-7183216$ & & & & & A & 02 & $A B C$ \\
\hline $671924-7183216$ & $671946-7183211$ & & & & & A & 02 & $A B C$ \\
\hline $671924-7183216$ & $671935-7183272$ & & & & & A & 02 & $A B C$ \\
\hline Posto: $82362 C 7825$ & $671952-7183089$ & 20.0 & 18.5 & 16. & 54.5 & & & ABC \\
\hline $671980-7183100$ & $671996-7183095$ & & & & & A & 02 & $\mathrm{ABC}$ \\
\hline $671980-7183100$ & $671980-7183124$ & & & & & A & 02 & $\mathrm{ABC}$ \\
\hline Posto: 82362C0452 & $671733-7183017$ & 22.7 & 23.0 & 24. & 69.7 & & & $\mathrm{ABC}$ \\
\hline Posto: 82362CC298 & $671774-7182995$ & 0.0 & 0.0 & 0.0 & 0.0 & & & $\mathrm{ABC}$ \\
\hline $671903-7183220$ & $671909-7183219$ & & & & & A & 02 & $\mathrm{ABC}$ \\
\hline $671946-7183211$ & $671974-7183205$ & & & & & $\mathrm{~A}$ & 02 & $\mathrm{ABC}$ \\
\hline $671935-7183272$ & $671937-7183282$ & & & & & $\mathrm{~A}$ & 02 & $\mathrm{ABC}$ \\
\hline $671935-7183272$ & $671946-7183258$ & & & & & Z & 01 & $\mathrm{ABC}$ \\
\hline Posto: 82362CL391 & $671996-7183095$ & 6.0 & 6.0 & 5.4 & 17.4 & & & $\mathrm{ABC}$ \\
\hline Posto: 82362C3767 & $671980-7183124$ & 24.9 & 23.6 & 22. & 71.3 & & & $\mathrm{AB}$ \\
\hline $671903-7183220$ & $671908-7183245$ & & & & & $\mathrm{~A}$ & 02 & $\mathrm{ABC}$ \\
\hline $671876-7183226$ & $671903-7183220$ & & & & & $\mathrm{~A}$ & 02 & $\mathrm{ABC}$ \\
\hline $671903-7183220$ & $671901-7183215$ & & & & & $\mathrm{~A}$ & 02 & $\mathrm{ABC}$ \\
\hline $671974-7183205$ & $671994-7183202$ & & & & & A & 02 & $\mathrm{ABC}$ \\
\hline $671937-7183282$ & $671951-7183279$ & & & & & A & 02 & $\mathrm{ABC}$ \\
\hline $671937-7183282$ & $671941-7183300$ & & & & & $\mathrm{~A}$ & 02 & $\mathrm{ABC}$ \\
\hline Posto: 82362C8876 & $671946-7183258$ & 6.0 & 4.1 & 4.0 & 14.1 & & & $A B$ \\
\hline $671876-7183226$ & $671876-7183229$ & & & & & Z & 01 & $A B$ \\
\hline $671851-7183231$ & $671876-7183226$ & & & & & A & 02 & $\mathrm{AB}$ \\
\hline
\end{tabular}




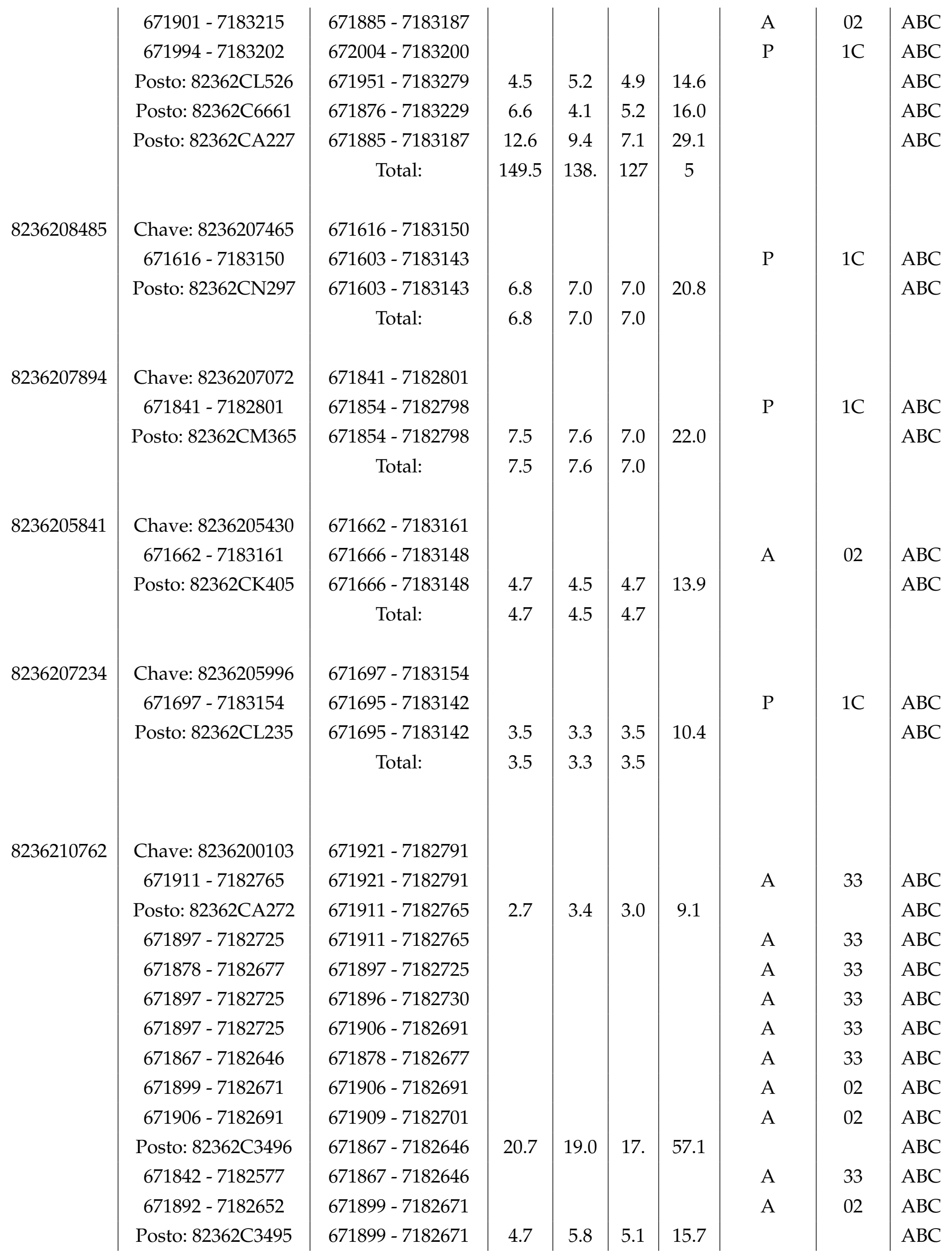




\begin{tabular}{|c|c|c|c|c|c|c|c|c|}
\hline $671909-7182701$ & $671919-7182728$ & & & & & $\mathrm{~A}$ & 02 & $\mathrm{ABC}$ \\
\hline $671839-7182572$ & $671842-7182577$ & & & & & $\mathrm{~A}$ & 33 & $\mathrm{ABC}$ \\
\hline $671842-7182577$ & $671866-7182570$ & & & & & $\mathrm{~A}$ & 33 & $\mathrm{ABC}$ \\
\hline $671840-7182578$ & $671842-7182577$ & & & & & $\mathrm{~A}$ & 33 & $\mathrm{ABC}$ \\
\hline $671856-7182553$ & $671892-7182652$ & & & & & $\mathrm{~A}$ & 02 & $\mathrm{ABC}$ \\
\hline $671919-7182728$ & $671916-7182727$ & & & & & $\mathrm{Z}$ & 01 & $\mathrm{ABC}$ \\
\hline $671919-7182728$ & $671934-7182764$ & & & & & $\mathrm{~A}$ & 02 & $\mathrm{ABC}$ \\
\hline $671833-7182554$ & $671839-7182572$ & & & & & $\mathrm{~A}$ & 33 & $\mathrm{ABC}$ \\
\hline $671866-7182570$ & $671893-7182558$ & & & & & $\mathrm{~A}$ & 33 & $\mathrm{ABC}$ \\
\hline $671812-7182587$ & $671840-7182578$ & & & & & $\mathrm{~A}$ & 02 & $\mathrm{ABC}$ \\
\hline $671850-7182537$ & $671856-7182553$ & & & & & $\mathrm{~A}$ & 02 & $\mathrm{ABC}$ \\
\hline Posto: 82362C7630 & $671916-7182727$ & 7.1 & 6.8 & 7.4 & 21.3 & & & $\mathrm{ABC}$ \\
\hline $671816-7182508$ & $671833-7182554$ & & & & & $\mathrm{~A}$ & 33 & $\mathrm{ABC}$ \\
\hline $671833-7182554$ & $671836-7182554$ & & & & & $\mathrm{Z}$ & 01 & $\mathrm{ABC}$ \\
\hline Posto: 82362C3497 & $671850-7182537$ & 4.3 & 5.4 & 5.3 & 15.0 & & & $\mathrm{ABC}$ \\
\hline $671850-7182537$ & $671846-7182528$ & & & & & $\mathrm{~A}$ & 02 & $\mathrm{ABC}$ \\
\hline Posto: 82362CA928 & $671836-7182554$ & 6.8 & 9.3 & 8.3 & 24.3 & & & $\mathrm{ABC}$ \\
\hline & Total: & 46.3 & 49.6 & 46. & & & & \\
\hline Chave: 8236205404 & $671946-7183211$ & & & & & & & \\
\hline $671946-7183211$ & $671957-7183225$ & & & & & A & 02 & $\mathrm{ABC}$ \\
\hline \multirow[t]{2}{*}{ Posto: $82362 \mathrm{CK} 510$} & $671957-7183225$ & 8.5 & 8.5 & 8.5 & 25.5 & & & $\mathrm{ABC}$ \\
\hline & Total: & 8.5 & 8.5 & 8.5 & & & & \\
\hline Chave: 8236206475 & $671994-7183202$ & & & & & & & \\
\hline $671994-7183202$ & $671996-7183216$ & & & & & $\mathrm{~A}$ & 02 & $\mathrm{ABC}$ \\
\hline \multirow[t]{2}{*}{ Posto: 82362CL777 } & $671996-7183216$ & 12.6 & 12.6 & 12. & 37.5 & & & $\mathrm{ABC}$ \\
\hline & Total: & 12.6 & 12.6 & 12. & & & & \\
\hline Chave: 8236202429 & $671896-7182730$ & & & & & & & \\
\hline \multirow[t]{2}{*}{$671784-7182750$} & $671896-7182730$ & & & & & $\mathrm{~A}$ & 33 & $\mathrm{ABC}$ \\
\hline & Total: & 0.0 & 0.0 & 0.0 & & & & \\
\hline Chave: 8236206061 & $671851-7183231$ & & & & & & & \\
\hline $671851-7183231$ & $671860-7183245$ & & & & & $\mathrm{~A}$ & 02 & $\mathrm{ABC}$ \\
\hline \multirow[t]{2}{*}{ Posto: 82362CL274 } & $671860-7183245$ & 3.0 & 3.3 & 3.0 & 9.2 & & & $\mathrm{ABC}$ \\
\hline & Total: & 3.0 & 3.3 & 3.0 & & & & \\
\hline Chave: 8236207115 & $672004-7183200$ & & & & & & & \\
\hline
\end{tabular}

8236204718

8236202049

8236207415
8236205854

8236202049

671851 - 7183231

Chave: 8236207115 


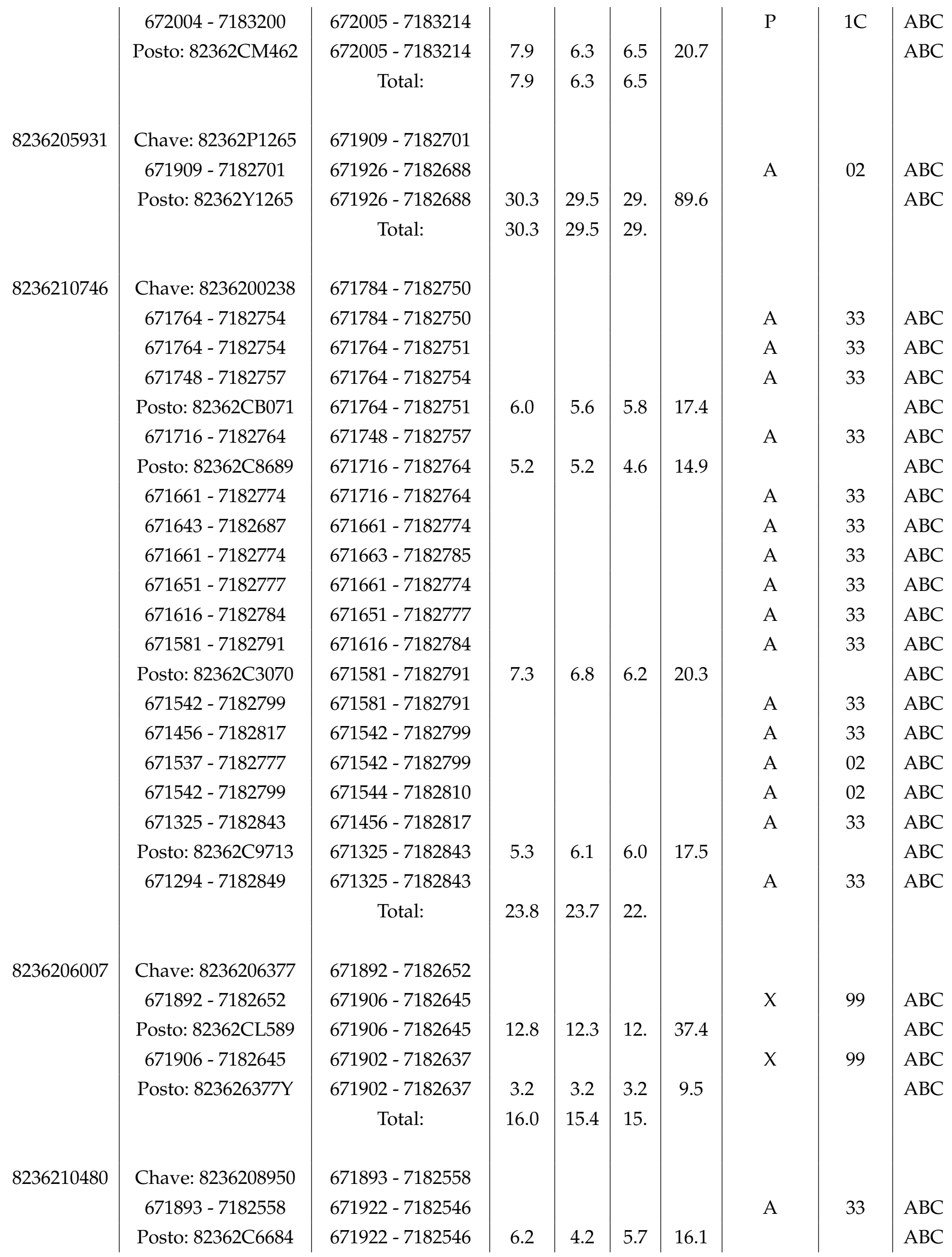




\begin{tabular}{|c|c|c|c|c|c|c|c|c|}
\hline 671922 - 7182546 & $671937-7182538$ & & & & & A & 33 & $\mathrm{ABC}$ \\
\hline $671937-7182538$ & $671975-7182522$ & & & & & $\mathrm{~A}$ & 33 & $\mathrm{ABC}$ \\
\hline $671937-7182538$ & $671943-7182550$ & & & & & $\mathrm{~A}$ & 02 & $\mathrm{ABC}$ \\
\hline $671973-7182513$ & $671975-7182522$ & & & & & $\mathrm{~A}$ & 33 & $\mathrm{ABC}$ \\
\hline $671975-7182522$ & $671987-7182544$ & & & & & A & 33 & $\mathrm{ABC}$ \\
\hline $671975-7182522$ & $671981-7182520$ & & & & & $\mathrm{~A}$ & 33 & $\mathrm{ABC}$ \\
\hline $671987-7182544$ & $672001-7182574$ & & & & & $\mathrm{~A}$ & 33 & $\mathrm{ABC}$ \\
\hline $672001-7182574$ & $672005-7182583$ & & & & & A & 33 & $\mathrm{ABC}$ \\
\hline $672005-7182583$ & $672016-7182607$ & & & & & $\mathrm{~A}$ & 33 & $\mathrm{ABC}$ \\
\hline $672005-7182583$ & $672000-7182586$ & & & & & $\mathrm{Z}$ & 01 & $\mathrm{ABC}$ \\
\hline $672016-7182607$ & $672019-7182616$ & & & & & $\mathrm{~A}$ & 33 & $\mathrm{ABC}$ \\
\hline Posto: 82362C9257 & $672000-7182586$ & 9.6 & 11.5 & 9.3 & 30.3 & & & $\mathrm{ABC}$ \\
\hline $672019-7182616$ & $672031-7182642$ & & & & & $\mathrm{~A}$ & 33 & $\mathrm{ABC}$ \\
\hline Posto: $82362 \mathrm{CM} 880$ & $672031-7182642$ & 10.8 & 12.7 & 9.1 & 32.6 & & & $\mathrm{ABC}$ \\
\hline $672031-7182642$ & $672041-7182669$ & & & & & $\mathrm{P}$ & $3 C$ & $\mathrm{ABC}$ \\
\hline $672041-7182669$ & $672051-7182664$ & & & & & $\mathrm{P}$ & $3 C$ & $\mathrm{ABC}$ \\
\hline $672041-7182669$ & $672031-7182678$ & & & & & $\mathrm{P}$ & $3 C$ & $\mathrm{ABC}$ \\
\hline $672041-7182669$ & $672044-7182674$ & & & & & $\mathrm{P}$ & $3 C$ & $\mathrm{ABC}$ \\
\hline $672051-7182664$ & $672083-7182650$ & & & & & $\mathrm{P}$ & $3 C$ & $\mathrm{ABC}$ \\
\hline \multirow[t]{2}{*}{$672083-7182650$} & $672095-7182645$ & & & & & $\mathrm{P}$ & $3 C$ & $\mathrm{AB}$ \\
\hline & Total: & 26.6 & 28.4 & 24. & & & & \\
\hline Chave: 8236202142 & $671812-7182587$ & & & & & & & \\
\hline $671791-7182590$ & $671812-7182587$ & & & & & A & 02 & $\mathrm{ABC}$ \\
\hline $671752-7182598$ & $671791-7182590$ & & & & & A & 02 & $\mathrm{ABC}$ \\
\hline $671790-7182584$ & $671791-7182590$ & & & & & A & 02 & $\mathrm{ABC}$ \\
\hline $671791-7182590$ & $671806-7182647$ & & & & & A & 02 & $\mathrm{ABC}$ \\
\hline Posto: 82362C1379 & $671752-7182598$ & 4.9 & 5.2 & 5.5 & 15.5 & & & $\mathrm{ABC}$ \\
\hline \multirow[t]{2}{*}{ Posto: 82362CE067 } & $671806-7182647$ & 5.7 & 6.1 & 6.3 & 18.1 & & & $\mathrm{ABC}$ \\
\hline & Total: & 10.6 & 11.3 & 11. & & & & \\
\hline Chave: 8236202053 & $671748-7182757$ & & & & & & & \\
\hline $671748-7182757$ & $671736-7182696$ & & & & & A & 02 & $\mathrm{ABC}$ \\
\hline \multirow[t]{2}{*}{ Posto: 82362CA249 } & $671736-7182696$ & 7.3 & 9.7 & 6.8 & 23.8 & & & $\mathrm{ABC}$ \\
\hline & Total: & 7.3 & 9.7 & 6.8 & & & & \\
\hline Chave: $82362 \mathrm{P} 1391$ & $671943-7182550$ & & & & & & & \\
\hline $671943-7182550$ & $671949-7182560$ & & & & & A & 02 & $\mathrm{ABC}$ \\
\hline \multirow[t]{2}{*}{ Posto: 82362Y1391 } & $671949-7182560$ & 25.2 & 25.2 & 25. & 75.8 & & & $\mathrm{ABC}$ \\
\hline & Total: & 25.2 & 25.2 & 25. & & & & \\
\hline Chave: 8236200790 & $671643-7182687$ & & & & & & & \\
\hline
\end{tabular}




\begin{tabular}{|c|c|c|c|c|c|c|c|c|}
\hline $671636-7182653$ & $671643-7182687$ & & & & & $\mathrm{~A}$ & 33 & $\mathrm{ABC}$ \\
\hline Posto: 82362CL074 & $671636-7182653$ & 9.4 & 9.6 & 8.8 & 27.7 & & & $\mathrm{ABC}$ \\
\hline $671618-7182563$ & $671636-7182653$ & & & & & $\mathrm{~A}$ & 33 & \\
\hline $671618-7182563$ & $671614-7182543$ & & & & & $\mathrm{~A}$ & 33 & \\
\hline $671599-7182475$ & $671614-7182543$ & & & & & $\mathrm{~A}$ & 33 & $\mathrm{AB}$ \\
\hline $671588-7182423$ & $671599-7182475$ & & & & & $\mathrm{~A}$ & 33 & $\mathrm{AB}$ \\
\hline Posto: 82362CK725 & $671599-7182475$ & 4.4 & 4.0 & 3.2 & 11.6 & & & $\mathrm{AB}$ \\
\hline $671588-7182423$ & $671659-7182408$ & & & & & $\mathrm{~A}$ & 33 & $B$ \\
\hline $671659-7182408$ & $671697-7182396$ & & & & & $\mathrm{~A}$ & 33 & $\mathrm{~B}$ \\
\hline $671697-7182396$ & $671714-7182387$ & & & & & $\mathrm{~A}$ & 33 & $A B C$ \\
\hline $671714-7182387$ & $671735-7182377$ & & & & & $\mathrm{~A}$ & 33 & $A B C$ \\
\hline $671735-7182377$ & $671754-7182376$ & & & & & $\mathrm{~A}$ & 33 & $A B C$ \\
\hline $671730-7182344$ & $671754-7182376$ & & & & & $\mathrm{~A}$ & 33 & $A B C$ \\
\hline $671754-7182376$ & $671770-7182398$ & & & & & $\mathrm{~A}$ & 33 & $A B C$ \\
\hline $671713-7182322$ & $671730-7182344$ & & & & & $\mathrm{~A}$ & 33 & $A B C$ \\
\hline $671770-7182398$ & $671780-7182414$ & & & & & $\mathrm{~A}$ & 33 & $\mathrm{ABC}$ \\
\hline $671691-7182292$ & $671713-7182322$ & & & & & $\mathrm{~A}$ & 33 & $\mathrm{ABC}$ \\
\hline $671780-7182414$ & $671797-7182452$ & & & & & $\mathrm{~A}$ & 33 & $\mathrm{ABC}$ \\
\hline $671676-7182272$ & $671691-7182292$ & & & & & $\mathrm{~A}$ & 33 & $\mathrm{ABC}$ \\
\hline $671691-7182292$ & $671663-7182315$ & & & & & $\mathrm{~A}$ & 02 & $\mathrm{ABC}$ \\
\hline $671797-7182452$ & $671816-7182508$ & & & & & $\mathrm{~A}$ & 33 & $\mathrm{ABC}$ \\
\hline $671797-7182452$ & $671800-7182452$ & & & & & $\mathrm{Z}$ & 01 & $\mathrm{ABC}$ \\
\hline Posto: 82362C3498 & $671676-7182272$ & 5.7 & 5.7 & 6.2 & 17.6 & & & $\mathrm{ABC}$ \\
\hline $671659-7182250$ & $671676-7182272$ & & & & & $\mathrm{~A}$ & 33 & $\mathrm{ABC}$ \\
\hline Posto: 82362C6467 & $671800-7182452$ & 2.7 & 2.7 & 1.8 & 7.2 & & & $\mathrm{ABC}$ \\
\hline $671639-7182222$ & $671659-7182250$ & & & & & $\mathrm{~A}$ & 33 & $\mathrm{ABC}$ \\
\hline 671615 - 7182190 & $671639-7182222$ & & & & & $\mathrm{~A}$ & 33 & $\mathrm{AB}$ \\
\hline $671602-7182173$ & $671615-7182190$ & & & & & $\mathrm{~A}$ & 33 & $\mathrm{ABC}$ \\
\hline $671615-7182190$ & $671618-7182190$ & & & & & $\mathrm{Z}$ & 01 & $\mathrm{ABC}$ \\
\hline $671584-7182151$ & $671602-7182173$ & & & & & $\mathrm{~A}$ & 33 & $\mathrm{AB}$ \\
\hline Posto: 82362C3499 & $671602-7182173$ & 5.3 & 2.7 & 4.1 & 12.1 & & & $\mathrm{ABC}$ \\
\hline Posto: 82362C1612 & $671618-7182190$ & 17.8 & 15.4 & 17. & 50.6 & & & $\mathrm{AB}$ \\
\hline $671572-7182123$ & $671584-7182151$ & & & & & $\mathrm{~A}$ & 33 & $\mathrm{ABC}$ \\
\hline $671584-7182151$ & $671587-7182150$ & & & & & $\mathrm{~A}$ & 02 & $\mathrm{ABC}$ \\
\hline $671568-7182111$ & $671572-7182123$ & & & & & $\mathrm{~A}$ & 33 & $\mathrm{ABC}$ \\
\hline Posto: $82362 \mathrm{CM} 987$ & $671587-7182150$ & 11.8 & 12.7 & 12. & 36.7 & & & $\mathrm{AB}$ \\
\hline $671560-7182086$ & $671568-7182111$ & & & & & $\mathrm{~A}$ & 33 & $\mathrm{AB}$ \\
\hline $671550-7182058$ & $671560-7182086$ & & & & & $\mathrm{~A}$ & 33 & $\mathrm{AB}$ \\
\hline $671560-7182086$ & $671585-7182079$ & & & & & $\mathrm{~A}$ & 33 & $\mathrm{AB}$ \\
\hline & Total: & 57.0 & 52.7 & 53. & & & & \\
\hline Chave: 8236202714 & $671973-7182513$ & & & & & & & \\
\hline
\end{tabular}




\begin{tabular}{|c|c|c|c|c|c|c|c|c|}
\hline $671960-7182484$ & $671973-7182513$ & & & & & $\mathrm{P}$ & $1 \mathrm{C}$ & $\mathrm{ABC}$ \\
\hline 671937 - 7182433 & $671960-7182484$ & & & & & $\mathrm{P}$ & $1 C$ & $\mathrm{ABC}$ \\
\hline $671930-7182408$ & $671937-7182433$ & & & & & $\mathrm{P}$ & $1 C$ & $\mathrm{ABC}$ \\
\hline $671930-7182408$ & $671934-7182365$ & & & & & $\mathrm{P}$ & $1 \mathrm{C}$ & $\mathrm{ABC}$ \\
\hline 671910 - 7182399 & $671934-7182365$ & & & & & $\mathrm{~A}$ & 02 & $\mathrm{ABC}$ \\
\hline $671934-7182365$ & 671952 - 7182339 & & & & & A & 02 & $\mathrm{ABC}$ \\
\hline 671910 - 7182399 & $671904-7182369$ & & & & & $\mathrm{P}$ & $1 \mathrm{C}$ & $\mathrm{ABC}$ \\
\hline $671884-7182438$ & $671910-7182399$ & & & & & A & 02 & $\mathrm{ABC}$ \\
\hline $671904-7182369$ & $671913-7182364$ & & & & & $\mathrm{P}$ & $1 \mathrm{C}$ & $\mathrm{ABC}$ \\
\hline $671876-7182449$ & $671884-7182438$ & & & & & $\mathrm{~A}$ & 02 & $\mathrm{ABC}$ \\
\hline $671913-7182364$ & $671894-7182368$ & & & & & $\mathrm{~J}$ & 40 & $\mathrm{ABC}$ \\
\hline 671859 - 7182474 & $671876-7182449$ & & & & & $\mathrm{~A}$ & 02 & $\mathrm{ABC}$ \\
\hline Posto: $82362 \mathrm{CM} 333$ & $671894-7182368$ & 38.7 & 38.7 & 38. & 116. & & & $\mathrm{ABC}$ \\
\hline $671894-7182368$ & $671894-7182374$ & & & & & $\mathrm{~J}$ & 40 & $\mathrm{ABC}$ \\
\hline Posto: 82362C6082 & $671859-7182474$ & 0.1 & 0.3 & 0.3 & 0.7 & & & $\mathrm{ABC}$ \\
\hline $671859-7182474$ & $671853-7182482$ & & & & & $\mathrm{~A}$ & 02 & $\mathrm{ABC}$ \\
\hline \multirow[t]{2}{*}{ Posto: $823627185 Y$} & $671894-7182374$ & 0.0 & 0.0 & 0.0 & 0.0 & & & $\mathrm{ABC}$ \\
\hline & Total: & 38.9 & 39.0 & 39. & & & & \\
\hline Chave: 8236209032 & $671616-7182784$ & & & & & & & \\
\hline $671616-7182784$ & $671611-7182773$ & & & & & $\mathrm{P}$ & $1 \mathrm{C}$ & $\mathrm{ABC}$ \\
\hline $671611-7182773$ & $671613-7182774$ & & & & & $\mathrm{Z}$ & 01 & $\mathrm{ABC}$ \\
\hline \multirow[t]{2}{*}{ Posto: 82362L0020 } & $671611-7182773$ & 0.0 & 0.0 & 0.0 & 0.0 & & & $\mathrm{ABC}$ \\
\hline & Total: & 0.0 & 0.0 & 0.0 & & & & \\
\hline Chave: $82362 \mathrm{P} 1264$ & $672001-7182574$ & & & & & & & \\
\hline $672001-7182574$ & $671977-7182576$ & & & & & $\mathrm{~A}$ & 02 & $\mathrm{ABC}$ \\
\hline \multirow[t]{2}{*}{ Posto: 82362Y1264 } & $671977-7182576$ & 9.1 & 9.1 & 9.0 & 27.2 & & & $\mathrm{ABC}$ \\
\hline & Total: & 9.1 & 9.1 & 9.0 & & & & \\
\hline Chave: 82362P0194 & $671960-7182484$ & & & & & & & \\
\hline $671960-7182484$ & $671942-7182487$ & & & & & $\mathrm{P}$ & $1 C$ & $\mathrm{ABC}$ \\
\hline \multirow[t]{2}{*}{ Posto: 82362Y0194 } & $671942-7182487$ & 8.2 & 8.2 & 8.2 & 24.6 & & & $\mathrm{ABC}$ \\
\hline & Total: & 8.2 & 8.2 & 8.2 & & & & \\
\hline Chave: 82362P1284 & $672016-7182607$ & & & & & & & \\
\hline $672016-7182607$ & $671997-7182620$ & & & & & A & 02 & $\mathrm{ABC}$ \\
\hline \multirow[t]{2}{*}{ Posto: $82362 Y 1284$} & $671997-7182620$ & 40.6 & 40.6 & 40. & 121. & & & $\mathrm{ABC}$ \\
\hline & Total: & 40.6 & 40.6 & 40. & & & & \\
\hline Chave: 8236201383 & $671537-7182777$ & & & & & & & \\
\hline $671524-7182720$ & $671537-7182777$ & & & & & $\mathrm{~A}$ & 02 & $\mathrm{ABC}$ \\
\hline
\end{tabular}




\begin{tabular}{|c|c|c|c|c|c|c|c|c|c|}
\hline & $671512-7182651$ & $671524-7182720$ & & & & & A & 02 & $\mathrm{ABC}$ \\
\hline & $671470-7182733$ & $671524-7182720$ & & & & & A & 02 & $\mathrm{ABC}$ \\
\hline & $671524-7182720$ & $671596-7182706$ & & & & & A & 02 & $\mathrm{ABC}$ \\
\hline & $671487-7182656$ & $671512-7182651$ & & & & & A & 02 & $\mathrm{ABC}$ \\
\hline & $671498-7182592$ & $671512-7182651$ & & & & & A & 02 & $A B C$ \\
\hline & $671512-7182651$ & $671521-7182649$ & & & & & A & 02 & $\mathrm{ABC}$ \\
\hline & Posto: 82362C9826 & $671470-7182733$ & 3.8 & 4.8 & 3.8 & 12.4 & & & $\mathrm{ABC}$ \\
\hline & $671470-7182733$ & $671441-7182738$ & & & & & A & 02 & $\mathrm{ABC}$ \\
\hline & Posto: $82362 \mathrm{C} 1871$ & $671596-7182706$ & 8.0 & 9.3 & 7.8 & 25.1 & & & $\mathrm{ABC}$ \\
\hline & $671596-7182706$ & $671629-7182700$ & & & & & A & 02 & $A B C$ \\
\hline & Posto: $82362 \mathrm{C} 1289$ & $671487-7182656$ & 15.3 & 11.5 & 10. & 37.7 & & & $\mathrm{ABC}$ \\
\hline & $671418-7182670$ & $671487-7182656$ & & & & & A & 02 & $\mathrm{ABC}$ \\
\hline & $671492-7182565$ & $671498-7182592$ & & & & & A & 02 & $\mathrm{ABC}$ \\
\hline & $671441-7182738$ & $671408-7182745$ & & & & & A & 02 & $\mathrm{ABC}$ \\
\hline & Posto: $82362 \mathrm{C} 1283$ & $671418-7182670$ & 10.2 & 12.5 & 10. & 32.8 & & & $\mathrm{ABC}$ \\
\hline & $671385-7182677$ & $671418-7182670$ & & & & & A & 02 & $\mathrm{ABC}$ \\
\hline & $671490-7182557$ & $671492-7182565$ & & & & & A & 02 & $\mathrm{ABC}$ \\
\hline & $671488-7182544$ & $671490-7182557$ & & & & & A & 02 & $\mathrm{ABC}$ \\
\hline & $671490-7182557$ & $671501-7182552$ & & & & & $\mathrm{P}$ & $1 \mathrm{C}$ & $A B C$ \\
\hline & $671490-7182557$ & $671468-7182569$ & & & & & $\mathrm{P}$ & $1 C$ & $\mathrm{ABC}$ \\
\hline & $671476-7182488$ & $671488-7182544$ & & & & & A & 02 & $\mathrm{ABC}$ \\
\hline & $671501-7182552$ & $671536-7182545$ & & & & & $\mathrm{P}$ & 1C & $A B C$ \\
\hline & $671468-7182569$ & $671432-7182576$ & & & & & $\mathrm{P}$ & $1 \mathrm{C}$ & $\mathrm{ABC}$ \\
\hline & Posto: 82362 CB072 & $671476-7182488$ & 7.6 & 6.0 & 6.1 & 19.7 & & & $A B C$ \\
\hline & $671461-7182416$ & $671476-7182488$ & & & & & A & 02 & $\mathrm{ABC}$ \\
\hline & Posto: $82362 \mathrm{CM} 590$ & $671536-7182545$ & 12.5 & 13.7 & 9.0 & 35.1 & & & $\mathrm{ABC}$ \\
\hline & Posto: $82362 \mathrm{CM} 307$ & $671432-7182576$ & 11.6 & 11.4 & 12. & 35.0 & & & $A B C$ \\
\hline & $671461-7182416$ & $671457-7182390$ & & & & & A & 02 & $\mathrm{ABC}$ \\
\hline & $671457-7182390$ & $671452-7182355$ & & & & & $\mathrm{P}$ & 1C & $\mathrm{ABC}$ \\
\hline & Posto: 82362CL990 & $671452-7182355$ & 15.1 & 11.3 & 11. & 38.0 & & & $\mathrm{ABC}$ \\
\hline & & Total: & 84.2 & 80.5 & 71. & & & & \\
\hline 8236209062 & Chave: 8236208470 & $672019-7182616$ & & & & & & & \\
\hline & $672019-7182616$ & $672008-7182628$ & & & & & $\mathrm{Z}$ & 01 & $A B C$ \\
\hline & Posto: 82362C5059 & $672008-7182628$ & 7.9 & 7.9 & 7.9 & 23.7 & & & $\mathrm{ABC}$ \\
\hline & & Total: & 7.9 & 7.9 & 7.9 & & & & \\
\hline 8236206680 & Chave: 8236205500 & $671952-7182339$ & & & & & & & \\
\hline & $671952-7182339$ & $671969-7182314$ & & & & & A & 02 & $\mathrm{ABC}$ \\
\hline & Posto: 82362C5057 & $671969-7182314$ & 4.1 & 5.0 & 3.5 & 12.6 & & & $\mathrm{ABC}$ \\
\hline & $671969-7182314$ & $672017-7182244$ & & & & & A & 02 & $\mathrm{ABC}$ \\
\hline & 672017 - 7182244 & $672036-7182216$ & & & & & A & 02 & $\mathrm{ABC}$ \\
\hline
\end{tabular}


8236206336

8236204906

8236208368

8236204650

8236200479

\begin{abstract}
672036 - 7182216
672036 - 7182216

672054 - 7182191

Posto: 82362CE492

672075 - 7182165

$672101-7182151$

672101 - 7182151
\end{abstract}

Posto: 82362C8933

Chave: 82362P1639

671884 - 7182438

Posto: 82362Y1639

Chave: 82362P0517

671697 - 7182396

Posto: 82362Y0517

Chave: 8236207185

671905 - 7182356

Posto: 82362CA578

Chave: 82362P0260

671876 - 7182449

Posto: 82362Y0260

Chave: 8236201382 671277 - 7182795

Posto: 82362C8236 671272 - 7182771

671248 - 7182659

671233 - 7182590

Posto: 82362C1247

671214 - 7182495

Posto: 82362C9264

Chave: 8236205833
672054 - 7182191

672040 - 7182216

672075 - 7182165

672040 - 7182216

$672101-7182151$

672147 - 7182132

672127 - 7182214

672127 - 7182214

Total:

671884 - 7182438

671900 - 7182446

671900 - 7182446

Total:

671697 - 7182396

$671682-7182362$

671682 - 7182362

Total:

671913 - 7182364

$671904-7182369$

671905 - 7182356

Total:

671876 - 7182449 671849 - 7182431

671849 - 7182431

Total:

671270 - 7182833 671270 - 7182833

671277 - 7182795 671277 - 7182795 671272 - 7182771 671248 - 7182659 671233 - 7182590 671233 - 7182590 671214 - 7182495

Total:

\begin{tabular}{|c|c|c|c|c|c|c|}
\hline \multirow{7}{*}{7.3} & & & & A & 02 & $\mathrm{ABC}$ \\
\hline & & & & Z & 01 & $\mathrm{ABC}$ \\
\hline & & & & A & 02 & $\mathrm{ABC}$ \\
\hline & 7.7 & 7.0 & 22.0 & & & $\mathrm{ABC}$ \\
\hline & & & & A & 02 & $\mathrm{ABC}$ \\
\hline & & & & A & 02 & $A B C$ \\
\hline & & & & A & 02 & $\mathrm{ABC}$ \\
\hline 15.5 & 14.3 & 13. & 43.4 & & & \\
\hline
\end{tabular}

A

\begin{tabular}{l|l|l|l}
2.7 & 2.7 & 2.7 & 8.2
\end{tabular}

2.7

2.7

2.7

0.0

0.0

\begin{tabular}{l|l|l}
0.0 & 0.0 & 0.0
\end{tabular}

0.0

0.0

5.0

5.0

2.7

2.7

2.7

8.2

2.7

2.7

5.5

15.4

P

A

02

4.4

5.3

4.9

14.6

A

A

A

A

8.6

8.6

8.6

25.8

2.4

2.

2.7

7.4

15.4

16.2

16.

02

$1 C$

02

$\mathrm{ABC}$

$\mathrm{ABC}$

$A B C$

$A B C$

$\mathrm{ABC}$

$A B C$

$\mathrm{ABC}$

$\mathrm{ABC}$

$671408-7182745$ 


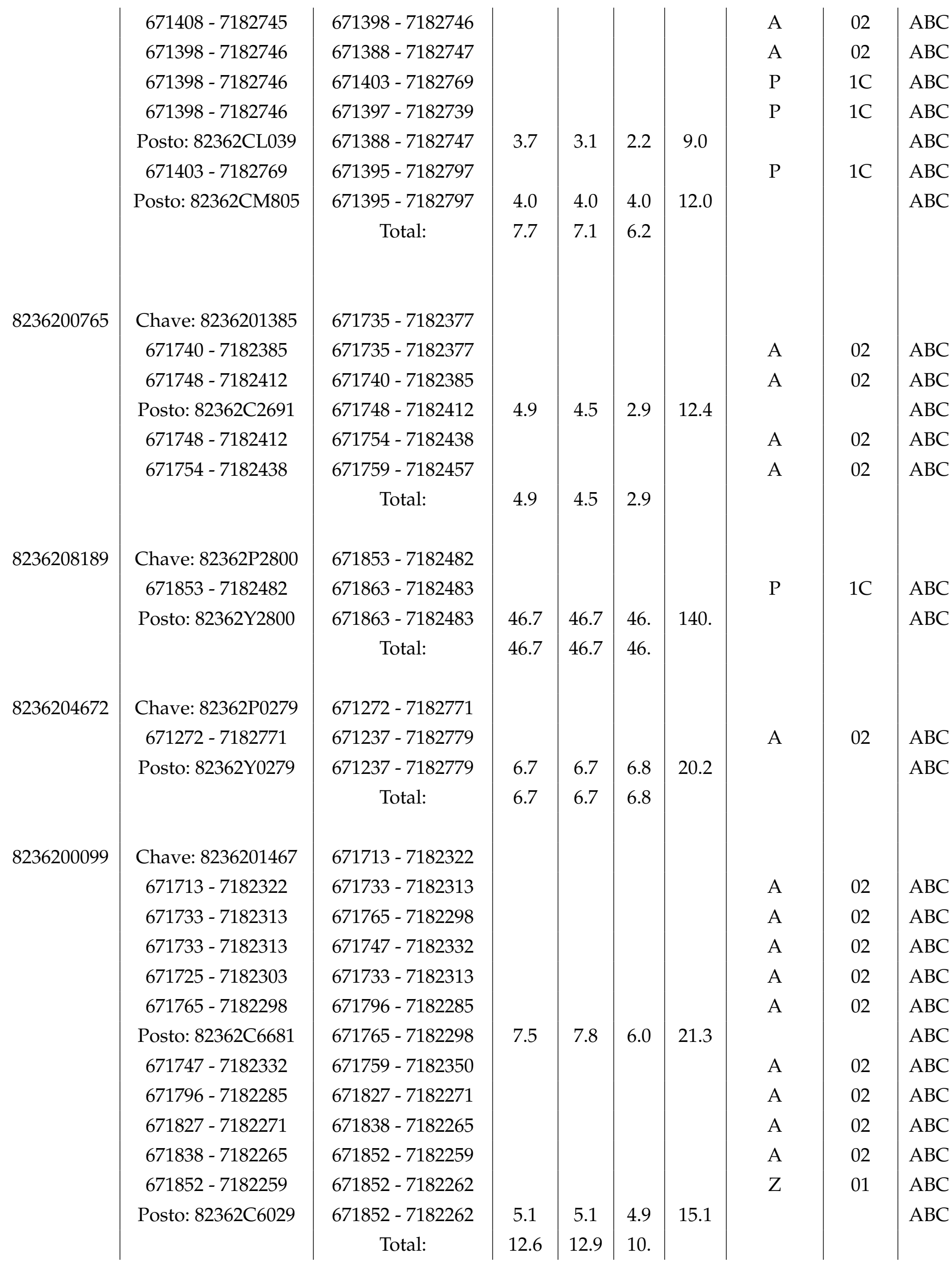




$8236200286 \quad \begin{gathered} \\ \text { Chave: } 8236201381 \\ 671149-7182828 \\ \text { Posto: } 82362 \text { CJ744 } \\ 671135-7182768 \\ 671110-7182644 \\ \text { Posto: } 82362 C 1244 \\ 671110-7182644 \\ 671104-7182612 \\ 671099-7182586 \\ \text { Posto: } 82362 C C 340\end{gathered}$

8236204671

8236204675

8236203599

8236200192
Chave: 82362P0283 671754 - 7182438

Posto: 82362Y0283

Chave: 8236203000 671048 - 7182815

Posto: 82362CN016 $671044-7182788$ 671039 - 7182767 $671039-7182767$ $671012-7182636$ 671016 - 7182772

Posto: 82362C0425 670986 - 7182779 $670956-7182785$ $670986-7182779$ 670925 - 7182791

Posto: 82362C5718

Chave: 8236201647 671636 - 7182338 $671587-7182382$
671155 - 7182858 $671155-7182858$ $671149-7182828$ $671149-7182828$ $671135-7182768$ 671110 - 7182644 $671104-7182612$ $671099-7182586$ $671072-7182591$ 671072 - 7182591 Total:

671248 - 7182659 $671287-7182651$ 671287 - 7182651 Total:

671754 - 7182438 $671728-7182443$ 671728 - 7182443

Total:

671061 - 7182877 671061 - 7182877 $671048-7182815$ $671048-7182815$ $671044-7182788$ $671048-7182765$ $671039-7182767$ $671039-7182767$ $671012-7182636$ $671016-7182772$ 670986 - 7182779 670986 - 7182782 $670956-7182785$ 670986 - 7182782 Total:

$671663-7182315$ $671663-7182315$ $671636-7182338$
A

02

\begin{tabular}{|l|l|l|l|}
\hline 1.3 & 1.3 & 1.3 & 3.9 \\
\hline
\end{tabular}

A

A

\begin{tabular}{|l|l|l|l|}
\hline 7.5 & 7.4 & 8.1 & 23.0 \\
\hline
\end{tabular}

P

$P$

$P$

\begin{tabular}{|l|l|l|l|}
\hline 2.4 & 1.6 & 0.7 & 4.6 \\
\hline
\end{tabular}

\begin{tabular}{l|l|l}
11.2 & 10.3 & 10.
\end{tabular}

A

10.8

10.8

0.0

0.0

10.8

10.8

0.0

0.0

27.5

23.9

14. 66.2 23.9

14.

A

02

$\mathrm{ABC}$

$A B C$

A

3.7

11.6

\begin{tabular}{l}
$3.3 \quad 4.6$ \\
\hline
\end{tabular}

02

$\mathrm{ABC}$ $A B C$ A

A

A

A

A

11.7

12.3

12.

36.0

02

$\mathrm{ABC}$

02

$\mathrm{ABC}$ 02

$A B C$

02

$A B C$

02

$A B C$

$A B C$

A

02

$\mathrm{ABC}$

A

Z

A

02

$A B C$

01

$\mathrm{ABC}$

02

$\mathrm{ABC}$

9.6

\begin{tabular}{l|l|l}
18.2 & 20.1 & 18.
\end{tabular}

$\mathrm{ABC}$

A

02

$\mathrm{ABC}$

A

02

$\mathrm{ABC}$ 


\begin{tabular}{|c|c|c|c|c|c|c|c|c|c|}
\hline & Posto: 82362C6846 & $671636-7182338$ & 10.7 & 14.9 & 12. & 38.2 & & & $\mathrm{ABC}$ \\
\hline & $671556-7182360$ & $671587-7182382$ & & & & & A & 02 & $\mathrm{ABC}$ \\
\hline & $671587-7182382$ & $671614-7182403$ & & & & & A & 02 & $\mathrm{ABC}$ \\
\hline & Posto: $82362 C 1377$ & $671556-7182360$ & 9.2 & 8.8 & 7.7 & 25.8 & & & $\mathrm{ABC}$ \\
\hline & $671497-7182316$ & $671556-7182360$ & & & & & A & 02 & $\mathrm{ABC}$ \\
\hline & $671497-7182316$ & $671505-7182305$ & & & & & $\mathrm{Z}$ & 01 & $\mathrm{ABC}$ \\
\hline & $671452-7182279$ & $671497-7182316$ & & & & & $\mathrm{~A}$ & 02 & $\mathrm{ABC}$ \\
\hline & Posto: $82362 C 1378$ & $671505-7182305$ & 12.4 & 12.9 & 10. & 35.9 & & & $\mathrm{ABC}$ \\
\hline & $671434-7182260$ & $671452-7182279$ & & & & & $\mathrm{~A}$ & 02 & $\mathrm{ABC}$ \\
\hline & $671426-7182245$ & $671434-7182260$ & & & & & $\mathrm{~A}$ & 02 & $\mathrm{ABC}$ \\
\hline & $671414-7182247$ & $671426-7182245$ & & & & & $\mathrm{~A}$ & 02 & $\mathrm{ABC}$ \\
\hline & $671411-7182204$ & $671426-7182245$ & & & & & $\mathrm{~A}$ & 02 & $\mathrm{ABC}$ \\
\hline & $671426-7182245$ & $671441-7182241$ & & & & & A & 02 & $\mathrm{ABC}$ \\
\hline & $671414-7182247$ & $671421-7182266$ & & & & & $\mathrm{~A}$ & 02 & $\mathrm{ABC}$ \\
\hline & $671374-7182256$ & $671414-7182247$ & & & & & $\mathrm{~A}$ & 02 & $\mathrm{ABC}$ \\
\hline & $671411-7182204$ & $671395-7182128$ & & & & & $\mathrm{P}$ & $1 \mathrm{C}$ & $\mathrm{ABC}$ \\
\hline & Posto: 82362 C9328 & $671411-7182204$ & 5.5 & 5.5 & 5.3 & 16.2 & & & $\mathrm{ABC}$ \\
\hline & $671421-7182266$ & $671428-7182304$ & & & & & A & 02 & $\mathrm{ABC}$ \\
\hline & $671339-7182263$ & $671374-7182256$ & & & & & $\mathrm{~A}$ & 02 & $\mathrm{ABC}$ \\
\hline & Posto: $82362 C 3576$ & $671374-7182256$ & 9.9 & 13.3 & 8.4 & 31.6 & & & $\mathrm{ABC}$ \\
\hline & $671395-7182128$ & $671387-7182120$ & & & & & $\mathrm{P}$ & $1 \mathrm{C}$ & $\mathrm{ABC}$ \\
\hline & Posto: $82362 \mathrm{CK} 183$ & $671428-7182304$ & 9.2 & 8.7 & 7.9 & 25.8 & & & $\mathrm{ABC}$ \\
\hline & $671339-7182263$ & $671356-7182271$ & & & & & $\mathrm{~A}$ & 02 & $\mathrm{ABC}$ \\
\hline & $671387-7182120$ & $671361-7182152$ & & & & & $\mathrm{P}$ & $1 \mathrm{C}$ & $\mathrm{ABC}$ \\
\hline & Posto: $82362 C 3575$ & $671356-7182271$ & 5.1 & 7.1 & 5.6 & 17.8 & & & $\mathrm{ABC}$ \\
\hline & Posto: $82362 \mathrm{CJ} 704$ & $671361-7182152$ & 4.9 & 4.4 & 4.4 & 13.8 & & & $\mathrm{ABC}$ \\
\hline & & Total: & 66.9 & 75.7 & 62. & & & & \\
\hline 8236205534 & Chave: $82362 \mathrm{P} 2663$ & $670982-7182913$ & & & & & & & \\
\hline & $670982-7182913$ & $670982-7182931$ & & & & & $\mathrm{~A}$ & 02 & $\mathrm{ABC}$ \\
\hline & Posto: 82362 Y2663 & $670982-7182931$ & 12.8 & 12.8 & 12. & 38.5 & & & $\mathrm{ABC}$ \\
\hline & & Total: & 12.8 & 12.8 & 12. & & & & \\
\hline 8236207450 & Chave: 8236206325 & $671075-7182935$ & & & & & & & \\
\hline & 671075 - 7182935 & 671079 - 7182958 & & & & & $\mathrm{P}$ & $1 \mathrm{C}$ & $\mathrm{ABC}$ \\
\hline & $671079-7182958$ & $671080-7182965$ & & & & & $\mathrm{P}$ & $1 \mathrm{C}$ & $\mathrm{ABC}$ \\
\hline & Posto: 82362CL644 & $671079-7182958$ & 2.5 & 2.7 & 3.3 & 8.5 & & & $\mathrm{ABC}$ \\
\hline & & Total: & 2.5 & 2.7 & 3.3 & & & & \\
\hline 8236202723 & Chave: 82362 P3009 & $671659-7182250$ & & & & & & & \\
\hline & $671659-7182250$ & $671641-7182260$ & & & & & $\mathrm{P}$ & $1 \mathrm{C}$ & $\mathrm{ABC}$ \\
\hline & Posto: 82362Y3009 & $671641-7182260$ & 12.2 & 12.2 & 12. & 36.6 & & & $\mathrm{ABC}$ \\
\hline
\end{tabular}


8236207289

8236211328

8236211253

8236200893

8236207451

Chave: 8236206223

671080 - 7182965

Posto: 82362CL321

Chave: 8236210098 $671796-7182285$

Posto: 82362CC724

Chave: 8236209998

671759 - 7182350

$671766-7182346$

Posto: 82362CCC06

Chave: 8236201380 670932 - 7182875

670915 - 7182794

670907 - 7182751

670915 - 7182794

670915 - 7182794

Posto: $82362 C 0760$

670900 - 7182720

670900 - 7182720

Posto: 82362CE325

670820 - 7182789

Posto: 82362CL466

670833 - 7182754

$670835-7182748$

$670835-7182748$

$670835-7182748$

8236211254

Chave: 82362PART6
$670812-7182814$
Total:

671639 - 7182222

671659 - 7182204

Total:

671796 - 7182285

671805 - 7182292

671805 - 7182292

Total:

671759 - 7182350

671766 - 7182346

671762 - 7182340

671762 - 7182340

Total:

670937 - 7182902

670937 - 7182902

670932 - 7182875

670915 - 7182794

670925 - 7182791

670812 - 7182814

670907 - 7182751

670907 - 7182751

$670820-7182789$

$670904-7182690$

670820 - 7182789

$670833-7182754$

$670904-7182690$

670835 - 7182748

670843 - 7182751

670842 - 7182723

670800 - 7182736

Total:

671080 - 7182965

671071 - 7182984

671071 - 7182984

Total:

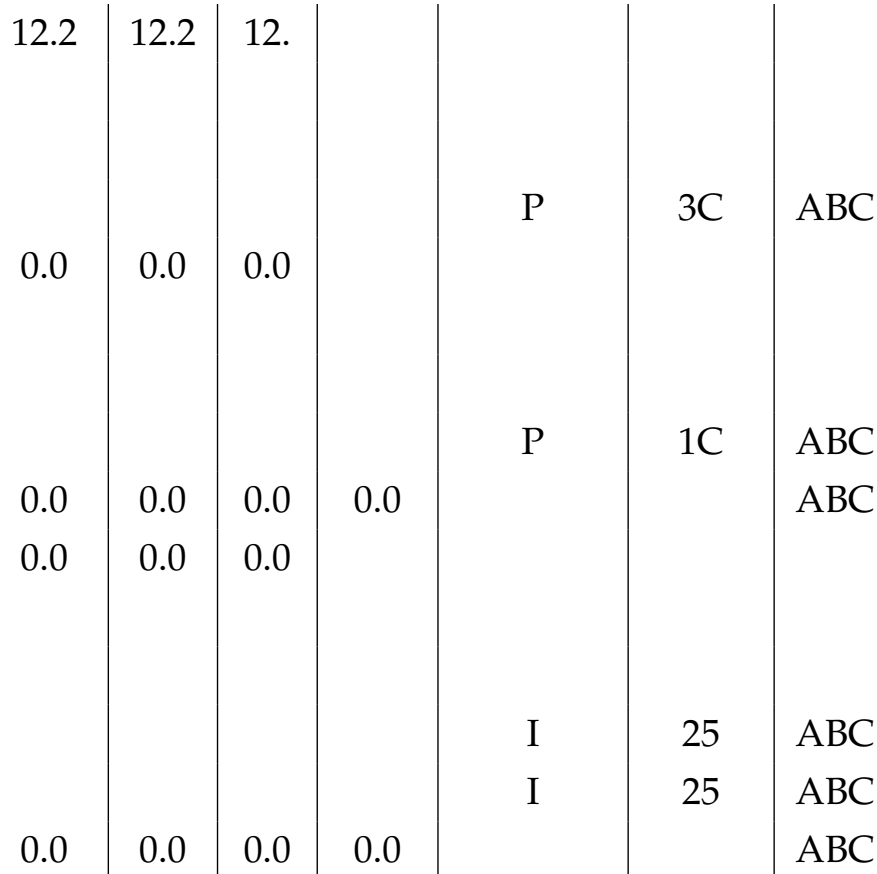

A

02

$\mathrm{ABC}$

A

A

A

A

4.4

5.0

4.8

14.2

02

$\mathrm{ABC}$

02

$A B C$

02

$A B C$

02

$\mathrm{ABC}$

$A B C$

02

$A B C$

A

02

$\mathrm{ABC}$

A

$11.3 \quad 11.2$

12.

35.1

02

$\mathrm{ABC}$

$\mathrm{ABC}$

02

$A B C$

6.7

6.9

4.7

18.3

A
A

A

A

A

22.4

22.

02

02

02

02

23.1

2.7
2.7

2.7

2.7

8.0

$1 C$
$\mathrm{ABC}$

$A B C$

$A B C$

$\mathrm{ABC}$

$A B C$

$A B C$

$A B C$ 


\begin{tabular}{|c|c|c|c|c|c|c|c|c|c|}
\hline & $671766-7182346$ & $671772-7182354$ & & & & & I & 25 & $\mathrm{ABC}$ \\
\hline & Posto: 82362Y9998 & $671772-7182354$ & 0.0 & 0.0 & 0.0 & 0.0 & & & $\mathrm{ABC}$ \\
\hline & & Total: & 0.0 & 0.0 & 0.0 & & & & \\
\hline 8236205510 & Chave: 82362P1501 & $671016-7182772$ & & & & & & & \\
\hline & $671016-7182772$ & $671008-7182748$ & & & & & $\mathrm{~A}$ & 02 & $\mathrm{ABC}$ \\
\hline & Posto: 82362Y1501 & $671008-7182748$ & 42.3 & 42.3 & 42. & 127. & & & $\mathrm{ABC}$ \\
\hline & & Total: & 42.3 & 42.3 & 42. & & & & \\
\hline 8236203161 & Chave: 8236203223 & $671568-7182111$ & & & & & & & \\
\hline & $671546-7182126$ & $671568-7182111$ & & & & & $\mathrm{~A}$ & 02 & $\mathrm{ABC}$ \\
\hline & $671525-7182130$ & $671546-7182126$ & & & & & $\mathrm{~A}$ & 02 & $\mathrm{ABC}$ \\
\hline & $671525-7182130$ & $671507-7182134$ & & & & & $\mathrm{~A}$ & 02 & $\mathrm{ABC}$ \\
\hline & Posto: $82362 \mathrm{C} 0317$ & $671507-7182134$ & 7.1 & 6.9 & 6.6 & 20.6 & & & $\mathrm{ABC}$ \\
\hline & $671507-7182134$ & $671485-7182138$ & & & & & $\mathrm{~A}$ & 02 & $\mathrm{ABC}$ \\
\hline & $671485-7182138$ & $671469-7182141$ & & & & & $\mathrm{~A}$ & 02 & $\mathrm{ABC}$ \\
\hline & $671485-7182138$ & $671485-7182135$ & & & & & $\mathrm{Z}$ & 01 & $\mathrm{ABC}$ \\
\hline & $671469-7182141$ & $671446-7182146$ & & & & & $\mathrm{P}$ & $1 \mathrm{C}$ & $\mathrm{ABC}$ \\
\hline & Posto: $82362 C A 225$ & $671485-7182135$ & 5.0 & 5.0 & 5.0 & 14.9 & & & $\mathrm{ABC}$ \\
\hline & $671446-7182146$ & $671441-7182147$ & & & & & $\mathrm{P}$ & $1 \mathrm{C}$ & $\mathrm{ABC}$ \\
\hline & & Total: & 12.1 & 11.9 & 11. & & & & \\
\hline 8236207862 & Chave: 8236206247 & $670762-7182981$ & & & & & & & \\
\hline & $670762-7182981$ & $670753-7183012$ & & & & & $\mathrm{~A}$ & 02 & $\mathrm{ABC}$ \\
\hline & Posto: 82362 CL527 & $670753-7183012$ & 3.3 & 3.1 & 3.2 & 9.5 & & & $\mathrm{ABC}$ \\
\hline & & Total: & 3.3 & 3.1 & 3.2 & & & & \\
\hline 8236200291 & Chave: 8236201386 & $671585-7182079$ & & & & & & & \\
\hline & 671585 - 7182079 & $671617-7182065$ & & & & & $\mathrm{~A}$ & 02 & $\mathrm{ABC}$ \\
\hline & $671617-7182065$ & $671655-7182047$ & & & & & $\mathrm{~A}$ & 02 & $\mathrm{ABC}$ \\
\hline & Posto: 82362C0955 & $671617-7182065$ & 12.2 & 10.5 & 11. & 34.3 & & & $\mathrm{ABC}$ \\
\hline & $671651-7182037$ & $671655-7182047$ & & & & & $\mathrm{~A}$ & 02 & $\mathrm{ABC}$ \\
\hline & 671655 - 7182047 & $671708-7182026$ & & & & & $\mathrm{~A}$ & 02 & $\mathrm{ABC}$ \\
\hline & 671655 - 7182047 & $671671-7182082$ & & & & & $\mathrm{~A}$ & 02 & $\mathrm{ABC}$ \\
\hline & $671708-7182026$ & $671766-7182001$ & & & & & $\mathrm{~A}$ & 02 & $\mathrm{ABC}$ \\
\hline & $671708-7182026$ & $671695-7182018$ & & & & & $\mathrm{~A}$ & 02 & $\mathrm{ABC}$ \\
\hline & $671671-7182082$ & $671684-7182076$ & & & & & $\mathrm{Z}$ & 01 & $\mathrm{ABC}$ \\
\hline & $671671-7182082$ & $671681-7182104$ & & & & & $\mathrm{~A}$ & 02 & $\mathrm{ABC}$ \\
\hline & $671766-7182001$ & $671786-7181992$ & & & & & $\mathrm{~A}$ & 02 & $\mathrm{ABC}$ \\
\hline & Posto: $82362 \mathrm{CK} 423$ & $671766-7182001$ & 12.4 & 12.2 & 9.0 & 33.6 & & & $\mathrm{ABC}$ \\
\hline & Posto: 82362CA435 & $671695-7182018$ & 9.0 & 9.7 & 9.8 & 28.5 & & & $\mathrm{ABC}$ \\
\hline
\end{tabular}




\begin{tabular}{|c|c|c|c|c|c|c|c|c|}
\hline Posto: 82362C1424 & $671684-7182076$ & 7.4 & 6.8 & 6.7 & 20.9 & & & $\mathrm{ABC}$ \\
\hline $671786-7181992$ & $671801-7182025$ & & & & & A & 02 & $\mathrm{ABC}$ \\
\hline $671776-7181969$ & $671786-7181992$ & & & & & $\mathrm{~A}$ & 02 & $\mathrm{ABC}$ \\
\hline $671786-7181992$ & $671796-7181987$ & & & & & $\mathrm{~A}$ & 02 & $\mathrm{ABC}$ \\
\hline $671801-7182025$ & 671812 - 7182051 & & & & & $\mathrm{~A}$ & 02 & $\mathrm{ABC}$ \\
\hline $671763-7181938$ & $671776-7181969$ & & & & & $\mathrm{~A}$ & 02 & $\mathrm{ABC}$ \\
\hline $671796-7181987$ & 671809 - 7181981 & & & & & $\mathrm{~A}$ & 02 & $\mathrm{ABC}$ \\
\hline $671812-7182051$ & $671818-7182065$ & & & & & A & 02 & $\mathrm{ABC}$ \\
\hline Posto: 82362CA996 & 671812 - 7182051 & 21.9 & 23.1 & 21. & 66.4 & & & $\mathrm{ABC}$ \\
\hline $671763-7181938$ & $671754-7181917$ & & & & & $\mathrm{~A}$ & 02 & $\mathrm{ABC}$ \\
\hline $671809-7181981$ & $671808-7181978$ & & & & & A & 02 & $\mathrm{ABC}$ \\
\hline $671809-7181981$ & $671824-7181975$ & & & & & A & 02 & $\mathrm{ABC}$ \\
\hline $671818-7182065$ & $671814-7182065$ & & & & & $\mathrm{Z}$ & 01 & $\mathrm{ABC}$ \\
\hline $671741-7181889$ & $671754-7181917$ & & & & & A & 02 & $\mathrm{ABC}$ \\
\hline $671754-7181917$ & $671752-7181918$ & & & & & $\mathrm{~A}$ & 02 & $\mathrm{ABC}$ \\
\hline Posto: 82362CM068 & $671808-7181978$ & 4.0 & 4.1 & 3.7 & 11.7 & & & $\mathrm{ABC}$ \\
\hline Posto: $82362 \mathrm{C} 0548$ & $671814-7182065$ & 6.0 & 6.7 & 6.6 & 19.4 & & & $\mathrm{ABC}$ \\
\hline $671729-7181860$ & $671741-7181889$ & & & & & $\mathrm{~A}$ & 02 & $\mathrm{ABC}$ \\
\hline Posto: 82362CM597 & $671741-7181889$ & 9.1 & 6.5 & 5.1 & 20.7 & & & $\mathrm{ABC}$ \\
\hline Posto: 82362C3683 & $671752-7181918$ & 6.2 & 7.1 & 7.0 & 20.3 & & & $\mathrm{ABC}$ \\
\hline $671729-7181860$ & $671727-7181861$ & & & & & A & 02 & $\mathrm{ABC}$ \\
\hline $671713-7181831$ & $671729-7181860$ & & & & & A & 02 & $\mathrm{ABC}$ \\
\hline \multirow[t]{2}{*}{ Posto: 82362CE718 } & $671727-7181861$ & 5.5 & 6.9 & 6.2 & 18.7 & & & $\mathrm{ABC}$ \\
\hline & Total: & 93.9 & 93.6 & 86. & & & & \\
\hline Chave: 8236205294 & $671525-7182130$ & & & & & & & \\
\hline $671525-7182130$ & $671532-7182164$ & & & & & Z & 01 & $\mathrm{ABC}$ \\
\hline $671532-7182164$ & $671531-7182181$ & & & & & Z & 01 & $\mathrm{ABC}$ \\
\hline \multirow[t]{2}{*}{ Posto: 82362CA109 } & $671531-7182181$ & 10.2 & 9.5 & 9.4 & 29.1 & & & $\mathrm{ABC}$ \\
\hline & Total: & 10.2 & 9.5 & 9.4 & & & & \\
\hline Chave: 82362P1430 & $671469-7182141$ & & & & & & & \\
\hline $671469-7182141$ & 671472 - 7182161 & & & & & A & 02 & $\mathrm{ABC}$ \\
\hline \multirow[t]{2}{*}{ Posto: 82362Y1430 } & $671472-7182161$ & 25.0 & 25.0 & 25. & 75.2 & & & $\mathrm{ABC}$ \\
\hline & Total: & 25.0 & 25.0 & 25. & & & & \\
\hline Chave: 8236208461 & $671446-7182146$ & & & & & & & \\
\hline $671446-7182146$ & $671443-7182135$ & & & & & $\mathrm{P}$ & $1 \mathrm{C}$ & $\mathrm{ABC}$ \\
\hline $671443-7182135$ & $671442-7182127$ & & & & & $X$ & 99 & $\mathrm{ABC}$ \\
\hline Posto: 82362CN716 & $671442-7182127$ & 13.1 & 13.1 & 12. & 39.0 & & & $\mathrm{ABC}$ \\
\hline $671442-7182127$ & $671440-7182119$ & & & & & $X$ & 99 & \\
\hline
\end{tabular}

8236206024

8236209788

8236204425

671469 - 7182141

Total: 


\begin{tabular}{|c|c|c|c|c|c|c|c|c|c|}
\hline & 671440 - 7182119 & $671445-7182118$ & & & & & $x$ & 99 & $\mathrm{ABC}$ \\
\hline & 671440 - 7182119 & $671438-7182109$ & & & & & $X$ & 99 & $\mathrm{ABC}$ \\
\hline & Posto: 82362CN775 & $671440-7182119$ & 9.7 & 9.7 & 9.7 & 29.0 & & & $\mathrm{ABC}$ \\
\hline & Posto: $82362 Y 8461$ & $671445-7182118$ & 15.4 & 15.4 & 15. & 46.1 & & & $\mathrm{ABC}$ \\
\hline & Posto: $82362 \mathrm{CN} 681$ & $671438-7182109$ & 8.7 & 8.7 & 8.7 & 26.0 & & & $\mathrm{ABC}$ \\
\hline & & Total: & 46.8 & 46.8 & 46. & & & & \\
\hline 8236208299 & Chave: 8236207831 & $671801-7182025$ & & & & & & & \\
\hline & $671801-7182025$ & 671792 - 7182037 & & & & & $\mathrm{P}$ & $1 \mathrm{C}$ & $\mathrm{ABC}$ \\
\hline & Posto: $82362 \mathrm{CN} 118$ & 671792 - 7182037 & 0.5 & 2.4 & 1.6 & 4.6 & & & $\mathrm{ABC}$ \\
\hline & & Total: & 0.5 & 2.4 & 1.6 & & & & \\
\hline 8236204695 & Chave: $82362 \mathrm{P} 0301$ & $671796-7181987$ & & & & & & & \\
\hline & 671796 - 7181987 & $671807-7182009$ & & & & & $\mathrm{~A}$ & 02 & $\mathrm{ABC}$ \\
\hline & Posto: 82362Y0301 & 671807 - 7182009 & 5.7 & 6.1 & 3.3 & 15.0 & & & $\mathrm{ABC}$ \\
\hline & & Total: & 5.7 & 6.1 & 3.3 & & & & \\
\hline 8236206954 & Chave: 8236207125 & $671763-7181938$ & & & & & & & \\
\hline & $671763-7181938$ & $671743-7181930$ & & & & & A & 02 & $\mathrm{ABC}$ \\
\hline & Posto: $82362 \mathrm{C} 2115$ & $671743-7181930$ & 7.8 & 7.8 & 7.8 & 23.4 & & & $\mathrm{ABC}$ \\
\hline & & Total: & 7.8 & 7.8 & 7.8 & & & & \\
\hline 8236202965 & Chave: 8236204110 & $671824-7181975$ & & & & & & & \\
\hline & $671824-7181975$ & $671853-7181962$ & & & & & A & 02 & $\mathrm{ABC}$ \\
\hline & 671853 - 7181962 & 671882 - 7181949 & & & & & $\mathrm{~A}$ & 02 & $\mathrm{ABC}$ \\
\hline & 671882 - 7181949 & $671901-7181940$ & & & & & $\mathrm{~A}$ & 02 & $\mathrm{ABC}$ \\
\hline & $671901-7181940$ & $671907-7181938$ & & & & & $\mathrm{~A}$ & 02 & $\mathrm{ABC}$ \\
\hline & 671873 - 7181872 & $671901-7181940$ & & & & & $\mathrm{P}$ & $1 \mathrm{C}$ & $\mathrm{ABC}$ \\
\hline & 671901 - 7181940 & 671916 - 7181975 & & & & & $\mathrm{P}$ & $1 \mathrm{C}$ & $\mathrm{ABC}$ \\
\hline & 671873 - 7181872 & $671861-7181837$ & & & & & $\mathrm{P}$ & $1 \mathrm{C}$ & $\mathrm{ABC}$ \\
\hline & Posto: $82362 \mathrm{C} 3427$ & 671916 - 7181975 & 24.0 & 25.0 & 21. & 70.5 & & & $\mathrm{ABC}$ \\
\hline & 671916 - 7181975 & $671928-7182002$ & & & & & $\mathrm{P}$ & $1 \mathrm{C}$ & $\mathrm{ABC}$ \\
\hline & $671861-7181837$ & $671858-7181823$ & & & & & $\mathrm{P}$ & $1 \mathrm{C}$ & $\mathrm{ABC}$ \\
\hline & $671928-7182002$ & $671914-7182006$ & & & & & $\mathrm{P}$ & $1 \mathrm{C}$ & $\mathrm{ABC}$ \\
\hline & 671934 - 7182017 & $671928-7182002$ & & & & & $\mathrm{P}$ & $1 \mathrm{C}$ & $\mathrm{ABC}$ \\
\hline & $671858-7181823$ & 671855 - 7181804 & & & & & $\mathrm{P}$ & $1 \mathrm{C}$ & $\mathrm{ABC}$ \\
\hline & $671858-7181823$ & 671895 - 7181839 & & & & & A & 02 & $\mathrm{ABC}$ \\
\hline & $671826-7181811$ & $671858-7181823$ & & & & & $\mathrm{~A}$ & 02 & $\mathrm{ABC}$ \\
\hline & Posto: $82362 \mathrm{C} 8708$ & $671914-7182006$ & 14.5 & 14.1 & 14. & 42.8 & & & $\mathrm{ABC}$ \\
\hline & 671895 - 7181839 & $671920-7181849$ & & & & & $\mathrm{~A}$ & 02 & $\mathrm{ABC}$ \\
\hline & Posto: $82362 C 3425$ & $671895-7181839$ & 13.5 & 11.5 & 9.7 & 34.6 & & & $\mathrm{ABC}$ \\
\hline & $671920-7181849$ & $671951-7181861$ & & & & & $\mathrm{P}$ & $1 \mathrm{C}$ & \\
\hline
\end{tabular}


8236209892

8236207206

8236209635

8236208284
$671951-7181861$
$671965-7181867$
$671965-7181867$
$671965-7181867$
$671976-7181851$

Chave: 8236207173

671853 - 7181962

Posto: 82362CM596

Chave: 82362P2101

671873 - 7181872

Posto: 82362Y2101

Chave: 8236207141

671934 - 7182017

Posto: 82362C6693

Chave: 8236207849

671986 - 7181825

Posto: 82362CN120
671965 - 7181867

671980 - 7181873

671960 - 7181874

671976 - 7181851

671986 - 7181825

Total:

671853 - 7181962 671847 - 7181948 $671847-7181948$

Total:

671873 - 7181872 671827 - 7181884 $671827-7181884$ Total:

671934 - 7182017 671921 - 7182021 671921 - 7182021

Total:

671986 - 7181825 $671983-7181812$ $671983-7181812$ Total:

\begin{tabular}{|c|c|c|c|c|c|c|}
\hline & & & & $\mathrm{P}$ & $1 \mathrm{C}$ & $A B C$ \\
\hline & & & & $\mathrm{P}$ & $1 \mathrm{C}$ & $\mathrm{ABC}$ \\
\hline & & & & $\mathrm{P}$ & $1 C$ & $\mathrm{ABC}$ \\
\hline & & & & $\mathrm{P}$ & $1 C$ & $\mathrm{ABC}$ \\
\hline & & & & $\mathrm{P}$ & $1 \mathrm{C}$ & $\mathrm{ABC}$ \\
\hline 52.0 & 50.6 & 45. & & & & \\
\hline & & & & $\mathrm{P}$ & $1 C$ & $\mathrm{ABC}$ \\
\hline 5.2 & 6.1 & 4.8 & 16.1 & & & $\mathrm{ABC}$ \\
\hline 5.2 & 6.1 & 4.8 & & & & \\
\hline & & & & $\mathrm{P}$ & $1 C$ & $\mathrm{ABC}$ \\
\hline 10.3 & 10.3 & 10. & 31.0 & & & $\mathrm{ABC}$ \\
\hline 10.3 & 10.3 & 10. & & & & \\
\hline & & & & $\mathrm{P}$ & $1 C$ & $\mathrm{ABC}$ \\
\hline 5.1 & 5.1 & 5.1 & 15.3 & & & $\mathrm{ABC}$ \\
\hline 5.1 & 5.1 & 5.1 & & & & \\
\hline & & & & $\mathrm{P}$ & $1 C$ & $\mathrm{ABC}$ \\
\hline 2. & 2.1 & 2.1 & 6.4 & & & $\mathrm{ABC}$ \\
\hline 2. & 2.1 & 2.1 & & & & \\
\hline
\end{tabular}




\section{APÊNDICE B - TRABALHOS PUBLICADOS}

SOUZA, A. A. A.; KAGAN, N. ; DE GEUS, KLAUS. A multiagent system approach and integer linear programming for transformers relocation in power distribution system. In: 2015 IEEE PES Conference on Innovative Smart Grid Technologies (ISGT Latin America), 2015, Montevideo. 2015 IEEE PES Conference on Innovative Smart Grid Technologies (ISGT Latin America), 2015.

SOUZA, A. A. A.; KAGAN, NELSON ; UDAETA, M. E. M. ; DE GEUS, KLAUS . Estudo de Viabilidade Econômica na Utilização de MicroGrid no Sistema de Distribuição Elétrica de Energia de Média Tensão. In: Cidel - International Congress on Electricity Distribution, 2014, Buenos Aires. Cidel - International Congress on Electricity Distribution, 2014.

SOUZA, A. A. A.; KAGAN, NELSON ; GEUS, K. . Otimização do Posicionamento do Transformador no Sistema de Distribuição de Energia. In: Cidel - International Congress on Electricity Distribution, 2014, Buenos Aires. Cidel - International Congress on Electricity Distribution, 2014.

SOUZA, A. A. A.; KAGAN, N. ; UDAETA, M. E. M. ; DE GEUS, KLAUS . Impact of Distributed Generation on the Operational Planning of Medium Voltage Distribution Networks Using Genetic Algorithm. In: IEEE PES Conference on Innovative Smart Grid Technologies 2014, 2014, Istambul. 2014 IEEE PES Conference on Innovative Smart Grid Technologies (ISGT Europe), 2014.

SOUZA, A. A. A.; KAGAN, N. ; DE GEUS, KLAUS.. Impact of distributed generation on the operational planning of low voltage distribution networks using genetic algorithms. In: 2013 IEEE PES Conference on Innovative Smart Grid Technologies (ISGT Latin America), 2013, Sao Paulo. 2013 IEEE PES Conference on Innovative Smart Grid Technologies (ISGT Latin America), 2013. 